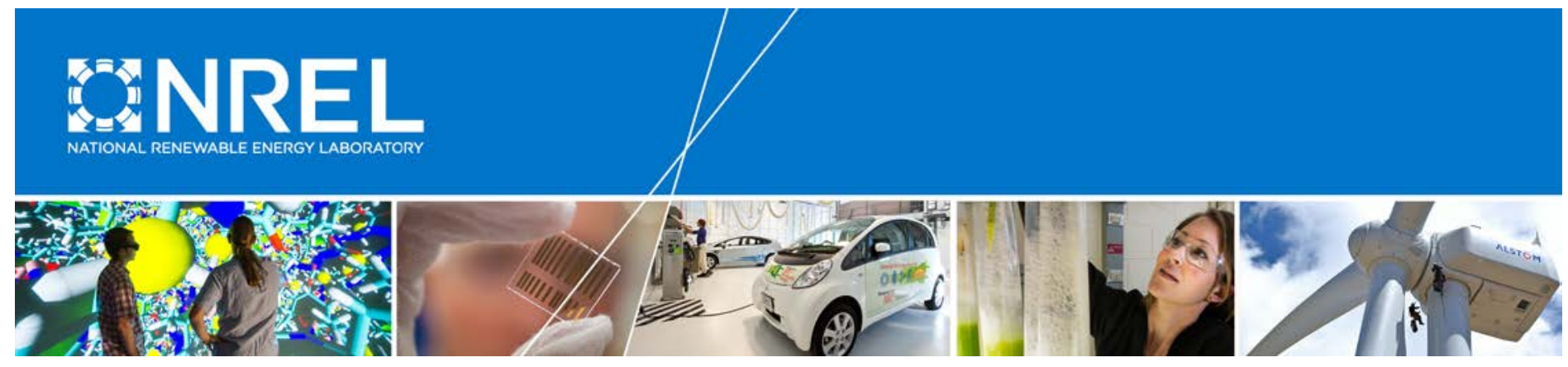

\title{
A Systematic Approach to Better Understanding Integration Costs
}

Gregory B. Stark, P.E. National Renewable Energy Laboratory

NREL is a national laboratory of the U.S. Department of Energy Office of Energy Efficiency \& Renewable Energy Operated by the Alliance for Sustainable Energy, LLC

This report is available at no cost from the National Renewable Energy Laboratory (NREL) at www.nrel.gov/publications.

Technical Report

NREL/TP-5D00-64502

September 2015 


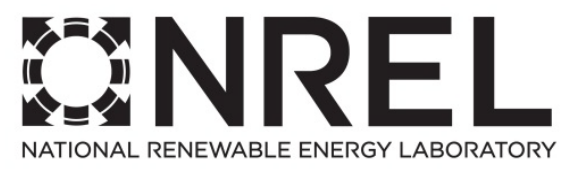

\section{A Systematic Approach to Better Understanding Integration Costs}

Gregory B. Stark, P.E.

National Renewable Energy Laboratory

Prepared under Task No. WE14.9B02

NREL is a national laboratory of the U.S. Department of Energy Office of Energy Efficiency \& Renewable Energy Operated by the Alliance for Sustainable Energy, LLC

This report is available at no cost from the National Renewable Energy Laboratory (NREL) at www.nrel.gov/publications.

National Renewable Energy Laboratory 15013 Denver West Parkway Golden, CO 80401

303-275-3000 • www.nrel.gov

\section{Technical Report}

NREL/TP-5D00-64502

September 2015

Contract No. DE-AC36-08G028308 


\section{NOTICE}

This report was prepared as an account of work sponsored by an agency of the United States government. Neither the United States government nor any agency thereof, nor any of their employees, makes any warranty, express or implied, or assumes any legal liability or responsibility for the accuracy, completeness, or usefulness of any information, apparatus, product, or process disclosed, or represents that its use would not infringe privately owned rights. Reference herein to any specific commercial product, process, or service by trade name, trademark, manufacturer, or otherwise does not necessarily constitute or imply its endorsement, recommendation, or favoring by the United States government or any agency thereof. The views and opinions of authors expressed herein do not necessarily state or reflect those of the United States government or any agency thereof.

This report is available at no cost from the National Renewable Energy Laboratory (NREL) at www.nrel.gov/publications.

Available electronically at SciTech Connect http:/www.osti.gov/scitech

Available for a processing fee to U.S. Department of Energy and its contractors, in paper, from:

U.S. Department of Energy

Office of Scientific and Technical Information

P.O. Box 62

Oak Ridge, TN 37831-0062

OSTI http://www.osti.gov

Phone: 865.576.8401

Fax: 865.576.5728

Email: reports@osti.gov

Available for sale to the public, in paper, from:

U.S. Department of Commerce

National Technical Information Service

5301 Shawnee Road

Alexandria, VA 22312

NTIS http://www.ntis.gov

Phone: 800.553 .6847 or 703.605 .6000

Fax: 703.605.6900

Email: orders@ntis.gov 


\section{Acknowledgments}

The National Renewable Energy Laboratory (NREL) thanks the U.S. Department of Energy's (DOE's) Office of Energy Efficiency and Renewable Energy and Office of Electricity Delivery and Energy Reliability for sponsoring the Integration Cost Study. Contributors include:

\section{Principal Investigator}

NREL

Greg Stark

\section{Technical Review Committee}

DOE
Sam Baldwin
Charlton Clark
Brendan Kirby
Ken Dragoon
Debra Lew
Richard Piwko
Andrew Mills
Aaron Bloom
Greg Brinkman
Kara Clark
Michael Milligan
Barbara O'Neill
Gary Jordan
Ken Schuyler
Justin Sharp
Curtis Miller
Mike Salva
Juha Kiviluoma
Mark Ahlstrom
Drake Bartlett

Electric Power System Consulting

Flink Energy Consulting

GE Energy

Lawrence Berkeley National Laboratory

NREL

NREL Consultant

PJM

Sharply Focused

Tri-State Generation and Transmission Association

VTT

WindLogics/NextEra Energy

Xcel Energy

Finally, we would like to thank Debbie Seidman and Katie Wensuc for their editing work. 


\section{List of Acronyms}

$50 \mathrm{SC}$

50SD

$\mathrm{CC}$

CT

Flex

FSG

HCLG

HGP

HPVG

IEEE

IIT

IR

LCHG

LFUA

LGP

LIUA

LPVG

MMBtu

MPVG

MW

MWh

NREL

PG\&E

PSCO

PSE

PV

SMUD

VO\&M

WECC

WWSIS-1

WWSIS-2
$50 \%$ of the coal plants self-committed

$50 \%$ of the coal plants self-dispatched

combined-cycle generator

combustion turbine generator

flexibility reserves

fast-start generation

high coal/low gas

high gas price

high-penetration variable generation

Institute of Electrical and Electronics Engineers

Illinois Institute of Technology

increased reserves

low coal/high gas

large flexible-unit addition

low gas price

large inflexible unit addition

low-penetration variable generation

million British thermal units

medium-penetration variable generation

megawatt

megawatt hour

National Renewable Energy Laboratory

Pacific Gas and Electric

Public Service Company of Colorado

Puget Sound Energy

photovoltaic

Sacramento Municipal Utility District

variable operations and maintenance

Western Electricity Coordinating Council

Western Wind and Solar Integration Study Phase 1

Western Wind and Solar Integration Study Phase 2 


\section{Executive Summary}

This research project was commissioned by the U.S. Department of Energy to investigate three integration cost-related questions: (1) How does the addition of new generation affect a system's operational costs? (2) How do generation mix and operating parameters and procedures affect costs? and (3) How does the amount of variable generation (non-dispatchable wind and solar) impact the accuracy of natural gas orders?

The National Renewable Energy Laboratory (NREL) performed the research in collaboration with an industry-based technical review committee (TRC).

\section{Integration Costs Definition}

For the purposes of the project, integration costs were defined as the change in production costs associated with a system's ability to accommodate the variability and uncertainty of the net load. The two sources of variability and uncertainty considered in the study were load and variable generation. Four components of integration costs, cycling costs, non-cycling variable operations and maintenance costs (VO\&M), fuel costs, and reserves provisioning costs, were investigated, and these are described below. Capital costs and other fixed costs were not included in the study.

Cycling costs were defined as wear-and-tear costs specific to generator starts, stops, and ramps (i.e., output changes that exceed $30 \%$ of the generator's rated capacity). Historically, cycling costs were included in VO\&M charges; however, in this report they were calculated separately to better monitor the effects of variable generation on the fossil-fueled generators. VO\&M costs were defined as per unit of generation costs used to recover maintenance costs such as wear-andtear not related to cycling as well as other regular equipment replacement and servicing costs. Fuel costs were defined as the per unit of generation costs associated with generator fuel use, and reserves provisioning costs were the per unit of reserves costs associated with making certain that sufficient reserves were available (e.g., starting an additional generator to ensure adequate contingency reserves).

\section{Study Approach}

The study used a production cost modeling approach similar to that used in Phase 2 of the Western Wind and Solar Integration Study (Lew et al. 2013). Security-constrained unit commitment and dispatch models were developed, and differences in production costs were used to estimate cost impacts.

The test system used was a modified version of Illinois Institute of Technology's (IIT's) Institute of Electrical and Electronics Engineers 118-bus model (IIT 2013) overlaid with projected operating loads from the Western Electricity Coordinating Council (WECC) for Sacramento Municipal Utility District, Public Service Colorado, and Puget Sound Energy. The system differed from the IIT system in two ways: (1) generator and transmission capacities were doubled, and (2) combined-cycle units replaced some coal units. These modifications and geographic regions were selected in consultation with the TRC so that the test system would provide a reasonable approximation of an actual interconnection, yet be small enough to allow the research team to investigate a large number of scenarios. 
The study year for the work was future year 2020 with WECC-provided load and NRELprovided wind and solar power estimates (actual year 2006 data were statistically scaled).

The reference simulation to which the other simulations were compared had nominal mixes of $40 \%$ coal, $47 \%$ gas, $11 \%$ hydro, and $2 \%$ variable generation on an annual energy-provided basis.

\section{New Generation Impacts}

Two types of new generation were investigated: the addition of increasing levels of variable generation (wind and photovoltaic solar in an approximate 3:1 ratio) and the addition of either a flexible or an inflexible 840-MW coal plant. ${ }^{1}$ The simulations differed only in the type and amount of new generation. As expected, adding variable generation increased cycling costs (see Figure ES- $1^{2}$ ), increasing system-wide cycling costs by $\$ 1.12 / \mathrm{MWh}$ of variable generation added in the $10 \%$ variable generation simulation and by $\$ 1.47 / \mathrm{MWh}$ for the $40 \%$ variable generation simulation. ${ }^{3}$ Likewise, new baseload also increased cycling costs, with costs increasing by $\$ 0.57 / \mathrm{MWh}$ of new, flexible baseload and by $\$ 0.31 / \mathrm{MWh}$ of new, inflexible baseload. ${ }^{4}$

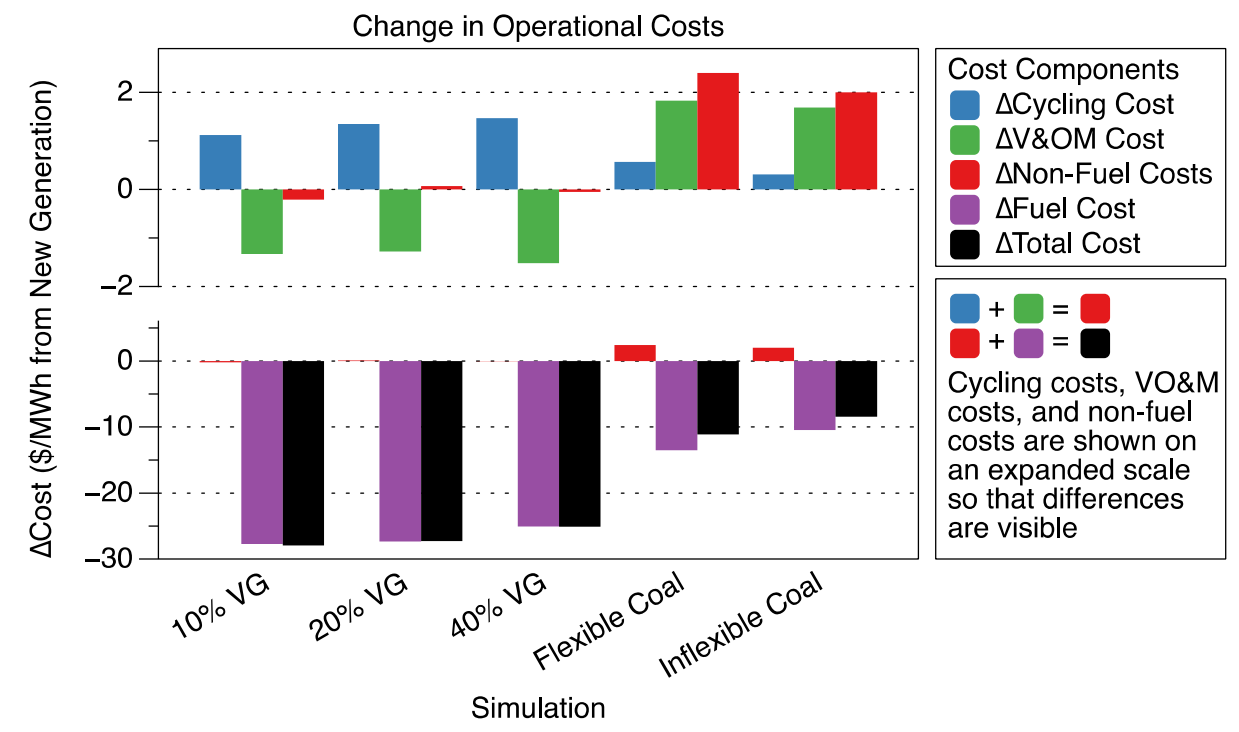

Figure ES-1. Breakout of incremental operating costs for new generation simulations

Although both types of new generation increased cycling costs, the variable generation also displaced system-wide variable operations and maintenance costs, thereby offsetting the increased cycling costs. In contrast, the addition of new baseload actually increased overall VO\&M costs by displacing the gas-fired generation that is less expensive to maintain. ${ }^{5}$ The net

\footnotetext{
${ }^{1}$ The flexible coal plant operated between $50 \%$ and $100 \%$ of its rated capacity, whereas the inflexible coal plant was limited to operating between $90 \%$ and $100 \%$ of its rated capacity.

${ }^{2}$ Non-fuel costs are the sum of the cycling and VO\&M costs. Total costs are the sum of the non-fuel and fuel costs.

${ }^{3}$ For simulations that included new generation, costs were normalized per unit of new energy provided by new generation, which helped facilitate direct comparisons among the new generation scenarios.

${ }^{4}$ Although somewhat counterintuitive, the cycling costs in the flexible coal scenario were higher than in the inflexible coal scenario. The cycling of the flexible unit allowed more expensive fuel-related costs to be displaced.

${ }^{5}$ Both the cycling costs and VO\&M costs used in the study were derived from APTECH's Power Plant Cycling Costs report (Kumar et al. 2012). This report was jointly commissioned by WECC and NREL.
} 
effect was that the non-fuel incremental costs of adding variable generation were small (ranging from a $\$ 0.21 / \mathrm{MWh}$ cost savings to a $\$ 0.07 / \mathrm{MWh}$ cost increase), whereas adding new baseload generation increased the overall non-fuel system costs moderately $(\$ 2.40 / \mathrm{MWh}$ for the flexible coal scenario and $\$ 2.00 / \mathrm{MWh}$ in the inflexible coal simulation).

The effects of gas price, new reserves, and coal retirement with the addition of new generation were also examined, and those results are presented in the main report.

\section{Overall System Impacts}

This section reports how changes in the generation mix and system parameters (e.g., generator start times and natural gas prices) affected production costs. The results are grouped into two sections: (1) generation mix effects, wherein three identically sized systems with various generation mixes were compared, and (2) operational parameter effects, wherein systems that are otherwise identical except for an operation parameter change (e.g., fuel price) or dispatch scheme (e.g., self-scheduling) were studied.

\section{Generation Mix Effects}

This section explores how generation mix affected production costs. Three generation mixes were investigated: (1) a low coal/high gas mix (15\% coal by annual energy delivered), (2) the reference scenario ( $40 \%$ coal), and (3) a high coal/low gas mix (65\% coal). The effect of generation mix on production costs is shown in Figure ES-2. Both cycling costs and VO\&M costs increased with coal penetration, with the combined costs (i.e., the non-fuel costs) increasing from $\$ 1.54 / \mathrm{MWh}$ in the low-coal system to $\$ 2.04 / \mathrm{MWh}$ in reference-coal system and $\$ 2.59 / \mathrm{MWh}$ in the high-coal system, an increase of $\$ 1.05 / \mathrm{MWh}(68 \%)$.

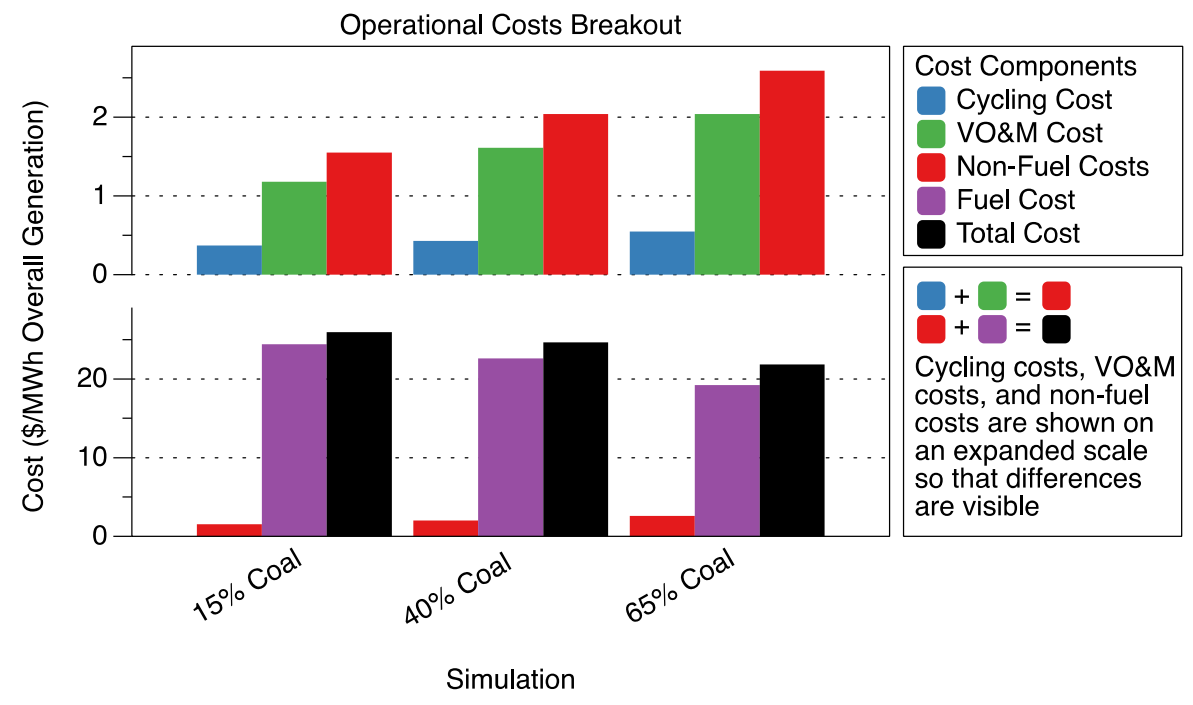

Figure ES-2. Operational costs for generation mix simulations

As coal penetration increased, both fuel costs and overall operating costs were reduced, with overall costs decreasing from $\$ 25.95 / \mathrm{MWh}$ in the low-coal system to $\$ 24.64$ at reference penetrations and $\$ 21.83 / \mathrm{MWh}$ at high penetrations, a reduction of $\$ 4.12 / \mathrm{MWh}(16 \%)$. The combined effect was that cycling and V\&OM cost increases reduced overall operational cost savings by almost $20 \%$ when compared to costs in the low-coal system. 
The main report provides additional information about how generation mix affects costs (e.g., the average cycling costs for the combined-cycle units more than tripled as the generation mix increased from $15 \%$ to $65 \%$ coal).

\section{Operational Parameter and Dispatch Scheme Effects}

The systems investigated in this section were identical except for changes in operational parameters or dispatch schemes. The effects of natural gas price, ${ }^{6}$ generator start times, ${ }^{7}$ and selfscheduling ${ }^{8}$ were investigated, and the effects of these factors on production costs are shown in Figure ES-3.

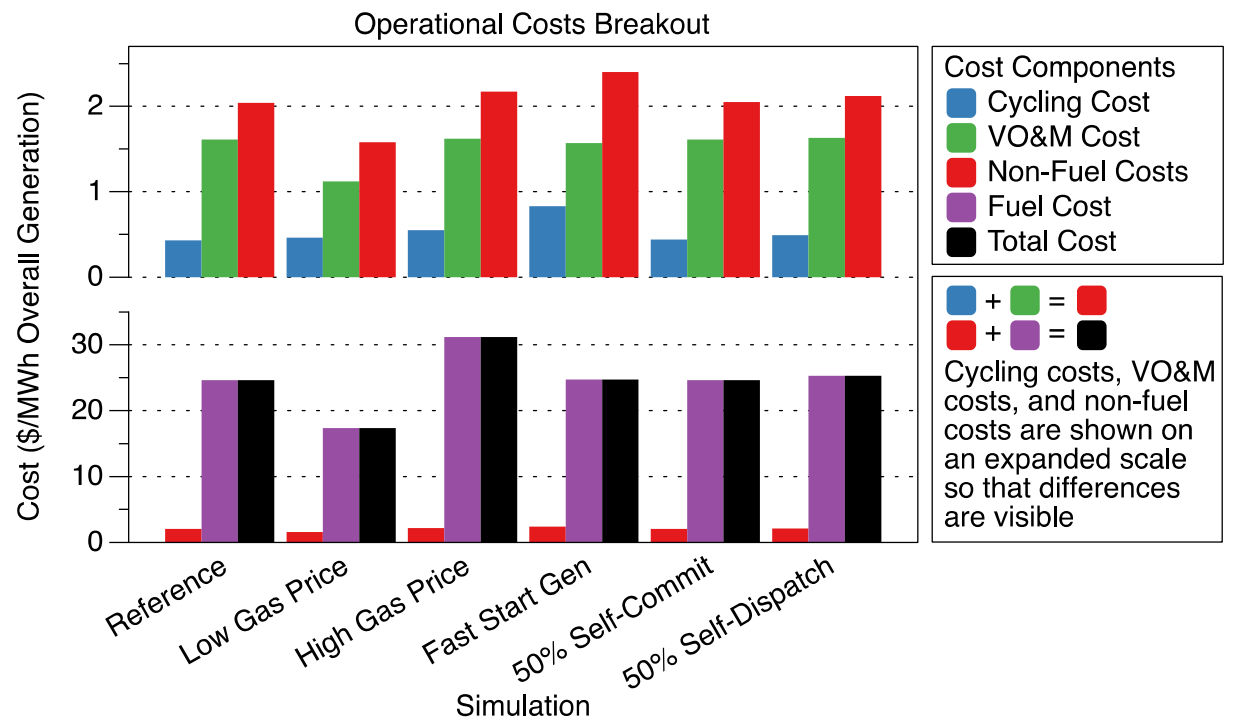

Figure ES-3. Operational costs for various operating schemes

The largest impact on non-fuel costs was in the fast-start generation simulation, in which increased cycling costs were traded for reduced fuel use. In the fast-start generation case, stopping and starting a fast-start machine was less expensive than leaving it running at minimum generation levels during low-load time periods. The high gas price simulation showed a similar trend-i.e., it was less expensive to shut down and restart gas-fired generation than to reduce its output.

Although it did not have the largest impact, cost effects related to self-dispatching were perhaps the most interesting. In a simulation that differed only in how the coal plants were dispatched $\left(50 \%\right.$ of the coal fleet was dispatched at rated capacity $\left.{ }^{9}\right)$, cycling costs increased $12 \%$ $(\$ 0.06 / \mathrm{MWh})$ and overall generation costs increased 3\% (\$0.67/MWh).

\footnotetext{
${ }^{6}$ A reference gas price of $\$ 4.50 / \mathrm{MMBtu}$ was used in all simulations except for the high and low gas price sensitivities. Gas prices of \$2.50/MMBtu and \$6.50/MMBtu were used in the low and high gas price simulations. ${ }^{7}$ Coal and combined-cycle start times were 4 hours and 1 hour in the fast-start generation simulation compared to 24 hours and 4 hours in the other scenarios.

${ }^{8}$ Two levels of self-scheduling were investigated: one in which $50 \%$ of the coal by capacity self-committed and another in which $50 \%$ of the coal was dispatched at full capacity.

${ }^{9}$ Discussions with the project's TRC revealed that self-dispatching rates for baseload plants are believed to be as high as $80 \%$ in some regions of the United States. The $50 \%$ value selected was considered conservative.
} 
Additional sensitivities are provided in the main report, including a study of self-scheduling in high-coal scenarios as well as a breakout of the cycling cost components and the integration costs effects for the various generator classes.

\section{Variable Generation and Gas Forecast Errors}

The last set of experiments investigated how day-ahead gas orders differed from actual gas use as the amount of variable generation increased. ${ }^{10}$ Differences were found to increase with variable generation penetration and are shown in Table ES-1.

Table ES-1. Gas Order Percentage Error Summary

\begin{tabular}{lrrrr} 
Error Magnitude & 2\% VG & 10\% VG & 20\% VG & 40\% VG \\
\hline$<10 \%$ Error & $100.0 \%$ & $86.6 \%$ & $73.4 \%$ & $52.6 \%$ \\
$10 \%-20 \%$ Error & $0.0 \%$ & $11.2 \%$ & $18.9 \%$ & $28.8 \%$ \\
$20 \%-30 \%$ Error & $0.0 \%$ & $1.6 \%$ & $5.8 \%$ & $12.1 \%$ \\
$>30 \%$ Error & $0.0 \%$ & $0.5 \%$ & $1.9 \%$ & $6.6 \%$
\end{tabular}

Order errors increased markedly as variable generation penetration increased - to the point at which $48 \%$ of the gas orders were off by more than $10 \%$ at the highest variable generation penetration level.

\section{Conclusions}

Although integration cost results will always be somewhat system specific, the research team believes that the study approach and model runs provide a useful body of work for ongoing analysis. The overall findings are summarized below, followed by suggestions for future work.

With respect to the cost impacts of adding new generation to an existing system, both new variable generation and baseload were found to increase cycling costs. However, cycling cost increases were offset by reductions in VO\&M costs in the variable generation scenarios, with the overall non-fuel cost impacts ranging from a decrease of $\$ 0.21 / \mathrm{MWh}$ to an increase of $\$ 0.07 / \mathrm{MWh}$. In contrast, new baseload non-fuel operating costs increased between $\$ 2.00 / \mathrm{MWh}$ and $\$ 2.40 / \mathrm{MWh}$, further driving up system-wide non-fuel operating costs and shifting cycling costs to other generators.

In terms of cost impacts related to generation mix, both cycling and system-wide VO\&M costs were found to increase with coal penetration. As the amount of energy from coal increased from $15 \%$ to $65 \%$, cycling costs increased from $\$ 0.37 / \mathrm{MWh}$ to $\$ 0.55 / \mathrm{MWh}$, an increase of almost $50 \%$.

Differences in operating parameters and dispatch schemes were also found to affect cycling costs. At high natural gas prices, cycling became cheaper than using fuel at minimum generation settings, and plants were shut down and restarted during times of low load, thereby saving fuel costs but increasing cycling costs (cycling costs were $\$ 0.46 / \mathrm{MWh}$ at a $\$ 2.50 / \mathrm{MMBtu}$ gas price

\footnotetext{
${ }^{10}$ Perfect load forecasts were used because load forecasts were not available. Consequently, all forecast errors were attributed to wind and solar, likely putting more of a burden on wind/solar forecasts than is realistic.
} 
but increased to $\$ 0.55 / \mathrm{MMBtu}$ at a $\$ 6.50 / \mathrm{MMBtu}$ gas price). In the dispatch group of experiments, one of the more interesting results was the effect of self-scheduling. Even at a rather modest self-dispatching rate of 50\%, cycling costs increased $12 \%(\$ 0.06 / \mathrm{MWh})$ and overall costs increased 3\% $(\$ 0.67 / \mathrm{MWh})$, with the cost increases shifted to generators that did not self-schedule.

Finally, in the gas order error investigation, gas order errors were found to increase with increasing variable generation penetration. At the highest penetration level in the study (40\% variable generation), day-ahead gas use estimates were found to be in error by more than $10 \%$ almost $50 \%$ of the time.

\section{Future Work}

Based on the above findings, we suggest three areas for future work: (1) an assessment of how differing types of integration costs affect both the system and its various generator classes, (2) further investigation into how dispatch schemes impact operational costs at high variable generation penetration levels, and (3) the development of a better understanding of the effect of gas order errors on system operations.

Increases in cycling costs can happen for very different reasons. In some cases, such as fast-start generation, increased cycling costs were traded for fuel use reductions, with the overall system costs decreasing because the fuel cost savings were greater than the cycling cost increases. In other situations, such as self-dispatching, reducing the coal fleet's flexibility increased overall costs and increased the cycling costs of other generator classes. Further investigation is suggested to better understand the nature of cycling costs impacts.

Self-dispatching negatively impacted integration costs even at moderate self-dispatching levels $(50 \%)$ and in the effective absence $(<2 \%)$ of variable generation. Additional work is suggested to develop a better understanding of the interrelationship between dispatch schemes and variable generation penetration.

Finally, the finding that gas order errors increased markedly with increasing variable generation penetration, especially given the recent reports of gas shortages in California, ${ }^{11}$ indicates the need for a better understanding of the relationship between variable generation penetration and natural gas use.

\footnotetext{
${ }^{11}$ See http://www.argusmedia.com/News/Article?id=1069150\&sector=POWER\&region=ALLREGION.
} 


\section{Table of Contents}

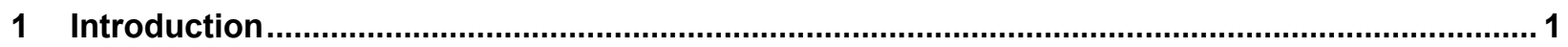

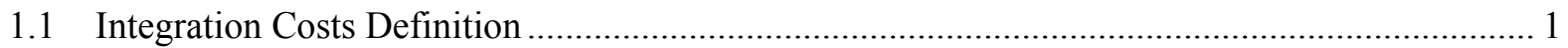

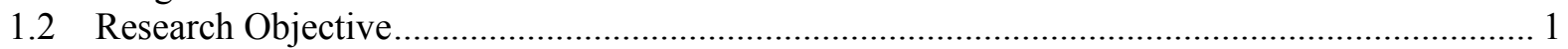

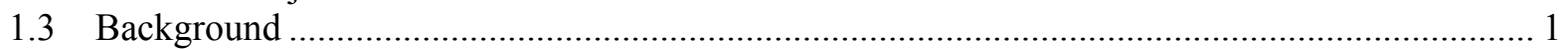

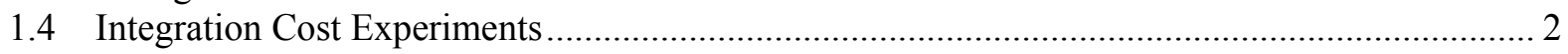

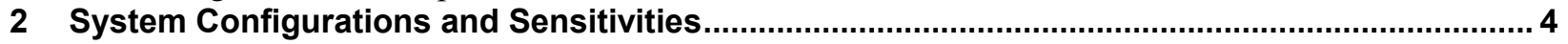

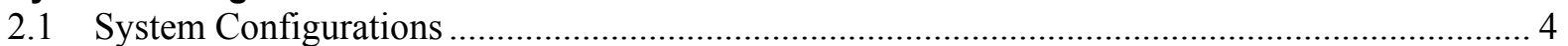

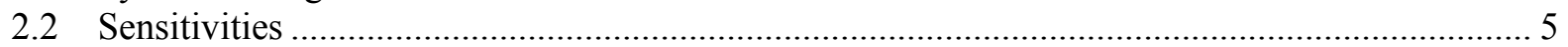

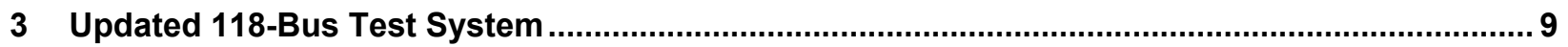

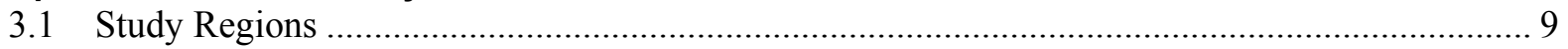

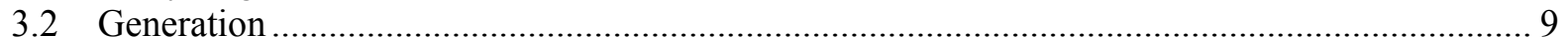

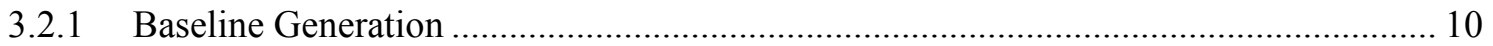

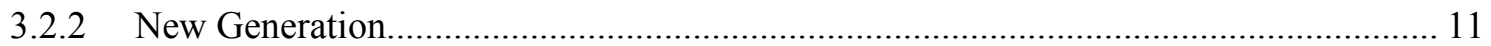

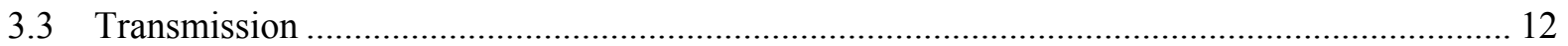

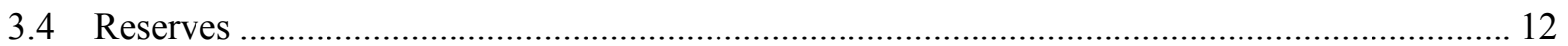

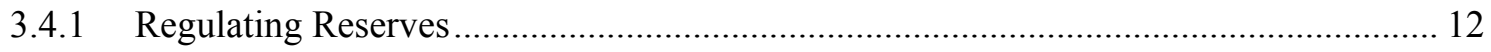

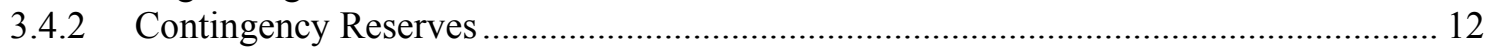

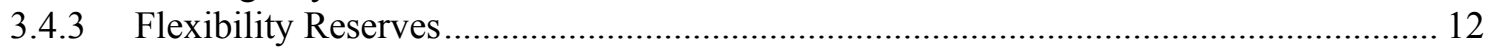

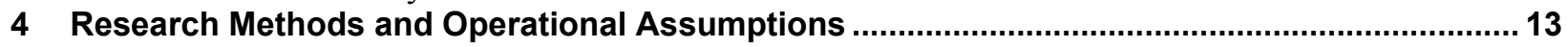

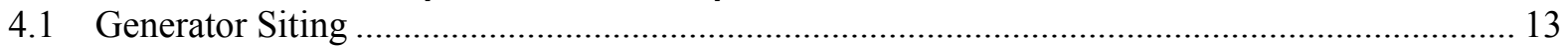

4.2 Production Simulation Methodologies and Operation Assumptions ...................................... 13

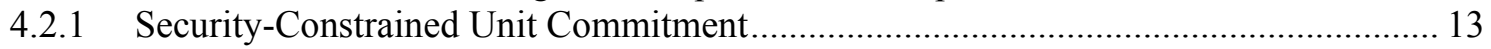

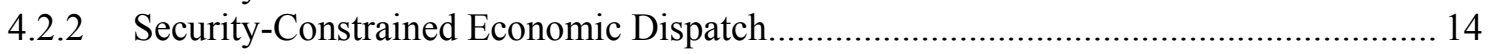

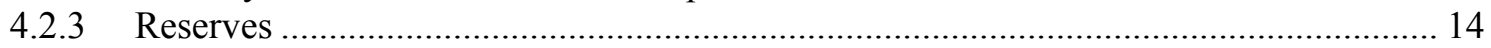

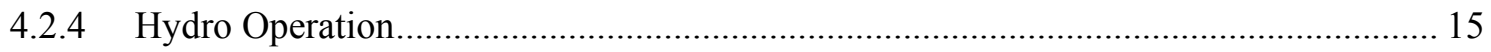

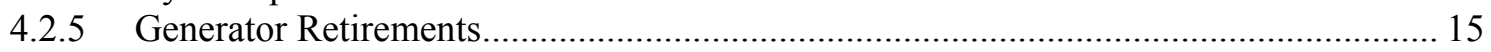

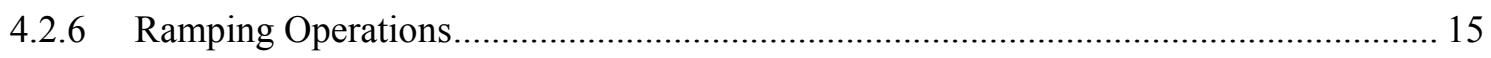

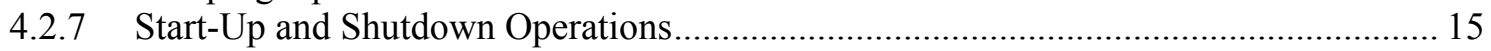

4.2.8 Maintenance and Expected Forced Outages ........................................................... 16

5 Input Data

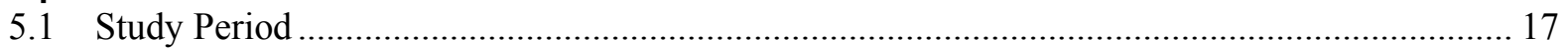

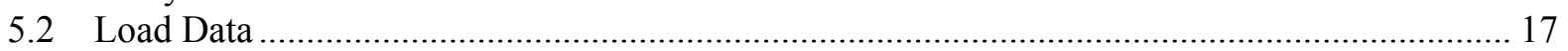

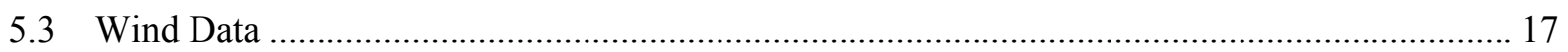

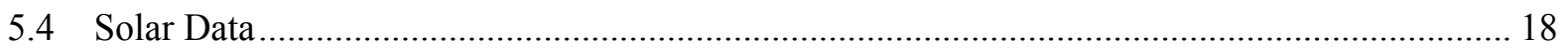

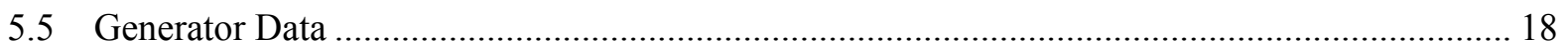

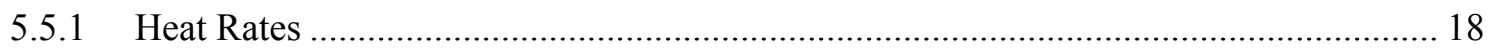

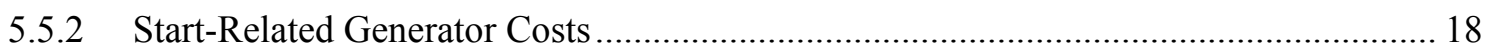

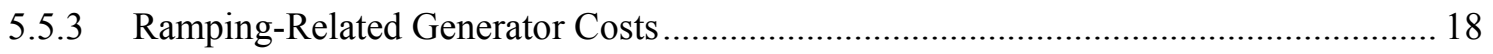

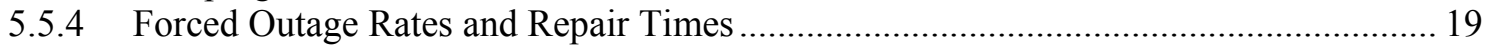

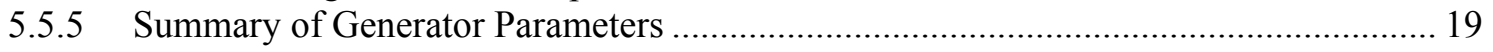

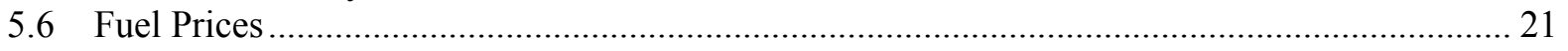

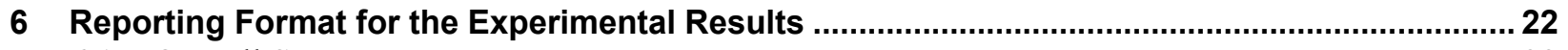

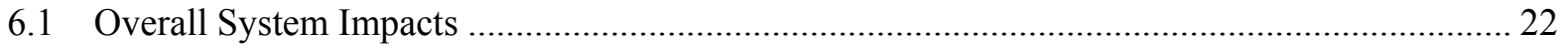

6.2 System Impacts per Unit of New Generation Added …................................................... 24

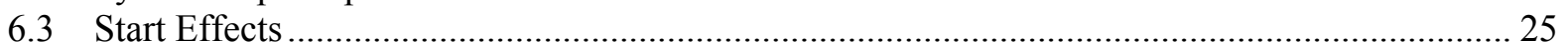

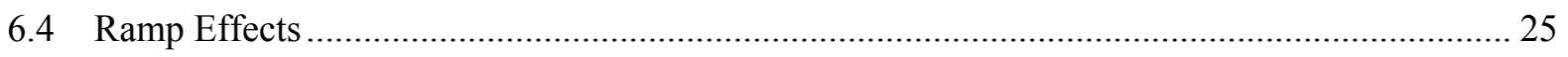

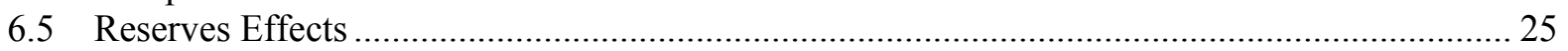

6.6 Capacity Factor and Curtailment Effects ….................................................................. 25

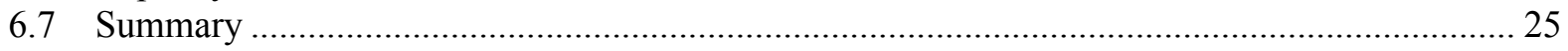




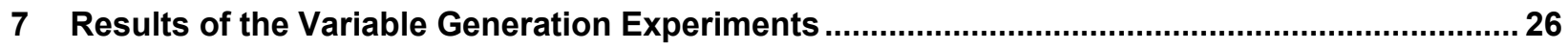

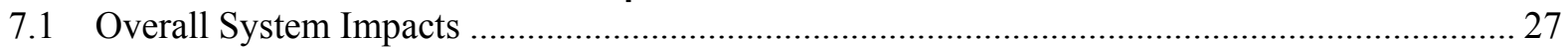

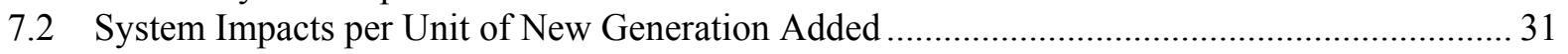

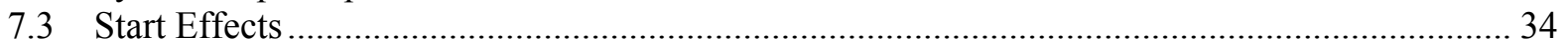

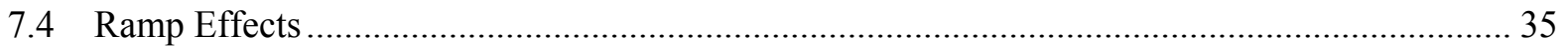

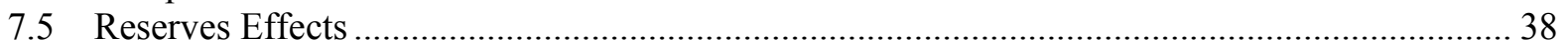

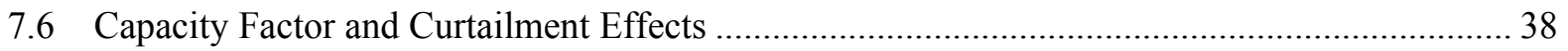

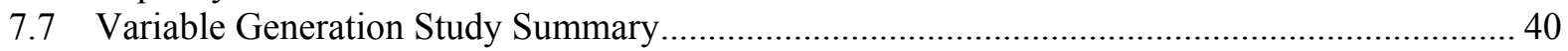

7.7.1 Variable Generation Summary: Cost Impacts per Unit of New Generation .................. 40

7.7.2 Variable Generation Summary: Overall System Costs per Unit of Overall System

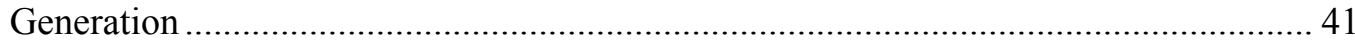

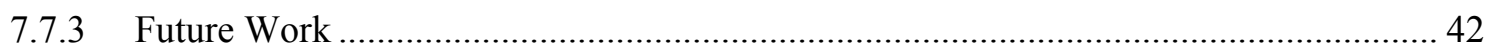

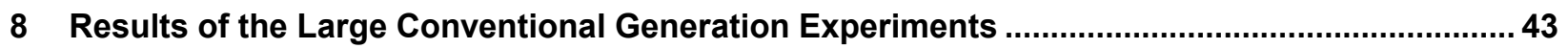

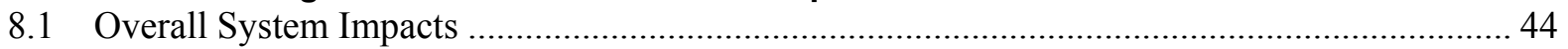

8.2 System Impacts per Unit of New Generation Added ...................................................... 47

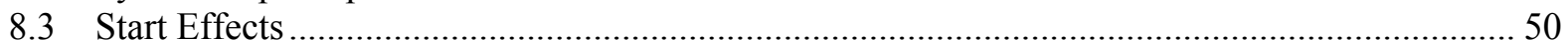

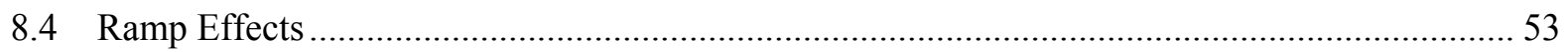

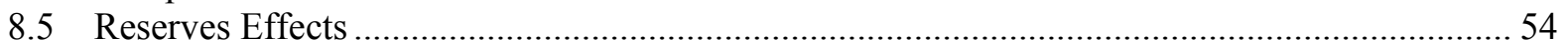

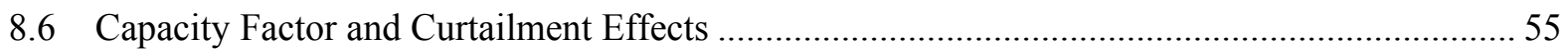

8.7 Large Conventional Generation Study Summary ................................................................... 56

8.7.1 Large Conventional Generation Summary: Cost Impacts per Unit of New Generation 57

8.7.2 Large Conventional Generation Summary: Overall System Costs per Unit of Overall

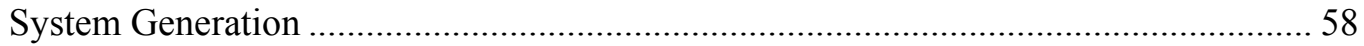

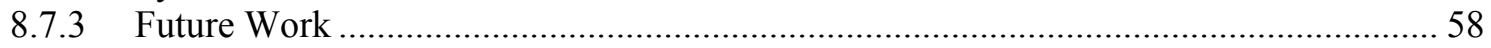

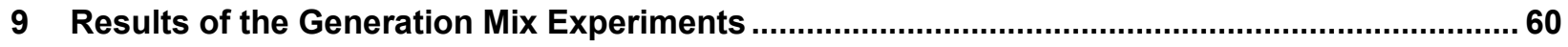

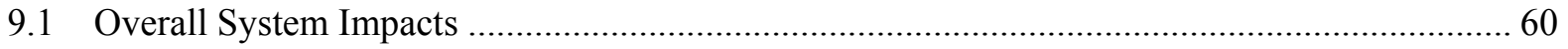

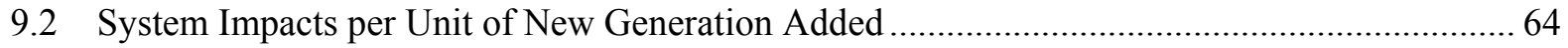

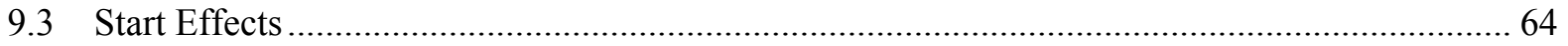

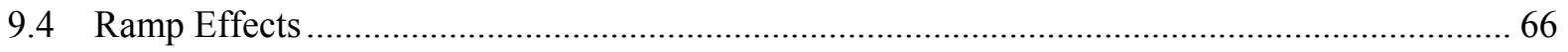

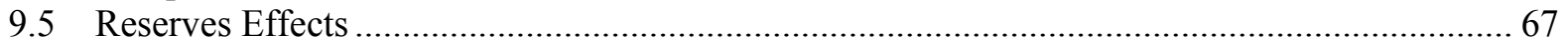

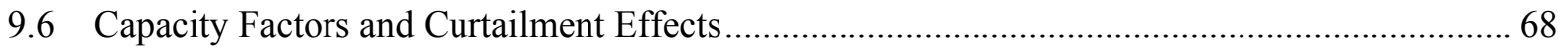

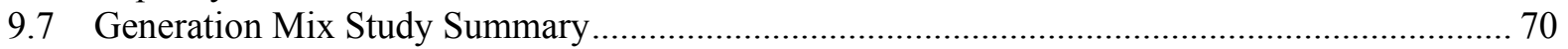

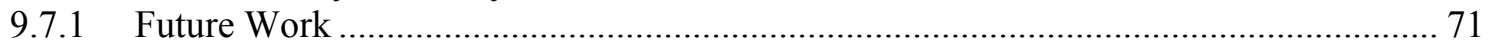

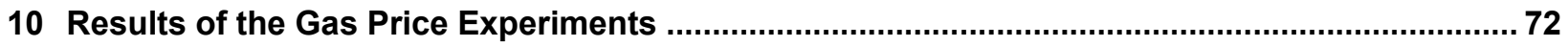

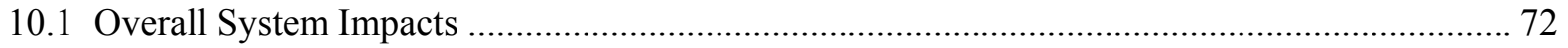

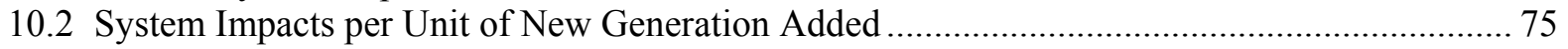

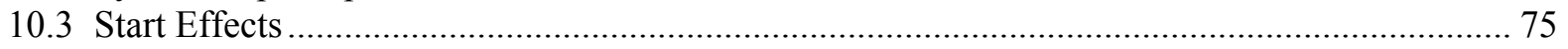

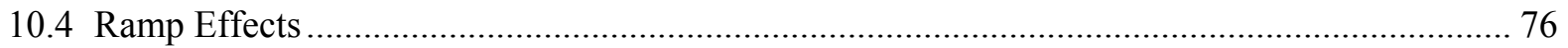

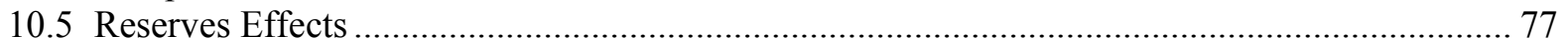

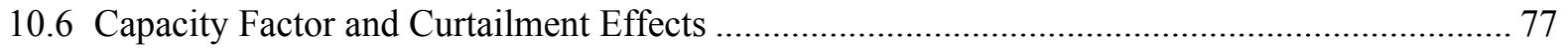

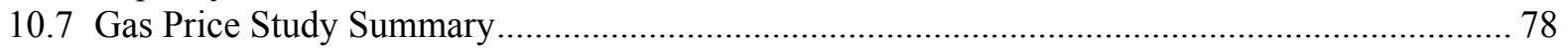

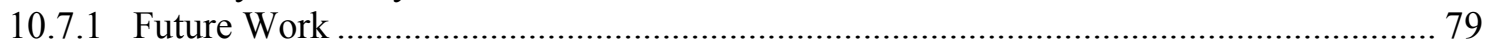

11 Results of the Fast-Start Generator Experiments $\ldots$

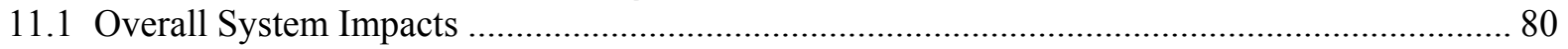

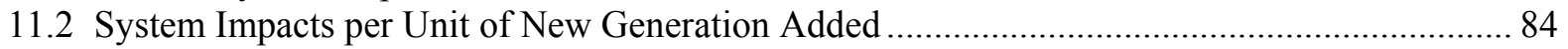

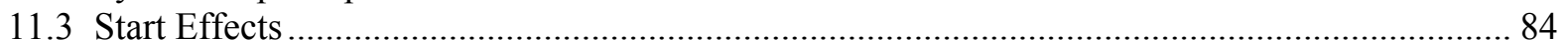

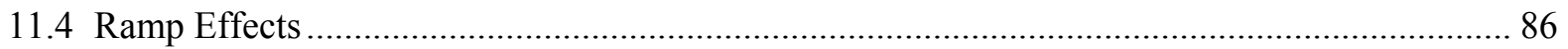

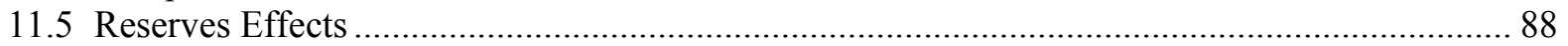

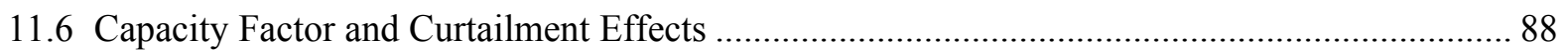

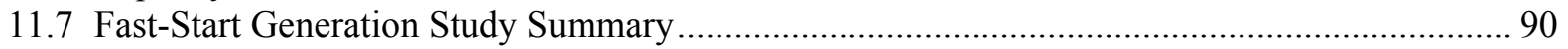

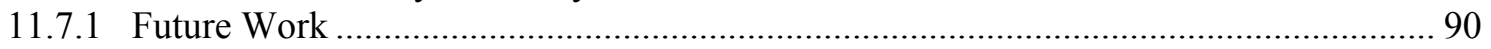




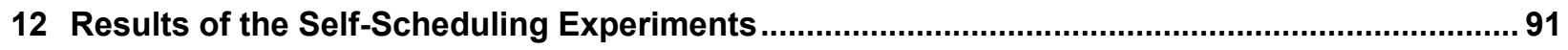

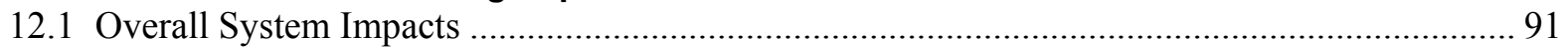

12.2 System Impacts per Unit of New Generation Added ..................................................... 94

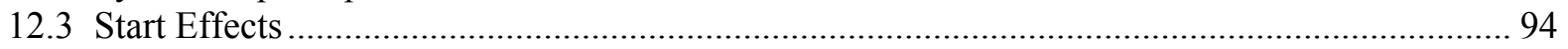

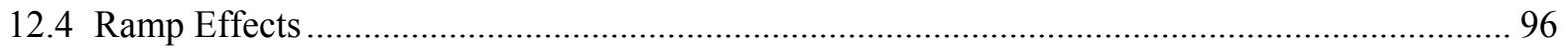

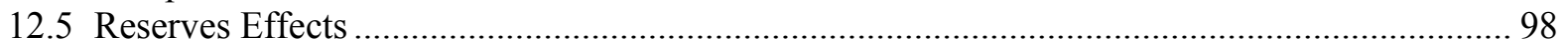

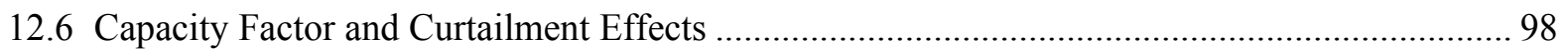

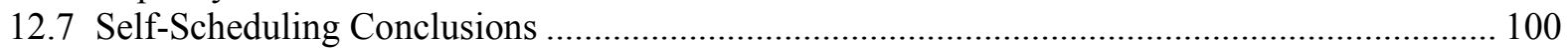

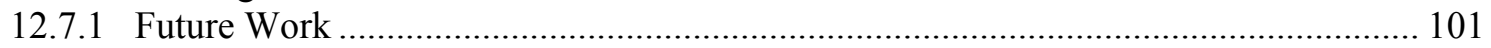

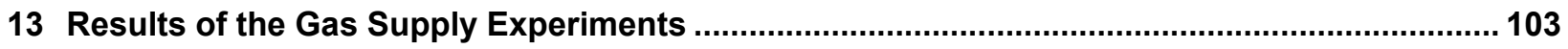

13.1 Day-Ahead Production Forecasts Compared to Actual Production ........................................ 103

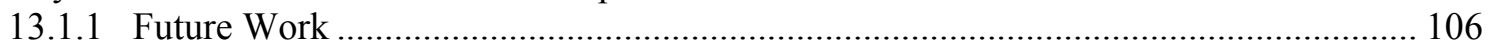

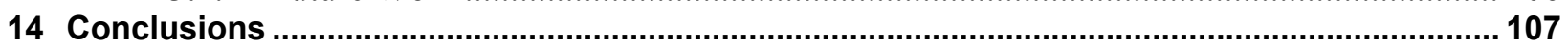

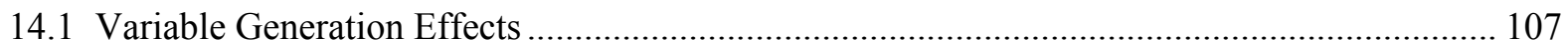

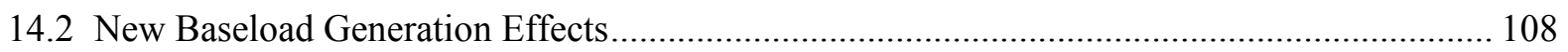

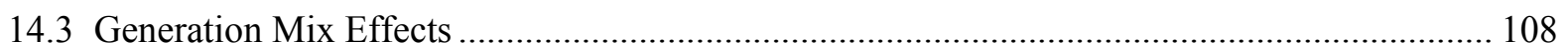

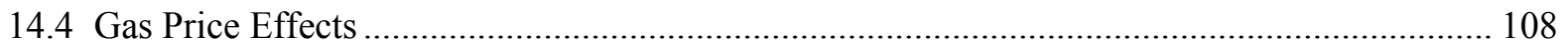

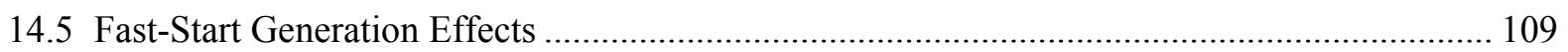

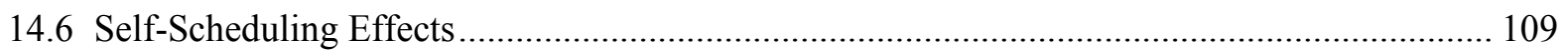

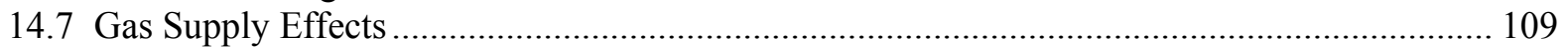

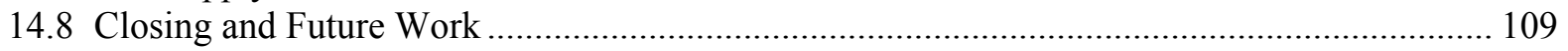

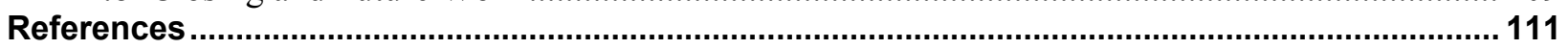

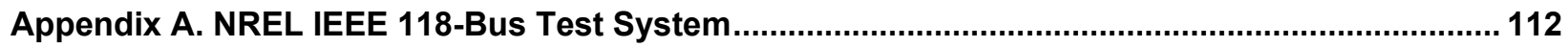

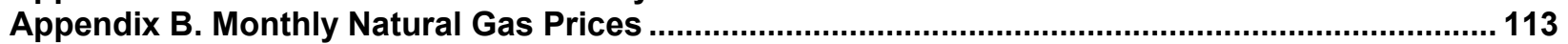

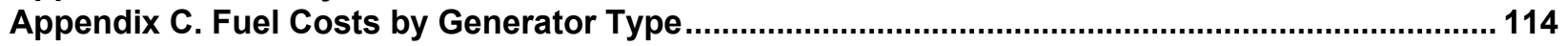

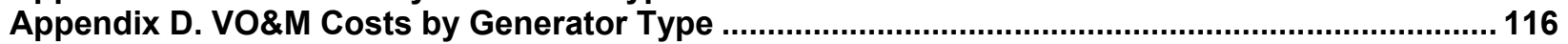

Appendix E. Study-Wide Production Cost Comparisons …............................................................ 118 


\section{List of Figures}

Figure ES-1. Breakout of incremental operating costs for new generation simulations .............................vi

Figure ES-2. Operational costs for generation mix simulations ...................................................... vii

Figure ES-3. Operational costs for various operating schemes ............................................................ viii

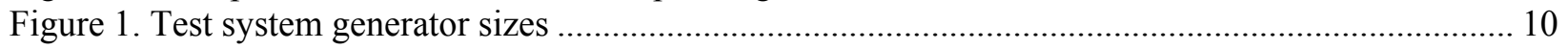

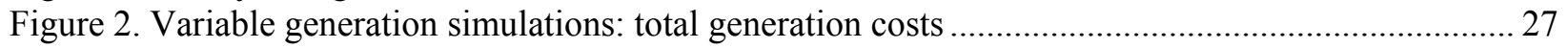

Figure 3. Variable generation simulations: energy delivered by generator type ................................... 28

Figure 4. Variable generation simulations: cycling costs by cost component type ...............................2 29

Figure 5. Changes in cycling costs compared to changes in generation ................................................ 30

Figure 6. Variable generation simulations: changes in production cost per MWh of new generation

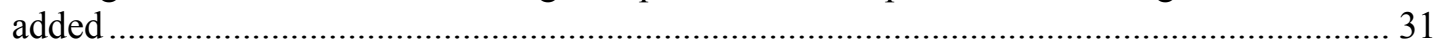

Figure 7. Variable generation simulations: non-fuel operating cost changes per unit of new generation

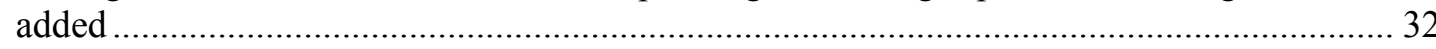

Figure 8. Variable generation simulations: changes in non-fuel operating cost per unit of new generation

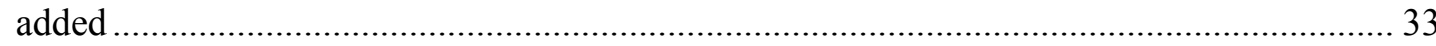

Figure 9. Variable generation simulations: number of starts by generator type .................................. 34

Figure 10. Variable generation simulations: average energy delivered per generator start ...................... 35

Figure 11. Variable generation simulations: number of ramps by generator type ................................. 36

Figure 12. Variable generation simulations: generator movement by generation type.............................. 36

Figure 13. Variable generation simulations: average amount of ramps per unit of energy delivered ........ 37

Figure 14. Variable generation simulations: average capacity factor by generator type .......................... 39

Figure 15. Variable generation simulations: variable generation curtailment ......................................... 39

Figure 16. Large conventional generation simulations: total generation costs ....................................... 44

Figure 17. Large conventional generation simulations: energy delivered by generator type .................... 45

Figure 18. Large conventional generation simulations: cycling costs by cost component type ................. 46

Figure 19. Large conventional generation simulations: changes in production costs per MWh of new

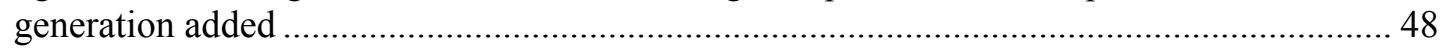

Figure 20. Large conventional generation simulations: changes in non-fuel operating costs per unit of new

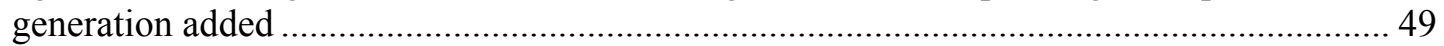

Figure 21. Large conventional generation simulations: changes in non-fuel operating costs per unit of new

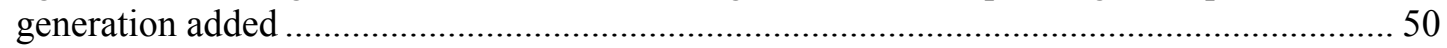

Figure 22. Large conventional generation simulations: number of starts by generator type .................... 51

Figure 23. Large conventional generation simulations: average hours online per generator start.............. 52

Figure 24. Large conventional generation simulations: average energy delivered per generator start....... 52

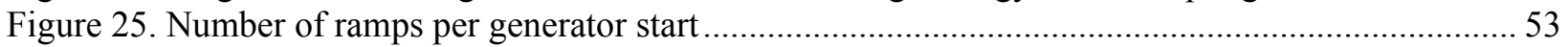

Figure 26. Large conventional generation simulations: average amount of ramp per unit of energy

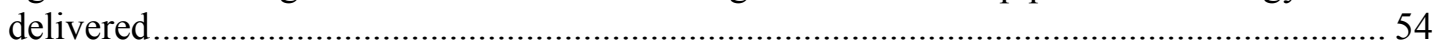

Figure 27. Large conventional generation simulations: average capacity factors by generator type ......... 56

Figure 28. Large conventional generation simulations: variable generation curtailment ......................... 56

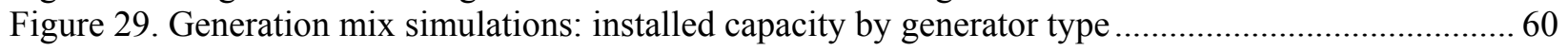

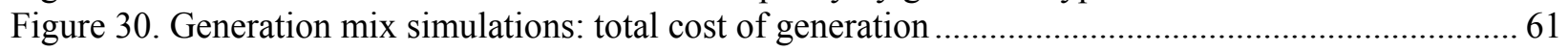

Figure 31. Generation mix simulations: energy delivered by generator type ....................................... 61

Figure 32. Generation mix simulations: cycling costs by cost component type ......................................63 63

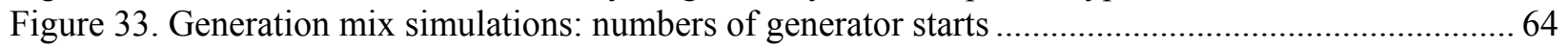

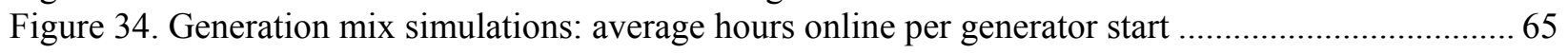

Figure 35. Generation mix simulations: average energy delivered per generator start........................... 65

Figure 36. Generation mix simulations: number of ramps by generator type....................................... 67

Figure 37. Generation mix simulations: average amount of ramp per unit of energy delivered................. 67

Figure 38. Generation mix simulations: average capacity factors by generator type ............................. 68

Figure 39. Generation mix simulations: amount of variable generation curtailed .................................... 69 


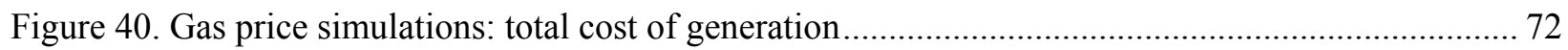

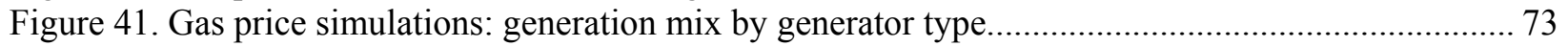

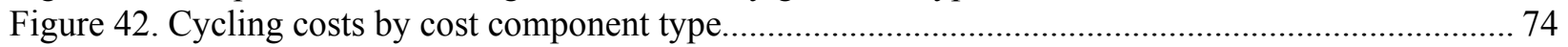

Figure 43. Gas price simulations: average energy delivered per generator start .................................... 75

Figure 44. Gas price simulations: average amount of ramp per unit of energy delivered ......................... 76

Figure 45. Gas price simulations: average capacity factor by generator type .......................................... 77

Figure 46. Gas price simulations: amount of variable generation curtailed............................................. 78

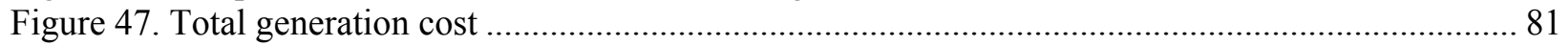

Figure 48. Fast-start generation simulations: energy delivered by generator type ….......................... 81

Figure 49. Fast-start generation simulations: cycling costs by cost component type .............................. 83

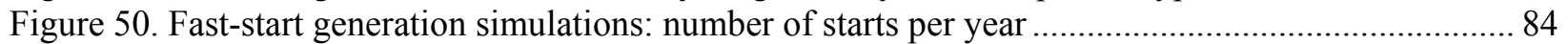

Figure 51. Fast-start generation simulations: average hours online per generator start............................ 85

Figure 52. Fast-start generation simulations: average energy delivered per generator start..................... 86

Figure 53. Fast-start generation simulations: number of ramps by generator type................................. 87

Figure 54. Fast-start generation simulations: amount of generator movement by generator type .............. 87

Figure 55. Fast-start generation simulations: average energy delivered per generator start...................... 87

Figure 56. Fast-start generation simulations: average capacity factor by generator type ......................... 89

Figure 57. Fast-start generation simulations: variable generation curtailment ........................................ 89

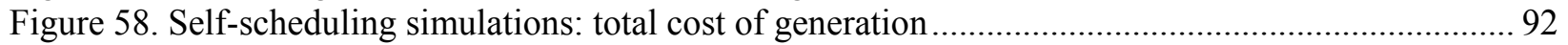

Figure 59. Self-scheduling simulations: energy delivered by generator type ..................................... 92

Figure 60. Self-scheduling simulations: cycling costs by cost component type .................................... 93

Figure 61. Self-scheduling simulations: number of starts by generator type........................................ 95

Figure 62. Self-scheduling simulations: hours online per generator start............................................. 95

Figure 63. Self-scheduling simulations: energy delivered per start by generator type ........................... 96

Figure 64. Self-scheduling simulations: number of ramps by generator type ....................................... 97

Figure 65. Self-scheduling simulations: average amount of ramp per unit of energy delivered ...............97

Figure 66. Self-scheduling simulations: average capacity factor by generator type............................... 99

Figure 67. Self-scheduling simulations: variable generation curtailment........................................... 99

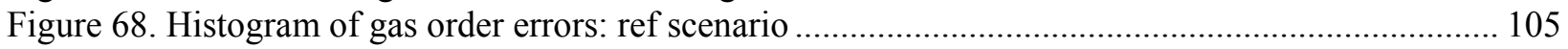

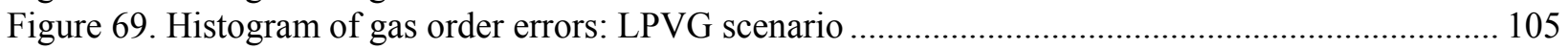

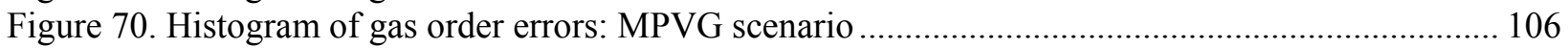

Figure 71. Histogram of gas order errors: HPVG scenario ................................................................... 106

\section{List of Tables}

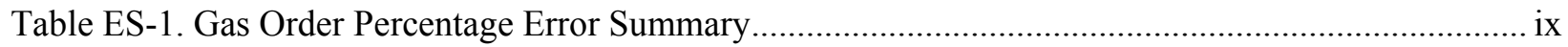

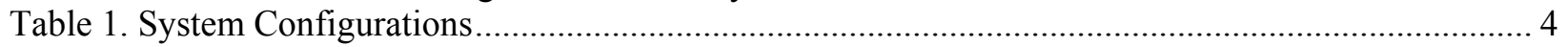

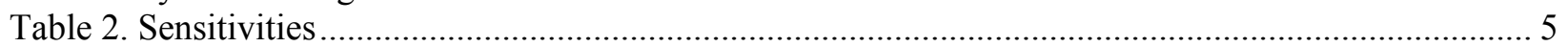

Table 3. Scenarios: System Configurations and Sensitivity Combinations ........................................... 7

Table 4. Experiments: System Configurations and Sensitivity Combinations ....................................... 8

Table 5. Generation Mix Used in the 118-Bus Reference Model ............................................................ 11

Table 6. Penalties for Unserved Load and Reserve Violations............................................................ 15

Table 7. Thermal Unit Simulation Parameters............................................................................... 20

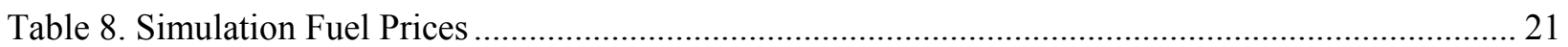

Table 9. Variable Generation Simulations: Average Generation Costs by Generator Type (\$/MWh)...... 28

Table 10. Variable Generation Simulations: Average Fuel Costs (\$MWh) ............................................ 28

Table 11. Variable Generation Simulations: Average Cycling Costs by Generator Type (\$/MWh)......... 29

Table 12. Variable Generation Simulations: Average VO\&M Costs (\$/MWh) ....................................... 30

Table 13. Variable Generation Simulations: Average Non-Fuel Operating Costs by Generator Type

$(\$ / \mathrm{MWh})$ 
Table 14. Variable Generation Simulations: Changes in Cycling Costs per MWh of Variable Generation

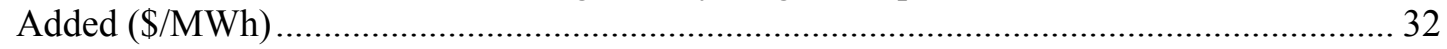

Table 15. Variable Generation Simulations: Changes in VO\&M Costs per MWh of Variable Generation

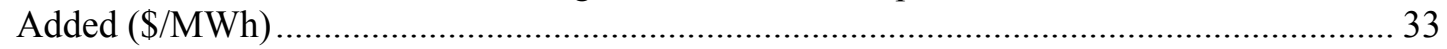

Table 16. Changes in Non-Fuel Operating Costs per MWh of Variable Generation Added (\$/MWh)...... 33

Table 17. Variable Generation Simulations: Average Combined Starts Costs by Generator Type $(\$ / M W h)$

Table 18. Variable Generation Simulations: Average Ramping Costs by Generator Type (\$/MWh)....... 37

Table 19. Variable Generation Simulations: Reserves Provisioning Costs ............................................. 38

Table 20. Variable Generation Simulations: Cost Summaries per Unit of New Generation Added .......... 40

Table 21. Variable Generation Simulations: Cost Summaries of System-Wide Generation...................... 41

Table 22. Large Conventional Generation Simulations: Test Cases..................................................... 43

Table 23. Large Conventional Generation Simulations: Generation by Generator Type (GWh)..............45

Table 24. Large Conventional Generation Simulations: Average Generation Costs (\$/MWh).................46

Table 25. Large Conventional Generation Simulations: Average Fuel Costs ( $\$$ MWh) ......................... 46

Table 26. Large Conventional Generation Simulations: Average Cycling Costs by Generator Type

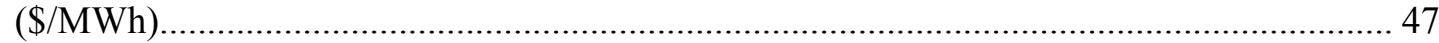

Table 27. Large Conventional Generation Simulations: Average VO\&M Costs $(\$ / M W h) \ldots \ldots \ldots \ldots \ldots \ldots \ldots . . . .47$

Table 28. Large Conventional Generation Simulations: Average Non-Fuel Operating Costs by Generator

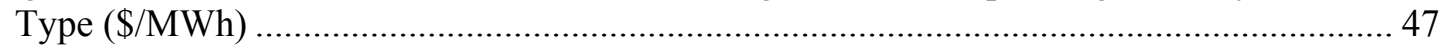

Table 29. Large Conventional Generation Simulations: Changes in Fuel Cost per MWh of New

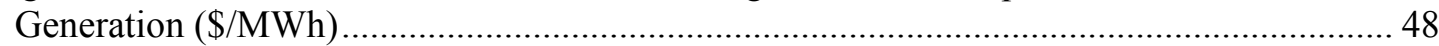

Table 30. Large Conventional Generation Simulations: Changes in Cycling Costs per MWH of New

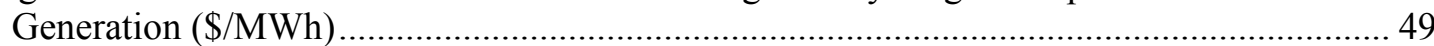

Table 31. Large Conventional Generation Simulations: Changes in VO\&M Costs per MWh of New

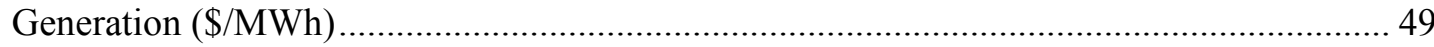

Table 32. Large Conventional Generation Simulations: Changes in Non-Fuel Operating Costs per MWh

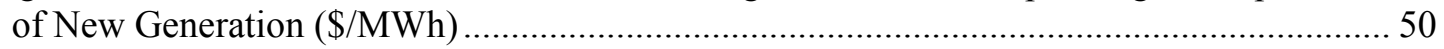

Table 33. Large Conventional Generation Simulations: Average Combined Start Costs by Generator

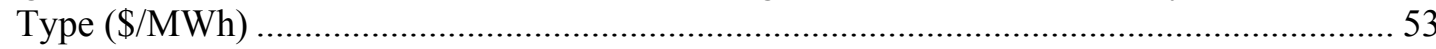

Table 34. Large Conventional Generation Simulations: Average Ramping Costs by Generator Type

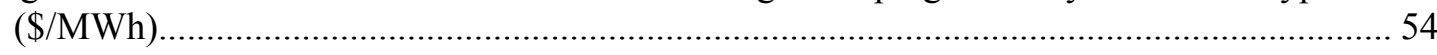

Table 35. Large Conventional Generation Simulations: Reserves Provisioning Costs ........................... 55

Table 36. Large Conventional Generation Simulations: Cost Summaries per Unit of New Generation

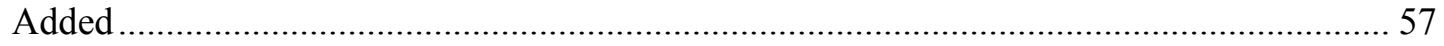

Table 37. Large Conventional Generation Simulations: Cost Summaries...............................................5 58

Table 38. Generation Mix Simulations: Energy Delivered by Generator Type (GWh) ......................... 62

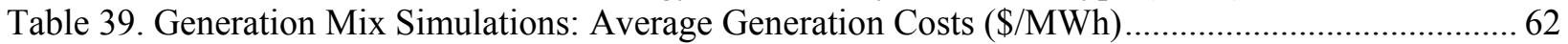

Table 40. Generation Mix Simulations: Average Fuel Cost (\$/MWh) .................................................. 62

Table 41. Generation Mix Simulations: Average Cycling Costs by Generator Type (\$/MWh Delivered) 63

Table 42. Generation Mix Simulations: Average VO\&M Costs (\$/MWh) ........................................... 63

Table 43. Generation Mix Simulations: Average Non-Fuel Operating Costs by Generator Type $(\$ / M W h)$

Table 44. Generation Mix Simulations: Average Combined Start Costs by Generator Type (\$/MWh Delivered)......

Table 45. Generation Mix Simulations: Average Ramping Costs by Generator Type

(\$/MWh Delivered)

Table 46. Generation Mix Simulations: Reserves Provisioning Costs .................................................. 68

Table 47. Generation Mix Simulations: Cost Summaries per Unit of Overall System Generation............. 70

Table 48. Gas Price Simulations: Average Generation Costs (\$/MWh) ................................................... 73

Table 49. Gas Price Simulations: Average Fuel Costs (\$/MWh) ........................................................ 73 
Table 50. Gas Price Simulations: Average Cycling Costs by Generator Type........................................ 74

Table 51. Gas Price Simulations: Average VO\&M Costs by Generator Type (\$/MWh) ........................ 74

Table 52. Gas Price Simulations: Average Non-Fuel Operating Costs by Generator Type (\$/MWh) ....... 75

Table 53. Gas Price Simulations: Average Combined Start Costs by Generator Type

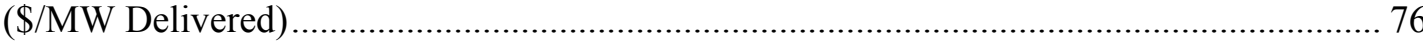

Table 54. Gas Price Simulations: Average Ramping Costs by Generator Type …................................... 77

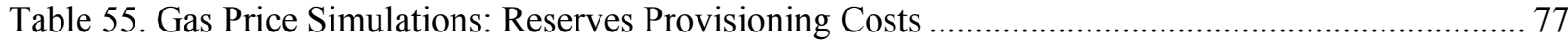

Table 56. Gas Price Simulations: Cost Summaries per Unit of Overall System Generation...................... 78

Table 57. Fast-Start Generation Simulations: Start Times and Ramp Rates ......................................... 80

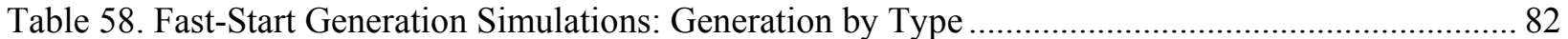

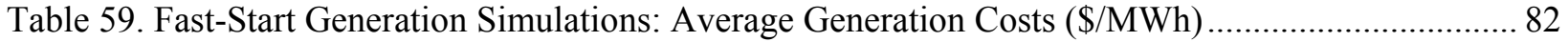

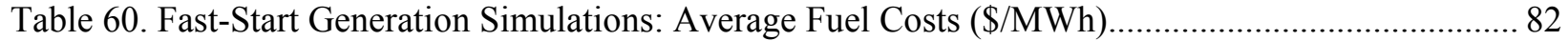

Table 61. Fast-Start Generation Simulations: Average Cycling Costs by Generator Type $(\$ / \mathrm{MWh})$........ 83

Table 62. Fast-Start Generation Simulations: Average VO\&M Costs $(\$ / M W h)$................................... 84

Table 63. Fast-Start Generation Simulations: Average Non-Fuel Operating Costs by Generator Type

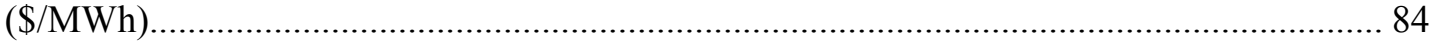

Table 64. Average Combined Start Costs by Generator Type (\$MWh) ............................................... 86

Table 65. Fast-Start Generation Simulations: Average Ramping Costs by Generator Type (\$/MWh) ......88

Table 66. Fast-Start Generation Simulations: Reserves Provisioning Costs ......................................... 88

Table 67. Fast-Start Generation Simulations: Cost Summaries per Unit of Overall System Generation ... 90

Table 68. Self-Scheduling Simulations: Average Generation Costs by Generator Type (\$/MWh) .......... 93

Table 69. Self-Scheduling Simulations: Average Fuel Costs (\$/MWh) .................................................. 93

Table 70. Self-Scheduling Simulations: Average Cycling Costs by Generator Type .............................. 94

Table 71. Self-Scheduling Simulations: Average VO\&M Costs (\$/MWh) ............................................. 94

Table 72. Self-Scheduling Simulations: Average Non-Fuel Operating Costs by Generator Type

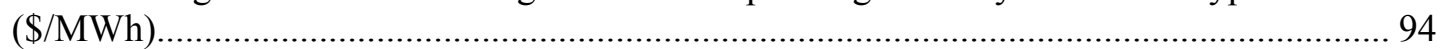

Table 73. Self-Scheduling Simulations: Average Combined Start Costs by Generator Type (\$/MWh).... 96

Table 74. Self-Scheduling Scenario: Average Ramping Costs by Generator Type (\$/MWh)................. 98

Table 75. Self-Scheduling Simulations: Reserves Provisioning Costs .................................................... 98

Table 76. Self-Scheduling Simulations: Cost Summaries per Unit of Overall System Generation ......... 100

Table 77. Annual Gas Forecast and Consumption (1,000,000 MMBtu) ................................................ 103

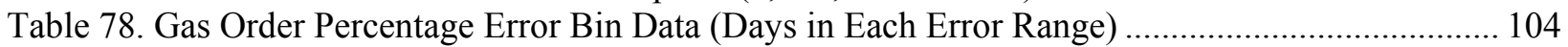

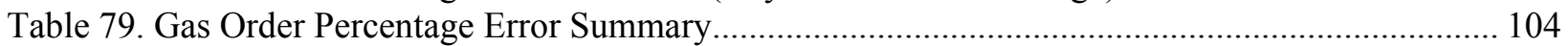

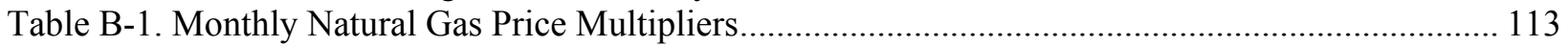

Table C-1. Variable Generation Simulations: Average Fuel Costs by Generator Type (\$/MWh) .......... 114

Table C-2. Large Conventional Generation Simulations: Average Fuel Costs by Generator

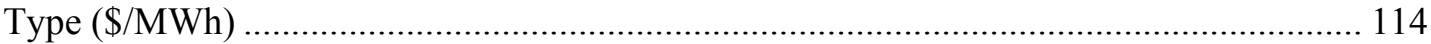

Table C-3. Generation Mix Simulations: Average Fuel Costs by Generator Type (\$/MWh) ................. 114

Table C-4. Gas Price Simulations: Average Fuel Costs by Generator Type (\$/MWh) ......................... 114

Table C-5. Fast-Start Generation Simulations: Average Fuel Costs by Generator Type (\$/MWh) ......... 114

Table C-6. Self-Scheduling Simulations: Average Fuel Costs by Generator Type (\$/MWh) ................ 115

Table D-1. Variable Generation Simulations: Average VO\&M Costs by Generator Type (\$/MWh)...... 116

Table D-2. Large Conventional Generation Simulations: Average VO\&M Costs by Generator Type

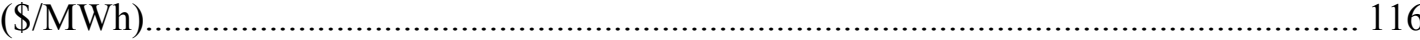

Table D-3. Generation Mix Simulations: Average VO\&M Costs by Generator Type (\$/MWh)............ 116

Table D-4. Gas Price Simulations: Average VO\&M Costs by Generator Type (\$/MWh)..................... 116

Table D-5. Fast-Start Generation Simulations: Average VO\&M Costs by Generator Type $(\$ / M W h)$.... 116

Table D-6. Self-Scheduling Simulations: Average VO\&M Costs by Generator Type (\$/MWh) ............ 117

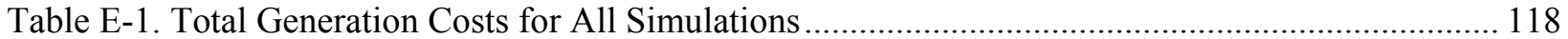

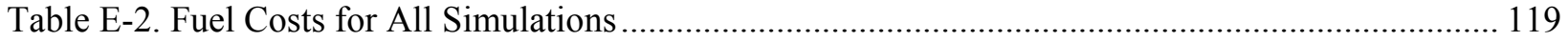

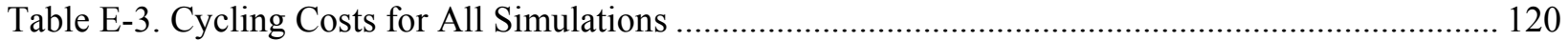

xvii 


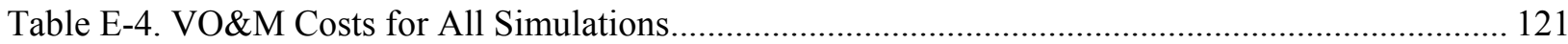

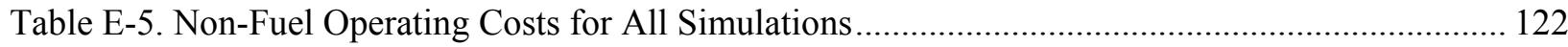

Table E-6. Reserves Provisioning Costs for All Simulations ................................................................ 123

Table E-7. Non-Fuel Operating Costs Plus Reserves Provisioning Costs for All Simulations ................ 124

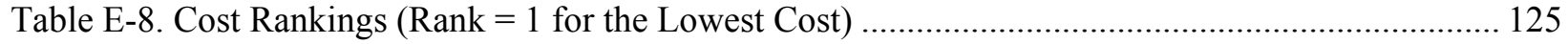

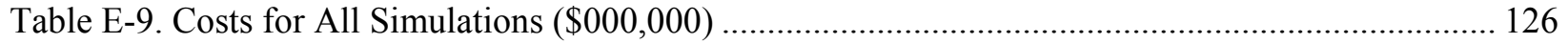




\section{Introduction}

This research project is the first in what the research team hopes to be several projects that assess the impact of adding new generation to existing power systems, whether that is large, inflexible generation such as a baseload nuclear power plant or variable and uncertain generation such as wind. The study was designed and executed in collaboration with a group of industry experts, ${ }^{12}$ and it examined how costs vary with generation mix, gas prices, self-scheduling practices, the addition of a large conventional unit, and penetration levels of variable generation.

\subsection{Integration Costs Definition}

For the purposes of this project, integration costs were defined as the change in production costs associated with a system's ability to accommodate the variability and uncertainty of the net load. The two sources of variability and uncertainty are the load and the nondeterministic nature of variable generation. In general, costs associated with the cycling of plants tend to reflect the variability of the system, and changes in ancillary service costs reflect uncertainty. However, the uncertainty in forecasts can affect cycling and other non-reserves costs-i.e., the effects of uncertainty go beyond reserves provisioning costs to non-cycling variable operations and maintenance costs (VO\&M) as well as cycling and fuel costs - so the choice was made to report integration-related costs directly without trying to divide the effects into categories of variability and uncertainty. Four major categories of integration-related costs are reported: cycling costs, non-cycling VO\&M costs, fuel costs, and reserves provisioning costs.

Capital costs and other fixed costs were not included in the study.

\subsection{Research Objective}

The primary objective was to characterize integration-related costs that are associated with making changes to a preexisting grid, whether those changes are additions of new generation or modifications to operating parameters. The secondary objective was to establish a test system that would simplify production cost-related research going forward.

No attempt was made to address how integration costs vary with the order in which assets are added to a system, a known problem when attempting to assign integration costs. (For example, two identical plants added to a system can have very different integration costs depending on when they are added.)

\subsection{Background}

Much of the motivation for the present work comes from Michael Milligan's work on integration costs. Wind Integration Cost and Cost-Causation discussed three approaches to calculating integration costs: flat block, separating variability and uncertainty, and comparison to a "perfect" unit (Milligan et al. 2013). This study selected a variation of the approach to separate variability and uncertainty to determine integration costs.

\footnotetext{
${ }^{12}$ Please see the acknowledgments for more information about the technical review committee that helped design and review this study.
} 
Additionally, changes in VO\&M costs were determined. Historically, such costs have not been included in integration costs; however, it seemed prudent to track all maintenance-related costs (start-up, ramping, and normal operation) given that changes to a system, whether adding new variable generation or a new baseload plant, directly affect these non-fuel operating costs.

Finally, for completeness, the fuel costs are reported. Combining the non-fuel operating costs (e.g., the cycling costs and VO\&M costs) with the fuel costs provides a total cost of generation.

Note that this study's approach was designed to make it possible to compare effects across scenarios (For example, do the costs associated with adding wind or new coal-fired baseload generation to a high-coal system differ from adding the same new generation to a low-coal system?). However, these comparisons are relative in nature and should not be interpreted as absolute given that the study found that integration costs are dependent on system configuration and system operation.

\subsection{Integration Cost Experiments}

The integration cost study consisted of seven sets of experiments:

- Variable generation

- Large conventional generation

- Generation mix

- Gas prices

- Fast-start generation

- Self-scheduling

- Gas supply constraints.

Brief descriptions of the scenario sets are below, and additional information is provided in the System Configurations and Sensitivities chapter (see Section 0).

The first set of experiments, on variable generation, was used to investigate the effect of adding various levels of variable generation (wind and solar photovoltaic [PV] panels) to the system. The study consisted of seven scenarios: the reference scenario that had approximately $2 \%$ wind energy, a low-penetration scenario with a nominal 12\% wind energy, the low-penetration system configuration (12\%) that had load-following (flexibility) reserves, a medium-penetration scenario with 5\% PV and 15\% wind energy, a high-penetration scenario with $10 \% \mathrm{PV}$ and $30 \%$ wind energy, the same high-penetration simulation but also including coal plant retirements equivalent to $12 \%$ of capacity of the newly added variable generation, and, finally, a highpenetration simulation that used a high gas price.

The large conventional generation experiments examined the costs associated with adding large, conventional generation to an existing system. Four scenarios were examined: the addition of a large, flexible generator; the addition of a large, flexible generator with additional contingency reserves; the addition of a large, inflexible generator; and the addition of a large, inflexible generator with additional contingency reserves.

The generation mix experiments provided the baseline for the project, and they included a reference system configuration along with configurations that had low coal penetrations and high 
coal penetrations. The nominal values for the amount of energy delivered by coal-fired generators in the low-coal, reference, and high-coal scenarios were $15 \%, 40 \%$, and $65 \%$.

The gas prices experiments also included three simulations - all based on the reference scenario mentioned above. The reference scenario used a nominal natural gas price of $\$ 4.50 / \mathrm{MMBtu}$, whereas the scenarios with the high and low gas prices used \$6.50/MMBtu and \$2.50/MMBtu, respectively.

The fast-start generation experiments studied the impact of generator start times on system costs. Two simulations were used: the reference scenario and a reference-based scenario in which coal plants started in 4 hours and combined-cycle units started in 1 hour.

The self-scheduling experiments consisted of two subsets: self-commitment and self-dispatching scenarios that were based on the reference case, and self-commitment and self-dispatching scenarios that were based on the high-coal ( $65 \%$ coal energy) system configuration.

Finally, gas supply experiments were conducted with a subset of the variable generation experiments. The study looked at how closely the real-time dispatch of natural gas-fired generators matched the day-ahead predictions and the magnitude of the deviations between the real-time gas use and the day-ahead gas orders. Four scenarios were examined: the reference scenario that had approximately $2 \%$ wind energy, a low-penetration scenario with a nominal $12 \%$ wind energy, a medium-penetration scenario with $5 \% \mathrm{PV}$ and $15 \%$ wind energy, and a high-penetration scenario with $10 \% \mathrm{PV}$ and $30 \%$ wind energy.

Additional information about these scenarios can be found in the next section. 


\section{System Configurations and Sensitivities}

Scenarios consisted of a combination of a system configuration and one or more sensitivities. System configurations described the physical layout of the system and differed in the numbers or types of generators. Sensitivities differed in the parameters that were used for the generators (e.g., natural gas prices or maximum ramp rates). Both the system configurations and the sensitivities were jointly developed with the technical review committee. ${ }^{13}$

\subsection{System Configurations}

Eight system configurations were considered: a reference configuration and seven variations (Table 1). The generation fleet for all configurations consisted of a mix of coal-fired steam plants, natural gas-fired combined-cycle units, natural gas- and oil-based combustion turbines, wind turbines, and solar PV systems. The amount of each type of generation in a given configuration distinguished one configuration from another. (For example, the high-penetration variable generation configuration had $30 \%$ wind, and the reference configuration had $2 \%$ wind.)

Table 1. System Configurations

\begin{tabular}{|c|c|c|}
\hline System Configuration & Acronym & Description \\
\hline Reference & Ref & $\begin{array}{l}\text { The reference system configuration had a nominal } 40 \% \text { of the energy } \\
\text { delivered by coal, with the balance provided by natural gas }(58 \%) \text {, hydro } \\
(11 \%) \text {, wind }(2 \%) \text {, and oil }(<0.1 \%) \text {. }\end{array}$ \\
\hline Low Coal/High Gas & LCHG & $\begin{array}{l}\text { The low-coal/high-gas system configuration had a nominal } 15 \% \text { of the } \\
\text { energy delivered by coal, with the balance provided by natural gas, hydro } \\
(11 \%) \text {, wind, and oil. Note that this system configuration differed from the } \\
\text { reference in that some of the large coal plants were replaced by } \\
\text { combined-cycle facilities. }\end{array}$ \\
\hline High Coal/Low Gas & HCLG & $\begin{array}{l}\text { The high-coal/low-gas system configuration had a nominal } 65 \% \text { of the } \\
\text { energy delivered by coal, with the balance provided by natural gas, hydro } \\
\text { (11\%), wind, and oil. Note that this system configuration differed from the } \\
\text { reference in that coal-fired plants replaced some of the large combined- } \\
\text { cycle facilities. }\end{array}$ \\
\hline $\begin{array}{l}\text { Large Flexible Unit } \\
\text { Addition }\end{array}$ & LFUA & $\begin{array}{l}\text { The system configuration with a large, flexible unit addition built on the } \\
\text { reference system configuration by adding a high-efficiency } 840-\mathrm{MW} \\
\text { generator to the reference system configuration. The new plant had } \\
\text { characteristics similar to that of a high-efficiency coal-fired plant. }\end{array}$ \\
\hline $\begin{array}{l}\text { Large Inflexible Unit } \\
\text { Addition }\end{array}$ & LIUA & $\begin{array}{l}\text { The system configuration with a large, inflexible unit addition was similar } \\
\text { to the system configuration with a large, flexible unit addition except that } \\
\text { the new plant had characteristics similar to that of a high-efficiency } \\
\text { nuclear plant (with limited flexibility in ramp rates and minimum } \\
\text { generation values). Note that although the new plant had operating } \\
\text { characteristics similar to a nuclear plant, coal was used as the fuel to } \\
\text { make cost comparisons straightforward. }\end{array}$ \\
\hline
\end{tabular}

${ }^{13}$ The technical review committee members are listed in the acknowledgements and consisted of a group of industry volunteers who helped guide and review this research. 


\begin{tabular}{lcl}
\hline System Configuration & Acronym & Description \\
\hline $\begin{array}{l}\text { Low-Penetration } \\
\text { Variable Generation }\end{array}$ & LPVG & $\begin{array}{l}\text { The low-penetration variable generation system configuration was } \\
\text { identical to the reference system configuration except that it had a } \\
\text { nominal } 10 \% \text { wind based on annual energy delivered. }\end{array}$ \\
$\begin{array}{l}\text { Medium-Penetration } \\
\text { Variable Generation }\end{array}$ & MPVG & $\begin{array}{l}\text { The medium-penetration variable generation system configuration was } \\
\text { identical to the reference system configuration except that it had a } \\
\text { nominal } 15 \% \text { wind and } 5 \% \text { PV based on annual energy delivered. }\end{array}$ \\
$\begin{array}{l}\text { High-Penetration } \\
\text { Variable Generation }\end{array}$ & HPVG & $\begin{array}{l}\text { The high-penetration variable generation system configuration was } \\
\text { identical to the reference system configuration except that it had a } \\
\text { nominal } 30 \% \text { wind and } 10 \% \text { PV based on annual energy delivered. }\end{array}$ \\
\hline
\end{tabular}

\subsection{Sensitivities}

Sensitivities were used to study how a given generation fleet responds to changes in operating conditions (Table 2). (For example, how do the generators in the reference case respond if natural gas prices increase?)

Table 2. Sensitivities

\begin{tabular}{|c|c|c|c|}
\hline Sensitivity & Level & Acronym & Description \\
\hline Gas Price & $\begin{array}{l}\text { Reference, } \\
\text { High, Low }\end{array}$ & HGP, LGP & $\begin{array}{l}\text { The nominal reference, high, and low gas prices were } \\
\$ 4.50 / \mathrm{MMBtu}, \$ 6.50 / \mathrm{MMBtu} \text {, and } \$ 2.50 / \mathrm{MMBtu} \text {. }\end{array}$ \\
\hline \multirow[t]{2}{*}{$\begin{array}{l}\text { Contingency } \\
\text { Reserves }\end{array}$} & \multirow[t]{2}{*}{$\begin{array}{l}\text { Reference, } \\
\text { Increased }\end{array}$} & \multirow[t]{2}{*}{ IR } & $\begin{array}{l}\text { The reference sensitivity had } 840 \mathrm{MW} \text { of contingency } \\
\text { reserves. }\end{array}$ \\
\hline & & & $\begin{array}{l}\text { The increased reserves sensitivity had 1,256 } \mathrm{MW} \text { (a } 50 \% \\
\text { increase) of contingency reserves. The reserve requirements } \\
\text { were shared proportionally among the three regions. }\end{array}$ \\
\hline \multirow[t]{2}{*}{$\begin{array}{l}\text { Fast-Start } \\
\text { Generation }\end{array}$} & \multirow[t]{2}{*}{$\begin{array}{l}\text { Reference, } \\
\text { Fast }\end{array}$} & \multirow[t]{2}{*}{ FSG } & $\begin{array}{l}\text { The reference generator start times were } 24 \text { hours for the } \\
\text { coal units, } 4 \text { hours for the combined-cycle plants, and real } \\
\text { time for the combustion turbines. }\end{array}$ \\
\hline & & & $\begin{array}{l}\text { The fast-start times were } 4 \text { hours for the coal units, } 1 \text { hour } \\
\text { for the combined-cycle plants, and real time for the } \\
\text { combustion turbines. }\end{array}$ \\
\hline \multirow[t]{2}{*}{$\begin{array}{l}\text { Flexibility } \\
\text { Reserves }\end{array}$} & \multirow{2}{*}{$\begin{array}{l}\text { Reference, } \\
\text { Flexibility } \\
\text { Reserves }\end{array}$} & \multirow[t]{2}{*}{ Flex } & $\begin{array}{l}\text { The reference sensitivity had no flexibility (load-following) } \\
\text { reserves. }\end{array}$ \\
\hline & & & $\begin{array}{l}\text { The flexibility reserves sensitivity had additional reserves } \\
\text { designed to cover } 70 \% \text { of the } 60 \text {-minute forecast errors of } \\
\text { wind. }\end{array}$ \\
\hline \multirow[t]{2}{*}{ Self-Commitment } & \multirow{2}{*}{$\begin{array}{l}\text { Reference, } \\
\text { Self- } \\
\text { Commitment }\end{array}$} & \multirow[t]{2}{*}{$50 \mathrm{SC}$} & In the reference sensitivity, no plants self-committed. \\
\hline & & & $\begin{array}{l}\text { For the self-commitment sensitivity, } 50 \% \text { (by energy) of the } \\
\text { coal plants self-committed for the whole year. }\end{array}$ \\
\hline \multirow[t]{2}{*}{ Self-Dispatch } & \multirow{2}{*}{$\begin{array}{l}\text { Reference, } \\
\text { Self-Dispatch }\end{array}$} & \multirow[t]{2}{*}{ 50SD } & In the reference sensitivity, no plants self-scheduled. \\
\hline & & & $\begin{array}{l}\text { For the self-scheduling sensitivity, } 50 \% \text { (by energy) of the } \\
\text { coal plants self-committed, and they were limited to full } \\
\text { capacity (i.e., they did not ramp up or down). }\end{array}$ \\
\hline
\end{tabular}




\begin{tabular}{|c|c|c|c|}
\hline Sensitivity & Level & Acronym & Description \\
\hline \multirow[t]{2}{*}{$\begin{array}{l}\text { Generator } \\
\text { Retirements }\end{array}$} & $\begin{array}{l}\text { Reference, } \\
\text { Coal } \\
\text { Retirements }\end{array}$ & Ret & $\begin{array}{l}\text { In the non-retirement sensitivities, no generators were } \\
\text { retired irrespective of how much variable or conventional } \\
\text { generation was added. }\end{array}$ \\
\hline & & & $\begin{array}{l}\text { For the retirement sensitivity, the capacity value }(12 \%) \text { of } \\
\text { the added variable generation was retired. The plants that } \\
\text { were retired were the least used coal plants. }\end{array}$ \\
\hline
\end{tabular}

The combination of a system configuration and sensitivity defines a scenario. For example, the reference system configuration in which $50 \%$ of the coal-fired generators were self-dispatched is labeled Ref:50SD; the prefix "Ref" represents the system configuration, and the suffix, "50SD," represents a sensitivity on the reference case. Note that results for the underlying base system configuration do not have a suffix. Among the various combinations of system configurations and sensitivities, the results for 20 scenarios are presented (see Table 3). 


\section{Table 3. Scenarios: System Configurations and Sensitivity Combinations}

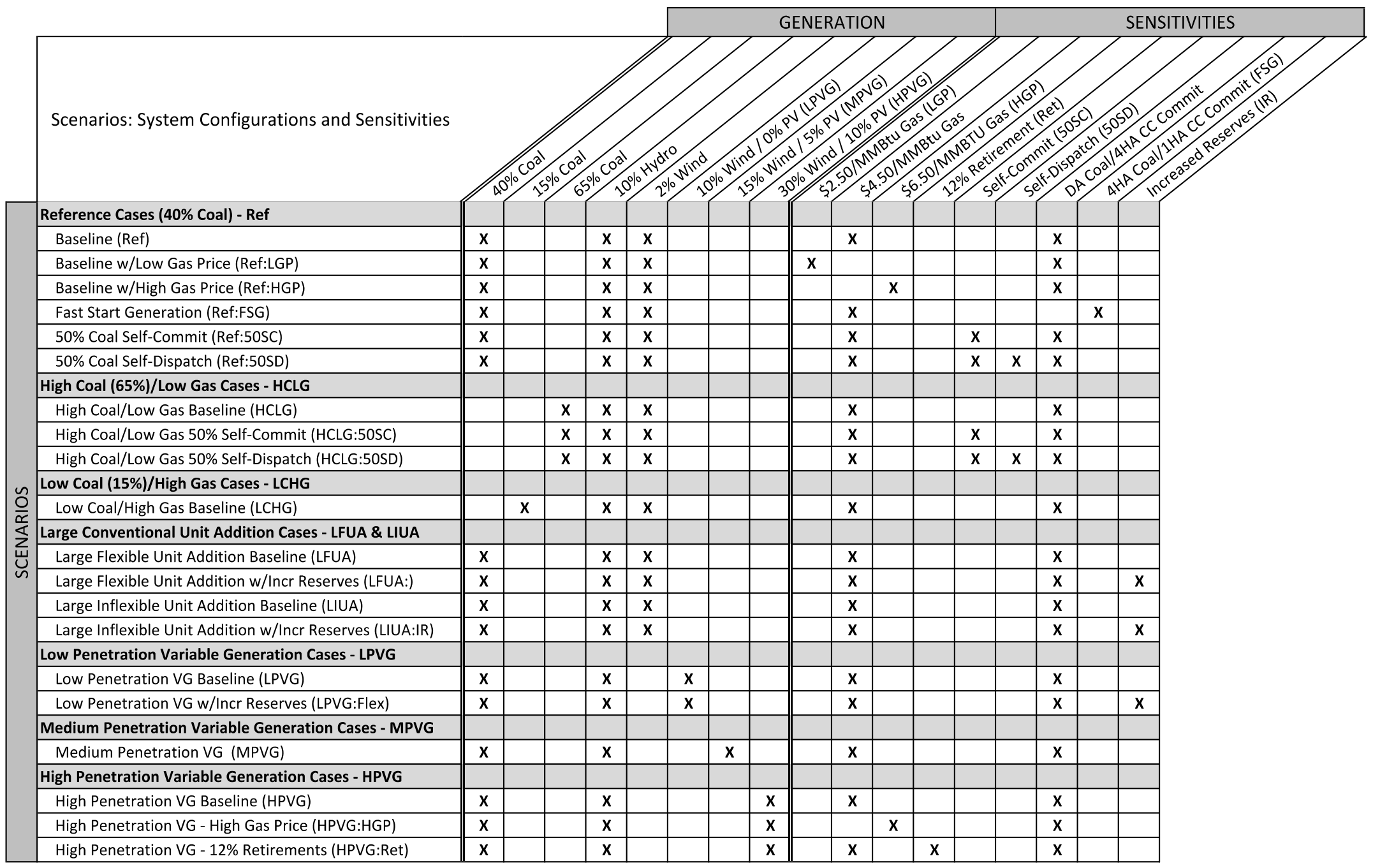

Note: sensitivities without acronyms (\$4.50/MMBtu Gas and DA Coal/4HA CC Commit) are reference values 
The above scenarios were used to create the seven sets of experiments described in Section 1.4, and the experiments included in each set are shown in Table 4 below.

Table 4. Experiments: System Configurations and Sensitivity Combinations

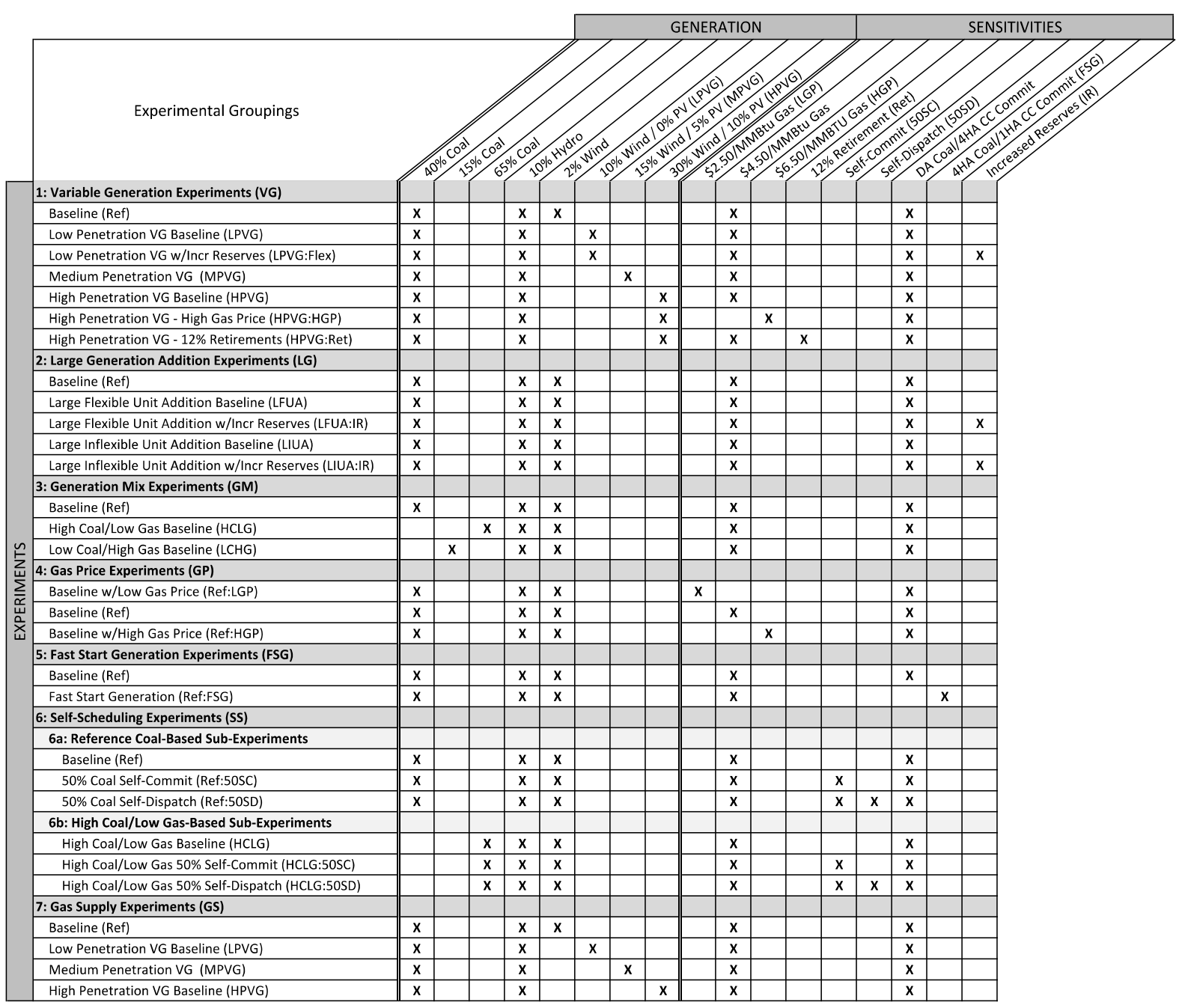

Note: sensitivities without acronyms (\$4.50/MMBtu Gas and DA Coal/4HA CC Commit) are reference values 


\section{Updated 118-Bus Test System}

The test system used in this study is a modified version of Illinois Institute of Technology's (IIT's) Institute of Electrical and Electronics Engineers (IEEE) three-region, 118-bus securityconstrained unit commitment model with wind (IIT 2013). The 118-bus model consists of three interconnected regions with a mix of generator types in each. Actual load date from balancing authority areas were used in each region (see Section 3.1). A one-line diagram of the reference version of the model can be found in Appendix B.

The changes made to the IIT model were twofold. First, the capacity parameters of the generation and transmission line were increased to be more representative of today's generator sizes. By making this change, we were better able to match the generation fleet to available operating cost data.

Second, although the initial intent was to maintain the generation mix ratio of the IIT model as the reference case, preliminary test runs showed that the IIT generation mix produced results in which more than $90 \%$ of the energy delivered (per annum) was from coal-a situation not particularly representative of today's generation practices. (For example, the Eastern Interconnection is approximately $40 \%$ coal.) To better represent today's generation fleets, some of the coal plants in the model were converted to one or more combined-cycle plants.

Additional information about the test system's generation and transmission configuration is provided in Section 3.2 and Section 3.3 below.

\subsection{Study Regions}

The three balancing authorities that were selected for the study were R1 Sacramento Municipal Utility District (SMUD), a region that has no coal-fired generation; R2 Public Service Company of Colorado (PSCO), a region rich in both wind and solar resources; and R3 Puget Sound Energy (PSE), a region with abundant hydro. These geographic regions were selected in consultation with the technical review committee to provide a reasonable approximation of an actual interconnection yet are small enough to allow the team to examine a large number of scenarios and sensitivity combinations.

An iterative process was used to overlay each balancing authority area's load onto a test system region's available generation. Regional loads were iteratively scaled until the generation available in a region was just able to meet the load demand and reserve requirements for the simulation year, including accounting for random forced outages that occurred throughout the simulation year. The intent was to provide a test system in which results were not skewed by loss-of-load charges or excess capacity.

\subsection{Generation}

Two types of generation are discussed below: baseline generation, which is the generation defined in the original test system (with the modifications noted above), and new generation, which is generation added to the baseline system to better understand the effects of adding various technology types to an existing grid. 


\subsubsection{Baseline Generation}

The change to generator size was a simple linear scaling in which all generators were doubled in size. Corresponding changes were made to the transmission network to accommodate the larger generators. (See Section 3.3 for additional information.) The change yielded generators that ranged from $40 \mathrm{MW}$ for the smallest combustion turbine to $840 \mathrm{MW}$ for the largest coal-fired, baseload facility. A distribution of the generator sizes in the baseline system is shown in Figure 1.

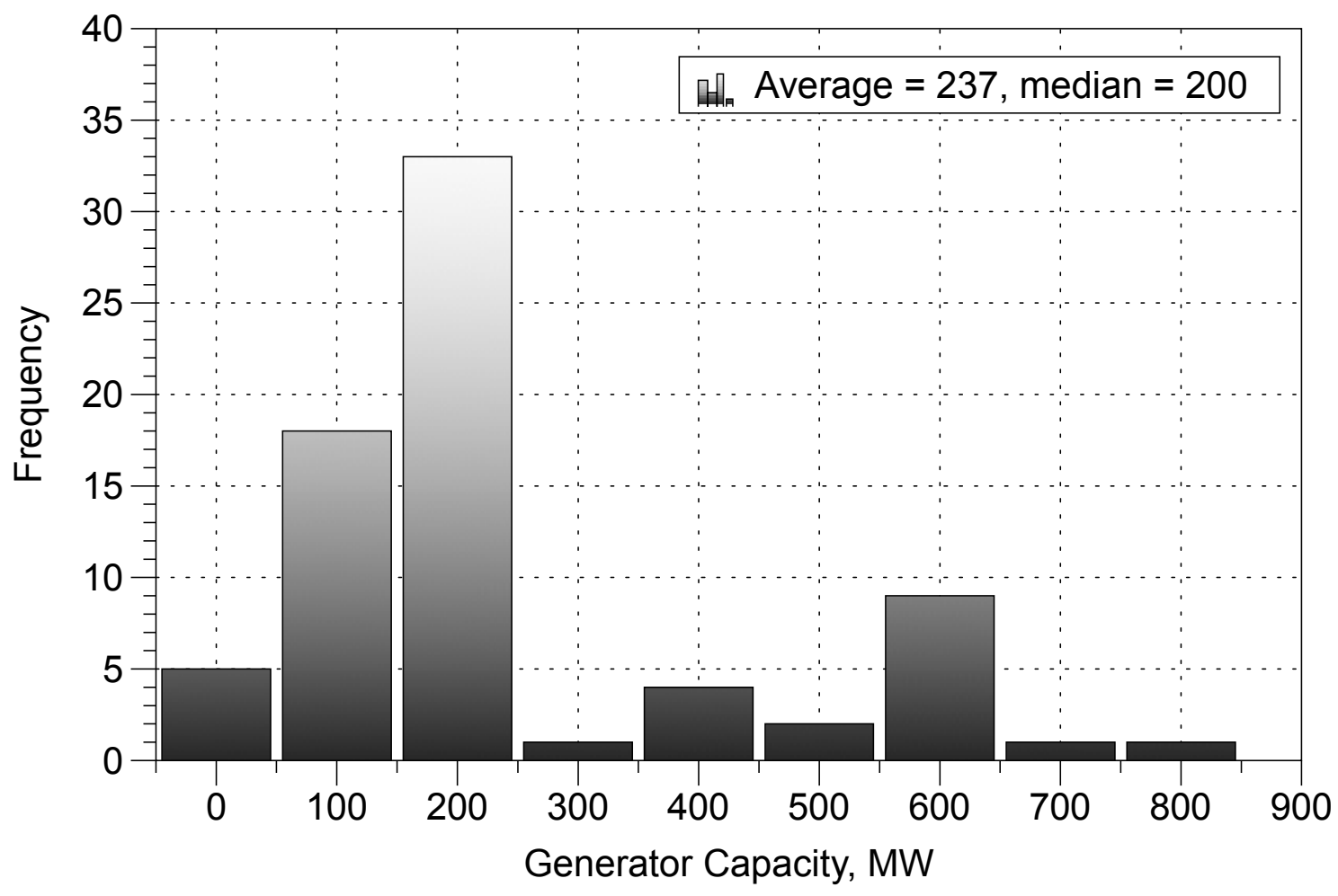

Figure 1. Test system generator sizes

As mentioned above, to achieve generation mix results that better represented recent practices, a number of the coal-fired steam plants from the IIT model were changed to combined-cycle units. The method used to convert a plant was simple. Smaller coal plants (less than $300 \mathrm{MW}$ ) were converted one-to-one. For example, a 200-MW coal plant became a 200-MW combined-cycle plant. Larger coal plants (300 MW or larger) were converted into two combined-cycle units, both on the same bus. For example, a 600-MW coal plant became a 2 x 300-MW combined-cycle plant.

The baseline generation mix for the updated system is shown in Table 5. 
Table 5. Generation Mix Used in the 118-Bus Reference Model

\begin{tabular}{|c|c|c|c|c|c|}
\hline Unit Type & $\begin{array}{l}\text { Fuel } \\
\text { Type }\end{array}$ & $\begin{array}{r}\text { Capacity } \\
\text { (MW) }\end{array}$ & Capacity (\%) & $\begin{array}{l}\text { Energy } \\
\text { (GWh) }\end{array}$ & $\begin{array}{r}\text { Energy } \\
(\%)\end{array}$ \\
\hline Combined Cycle & Gas & 7,850 & $45 \%$ & 27,946 & $43.56 \%$ \\
\hline Hydro & - & 1,418 & $8 \%$ & 7,065 & $11.00 \%$ \\
\hline Steam & Coal & 3,700 & $21 \%$ & 26,982 & $42.06 \%$ \\
\hline $\begin{array}{l}\text { Combustion } \\
\text { Turbine }\end{array}$ & Gas & 3,560 & $20 \%$ & 979 & $1.53 \%$ \\
\hline $\begin{array}{l}\text { Combustion } \\
\text { Turbine }\end{array}$ & Oil & 640 & $4 \%$ & 8 & $0.01 \%$ \\
\hline PV & - & 0 & $0 \%$ & 0 & $0.00 \%$ \\
\hline Wind & - & 366 & $2 \%$ & 1,174 & $1.83 \%$ \\
\hline Total & & 17,534 & $100 \%$ & 64,154 & $100.00 \%$ \\
\hline
\end{tabular}

A one-line diagram of the test system can be found in Appendix B, and additional information about the generation parameters used for the test system can be found in Section 0 .

\subsubsection{New Generation}

This section describes the new generation added to the reference model to create large conventional generation, large inflexible generation, and variable generation scenarios:

- New baseload generation with moderate flexibility (large flexible generation)

$\circ$ The new coal plant was sized to match the largest existing baseload generator (840 MW). The new generator's operational parameters were identical to those of the existing 840-MW generator except that it had slightly improved efficiency (a nominal heat rate of $10,000 \mathrm{Btu} / \mathrm{kWh}$ compared to 10,080 for the existing plant).

- New baseload generation with limited flexibility (large inflexible generation)

- The new, limited-flexibility generator was identical to the new, moderately flexible generator except that its minimum stable level and the maximum ramp rates were set to mimic a generator with limited flexibility. (A minimum stable level of $90 \%$ and a maximum ramp rate of $2.5 \mathrm{MW} / \mathrm{min}$ were used instead of $50 \%$ and $9.25 \mathrm{MW} / \mathrm{min}$, respectively, for the new moderately flexible baseload plant.)

- New variable generation

- New wind and solar power plants were distributed among the three regions. When penetration levels of variable generation for a given scenario increased, plants were added iteratively until the wind and solar production totals matched the target energy values for that scenario. In all scenarios except the high-penetration variable generation scenario, only actual wind and solar power plants from the region of study were used for that region. However, in the high-penetration scenario, there was not enough variable generation in all regions in the Western Electricity Coordinating Council (WECC 2011) Transmission Expansion Planning Policy Committee 2020 test case to meet the desired penetration goals, and in such cases variable generation from adjacent regions was used to 
supplement a region's variable generation. (For example, nearby solar PV in the PG\&E valley region could be used to supplement the PV in the SMUD region.)

Note that although an effort was made to distribute the variable generation within a region so that its addition would not cause undue congestion, no effort was made to optimize the placement of this new generation within a region or overall system.

\subsection{Transmission}

In the initial configuration, the transmission parameters used in the simulation were those of the IIT's 118-bus system scaled by a factor of two. (For example, a 100-MW line in the IIT model became a 200-MW line in the study model.) Once this preliminary model was configured, a trial simulation of the reference scenario was performed, and the results were examined to confirm that the transmission parameters were realistic. Lines with load limits that caused average shadow prices higher than $\$ 10 / \mathrm{MW}$ were iteratively increased in capacity until the average shadow prices for that line were less than the $\$ 10 / \mathrm{MW}$ limit. Note that only 7 of the 186 lines had non-zero shadow prices, and of those most prices (all but two) were less than \$1/MW. The updated line limits remained constant in all scenarios and sensitivity simulations.

For most scenarios, the average shadow prices on the lines remained much less than \$10/MW. However, for the medium- and high-penetration runs, the average shadow price of one line - the one that connected Bus 99 to Bus 100 - exceeded the \$10/MW limit. (The average price reached \$11.25/MW for the MPVG simulations and \$24.12/MW for the HPVG simulations.) The project team considered raising the limit of this line but decided that congestion was reasonable between one region with abundant variable generation resources and one with lesser resources.

\subsection{Reserves}

Three types of spinning reserves were used in the simulations: regulating, contingency, and flexibility. The methods used to calculate each respective reserve type are described below.

\subsubsection{Regulating Reserves}

The regulating reserves were the same for all scenarios: $1 \%$ of load. Regulating reserves were apportioned by region according to regional load. Only generators within a given region were permitted to provide reserves for that region.

\subsubsection{Contingency Reserves}

The nominal contingency reserves were sized to match the full outage of the largest baseload generator, $840 \mathrm{MW}$. The reserves were increased 50\% to 1,260 MW for the two increased reserve sensitivity runs. Contingency reserves were apportioned by region (proportional to regional load). Only generators within a given region were permitted to provide reserves for that region.

\subsubsection{Flexibility Reserves}

Flexibility reserves - designed specifically to address load-following needs for wind - were held to cover $70 \%$ of the 1-hour forecast errors of wind as in the Western Wind and Solar Integration Study (Lew et al. 2013). Flexibility reserves were shared among the three regions. 


\section{Research Methods and Operational Assumptions}

This section describes generator siting procedures, production simulation methodologies, and operation assumptions used in the integration cost studies.

\subsection{Generator Siting}

For the reference scenario, the locations of the generators were those defined by IIT's 118-bus model. The methods used for the generator siting in scenarios that include new generation are described below.

The amount of new variable generation that was assigned to a given region in the variable generation simulations was selected in proportion to the availability of variable generation in the Transmission Expansion Planning Policy Committee 2020 base case. For all of the variable generation scenarios, the wind and solar data were derived from WWSIS-2 (Lew et al. 2013). In most cases, there were adequate variable generation resources within the database to meet the desired penetration goals; however, in the HPVG test cases, it was necessary to use wind and solar from adjacent regions when the wind or solar in a particular region was inadequate to meet penetration targets of variable generation. (For example, solar from the PG\&E valley sites was used to supplement SMUD solar.)

Siting of the large conventional unit additions was driven by practicality. Both the large, flexible plant and the large, inflexible plant were sited in Region 2 (PSCO) because PSCO already had a number of coal plants. Both generators were placed on the same bus (65); however, at any given time, only one was active in a scenario. To ensure that the generation placement did not create undue congestion, the congestion around Bus 65 was examined after the new baseload generators were added, and the congestion changes were found to be unremarkable.

\subsection{Production Simulation Methodologies and Operation Assumptions}

Of the three balancing authority areas selected for the current study, two are vertically integrated utilities that balance their systems with their own generation and confidential bilateral transactions with neighboring utilities. This creates a system that is difficult to model because much of the information about the system's operation is confidential. Given that information about bilateral agreements was unavailable, a security-constrained, least-cost, economic dispatch approach without hurdle rates among regions was used for the simulations.

Future year 2020 was modeled from historical weather patterns and loads from 2006.

\subsubsection{Security-Constrained Unit Commitment}

For all but the fast-start generation sensitivity studies, two unit commitment runs were used: a day-ahead unit commitment for hydro and coal generation and a 4-hour ahead unit commitment for the combined-cycle plants. The two commitment runs were used so that the model could incorporate improving forecasts over the two time horizons. Additional information about each commitment run is provided below. 
A day-ahead unit commitment model was used to commit the coal and hydro units. The model included day-ahead wind and solar forecasts, used a resolution of 1 hour, and had an optimization horizon of 48 hours. Data from the first 24 hours of horizon were saved to provide hydro and coal plant commitment information to the 4-hour-ahead model and then later to the real-time dispatch model; and the extra 24 hours in the optimization horizon helped ensure that the coal plants, with long start times and high start costs, were properly committed.

Next, a 4-hour-ahead unit commitment simulation was used to commit the combined-cycle plants. The 1-hour resolution model included 4-hour-ahead wind and solar forecasts along with the hydro and coal commitments from the day-ahead model. The 4-hour-ahead commitment model used an 8-hour time horizon. Commitment data from the first 4 hours from each run were saved for the real-time model, and the extra 4 hours in the optimization horizon helped ensure that the combined-cycle units were optimally dispatched.

The fast-start generation sensitivity simulations differed in that only hydro was committed in the day-ahead unit commitment model; coal was committed in a 4-hour-ahead model; and a new, hour-ahead commitment model along hour-ahead forecasts and a 2-hour optimization horizon was used to commit the fast-start combined-cycle units.

Note that for all unit commitment simulations (day-ahead, 4-hour-ahead, and hour-ahead), the load forecasts were assumed to be perfect because a consistent set of load forecasts were unavailable. As a result, all operations uncertainty came from wind and solar, and this assumption likely resulted in putting a greater burden on wind and solar than is realistic. Variability, on the other hand, came from load, wind, and solar.

\subsubsection{Security-Constrained Economic Dispatch}

After the unit commitment simulations were complete, a real-time economic dispatch model with 5-minute resolution and a 2-hour look-ahead was used to dispatch the remaining units (i.e., combustion turbines). Hydro, coal, and combined-cycle commitments were passed to the realtime dispatch model from the 4-hour-ahead (hour-ahead in the case of the fast-start generation simulations). The 2-hour look-ahead period was implemented to capture how an operator would account for their expectations for the near future before deciding to start a machine.

\subsubsection{Reserves}

Regulating and contingency reserves were held in the day-ahead, 4-hour-ahead, hour-ahead, and real-time markets. Flexibility reserves, when used, were held in the day-ahead and 4-hour-ahead markets and released in the real-time market. Penalties for violating load and regulating, contingency, and flexibility reserve requirements are shown in Table 6 . These penalties were chosen to be high enough that starting a new unit to provide reserves would typically lower system costs rather than allow the reserves to go unserved. Infrequently, small reserve violations $(<1 \mathrm{MW})$ occurred in situations when it was more expensive to start a machine than allow the violation; however, all loads were served throughout the simulations. 
Table 6. Penalties for Unserved Load and Reserve Violations

\begin{tabular}{lr} 
Loads and Reserves & Penalty (\$/MWh) \\
\hline Load & 6,000 \\
Regulating Reserves & 4,100 \\
Contingency Reserves & 4,000 \\
Flexibility Reserves & 3,900
\end{tabular}

\subsubsection{Hydro Operation}

Hydro generation was optimized on a monthly basis, with limits iteratively adjusted in the preliminary configuration runs until hydro provided approximately $11 \%$ of the annual energy. The individual units were operated with a minimum stable level set to $25 \%$ of their maximum capacity, and the ramp rates were limited to $10 \%$ of the unit's maximum capacity per minute.

\subsubsection{Generator Retirements}

In general, when new generation was added to a given scenario, none of the existing generation was retired. The one exception to this was the HPVG:Ret simulation, in which coal plants were retired. For this simulation, the equivalent of $12 \%$ of the variable generation capacity was retired. The coal plants that were retired were those with the lowest capacity factors.

\subsubsection{Ramping Operations}

Two types of ramp-related phenomena were tracked in the simulations: ramp events and amount of ramp. The first item tracked generator events in which a generator moved more than $30 \%$ of its rated capacity while in operation. Although costs were assigned to each ramp, these costs were calculated post simulation (i.e., these ramping costs were not considered in the optimization).

We also tracked how much generators moved, either up or down, during the process of generating power. Ramp-related charges were assigned to this type of ramping, and they were accounted for in the unit commitment and market dispatch optimizations. (See Table 7 in the next chapter.)

\subsubsection{Start-Up and Shutdown Operations}

Several items related to start-up and shutdown were simulated, including minimum up time after a start, minimum downtime after a shutdown, start-up fuel use, start-up-related non-fuel VO\&M (e.g., auxiliary power costs), and the number of start-up/shutdown cycles and their associated wear-and-tear costs.

In the study, no differentiation was made between hot, warm, or cold starts. Instead, the average of the median start parameters was used. Additionally, all generators were assumed to start with their primary fuel. Although this assumption likely underestimated start fuel costs (especially for the coal-fired plants, in which natural gas is often used), these costs were so small compared to other start costs that this simplification was adequate for modeling purposes.

Start costs and start fuel requirements were based on those used in WWSIS-2 (Lew et al. 2013), and start-up and shutdown costs were grouped together (i.e., the costs associated with starting 
and stopping a generator were considered a single cost). These parameters are detailed in Section 5.5.5.

\subsubsection{Maintenance and Expected Forced Outages}

Maintenance outages were not simulated.

Forced outages were simulated using a simple random uniform distribution with fixed outage durations. To help ensure that outage times for generators did not vary among simulation runs, each generator was assigned a unique random number generator seed that remained fixed from one simulation to another. This approach was chosen to reduce cost artifacts caused by shifts in in the occurrences of forced outages. 


\section{Input Data}

Wind, solar, and load data from WECC's SMUD, PSCO, and PSE balancing authority areas were mapped to regions 1, 2, and 3 of the 118-bus model, respectively. These three regions were selected in an attempt to capture the general characteristics of the Western Interconnection yet keep the overall model simple enough that a large number of scenarios and sensitivity combinations could be explored.

The SMUD balancing authority area was mapped to Region 1. Its generation fleet consisted of gas (combined-cycle units and combustion turbine units) and moderate hydro. PSCO was mapped to Region 2, which had a fleet of coal, gas, and oil generation. And PSE was mapped to Region 3, which had a mixed generation fleet that included abundant hydro. Load data were scaled to match the available capacity in each region.

The wind, solar, and load data as well as generator operating parameters (e.g., ramp rates and start times) were obtained from WWSIS-2 (Lew et al. 2013). Additional information about the input data is provided below.

\subsection{Study Period}

The study period for this work was from January 1, 2020, through December 31, 2020, with the underlying load and meteorological data from 2006. The day-ahead and 4-hour-ahead commitment runs used 1-hour load and forecast data. The real-time market simulations used 5minute load, solar, and wind data. All data used were time synchronized to maintain the proper correlations among load, solar irradiance, and wind velocity.

\subsection{Load Data}

The original source of the load data was the WECC Variable Generation Subcommittee, which provided 1-minute load data that had been statistically scaled to match the Transmission Expansion Planning Policy Committee 2020 load projections. Load forecast data were not available, so perfect load forecasts were used in both the day-ahead and 4-hour-ahead unit commitment simulations.

Note that the use of perfect load forecasts caused all operations uncertainty to be attributed to wind and solar.

\subsection{Wind Data}

The wind data used in this study were derived from a data set that was created by 3TIER for the Western Wind and Solar Integration Study Phase 1 (GE Energy 2010). This data set included both day-ahead forecasts as well as wind "actuals" (3TIER 2010; Potter et al. 2008; Potter et al. 2007). ${ }^{14}$

\footnotetext{
${ }^{14}$ Information about how the WWSIS-2 team used the 3TIER data to create the wind day-ahead forecasts, 4-hourahead forecasts, and wind output data ("actuals") can be found in Section 2.4 of WWSIS-2 (Lew et al. 2013).
} 


\subsection{Solar Data}

Hummon and colleagues (2012) developed the solar data by using NREL-developed statistical algorithms to combine data from WWSIS-1; satellite-derived irradiance data from Clean Power Research's SolarAnywhere data, which were based on a semiempirical model developed by Perez (2002) and Perez and colleagues (2002); and subhourly data collected through NREL's Measurement and Instrumentation Data Center. ${ }^{15}$ Section 2.5 of WWSIS-2 (Lew et al. 2013) describes how the WWSIS-2 team created the wind day-ahead forecasts, 4-hour-ahead forecasts, and solar output data ("actuals").

\subsection{Generator Data}

The generator data came from Intertek-APTECH's report on Power Plant Cycling Costs (Kumar et al. 2012), which was jointly commissioned by WECC and NREL as part of WWSIS-2. An exception was the heat rate data, which were derived from WWSIS-2 (Lew et al. 2013).

\subsubsection{Heat Rates}

As mentioned above, the generator heat rates used for the integration costs were derived from WWSIS-2. They differed slightly from WWSIS-2 values in that the coal and combined-cycle generators categories were divided into two: small generators and large generators. The dividing point was $300 \mathrm{MW}$ for the coal plants and $200 \mathrm{MW}$ for the combined-cycle plants, and the heat rates assigned to the larger plants were assumed to be slightly better than those of the smaller plants (see Table 7).

Although heat rate degradation is a known problem associated with generator cycling (Kumar et al. 2012), these effects were not included in the current study.

\subsubsection{Start-Related Generator Costs}

Start costs and start fuel requirements were derived from APTECH's report on Power Plant Cycling Costs (Kumar et al. 2012). Start penalties (start-related wear-and-tear), start fuel, nonfuel start-related VO\&M (auxiliary power, chemicals, etc.) were modeled; and all values were set to median values, except for the start penalties, which were set to the average of the hot-, warm-, and cold-start median values (i.e., no differentiation was made among start types, and average values were used).

To simplify modeling efforts, all units started with their primary fuel. Although this assumption likely underestimated start fuel costs, these costs were small compared to other start costs so the simplification was found to be adequate for modeling purposes.

A summary of the nominal generator start parameters is shown in Table 7.

\subsubsection{Ramping-Related Generator Costs}

Two types of ramping costs were calculated: ramp event costs and ramping costs. Ramp event costs were calculated post simulation with the method described in WWSIS-2, and ramping costs

${ }^{15}$ See www.nrel.gov/midc. 
were calculated during the optimization using ramping charges derived from those used in WWSIS-2.

Ramp events were determined post simulation by examining generator movement over time. Any time a generator's output moved more than $30 \%$ of its rated capacity (excluding on/off cycles and independent of operating duration), a ramp event charge was created and the ramp starting point was reset. The ramp event charge used in the calculations was as determined in (Kumar et al. 2012).

Ramping costs were included so that the ramp-related financial impacts of ramping would be included in the commitment and dispatch optimizations. Ramp charges were derived from ramp event charges by dividing a generator's ramp event charge by the rated capacity of the generator to create a $\$ / \mathrm{MW}$ of the generator movement charge (i.e., a ramp charge). The ramp charge was then included in the production cost model calculations for both the unit commitment and market dispatch simulations. A summary of the generator ramp parameters can be found in Table 7 .

\subsubsection{Forced Outage Rates and Repair Times}

Although forced outage rate degradation is a known concern associated with generator cycling (Kumar et al. 2012), these effects were not included in the current study. Outage durations (mean time to repair) were fixed for a given generator type. A summary of the parameters of the equivalent forced outage rates and mean times to repair can be found in Table 7.

\subsubsection{Summary of Generator Parameters}

Table 7 summarizes the key generator parameters that were used in the production cost modeling optimizations. 
Table 7. Thermal Unit Simulation Parameters

\begin{tabular}{|c|c|c|c|c|c|c|c|}
\hline & $\begin{array}{r}\text { Baseload Coal } \\
\geq 700 \mathrm{MW} \\
\end{array}$ & $\begin{array}{l}\text { Large Coal } \\
<700 \mathrm{MW} \\
\geq 300 \mathrm{MW}\end{array}$ & $\begin{array}{r}\text { Small Coal } \\
<300 \mathrm{MW}\end{array}$ & $\begin{array}{r}\text { Large CC } \\
\geq 200 \mathrm{MW} \\
\end{array}$ & $\begin{array}{r}\text { Small CC } \\
<200 \mathrm{MW} \\
\end{array}$ & CT Gas & $\mathrm{CT} \mathrm{Oi}$ \\
\hline Heat Rate (BTU/kWh) & 10,000 & 10,080 & 10,940 & 7,020 & 7,220 & 12,580 & 12,710 \\
\hline $\begin{array}{l}\text { Equivalent Forced Outage } \\
\text { Rate (\%) }\end{array}$ & $5.82 \%$ & $5.82 \%$ & $4.51 \%$ & $5.91 \%$ & $5.57 \%$ & $4.28 \%$ & $3.91 \%$ \\
\hline $\begin{array}{l}\text { Mean Time to Repair } \\
\text { (h) }\end{array}$ & 40 & 38 & 35 & 24 & 24 & 55 & 67 \\
\hline $\begin{array}{l}\text { Minimum Generation } \\
\text { (\% of Maximum Capacity) }\end{array}$ & $50 \%$ & $50 \%$ & $50 \%$ & $50 \%$ & $50 \%$ & $50 \%$ & $50 \%$ \\
\hline $\begin{array}{l}\text { Minimum Up Time After } \\
\text { Generator Start-Up (h) }\end{array}$ & 10 & 8 & 5 & 2 & 2 & 1 & 1 \\
\hline $\begin{array}{l}\text { Minimum Downtime After } \\
\text { Generator Shutdown (h) }\end{array}$ & 24 & 24 & 20 & 4 & 4 & 1 & 1 \\
\hline Ramp Rate (\%/minute) & $1.1 \%$ & $1.1 \%$ & $1.1 \%$ & $0.9 \%$ & $0.9 \%$ & $4.5 \%$ & $4.5 \%$ \\
\hline Ramp Charge (\$/MW) & 2.45 & 2.45 & 3.34 & 0.64 & 0.77 & 1.59 & 2.07 \\
\hline $\begin{array}{l}\text { Ramp Event Charge } \\
{\text { (\$/Ramp Event })^{16}}^{\text {(Ram }}\end{array}$ & 245 & 245 & 334 & 64 & 77 & 159 & 207 \\
\hline $\begin{array}{l}\text { Start Cost: Non-Fuel VO\&M } \\
\text { (\$/MW Capacity/Start) }\end{array}$ & 8.67 & 7.91 & 6.22 & 1.11 & 1.01 & 0.95 & 1.24 \\
\hline $\begin{array}{l}\text { Start Cost: Wear and Tear } \\
\text { (\$/MW Capacity/Start) }\end{array}$ & 75 & 76 & 133 & 56 & 67 & 87 & 107 \\
\hline $\begin{array}{l}\text { Start Fuel } \\
\text { (MMBTU/MW Capacity) }\end{array}$ & 15.8 & 10.5 & 7.0 & 0.21 & 0.25 & 0.2 & 0.26 \\
\hline VO\&M (\$/MWh) & 2.96 & 2.68 & 2.82 & 1.02 & 1.22 & 0.57 & 0.74 \\
\hline
\end{tabular}

\footnotetext{
${ }^{16}$ Ramp events occur any time a generator moves more than $30 \%$ of its rated capacity (e.g., a 100-MW unit moved from $55 \mathrm{MW}$ to $86 \mathrm{MW}$ ).
} 


\subsection{Fuel Prices}

The fuel prices used in the production cost modeling are shown in Table 8. The low gas price (LGP) and the high gas price (HGP) values for natural gas were used only in the LGP and HGP sensitivities.

Table 8. Simulation Fuel Prices

\begin{tabular}{lc} 
Fuel Type & $\begin{array}{c}\text { Price } \\
\text { (\$/MMBTU) }\end{array}$ \\
\hline Coal & 1.80 \\
Natural Gas (Reference) & 4.50 \\
Natural Gas (HGP) & 6.50 \\
Natural Gas (LGP) & 2.50 \\
Oil & 20.00
\end{tabular}

To account for the volatility in natural gas prices, nominal gas prices for both the unit commitment and market dispatch simulations varied monthly (see Appendix D). Prices for coal and oil were held constant throughout all simulations. 


\section{Reporting Format for the Experimental Results}

This section describes the reporting format used to present the results. The integration cost study consisted of seven groups of experiments:

- Variable generation-Chapter 0

- Large conventional generation-Chapter 8

- Generation mix-Chapter 9

- Gas prices-Chapter 10

- Fast-start generation-Chapter 11

- Self-commitment/self-dispatch-Chapter 12

- Gas supply constraints - Chapter 13.

Results in chapters 7 through 12 are divided into seven sections, and these are described below. The same numbering scheme is used from one chapter to another so that results can be easily compared.

- Overall system impacts-Section 6.1

- System impacts per unit of new generation added-Section 6.2

- Start effects-Section 6.3

- Ramp effects-Section 6.4

- Reserves effects-Section 6.5

- Capacity factor and curtailment effects-Section 6.6

- Summary-Section 6.7.

Note that only the first six sets of experiments followed the format presented here. The seventh set of results - the gas supply experiments in Section 13-differed markedly from the other experiments, so it has a much different format.

Finally, the reporting period for each set of experiments is the entire 1-year study period, from January 1, 2020, through December 31, 2020. (Note: costs and generation values are per year unless noted otherwise.)

\subsection{Overall System Impacts}

The system impacts subsection allows the reader to see the overall results at a glance, and the following system metrics are reported:

- Total generation costs

- Energy delivered by generator type

- Average generation cost by generator type

- Average fuel cost by generator type

- Cycling costs by cost component type

- Average cycling costs by generator type

- Average VO\&M costs by generator type

- Average non-fuel operating costs by generator type. 
Generation costs are defined as:

$$
\text { Generation Costs }=\text { Cycling Costs }+ \text { VO\&M Costs }+ \text { Operating Fuel Costs }
$$

The generation cost figures help orient the reader to how various system changes affect the overall operating cost. The production costs are broken out in terms of the cost component of each generation type (e.g., coal, combined cycle, or combustion turbine).

The energy delivered by generator type figures show how a difference between scenarios affects various generator types (For example, coal plants and combined cycle units) within the system.

The average generation cost by generator type tables allow for easy comparison of costs in terms of how this system compares to other systems. (For example, how do the costs in this study compare to those of NREL's WWSIS-2?)

Next, the average generation costs are broken out into their components. Tables that present the average fuel cost by generator type are first because fuel costs are the largest component of the production costs. The fuel costs are reported on a basis of cost per unit of energy to allow easy comparison among studies.

Next, the cycling costs are reported. These are defined as:

$$
\text { Cycling Costs }=\text { Startup Costs }+ \text { Ramping Costs }
$$

The cycling costs are presented two ways: cycling costs by cost component type and average cycling costs by generator type.

The cycling costs by component type help capture how a given system configuration responds to the variability in the load and generation in terms of start-up and ramping-related costs. The start-up costs captured the start fuel costs, as shown in the following equation:

$$
\text { Startup Costs }=\text { Start VO\&M Costs }+ \text { Start Wear \& Tear Costs }+ \text { Start Fuel Cost }
$$

However, these costs were so small that the start-up and cycling costs were not separated from the non-fuel costs. Start VO\&M costs include auxiliary power and chemicals costs, and the start wearand-tear costs include the wear-and-tear costs related to VO\&M costs.

The average cycling costs by generator type tables provide a per-unit cycling cost that can be compared directly to other operating costs, and it allows readers to see how much of the overall operating costs are due to generator cycling.

The average VO\&M costs by generator type tables capture how various system configurations affect the system's operating VO\&M costs. (For example, does adding new generation increase or decrease VO\&M costs?) Note that these costs exclude the start-up and ramping-related VO\&M costs because these cycling-related VO\&M costs were tracked separately. 
Finally, the tables that present the average non-fuel operating costs by generator type include a metric that is the sum of the cycling costs and VO\&M costs. This metric shows the overall impact that a change in the system has on the system.

$$
\text { Non }- \text { Fuel Operating Costs }=\text { Cycling Costs }+ \text { VO\&M Costs }
$$

This metric can be thought of as the integration cost per unit of system energy ( $\$ / \mathrm{MWh})$, and it includes both the cycling and operations and maintenance impacts of the system changes.

All of the per-unit metrics provided above can be used among the experiment sets, including the weighted average costs metrics that were calculated by weighing the costs for a given generator class by the amount of energy delivered by that type of generator. (For example, the impact that increasing the coal penetration has on VO\&M cost can be compared to how self-dispatch increases VO\&M costs.)

\subsection{System Impacts per Unit of New Generation Added}

For studies that include the addition of new generation, results are normalized in terms of the new generation added to the system.

The following metrics are reported:

- Change in generation cost per unit of new generation added

- Non-fuel operating cost changes per unit of new generation added

- Change in cycling costs per unit of new generation added.

The metric for the change in generation cost per unit of new generation added provides a summary of the fuel, start, ramp, and VO\&M incremental costs. It captures the changes in the system's overall generation cost (see Equation 6-1) normalized by the amount of new generation added to the system, and it allows the reader to see at a glance how a particular new generation scenario impacts the overall costs.

The metric for the non-fuel operating cost changes per unit of new generation added allows an examination of how new generation affects the non-fuel components (see Equation 6-4) of the operating costs to examine how much of the changes to overall system costs are due to the combined start, ramp, or VO\&M cost impacts. This metric, too, has been normalized by the amount of new generation added to the system.

Finally, the sum of the start, ramp, or VO\&M costs are presented according to change in cycling costs per unit of new generation added. This metric allows the direct comparison of how the addition of new generation affects cycling costs per amount of new generation added-i.e., it captures the incremental changes in Equation 6-2 normalized on a basis of new generation added. As with the other two per units of new generation metrics, it is useful to compare costs within a given set of experiments as well as among experiments. (For example, the variable generation numbers can be compared to the large conventional generation numbers.) 


\subsection{Start Effects}

The metrics reported in the study are:

- Number of starts

- Energy delivered per start.

The number of starts metric helps capture how system changes affect the start patterns of the various generator classes, and the energy delivered per start metric provides an efficiency per start measure of system operation.

\subsection{Ramp Effects}

The ramping-related metrics follow next. The ramping metrics reported in this study are:

- Number of ramp events

- Amount of ramp

- Amount of ramp per unit of energy delivered.

The number of ramps is a count of how many times a generator moves $30 \%$ or more of its rated capacity. (For example, if a 100-MW generator mores $30 \mathrm{MW}$ or more, that is a ramp event.) The amount of ramp metric captures the generator movement by tracking changes in generator output. (For example, a generation output decrease from $72 \mathrm{MW}$ to $70 \mathrm{MW}$ would be 2 units of ramp.) And the amount of ramp per unit of energy delivered metric is how much ramping occurs per MWh of energy delivered.

\subsection{Reserves Effects}

The costs of reserves provisioning are reported both on the overall system and per unit of energy delivered.

\subsection{Capacity Factor and Curtailment Effects}

This final section reports how configuration changes affect the system's capacity factors and curtailment values.

\subsection{Summary}

Each chapter closes with a summary of the experimental results. This section allows the reader to see the major findings of the experimental work. 


\section{Results of the Variable Generation Experiments}

The variable generation experiments were designed to help improve the understanding of how increasing levels of wind and solar PV affect the operation of a preexisting grid. Seven scenarios were studied with penetration levels of variable generation from $2 \%$ to $43 \%$ on a basis of energy supplied, and the names and designations of these simulations are below:

- Reference (Ref)-2\% wind

- Low-penetration variable generation (LPVG)-13\% wind

- Low-penetration variable generation with flexibility reserves (LPVG:Flex) - $13 \%$ wind

- Medium-penetration variable generation (MPVG)-5\% PV, 16\% wind

- High-penetration variable generation (HPVG)-11\% PV, 32\% wind

- High-penetration variable generation with high-priced natural gas (HPVG:HGP) - 11\% PV, $32 \%$ wind

- High-penetration variable generation with $12 \%$ equivalent coal retirement (HPVG:Ret) $11 \%$ PV, $32 \%$ wind.

The underlying scenario for all of the variable generation simulations was the reference scenario. Variable generation was added as needed to achieve the target amounts. (See Section 3.2.2 for a discussion about how the new generation was added to the system.) No conventional generation was retired when adding variable generation except in the simulation of high-penetration variable generation with coal retirement (HPVG:Ret), in which coal plants with an aggregate equivalent capacity of $12 \%$ of the installed wind were retired. The coal plants selected for retirement were those that had the lowest capacity factors in the reference scenario.

In addition to penetration level, two factors were examined: the value of flexibility reserves and the impact of high gas prices. The LPVG:Flex simulation was identical to the low-penetration variable generation (LPVG) scenario except that flexibility reserves covering $70 \%$ of the 60 -minute forecast errors of the wind were provisioned as load-following or flexibility reserves. The HPVG:HGP scenario was identical to the high-penetration variable generation (HPVG) simulation except that the nominal gas price for this simulation was $\$ 6.50 / \mathrm{MMBtu}$ rather than the reference price of \$4.50/MMBtu used in the HPVG and other scenarios.

Note that the LPVG:Flex, HPVG:HGP, and HPVG:Ret runs are included for completeness, and although they provide important information, they should be compared only to like runs. Specifically, the LPVG: Flex scenario should be compared to the LPVG, because it investigates the value of adding flexibility (load-following) reserves to a system. Likewise, the HPVG:HGP and HPVG:Ret results should be compared only to the HPVG scenario. These two HPVG-based runs investigated how high gas prices would affect system operations at high penetrations of variable generation and how operations change if the capacity value equivalent of the conventional generation is retired in a high-penetration system. 


\subsection{Overall System Impacts}

Figure 2 shows the overall generation costs for the scenarios broken out by generator type. The first trend that is apparent is that as the amount of renewable energy increased, the overall costs dropped. The next trend that is apparent is that as the variable generation increased, combined-cycle generation was displaced. Although most of the displaced combined-cycle generation was replaced by variable generation, a significant amount of combined-cycle generation (up to three times for the highest penetrations of variable generation) was displaced by gas-fired combustion turbines (Figure 3).

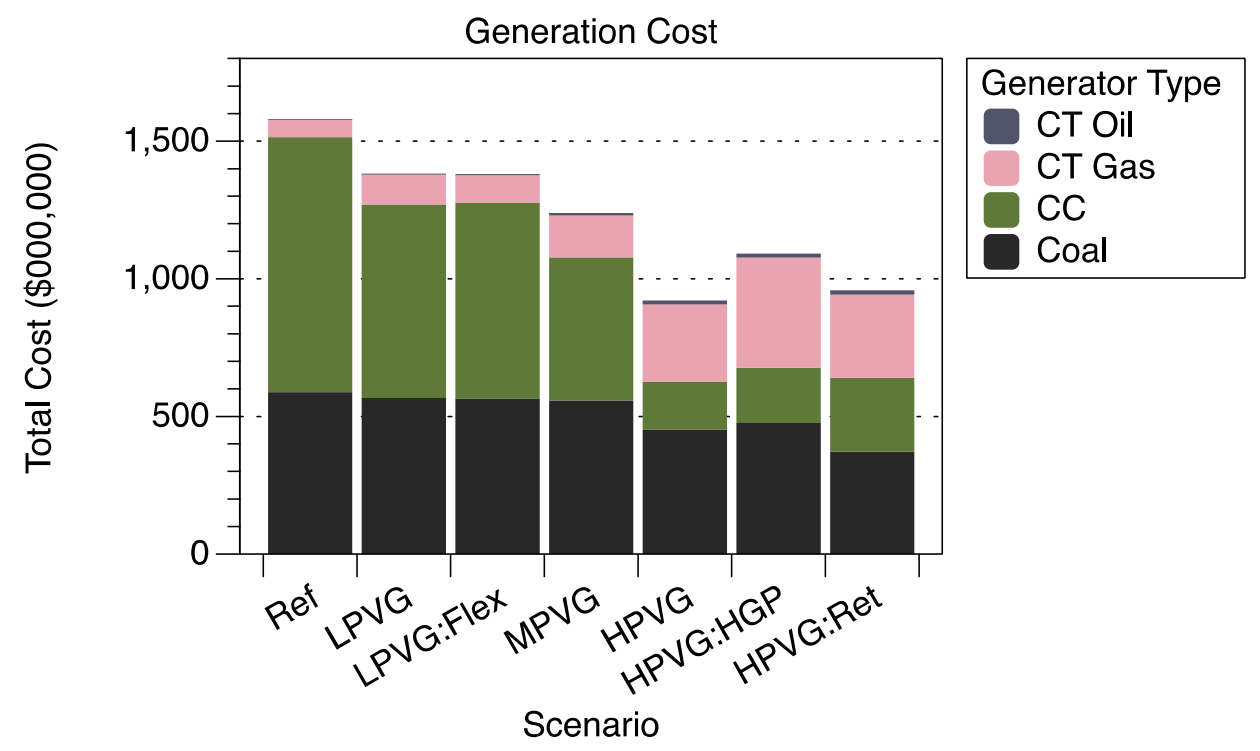

Figure 2. Variable generation simulations: total generation costs

At penetrations up to $21 \%$ (the MPVG scenario), the amount of energy delivered by coal changed little; however, at the high penetration levels, coal generation was impacted, dropping by almost $25 \%$. 


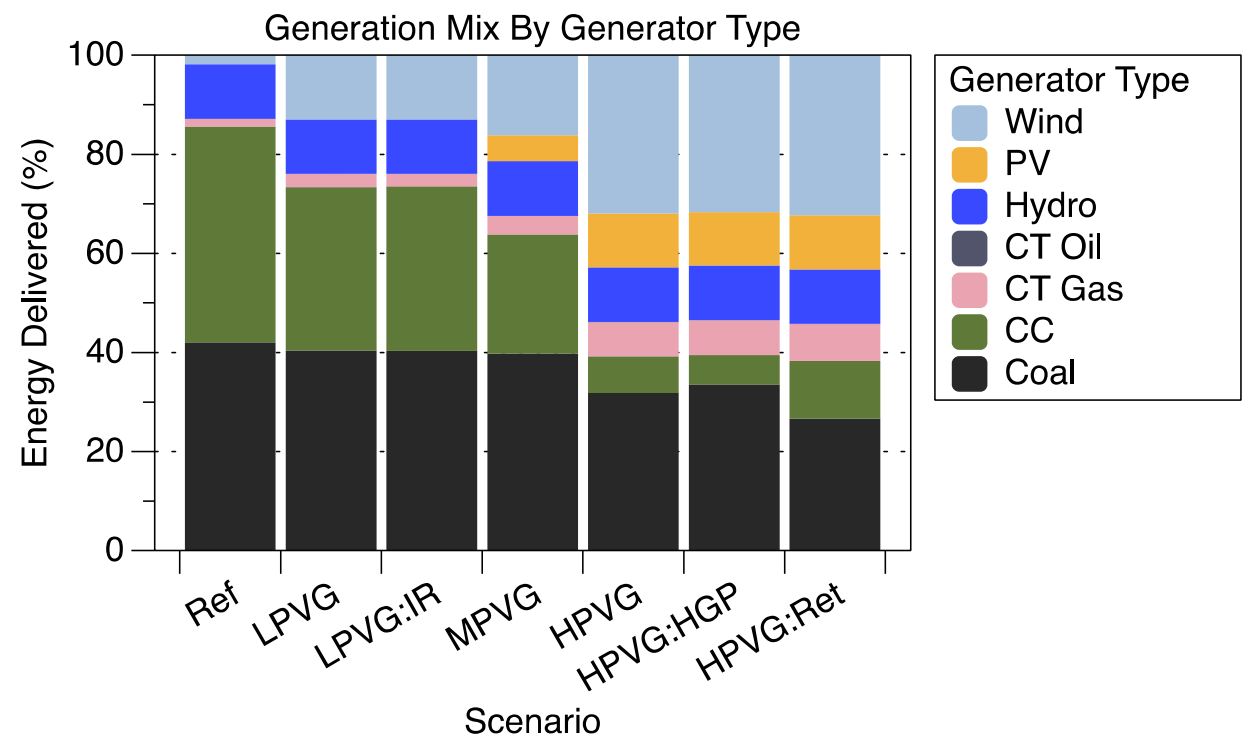

Figure 3. Variable generation simulations: energy delivered by generator type

The overall per-unit costs for the variable generation simulations are shown in Table 9. As the amount of variable generation increased, the overall system costs dropped, ranging from a $12.7 \%$ reduction at the $13 \%$ penetration level to a $41.8 \%$ reduction at the $43 \%$ penetration level. Additionally, as the variable generation displaced conventional generation, the per-unit cost of the coal- and combined-cycle generation increased, albeit modestly.

Table 9. Variable Generation Simulations: Average Generation Costs by Generator Type (\$/MWh)

\begin{tabular}{lrrrrrrr} 
Type & Ref & LPVG & LPVG:Flex & MPVG & HPVG & HPVG:HGP & HPVG:Ret \\
\hline Coal & 21.80 & 21.84 & 21.84 & 21.85 & 22.15 & 22.07 & 21.80 \\
CC & 33.19 & 33.27 & 33.30 & 33.79 & 36.47 & 52.84 & 35.60 \\
CT Gas & 62.91 & 63.02 & 62.64 & 62.98 & 63.20 & 89.21 & 63.64 \\
\hline Wt. Avg. & 24.64 & 21.53 & 21.51 & 19.31 & 14.35 & 17.01 & 14.92
\end{tabular}

The next few paragraphs break the overall costs into components of fuel costs, cycling costs, and VO\&M costs. Table 10 shows how the average system-wide fuel costs dropped with increasing variable generation. Costs dropped by $45 \%$ when the penetration level hit $43 \%$.

Table 10. Variable Generation Simulations: Average Fuel Costs (\$/MWh)

\begin{tabular}{rrrrrrrr} 
& Ref & LPVG & LPVG:Flex & MPVG & HPVG & HPVG:HGP & HPVG:Ret \\
\hline Wt. Avg. & 22.60 & 19.52 & 19.51 & 17.26 & 12.33 & 14.83 & 12.93
\end{tabular}

Figure 4 shows the total cycling costs for each simulation. Cycling costs increased with increasing penetrations of variable generation, with the costs more than doubling at the highest penetrations. 


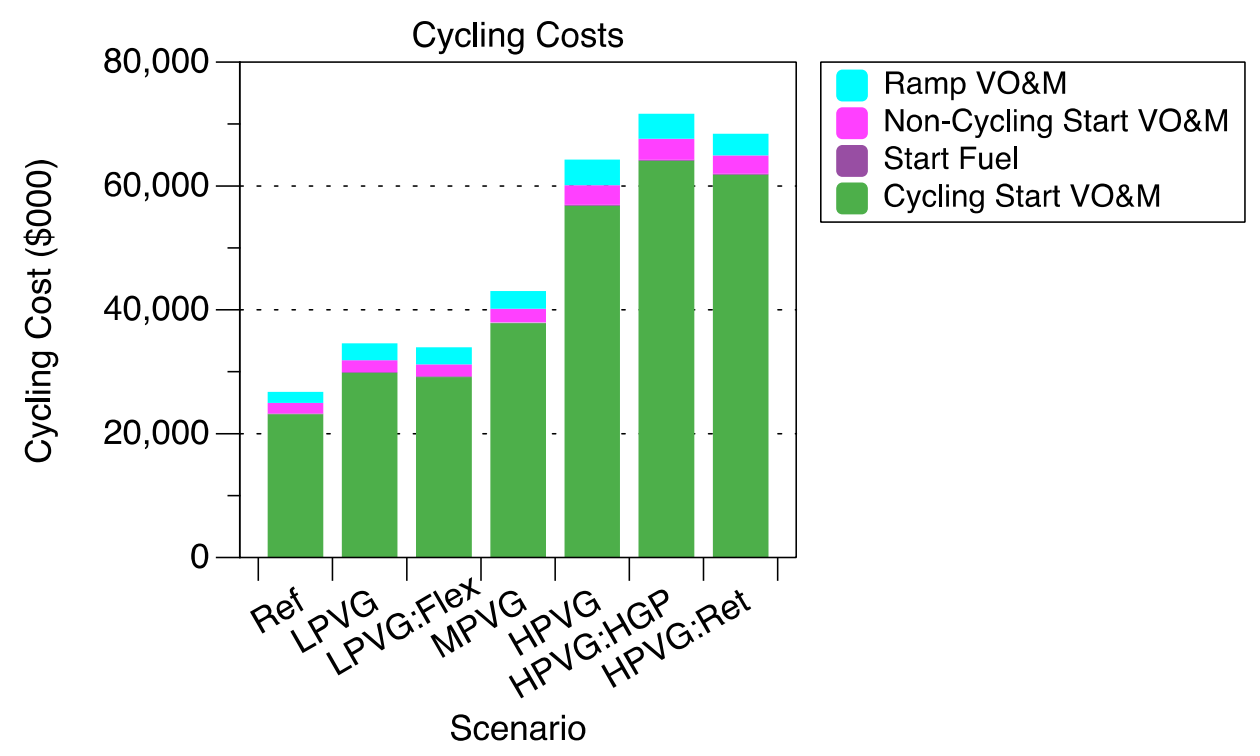

Figure 4. Variable generation simulations: cycling costs by cost component type

Table 11 shows cycling costs per unit of energy delivered broken out by generator type. The costs increased with variable generation for both the coal and combined-cycle fleets. The cycling costs of the combustion turbine fleet were not quite as clear: the costs were highest for the reference case, lowest for the low-penetration scenario, and trended upward with increasing penetrations of variable generation.

Table 11. Variable Generation Simulations: Average Cycling Costs by Generator Type (\$/MWh)

\begin{tabular}{lrrrrrrr} 
Type & Ref & LPVG & LPVG:Flex & MPVG & HPVG & HPVG:HGP & HPVG:Ret \\
\hline Coal & $\$ 0.26$ & $\$ 0.31$ & $\$ 0.31$ & $\$ 0.33$ & $\$ 0.67$ & $\$ 0.57$ & $\$ 0.54$ \\
CC & $\$ 0.47$ & $\$ 0.79$ & $\$ 0.81$ & $\$ 1.28$ & $\$ 4.49$ & $\$ 6.99$ & $\$ 3.47$ \\
CT Gas & $\$ 6.34$ & $\$ 5.43$ & $\$ 5.10$ & $\$ 5.53$ & $\$ 5.83$ & $\$ 6.66$ & $\$ 6.19$ \\
\hline Wt. Avg. & $\$ 0.43$ & $\$ 0.56$ & $\$ 0.55$ & $\$ 0.70$ & $\$ 1.04$ & $\$ 1.16$ & $\$ 1.10$
\end{tabular}

Although the methods used to calculate the cycling costs differed slightly from those in WWSIS-2 (ramping costs were included in the production cost optimization in the current work, but they were added ex post in WWSIS-2), the cycling costs presented here compare favorably to the $\$ 0.45 / \mathrm{MWh}$ cost in the WWSIS-2 no-renewables scenario and the \$0.97/MWh for the WWSIS-2 high-wind scenario (Lew 2012). The slightly higher high cycling costs of the HPVG scenario (\$1.04/MWh) are likely because of the higher penetration rate as well as less geographic diversity of the variable generation in the current study.

Interestingly, the relationship between the change in overall generation cost and the change in cycling costs was approximately linear, with a $\$ 2$ decrease in operating costs for every $\$ 0.10$ increase in cycling costs (see Figure 5). Adding variable generation did increase cycling costs; however, cost increases were proportional to the amount of variable generation added. 


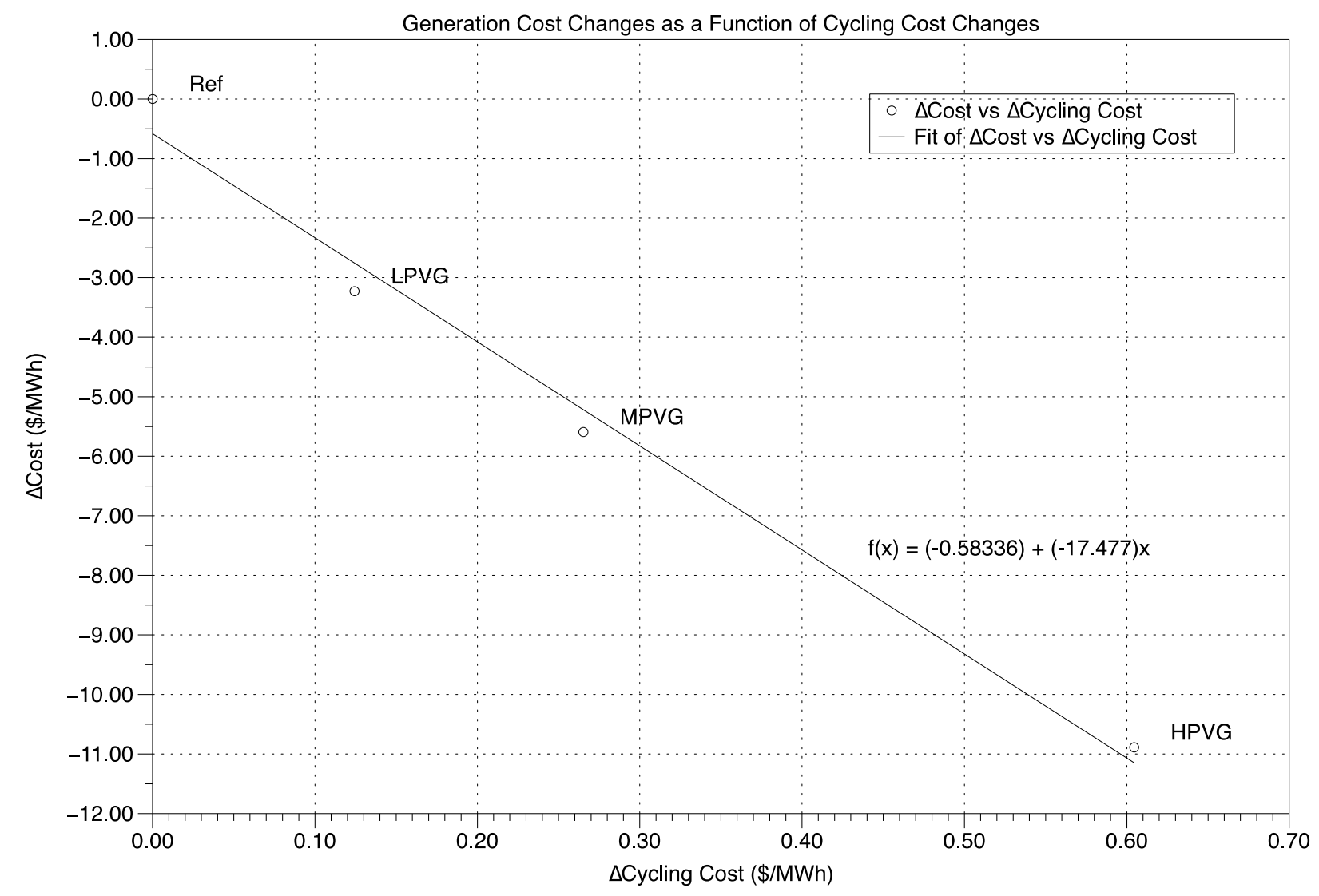

Figure 5. Changes in cycling costs compared to changes in generation

Finally, Table 12 shows the VO\&M costs for the various penetration levels of variable generation. Interestingly, adding variable generation decreased the overall VO\&M costs. The VO\&M cost reductions ranged between $9 \%$ and $45 \%$.

Table 12. Variable Generation Simulations: Average VO\&M Costs (\$/MWh)

\begin{tabular}{lrrrrrrr} 
& Ref & LPVG & LPVG:Flex & MPVG & HPVG & HPVG:HGP & HPVG:Ret \\
\hline Wt. Avg. & 1.61 & 1.46 & 1.46 & 1.36 & 0.99 & 1.02 & 0.89
\end{tabular}

Combining the cycling costs with the VO\&M costs gave the non-fuel operating costs for the system. These costs summarize how adding variable generation affects the non-fuel operating costs of the system. As shown in Table 13, the overall cost impacts of adding variable generation to the system were modest, and in most cases adding variable generation decreased the non-fuel operating costs. 
Table 13. Variable Generation Simulations:

Average Non-Fuel Operating Costs by Generator Type (\$/MWh)

\begin{tabular}{lrrrrrrr} 
Type & Ref & LPVG & LPVG:Flex & MPVG & HPVG & HPVG:HGP & HPVG:Ret \\
\hline Coal & 3.00 & 3.04 & 3.04 & 3.07 & 3.40 & 3.30 & 3.26 \\
CC & 1.50 & 1.81 & 1.83 & 2.30 & 5.50 & 8.00 & 4.49 \\
CT Gas & 6.90 & 5.99 & 5.67 & 6.10 & 6.40 & 7.23 & 6.76 \\
\hline Wt. Avg. & 2.04 & 2.02 & 2.00 & 2.05 & 2.02 & 2.18 & 1.99
\end{tabular}

The costs ranged from a cost increase of $0.5 \%$ for the medium-penetration simulation to a cost reduction of $1 \%$ in the high-penetration simulation - essentially unchanged from the reference scenario. Note that these results represent only the average overall impacts, and cost impacts on a specific generator may be significant.

\subsection{System Impacts per Unit of New Generation Added}

The next three plots show cost changes per unit of new generation added. This method of normalization was chosen so that these costs could be easily compared to other generation technologies. (For example, what kind of impact is there for each MWh of baseload coal added?) All comparisons were made to the reference case.

Figure 6 shows that for all variable generation simulations, the fuel savings were enough to offset the additional start-up, ramping, and operating VOM costs associated with the new generation.

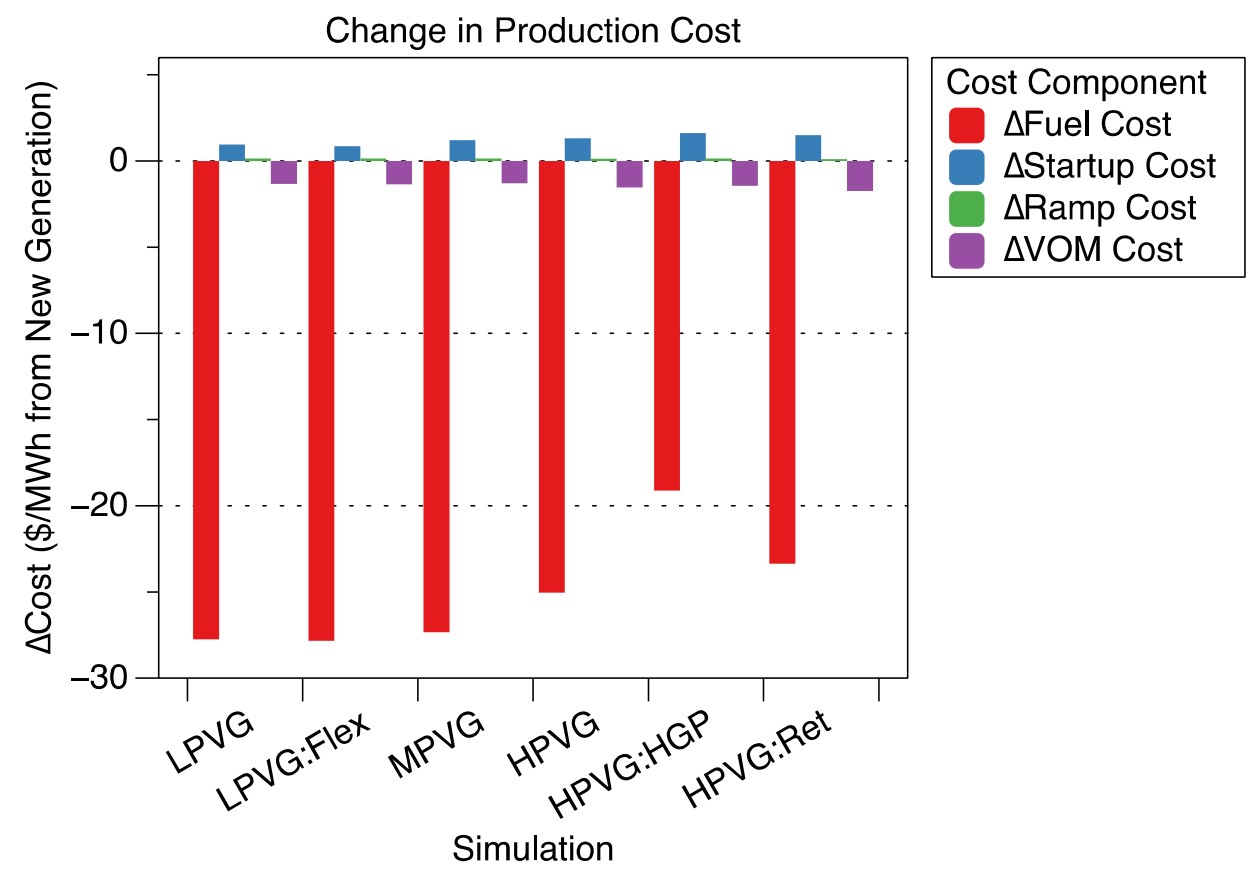

Figure 6. Variable generation simulations: changes in production cost per MWh of new generation added 
A more detailed look at the non-fuel operating cost components is shown in Figure 7. Note how the overall start-up costs increased with increasing penetrations of variable generation, whereas the ramping costs changed little. In all cases, system-wide VO\&M costs decreased with the addition of variable generation.

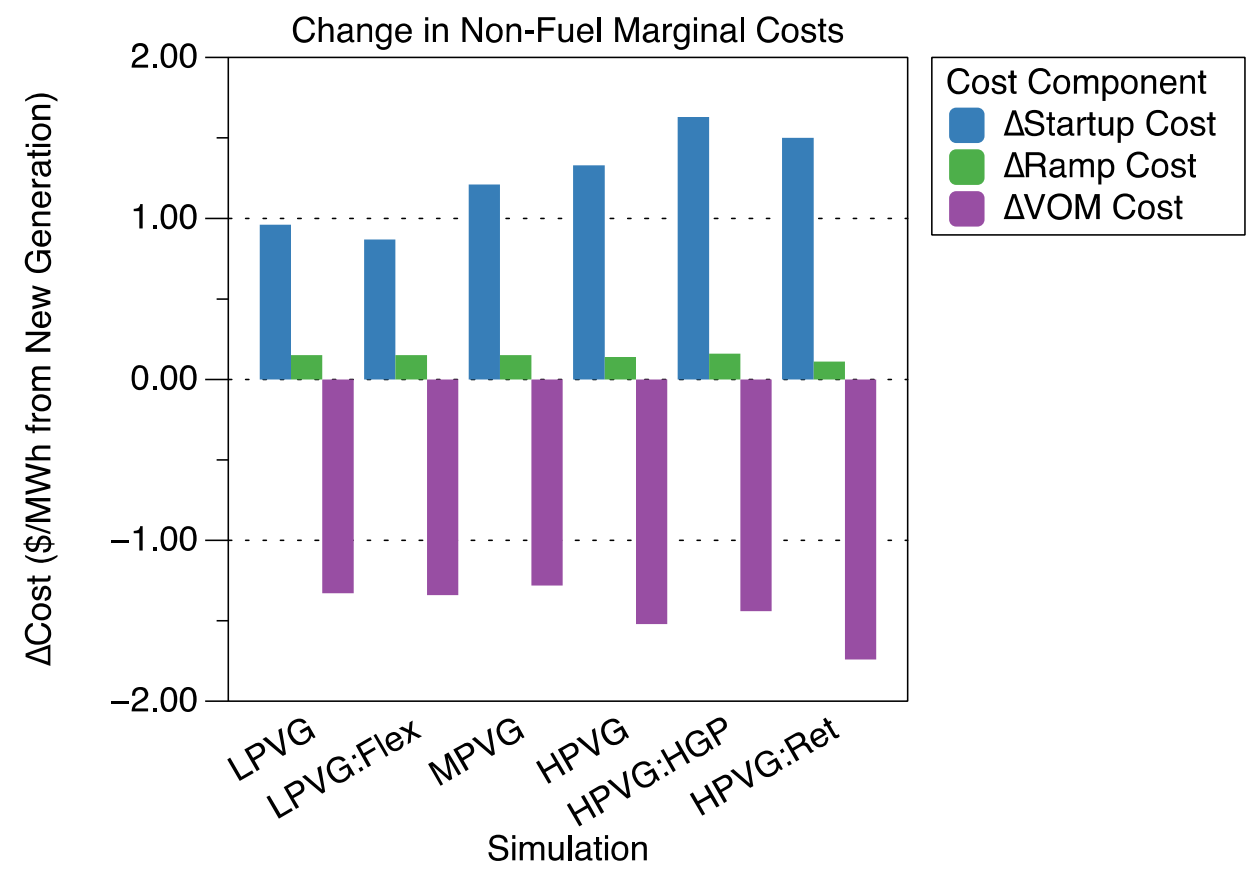

Figure 7. Variable generation simulations:

non-fuel operating cost changes per unit of new generation added

Combining the start and ramping costs from Figure 6 provides the cycling costs (see Table 14). In general, the cycling costs trended upward with increasing penetrations of variable generation.

Table 14. Variable Generation Simulations:

Changes in Cycling Costs per MWh of Variable Generation Added (\$/MWh)

\begin{tabular}{lrrrrrr} 
Type & LPVG & LPVG:Flex & MPVG & HPVG & HPVG:HGP & HPVG:Ret \\
\hline Coal & 0.14 & 0.14 & 0.12 & 0.26 & 0.20 & 0.09 \\
CC & 0.49 & 0.56 & 0.52 & 0.30 & 0.50 & 0.48 \\
CT Gas & 0.43 & 0.29 & 0.57 & 0.75 & 0.91 & 0.87 \\
\hline Total & 1.12 & 1.02 & 1.35 & 1.47 & 1.79 & 1.62
\end{tabular}

The VO\&M cost changes per unit of new generation added are shown in Table 15. Interestingly, the addition of variable generation decreased the system's non-cycling VO\&M costs by displacing the fossil-fueled units, which are more costly to maintain. 
Table 15. Variable Generation Simulations:

Changes in VO\&M Costs per MWh of Variable Generation Added (\$/MWh)

\begin{tabular}{lrrrrrr} 
Type & LPVG & LPVG:Flex & MPVG & HPVG & HPVG:HGP & HPVG:Ret \\
\hline Coal & $(0.40)$ & $(0.44)$ & $(0.32)$ & $(0.69)$ & $(0.57)$ & $(1.03)$ \\
CC & $(0.99)$ & $(0.96)$ & $(1.03)$ & $(0.90)$ & $(0.95)$ & $(0.79)$ \\
CT Gas & 0.06 & 0.05 & 0.06 & 0.08 & 0.08 & 0.08 \\
\hline Total & $(1.33)$ & $(1.34)$ & $(1.28)$ & $(1.52)$ & $(1.44)$ & $(1.74)$
\end{tabular}

When the operating costs (start-up, ramp, and VO\&M costs) were combined, the VO\&M savings tended to cancel the additional start-up and ramping costs associated with the addition of variable generation (see Figure 8 and Table 16).

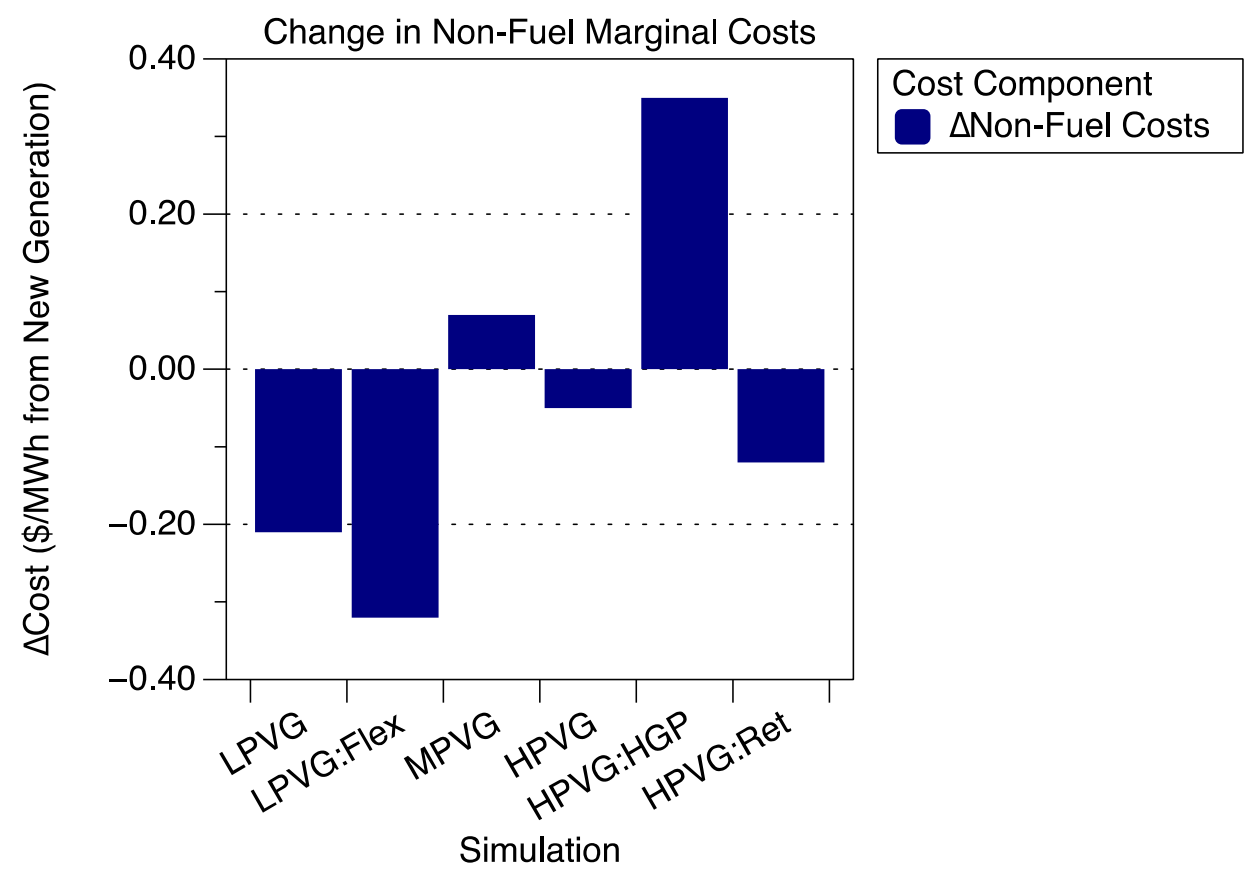

Figure 8. Variable generation simulations:

changes in non-fuel operating cost per unit of new generation added

The non-fuel operating costs are broken out by generator type in Table 16. Costs decreased for both the coal and combined-cycle units. These units were displaced, and the VO\&M contribution to the non-fuel operating costs decreased accordingly.

Table 16. Changes in Non-Fuel Operating Costs per MWh of Variable Generation Added (\$/MWh)

\begin{tabular}{lrrrrrr} 
Type & LPVG & LPVG:Flex & MPVG & HPVG & HPVG:HGP & HPVG:Ret \\
\hline Coal & $(0.27)$ & $(0.30)$ & $(0.20)$ & $(0.43)$ & $(0.37)$ & $(0.95)$ \\
CC & $(0.50)$ & $(0.40)$ & $(0.51)$ & $(0.60)$ & $(0.45)$ & $(0.31)$ \\
CT Gas & 0.49 & 0.34 & 0.63 & 0.83 & 0.99 & 0.95 \\
\hline Total & $(0.21)$ & $(0.32)$ & 0.07 & $(0.04)$ & 0.34 & $(0.13)$
\end{tabular}


The combined non-fuel operating cost impacts (excluding fuel price effects) ranged between a $\$ 0.32$ decrease to a $\$ 0.07$ increase per MWh of energy provided by variable generation, with most simulations showing modest decreases in the non-fuel operating costs when significant amounts of variable generation were added to the system.

The following sections investigate how the addition of the new generation affects the system in terms of starts, ramping, reserves, capacity factors, and curtailment.

\subsection{Start Effects}

Up to the medium penetration levels, the variable generation had yet to displace baseload generation, and consequently coal operations were minimally impacted in number of starts, hours online per start, or energy delivered per start. However, at high penetrations the variable generation began to replace baseload, and that was shown in coal operations when starts increased and the amount energy delivered per start decreased (Figure 9 and Figure 10).

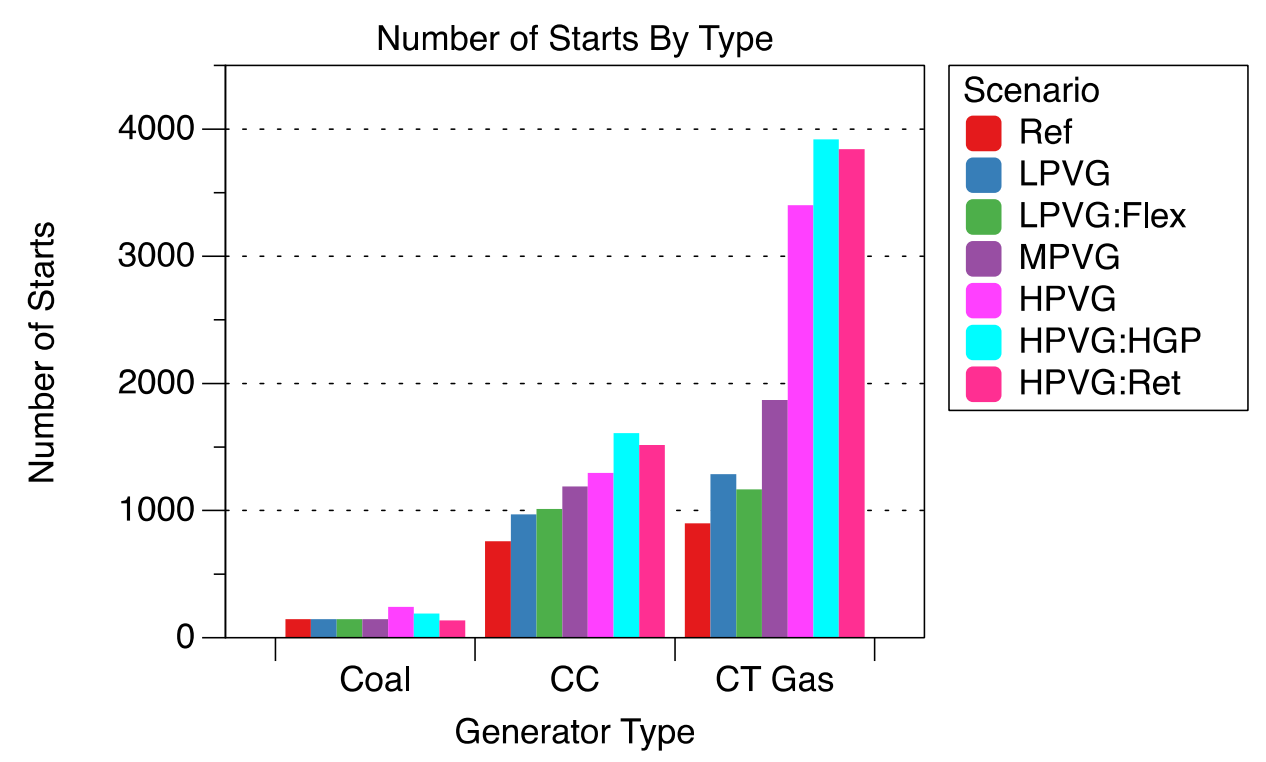

Figure 9. Variable generation simulations: number of starts by generator type

The impacts were different for the load-following and peaking resources. For load-following assets (i.e., the combined-cycle machines), the numbers of starts increased as penetrations of variable generation increased. However, the energy delivered per start decreased with increasing penetrations, and the average per-unit start costs increased more than tenfold (Table 17). For the peaking units, the trend was less clear. Although the number of starts increased with increasing penetrations, the per-unit start costs initially decreased but then increased as penetration levels of variable generation increased. 


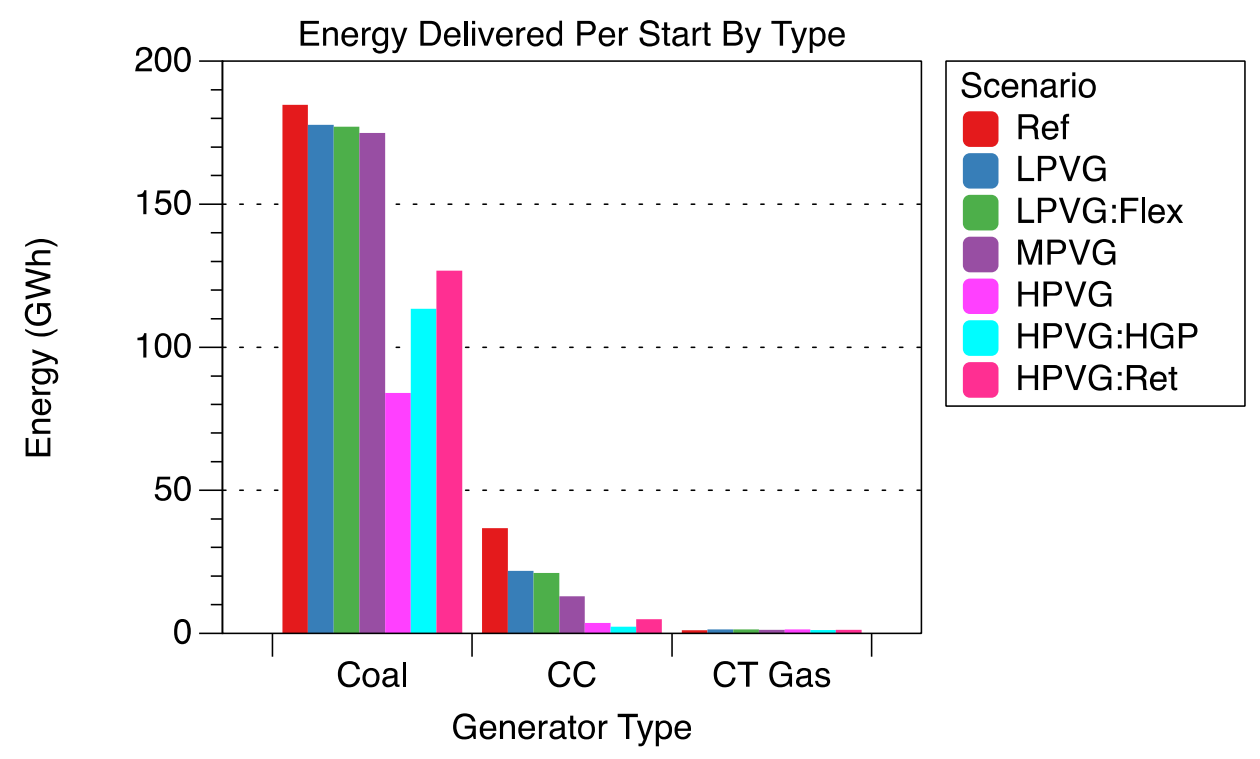

Figure 10. Variable generation simulations: average energy delivered per generator start

The overall weighted average start costs increased as penetrations of variable generation increased (see Table 17), growing by almost 2.5 times. The addition of flexibility reserves did decrease start costs, albeit by only $2.2 \%$.

Table 17. Variable Generation Simulations:

Average Combined Starts Costs by Generator Type (\$/MWh)

\begin{tabular}{lrrrrrrr} 
Type & Ref & LPVG & LPVG:Flex & MPVG & HPVG & HPVG:HGP & HPVG:Ret \\
\hline & 0.22 & 0.23 & 0.23 & 0.23 & 0.45 & 0.34 & 0.34 \\
CC & 0.42 & 0.71 & 0.73 & 1.17 & 4.30 & 6.76 & 3.31 \\
CT Gas & 6.21 & 5.31 & 4.99 & 5.39 & 5.63 & 6.47 & 5.99 \\
\hline Wt. Avg. & 0.39 & 0.50 & 0.49 & 0.63 & 0.94 & 1.05 & 1.01
\end{tabular}

\subsection{Ramp Effects}

In addition to overall ramping-related operating costs, three metrics were observed. The first ramp metric studied the number of ramps per year, in which a ramp was defined as any generator movement up or down that met or exceeded $30 \%$ of the generator's nameplate capacity value independent of the time that had elapsed. The second metric studied the amount of generator movement (ramping) that occurred throughout the year. The third metric studied the amount of ramps that occurred per MWh of energy delivered.

In terms of ramping effects, the trends for coal plants were straightforward. The number of large ramps (Figure 11), the amount of generator movement (Figure 12), and the amount of ramping that occurred per unit of energy delivered all increased as the amount of variable generation increased (by more than $400 \%$ for all three metrics). 
The number of coal ramps increased by more than $400 \%$ at the high-penetration levels, and the amount of ramping showed similar trends. The largest changes were in the amount of ramping that occurred per unit of energy delivered, with increases more than $600 \%$.

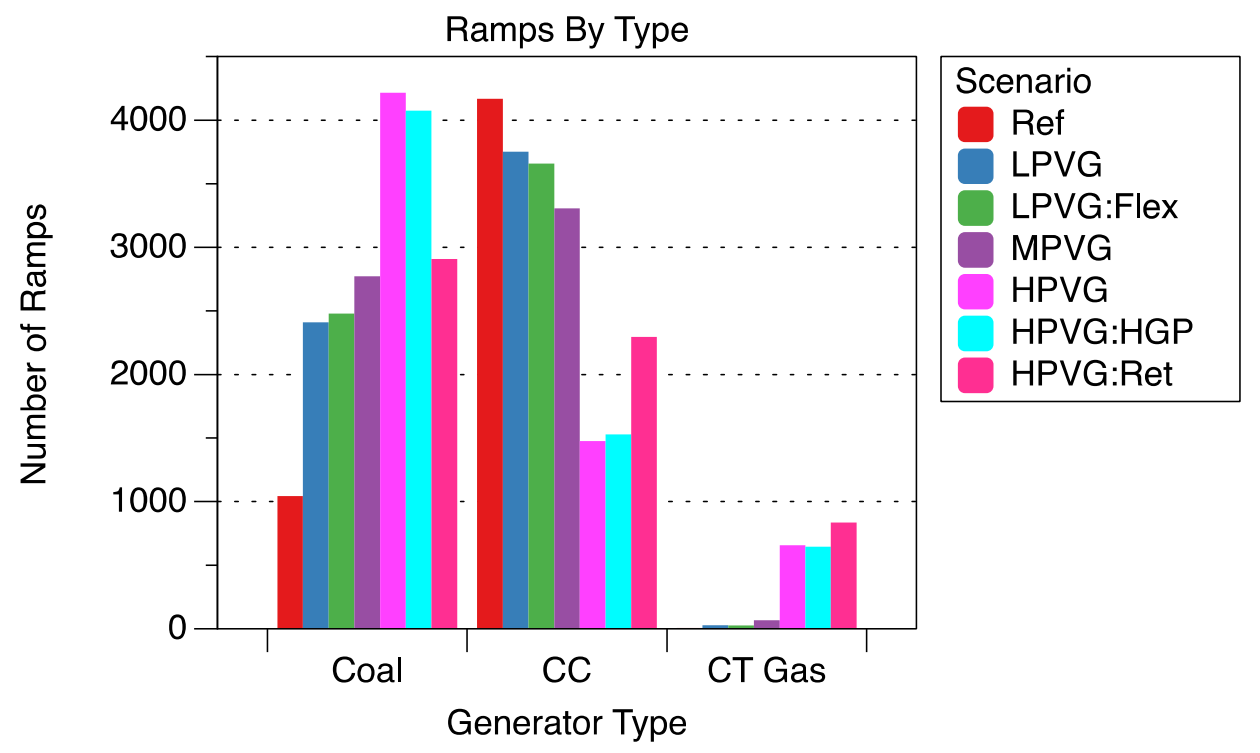

Figure 11. Variable generation simulations: number of ramps by generator type

For the combined-cycle units, the number of large ramps, the amount of generator movement, and the amount of ramps per unit of energy all decreased as the penetration of variable generation increases. The number of ramps decreased by $65 \%$, the amount of ramping by $72 \%$, and the ramps per unit of energy delivered grew by almost $200 \%$.

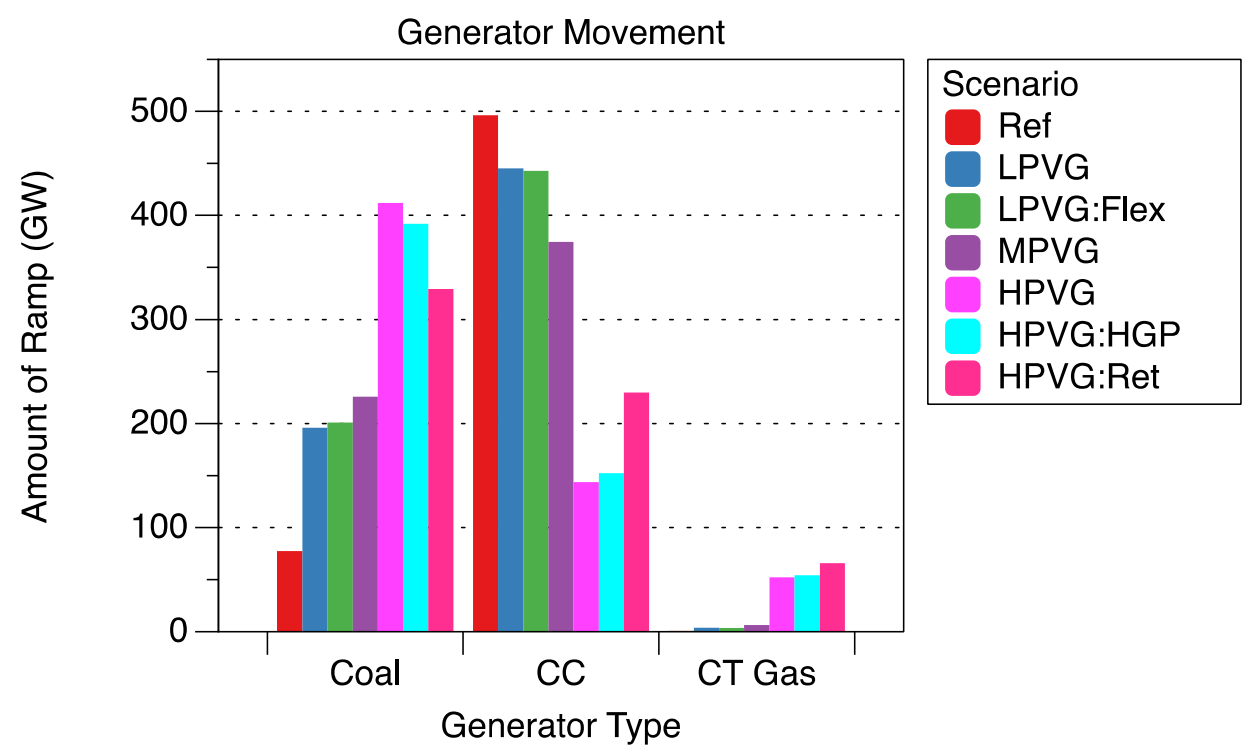

Figure 12. Variable generation simulations: generator movement by generation type 
The changes in the combustion turbine operations were even more affected. The number of ramps increased by more than $1,000 \%$, the amount of ramping increased by more than $70 \%$, and the amount of ramps per unit of energy delivered increased by $100 \%$.

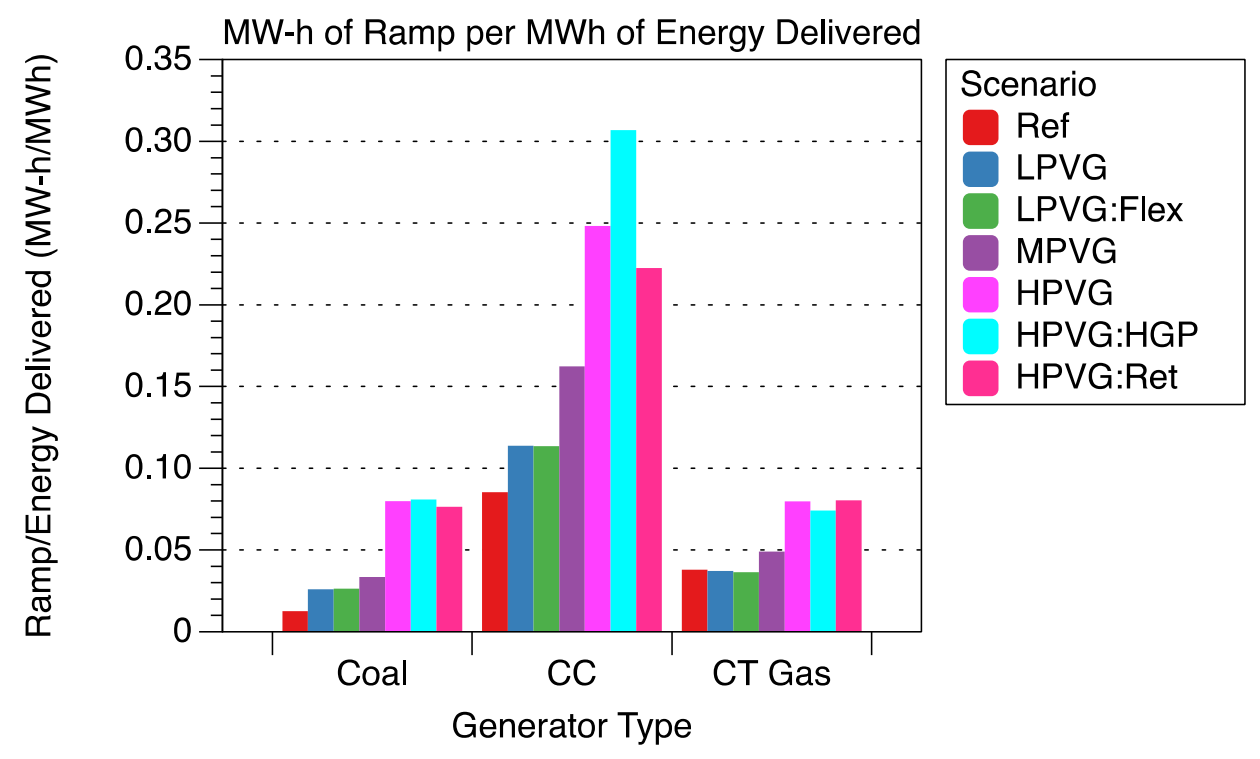

Figure 13. Variable generation simulations: average amount of ramps per unit of energy delivered

The impact of variable generation on ramping costs (see Table 18) was most pronounced for the coal-fired generators, in which the average ramping-related costs rose by more than $500 \%$ with the increased variable generation. Costs for combined-cycle starts increased by a little more than $300 \%$ as the penetrations of variable generation increased. And combustion turbine costs, after an initial decrease for the low-penetration simulation, increased by approximately $60 \%$.

Table 18. Variable Generation Simulations: Average Ramping Costs by Generator Type (\$/MWh)

\begin{tabular}{lrrrrrrr} 
Type & Ref & LPVG & LPVG:Flex & MPVG & HPVG & HPVG:HGP & HPVG:Ret \\
\hline Coal & 0.04 & 0.08 & 0.08 & 0.10 & 0.23 & 0.23 & 0.21 \\
CC & 0.06 & 0.08 & 0.08 & 0.11 & 0.18 & 0.23 & 0.16 \\
CT Gas & 0.12 & 0.12 & 0.11 & 0.14 & 0.20 & 0.20 & 0.20 \\
\hline Wt. Avg. & 0.04 & 0.06 & 0.06 & 0.07 & 0.10 & 0.11 & 0.09
\end{tabular}

The trend for the weighted average ramping costs was straightforward: average ramping costs increased as the amount of variable generation increased. Note that although ramping cost increases were significant (they more than doubled in the high-penetration simulations), the magnitude of these costs differences was small compared to other VO\&M-related cost impacts. (For example, start cost increased, and VO\&M costs decreased.)

Next, the impact of variable generation on reserves is examined. 


\subsection{Reserves Effects}

This section investigates how increases in the amount of variable generation in the system affects the cost of provisioning reserves.

Table 19 shows reserve provisioning costs for the variable generation experiments. As shown, the results were near the near the limits of precision for the study; however, they do show a trend of increasing provisioning costs with increasing penetrations of variable generation. The magnitude of the reserves provisioning cost changes is the smallest of all the cost impacts.

Table 19. Variable Generation Simulations: Reserves Provisioning Costs

\begin{tabular}{lrrrr} 
Scenario & $\begin{array}{r}\text { Reserves } \\
\text { Provisioning } \\
\text { Cost } \mathbf{( \$ 0 0 0 , 0 0 0 )}\end{array}$ & $\begin{array}{r}\boldsymbol{\Delta} \mathbf{0} \text { Cost } \\
(\mathbf{\$ 0 0 0 , 0 0 0 )}\end{array}$ & $\begin{array}{r}\mathbf{\$} / \mathbf{M W h} \\
\text { Energy }\end{array}$ & $\begin{array}{r}\Delta \mathbf{\$} / \mathbf{M W h} \\
\text { Energy }\end{array}$ \\
\hline Ref & 2 & - & 0.02 & - \\
LPVG & 2 & - & 0.03 & 0.01 \\
LPVG:Flex & 2 & 1 & 0.03 & 0.01 \\
MPVG & 3 & 1 & 0.04 & 0.02 \\
HPVG & 4 & 2 & 0.06 & 0.04 \\
HPVG:HGP & 5 & 3 & 0.07 & 0.05 \\
HPVG:Ret & 2 & - & 0.03 & 0.01
\end{tabular}

\subsection{Capacity Factor and Curtailment Effects}

Not unexpectedly, the average capacity factors for the coal and combined-cycle fleets declined (see Figure 14) as the variable generation increased, with the largest impact to the combined-cycle assets. (Average capacity factors decreased from $41 \%$ to a little less than $7 \%$ as the amount of variable generation increased.) Part of the reason for the decline in the capacity factors is that with the addition of variable generation, the system had excess capacity. However, the primary driver behind the decline is that the conventional generation was displaced by generation that had no fuel costs.

Capacity factors for the combustion turbines increased as the amount of variable generation increased, rising from approximately $3 \%$ in the reference scenario to slightly more than $14 \%$ for the high-penetration scenario. The increase in the combustion turbine numbers is a result of the system's need to accommodate the uncertainty and variability in the wind and solar generation. 


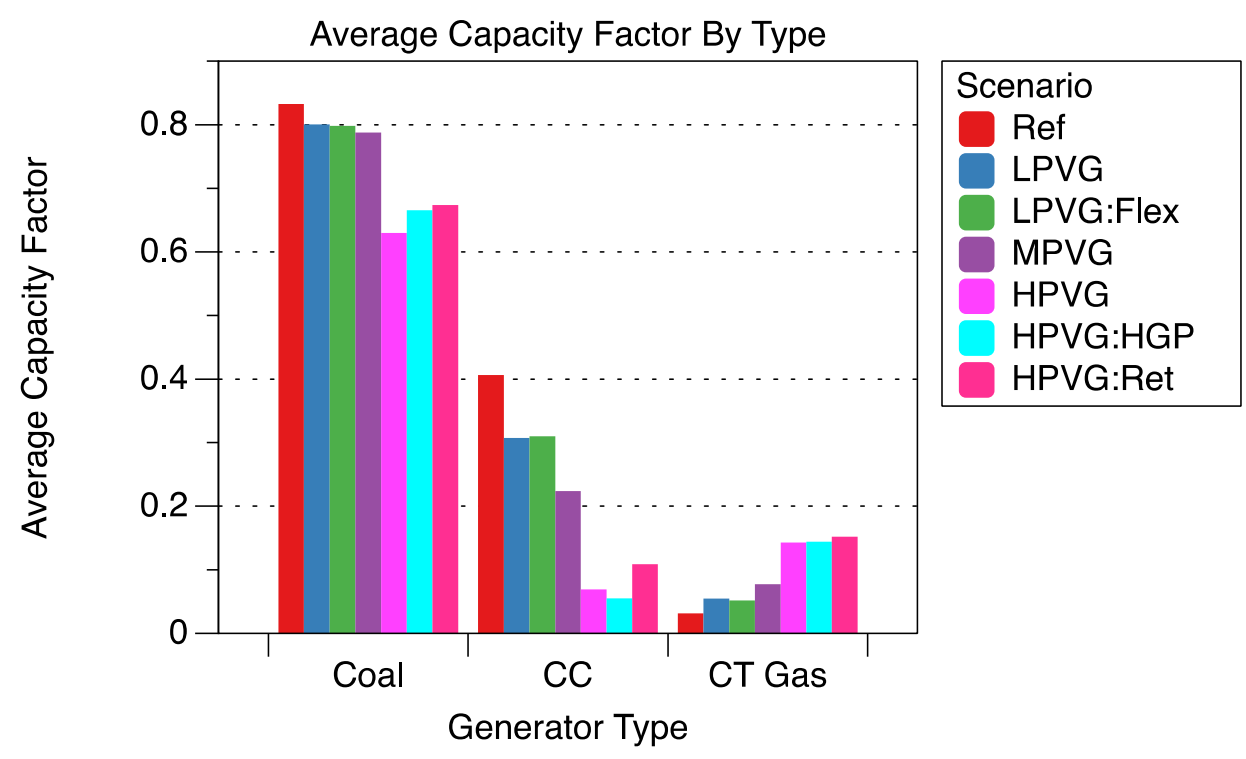

Figure 14. Variable generation simulations: average capacity factor by generator type

In general, curtailment increased as the amount of variable generation increased, ranging from less than $1 \%$ for the low-penetration simulation to slightly less than $7 \%$ for the high-penetration simulation.

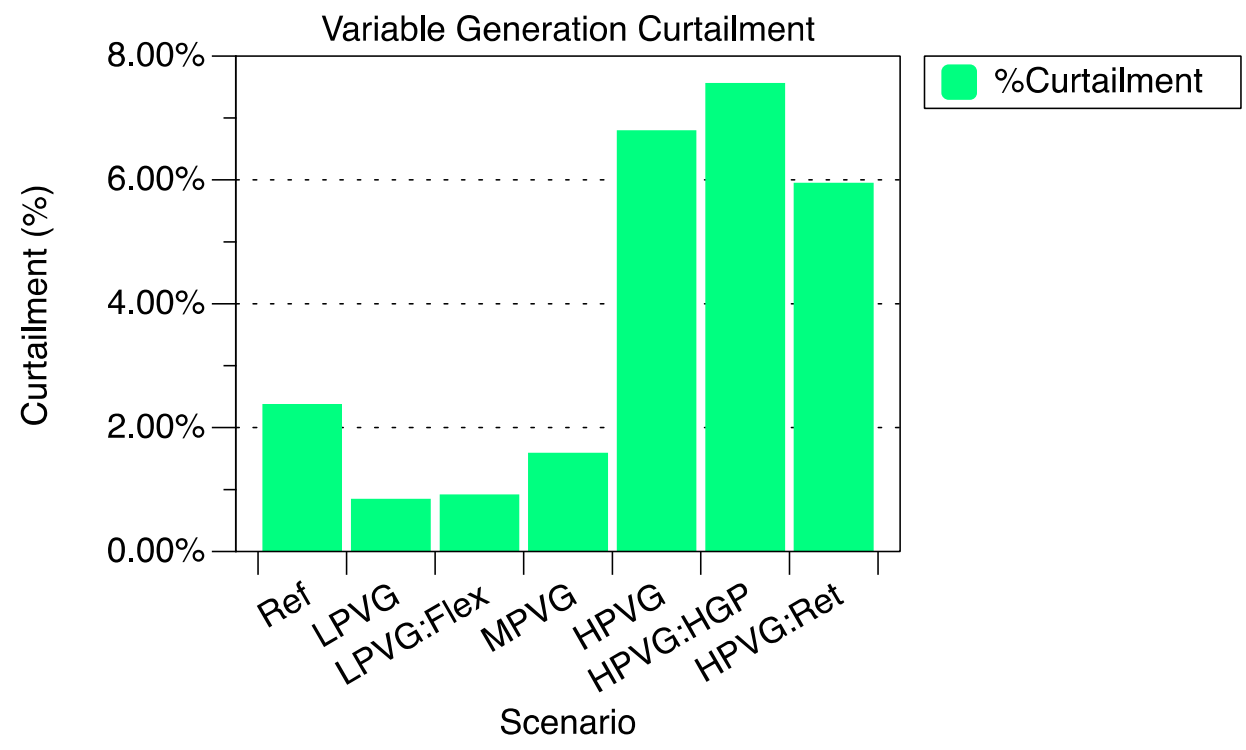

Figure 15. Variable generation simulations: variable generation curtailment

As expected, increasing the gas price (HPVG:HGP) increased the amount of curtailment, and retiring some of the coal fleet (HPVG:Ret) decreased the amount of variable generation curtailed. 


\subsection{Variable Generation Study Summary}

This section summarizes the overall cost-related findings of the variable generation experiments. The results are divided into two parts: costs per unit of new generation and costs per unit of overall system generation.

\subsubsection{Variable Generation Summary: Cost Impacts per Unit of New Generation}

The impacts per unit of new generation added are highlighted in Table 20.

Table 20. Variable Generation Simulations: Cost Summaries per Unit of New Generation Added

\begin{tabular}{|c|c|c|}
\hline Topic & Subtopic & Results Summary \\
\hline \multirow[t]{4}{*}{$\begin{array}{l}\text { New Generation Impacts } \\
\text { (Changes per Unit of New } \\
\text { Generation Added) }\end{array}$} & - Fuel Costs & $\begin{array}{l}\text { Fuel costs decreased as penetrations of } \\
\text { variable generation increased, with the } \\
\text { average fuel costs decreases exceeding } \$ 25 \\
\text { per MWh of new generation. }\end{array}$ \\
\hline & $\begin{array}{l}\text { - Cycling Costs (Combined Start } \\
\text { + Ramp Costs) }\end{array}$ & $\begin{array}{l}\text { Cycling costs increased as penetrations of } \\
\text { variable generation increased. At the lowest } \\
\text { penetrations ( } 12 \% \text { variable generation), } \\
\text { cycling costs increased by } \$ 1.12 \text { per MWh of } \\
\text { new generation. At the highest penetration } \\
\text { ( } 43 \% \text { variable generation), cycling costs } \\
\text { increased by } \$ 1.47 \text { per MWh of new } \\
\text { generation. }\end{array}$ \\
\hline & - VO\&M Costs & $\begin{array}{l}\text { VO\&M costs decreased as the amount of } \\
\text { variable generation increased, with cost } \\
\text { decreases of } \$ 1.33 \text { per } \mathrm{MWh} \text { of new } \\
\text { generation at the lowest penetrations and } \\
\$ 1.44 \text { per MWh of new generation at the } \\
\text { highest penetrations. }\end{array}$ \\
\hline & - Non-Fuel Operating Costs & $\begin{array}{l}\text { Impacts on the non-fuel operating costs } \\
\text { were small because the VO\&M cost savings } \\
\text { offset cycling cost increases. In most cases, } \\
\text { VO\&M cost savings offset cycling cost } \\
\text { increases. Cost impacts ranged from a } \\
\text { decrease of } \$ 0.21 \text { to an increase of } \$ 0.07 \text { per } \\
\text { MWh of new generation. }\end{array}$ \\
\hline
\end{tabular}

The addition of variable generation had minimal cost impacts from an overall cost perspective. Although adding variable generation did increase cycling costs, it also decreased VO\&M costs, with the net result that cost impacts were modest. In the low- and high-penetration simulations, the addition of variable generation reduced costs between $\$ 0.04$ and $\$ 0.21$ per MWh of variable generation added. In the medium-penetration simulation, non-fuel operating costs increased by \$0.07 per MWh of variable generation added to the system. 


\subsubsection{Variable Generation Summary: Overall System Costs per Unit of Overall System Generation}

The system level cost impacts are summarized in Table 21 below.

Table 21. Variable Generation Simulations:

Cost Summaries of System-Wide Generation

\begin{tabular}{|c|c|c|}
\hline Topic & Subtopic & Results Summary \\
\hline \multirow[t]{5}{*}{$\begin{array}{l}\text { Overall System Impacts } \\
\text { (Changes per Unit of Overall } \\
\text { System Generation) }\end{array}$} & - Total Generation Costs & $\begin{array}{l}\text { Total generation costs decreased with } \\
\text { increasing variable generation, } 42 \% \\
\text { ( } \$ 10.29 / \mathrm{MWh} \text { ) at the highest penetration. }\end{array}$ \\
\hline & - Fuel Costs & $\begin{array}{l}\text { Fuel costs decreased as penetrations of } \\
\text { variable generation increased, with the } \\
\text { average fuel costs decreasing by } 45 \% \\
\text { (\$7.77/MWh) in the high-penetration } \\
\text { scenario. }\end{array}$ \\
\hline & $\begin{array}{l}\text { - Cycling Costs (Combined Start } \\
\text { + Ramp Costs) }\end{array}$ & $\begin{array}{l}\text { Cycling costs increased as penetrations of } \\
\text { variable generation increased, with the } \\
\text { average cycling costs increasing by } 142 \% \\
\text { (\$0.61/MWh) in the high-penetration } \\
\text { scenario. }\end{array}$ \\
\hline & - VO\&M Costs & $\begin{array}{l}\text { VO\&M costs decreased as the amount of } \\
\text { variable generation increased. Impacts } \\
\text { ranged from a } 9 \% \text { ( } \$ 0.18 / \mathrm{MWh} \text { ) reduction in } \\
\text { the LPVG scenario to a } 45 \%(\$ 0.59 / \mathrm{MWh}) \\
\text { reduction in the HPVG scenario. }\end{array}$ \\
\hline & - Non-Fuel Operating Costs & $\begin{array}{l}\text { Impacts on the non-fuel operating costs } \\
\text { were small, with VO\&M cost savings } \\
\text { offsetting the cycling costs increases. In most } \\
\text { cases, the addition of variable generation } \\
\text { reduced non-fuel operating costs (the VO\&M } \\
\text { savings were larger than the cycling cost } \\
\text { increases). Cost impacts ranged from a } \\
\$ 0.04 / \mathrm{MWh} \text { decrease to a } \$ 0.01 / \mathrm{MWh} \\
\text { increase. }\end{array}$ \\
\hline Start Effects & - Start Costs & $\begin{array}{l}\text { Average start costs increased with increasing } \\
\text { variable generation, increasing by } 140 \% \\
(\$ 0.55 / \mathrm{MWh}) \text { at the highest penetrations. }\end{array}$ \\
\hline Ramp Effects & - Ramp Costs & $\begin{array}{l}\text { Average ramping costs increased with } \\
\text { increasing variable generation, increasing by } \\
169 \%(\$ 0.06 / \mathrm{MWh}) \text { at the highest } \\
\text { penetrations. }\end{array}$ \\
\hline Reserves Effects & - Reserves Costs & $\begin{array}{l}\text { Reserves costs increased with increasing } \\
\text { penetrations of variable generation, } \$ 165 \% \\
(\$ 0.04 / \mathrm{MWh}) \text { at the highest penetration. }\end{array}$ \\
\hline
\end{tabular}


The key finding at the system level in the variable generation experiments was that although the addition of variable generation did markedly increase cycling costs, it similarly decreased normal VO\&M costs, with the net effect that the addition of variable generation did not adversely affect the non-fuel operating costs. (In most cases, the addition of variable generation actually decreased nonfuel operating costs slightly.)

\subsubsection{Future Work}

The current work was conducted based on assumptions that generators of the future will behave like the generators of today. However, a number of vendors are promoting flexibility in their new designs ${ }^{17}$ so the grid of the future is likely to be markedly more flexible than the system of today. Consequently, high-penetration variable generation in combination with more flexible conventional generation should be investigated.

\footnotetext{
${ }^{17}$ Please see http://www.power-eng.com/articles/print/volume-117/issue-6/features/gas-turbine-combined-cycle-faststart-the-physics-behind-the-con.html for a discussion about the topic.
} 


\section{Results of the Large Conventional Generation Experiments}

The large conventional generation simulations were designed to examine the effects of adding a large, conventional generator to an existing system. Four test cases were built, and all were derived from the same underlying reference system configuration. Each test case included a new, 840-MW coal-fired steam generator. Coal was selected as a proxy for low-cost generation, and because it was used for all the large generator simulations, there was no need to adjust any of the results for fuel cost.

The size of the new generator was chosen to match the size of the largest existing generator in the fleet. It differed from other generators in the system because it had a slightly better heat rate $(10,000$ compared to 10,080$)$, albeit with a more expensive start cost $(\$ 8.67 / \mathrm{MW}$ compared to $\$ 7.91 / \mathrm{MW})$.

Four test cases were used to study two parameters: generator flexibility and reserve requirements (see Table 22). Note that $840 \mathrm{MW}$ is the same contingency reserve used in the reference case.

Table 22. Large Conventional Generation Simulations: Test Cases

\begin{tabular}{|c|c|c|}
\hline \multirow{3}{*}{ 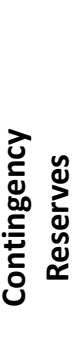 } & \multicolumn{2}{|c|}{ Generator Flexibility } \\
\hline & $\begin{array}{l}\text { 840-MW flexible generator } \\
840 \mathrm{MW} \text { of contingency reserves }\end{array}$ & $\begin{array}{l}\text { 840-MW inflexible generator } \\
840 \mathrm{MW} \text { of contingency reserves }\end{array}$ \\
\hline & $\begin{array}{l}\text { 840-MW flexible generator } \\
1,260 \mathrm{MW} \text { of contingency reserves }\end{array}$ & $\begin{array}{l}\text { 840-MW inflexible generator } \\
1,260 \mathrm{MW} \text { of contingency reserves }\end{array}$ \\
\hline
\end{tabular}

The flexible units had the same ramp rates and minimum stable levels $(1.1 \%$ of rated capacity/minute and $50 \%$ of rated capacity, respectively) as the existing large coal units. The inflexible units differed in that ramp rates and minimum stable levels of $0.3 \%$ and $90 \%$ were used.

The two increased contingency reserves test cases were used to represent the risks associated with adding a new generator at the same physical site as the largest exiting generator.

For all simulations, the new units were sited at Bus 65, a location on the high-voltage backbone known to have adequate transmission capability. In each simulation, the new generator was colocated with the largest existing generator, but it was not connected to the same bus. (The existing machine is on Bus 66.)

The naming convention for the large conventional generation simulations is as follows:

- Reference (Ref)

- Large flexible unit addition (LFUA)

- Large flexible unit with increased reserves (LFUA:IR)

- Large inflexible unit addition (LIUA) 
- Large inflexible unit addition and increased reserves (LIUA:IR).

Note that all large generator test cases were compared to the reference test case.

\subsection{Overall System Impacts}

The total generation cost for the system is shown in Figure 16. As expected, the generation costs for the overall system went down when a new, low-cost generator was added to the system. The system decreased by $4.3 \%$ when a low-cost, flexible generator was added and by $3.6 \%$ when a low-cost, inflexible power plant was added.

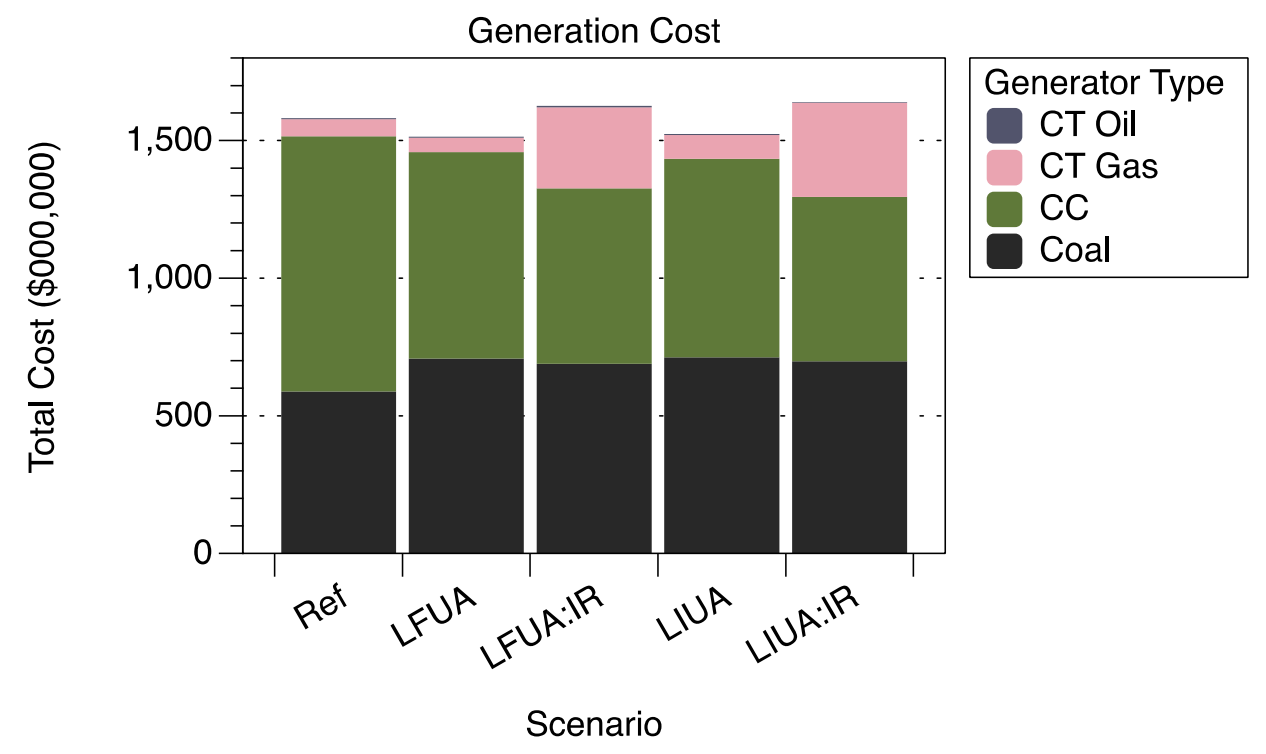

Figure 16. Large conventional generation simulations: total generation costs

However, the cost savings disappeared when the contingency reserve requirements were increased, adding $2.8 \%$ and $3.8 \%$ to the costs when a flexible or an inflexible generator was added in each large conventional generation scenario. The main reason for this is because the additional reserves were provided by gas combustion turbines.

Figure 17 shows the energy delivered by generator type shows and how the new generation affects the balance of the system. 


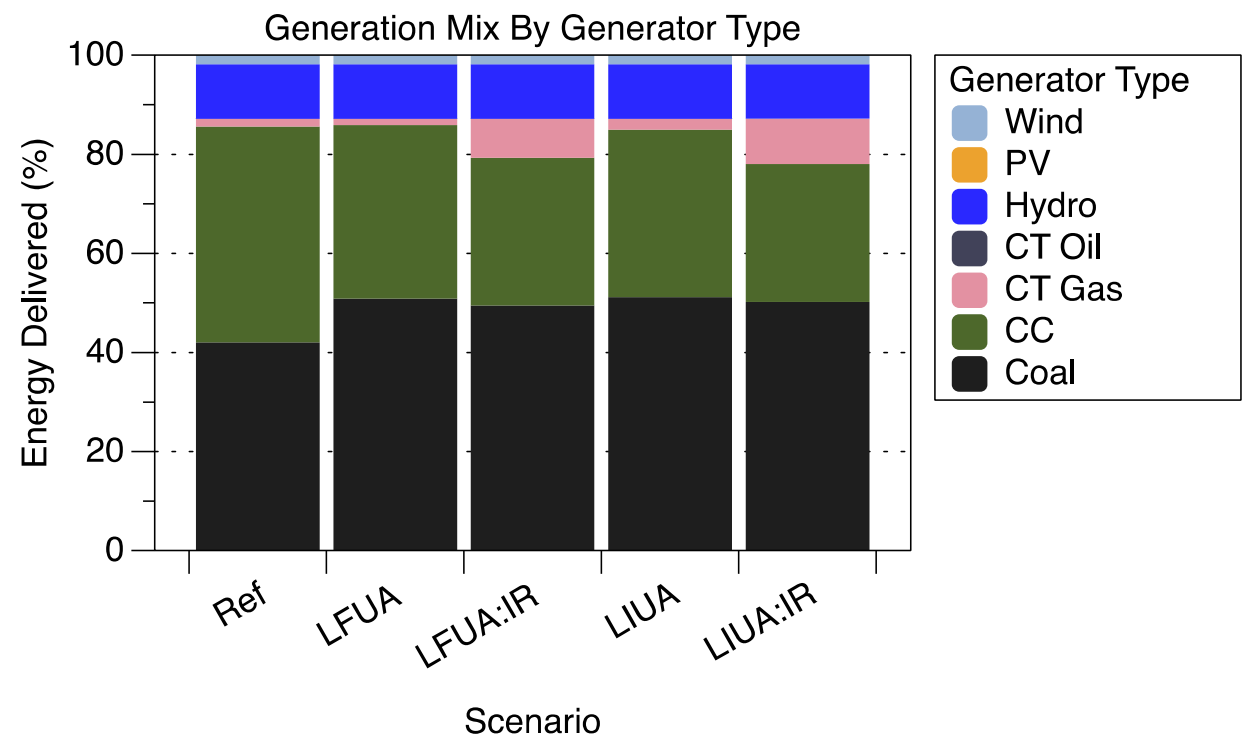

Figure 17. Large conventional generation simulations: energy delivered by generator type

In all cases, adding the new, low-cost coal generation displaced combined-cycle generation, and, except in the simulation of a large flexible unit addition (LFUA), adding new baseload generation also increased the amount of generation required from the combustion turbine units (see Table 23).

Table 23. Large Conventional Generation Simulations: Generation by Generator Type (GWh)

\begin{tabular}{lrrrrr} 
Type & Ref & LFUA & LFUA:IR & LIUA & LIUA:IR \\
\hline Coal & 26,982 & 32,637 & 31,742 & 32,834 & 32,182 \\
CC & 27,946 & 22,468 & 19,139 & 21,685 & 17,889 \\
CT Gas & 979 & 805 & 5,032 & 1,391 & 5,851 \\
CT Oil & 8 & 10 & 12 & 11 & 7 \\
Hydro & 7,065 & 7,064 & 7,063 & 7,063 & 7,063 \\
PV & - & - & - & - & - \\
Wind & 1,174 & 1,171 & 1,166 & 1,170 & 1,162 \\
\hline Total & 64,154 & 64,154 & 64,154 & 64,154 & 64,154
\end{tabular}

The decreases in the combined-cycle generation ranged from $20 \%$ to $36 \%$. The two largest changes were in the increased reserves simulations in which the combined-cycle plants were replaced not only by the new coal plant but also by combustion turbines.

The effects to per-unit costs of adding a new low-cost generator are shown in Table 24. Most changes were modest, with the largest change the reduction in the combustion turbine gas costs for the two simulations with increased reserves (LFUA:IR and LIUA:IR). These cost reductions are because the combustion turbines delivered more of the system's energy and thereby defrayed some of the start-related costs. 
Table 24. Large Conventional Generation Simulations: Average Generation Costs (\$/MWh)

\begin{tabular}{lrrrrr} 
Type & Ref & LFUA & LFUA:IR & LIUA & LIUA:IR \\
\hline Coal & 21.80 & 21.69 & 21.71 & 21.69 & 21.70 \\
CC & 33.19 & 33.35 & 33.30 & 33.30 & 33.37 \\
CT Gas & 62.91 & 64.74 & 58.54 & 61.66 & 58.43 \\
\hline Wt. Avg. & 24.64 & 23.59 & 25.33 & 23.76 & 25.57
\end{tabular}

The average fuel costs for each of the scenarios is shown in Table 25. Adding a new generator reduced the fuel costs in scenarios in which the reserves remained unchanged, and it increased average fuel costs in scenarios in which the reserves were increased.

Table 25. Large Conventional Generation Simulations: Average Fuel Costs (\$/MWh)

\begin{tabular}{lrrrrr} 
& Ref & LFUA & LFUA:IR & LIUA & LIUA:IR \\
\hline Wt. Avg. & 22.60 & 21.33 & 23.16 & 21.51 & 23.37
\end{tabular}

Figure 18 shows the overall cycling (start-up plus ramp) costs for the simulations with large conventional generation additions, and Table 26 shows the per-unit cost information in tabular form.

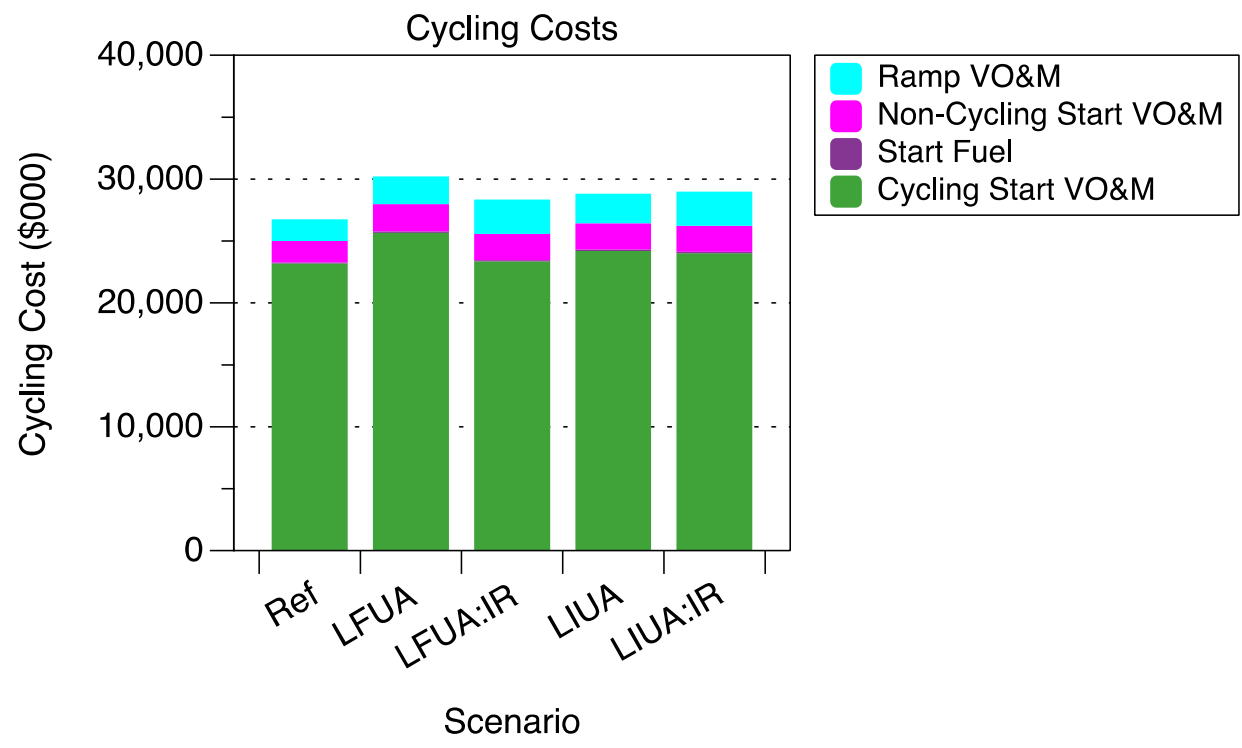

Figure 18. Large conventional generation simulations: cycling costs by cost component type

In all cases, the cycling costs increased with the addition of the new generation. These cost increases ranged from $5 \%$ to $14 \%$, with the largest increase associated with the addition of a flexible generator (LFUA). Although this may seem counterintuitive, the lack of additional constraints allowed the system to trade start-up costs for fuel cost savings and thereby minimize the overall system cost. 
Table 26. Large Conventional Generation Simulations: Average Cycling Costs by Generator Type (\$/MWh)

\begin{tabular}{lrrrrr} 
Type & Ref & LFUA & LFUA:IR & LIUA & LIUA:IR \\
\hline Coal & 0.26 & 0.27 & 0.29 & 0.27 & 0.29 \\
CC & 0.47 & 0.63 & 0.59 & 0.58 & 0.65 \\
CT Gas & 6.34 & 8.28 & 1.47 & 4.90 & 1.33 \\
\hline Wt. Avg. & 0.43 & 0.49 & 0.45 & 0.47 & 0.47
\end{tabular}

The normal operating maintenance costs (as opposed to the start-up and ramping related maintenance costs) are shown in Table 27. Similar to the cycling cost results, the addition of a new, large generator increased these costs (to between $7 \%$ and $11 \%$ ) because the new generator displaced combined-cycle machines that had lower VO\&M costs.

Table 27. Large Conventional Generation Simulations: Average VO\&M Costs (\$/MWh)

\begin{tabular}{rrrrrr} 
& Ref & LFUA & LFUA:IR & LIUA & LIUA:IR \\
\hline Wt. Avg. & 1.61 & 1.78 & 1.72 & 1.78 & 1.73
\end{tabular}

Table 28 combines the cycling costs (i.e., the operating start-up and ramp-related costs) with the normal operating maintenance costs to provide overall non-fuel operating costs for the simulations studied. Costs for the simulations of additions of both flexible and inflexible generation increased between $7 \%$ and $11 \%$.

Table 28. Large Conventional Generation Simulations: Average Non-Fuel Operating Costs by Generator Type (\$/MWh)

\begin{tabular}{lrrrrr} 
Type & Ref & LFUA & LFUA:IR & LIUA & LIUA:IR \\
\hline Coal & 3.00 & 3.05 & 3.07 & 3.05 & 3.07 \\
CC & 1.50 & 1.65 & 1.61 & 1.60 & 1.67 \\
CT Gas & 6.90 & 8.84 & 2.04 & 5.47 & 1.90 \\
\hline Wt. Avg. & 2.04 & 2.27 & 2.18 & 2.25 & 2.20
\end{tabular}

\subsection{System Impacts per Unit of New Generation Added}

The next three plots show cost changes per unit of new generation added. As an example, Figure 19 shows that the fuel cost for the overall system was reduced on average by approximately $\$ 10$ for each MWh of energy provided by a new, large, inflexible unit (LIUA). This method of normalization was chosen so that cost impacts could be easily compared among generation technologies (e.g., wind and solar). All comparisons were made to the reference case.

Figure 19 shows that for both the LFUA and LIUA simulations, the fuel savings were enough to offset the additional start-up, ramping, and operating VOM costs associated with the new generation. However, the figure also shows that if the new generation requires increased reserve requirements, the fuel required to provide the increased reserves may offset any direct fuel savings from the new generation and could lead to increased overall system costs. The two examples shown here increased the system-wide fuel costs between $\$ 6$ and $\$ 8$ per each MWh of energy supplied by the new generation. 


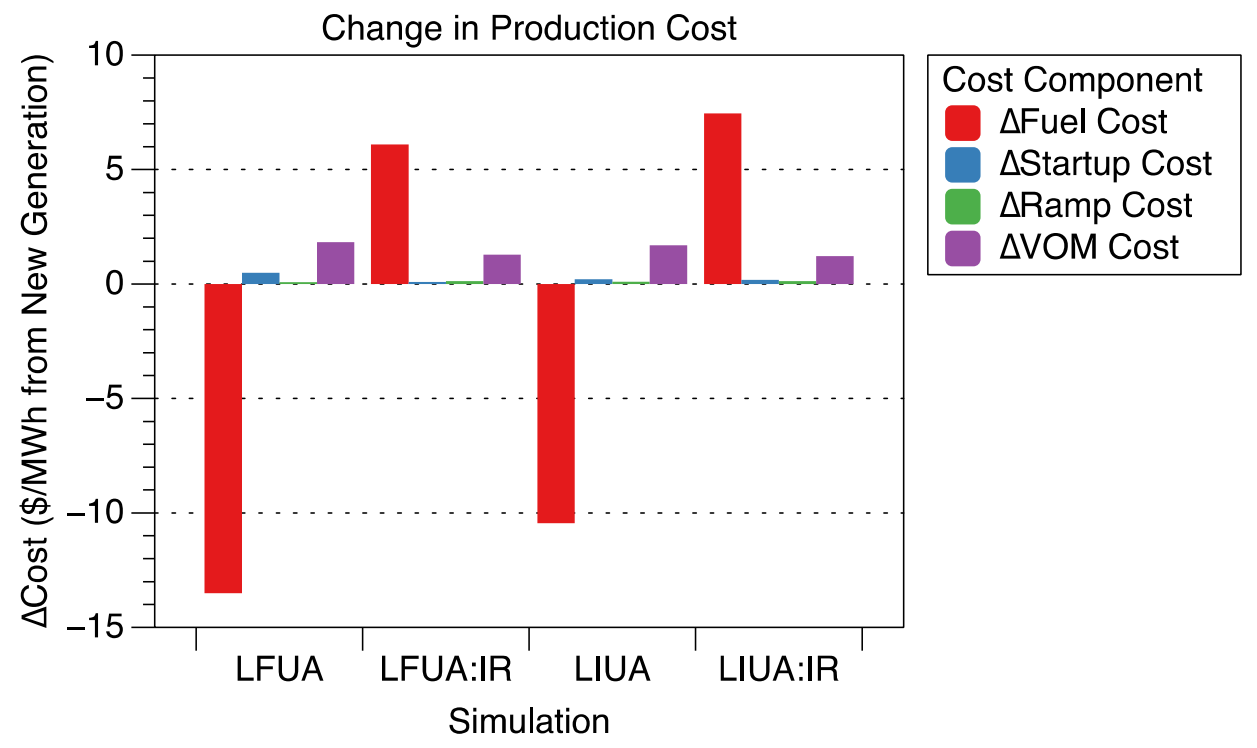

Figure 19. Large conventional generation simulations: changes in production costs per MWh of new generation added

Table 29 shows the fuel costs changes by generator type. Note that the addition of the new baseload generation reduced average fuel costs by $\$ 10.45$ and $\$ 13.51$ for each MWh of new baseload generation added. The scenarios with additional reserves saw an increase in cost of approximately $\$ 1.80 / \mathrm{MWh}$.

Table 29. Large Conventional Generation Simulations: Changes in Fuel Cost per MWh of New Generation (\$/MWh)

\begin{tabular}{lrrrr} 
Type & LFUA & LFUA:IR & LIUA & LIUA:IR \\
\hline Coal & 16.76 & 14.35 & 15.68 & 13.91 \\
CC & $(28.72)$ & $(47.46)$ & $(29.75)$ & $(48.07)$ \\
CT Gas & $(1.63)$ & 39.04 & 3.50 & 41.64 \\
\hline Total & $(13.51)$ & 6.10 & $(10.45)$ & 7.46
\end{tabular}

The non-fuel operating costs are shown in Figure 20. (The start-up costs included start fuel costs; however, these costs were so small relative to other costs that they could be ignored.) The non-fuel operating costs (start, ramping, and operating) increased throughout the overall system, although the addition of reserves lessened VO\&M costs. Although the new baseload plants were less expensive from a fuel-cost perspective, their start, ramp, and VO\&M costs were all more expensive than those of the combined-cycle units that the new generation replaced. 


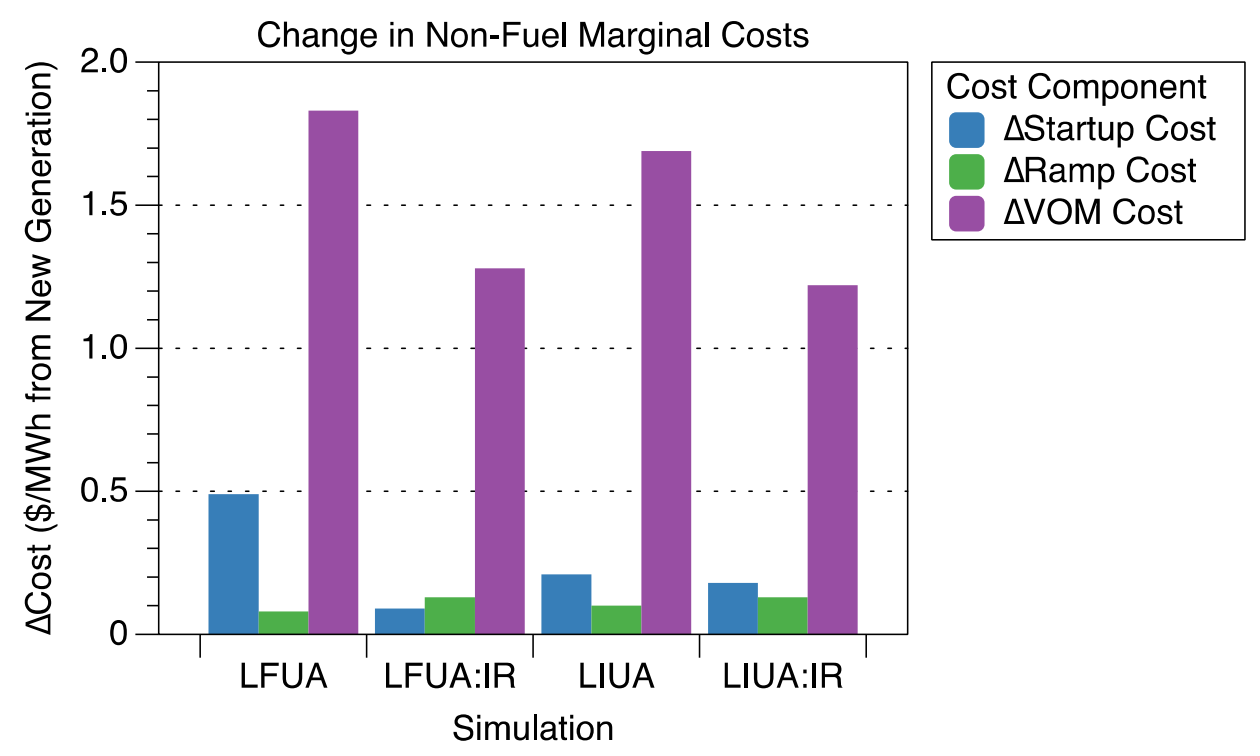

Figure 20. Large conventional generation simulations: changes in non-fuel operating costs per unit of new generation added

Table 30 shows the cycling costs by generator type. The cycling costs for the LFUA were highest, driven by an increase in combined-cycle start costs. (With the addition of the new generation, combined-cycle units started more often and for shorter periods of time.)

Table 30. Large Conventional Generation Simulations: Changes in Cycling Costs per MWH of New Generation (\$/MWh)

\begin{tabular}{lrrrr} 
Type & LFUA & LFUA:IR & LIUA & LIUA:IR \\
\hline Coal & 0.30 & 0.38 & 0.30 & 0.35 \\
CC & 0.15 & $(0.34)$ & $(0.10)$ & $(0.24)$ \\
CT Gas & 0.08 & 0.20 & 0.09 & 0.24 \\
\hline Total & 0.57 & 0.22 & 0.31 & 0.31
\end{tabular}

Although VO\&M costs increased for all simulations, these costs did not decrease for some generator classes (see Table 31). The cause of the decrease is the same as in the variable generation scenarios: the new generation displaced some generation (e.g., combined-cycle generation), and VO\&M was avoided on these machines.

Table 31. Large Conventional Generation Simulations: Changes in VO\&M Costs per MWh of New Generation (\$/MWh)

\begin{tabular}{lrrrr} 
Type & LFUA & LFUA:IR & LIUA & LIUA:IR \\
\hline Coal & 2.78 & 2.43 & 2.62 & 2.37 \\
CC & $(0.94)$ & $(1.54)$ & $(0.97)$ & $(1.56)$ \\
CT Gas & $(0.02)$ & 0.39 & 0.04 & 0.42 \\
\hline Total & 1.83 & 1.28 & 1.69 & 1.22
\end{tabular}


The combined non-fuel operating costs are shown in Figure 21. The cost increases varied between $\$ 2.00$ and $\$ 2.40$ per MWh of energy provided by new generation (excluding the simulations in which the amount of reserves was increased).

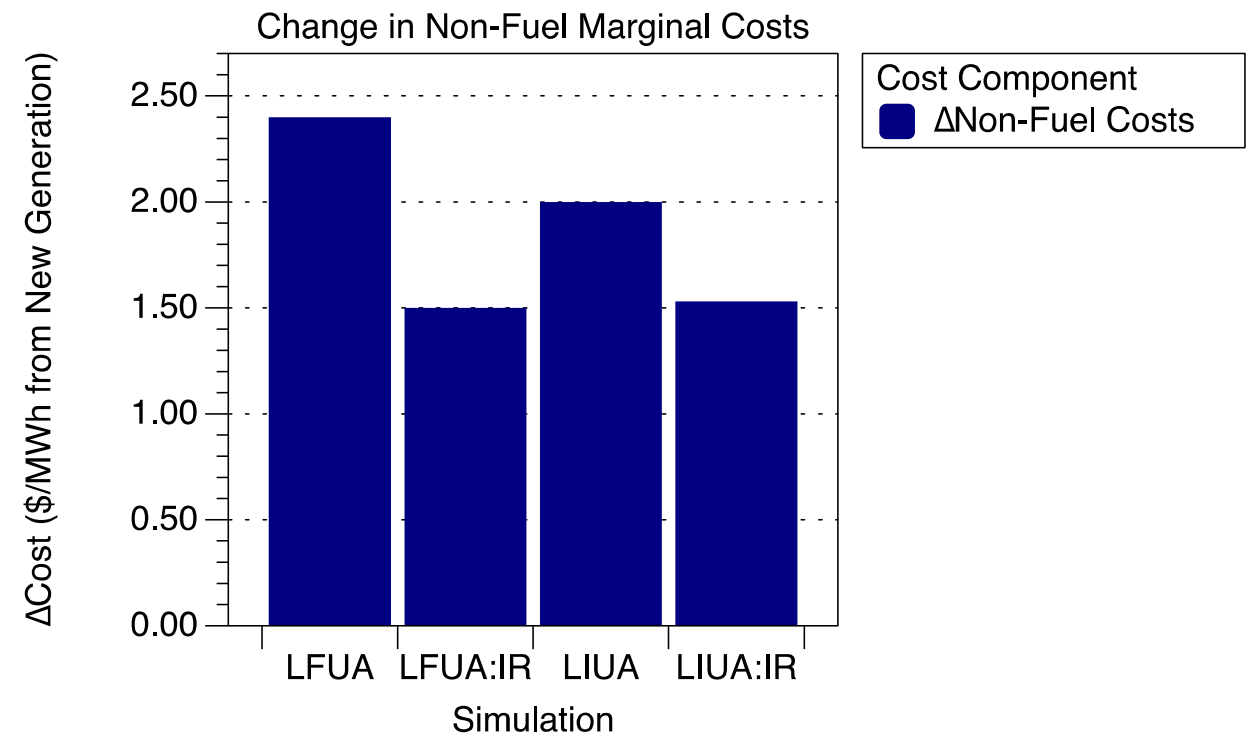

Figure 21. Large conventional generation simulations: changes in non-fuel operating costs per unit of new generation added

The non-fuel operating costs by generator type are shown in Table 32. Although the costs were reduced for certain generator types (primarily the combined-cycle fleet), the overall weighted average costs increased in all scenarios.

Table 32. Large Conventional Generation Simulations: Changes in Non-Fuel Operating Costs per MWh of New Generation (\$/MWh)

\begin{tabular}{lrrrr} 
Type & LFUA & LFUA:IR & LIUA & LIUA:IR \\
\hline Coal & 3.08 & 2.82 & 2.92 & 2.72 \\
CC & $(0.79)$ & $(1.89)$ & $(1.07)$ & $(1.80)$ \\
CT Gas & 0.06 & 0.60 & 0.13 & 0.66 \\
\hline Total & 2.40 & 1.51 & 2.00 & 1.53
\end{tabular}

The following sections investigate how the addition of the new generation affects the system's starts, ramping, and combined cycling.

\subsection{Start Effects}

The effects of the different scenarios did not show a defined pattern. Coal starts remained relatively unchanged from one simulation to another, with a slight increase in starts for the one new plant that was added to the system. Combined-cycle starts varied but decreased in the reserve sensitivities (LFUA:IR and LIUA:IR) in which combined-cycle units were replaced by combustion turbines. (The increased reserve requirements require response times that cannot be met by the combined- 
cycle units alone, so the combustion turbine units were used to provide both rapid response and energy.)

When considered outside of the reserves changes, the start pattern varied with the flexibility of the added generator. The addition of the large, flexible generator displaced some of the combined-cycle units that had been doing load following, so the combined-cycle units started and stopped more often.

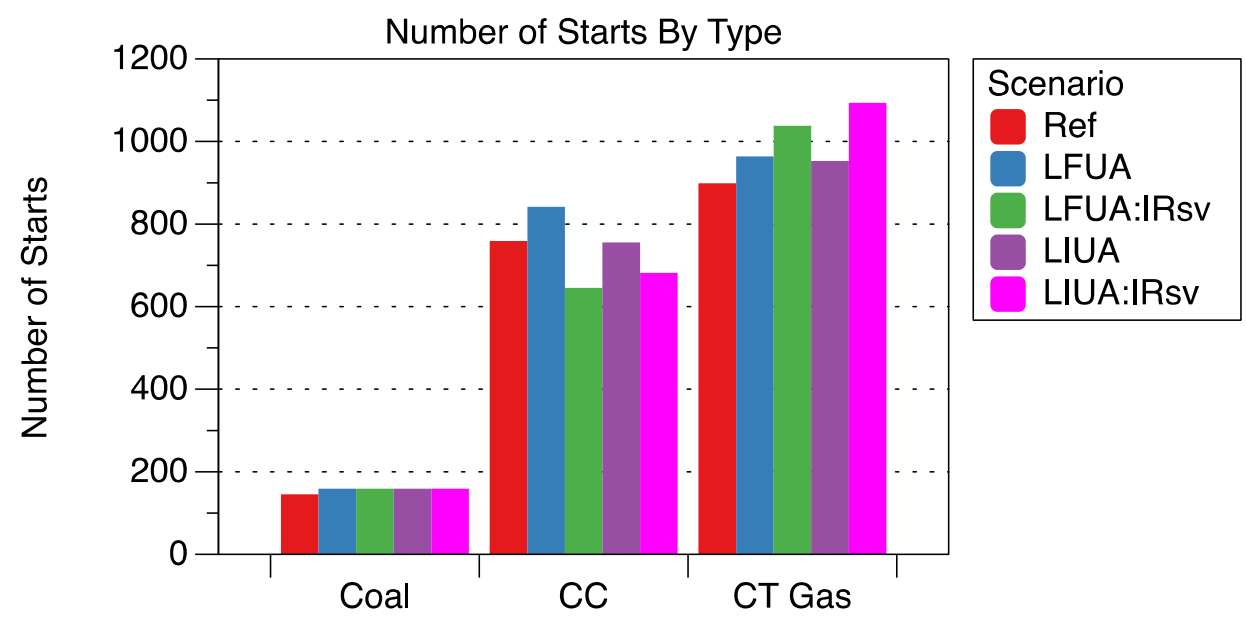

\section{Generator Type}

Figure 22. Large conventional generation simulations: number of starts by generator type

The largest impact to hours online per start are shown in the inflexible generator simulations. The hours online for the average coal plant decreased markedly for the two LIUA simulations, with the large, less expensive generator displacing the other coal plants. (The average hours online dropped by almost $80 \%$.) The combined-cycle units and combustion turbine units both stayed online longer per start, although for different reasons. Fewer combined-cycle units were online, and the units that were running were online longer, whereas the combustion turbine units were used to provide more energy (see Figure 24) and reserves. (Combustion turbine units provided approximately six times more energy and reserves in the LIUA scenarios than they did in the reference scenario.) 


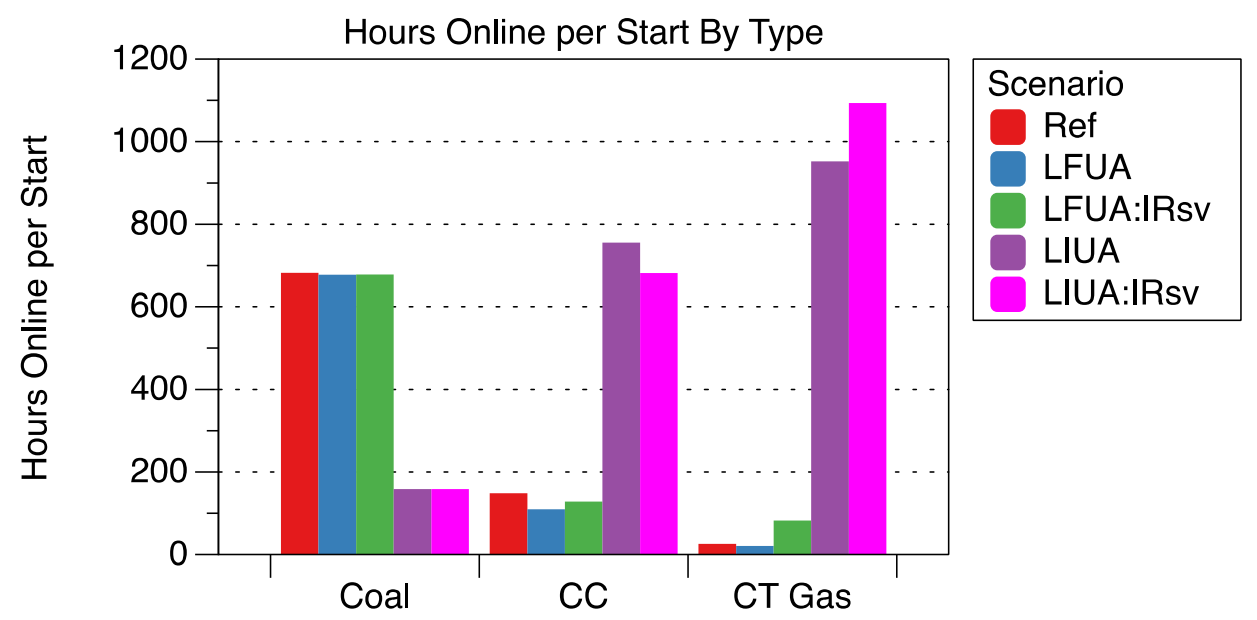

Generator Type

Figure 23. Large conventional generation simulations: average hours online per generator start

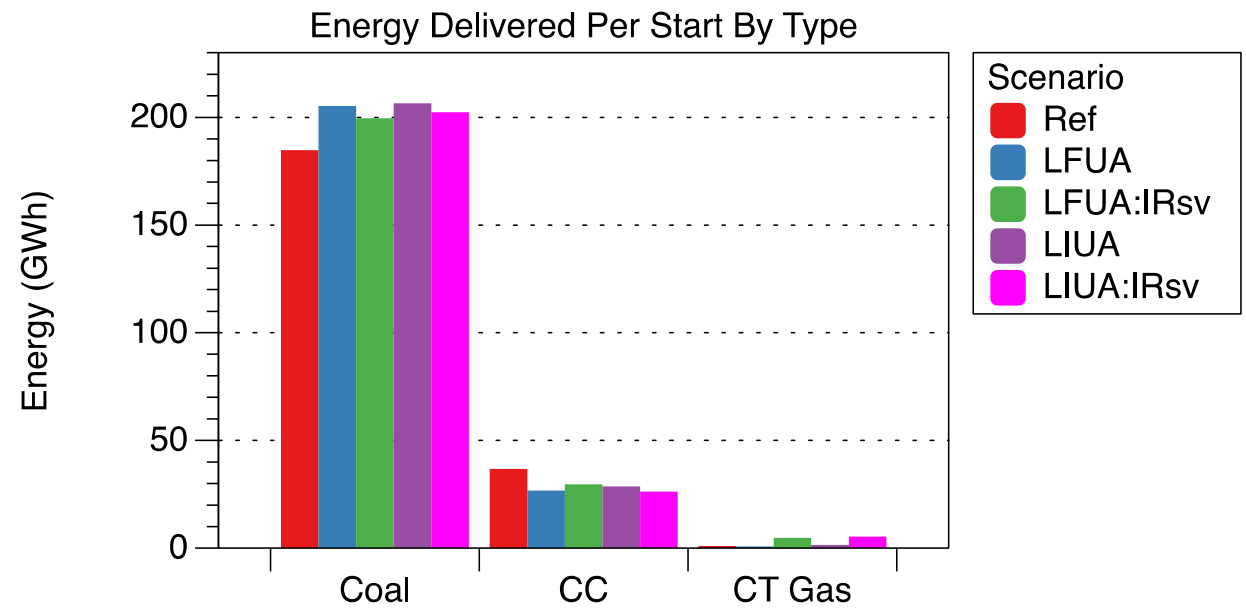

Generator Type

Figure 24. Large conventional generation simulations: average energy delivered per generator start

One of the more notable changes in average start costs for the gas combustion turbine units was in the increased reserves scenarios. The changes were dramatic, with the costs reducing by more than $75 \%$. This is because the combustion turbine units stayed online in these simulations (LFUA:IR and LIUA:IR) to provide both energy and reserves. 
Table 33. Large Conventional Generation Simulations: Average Combined Start Costs by Generator Type (\$/MWh)

\begin{tabular}{lrrrrr} 
Type & Ref & LFUA & LFUA:IR & LIUA & LIUA:IR \\
\hline Coal & 0.22 & 0.22 & 0.22 & 0.22 & 0.22 \\
CC & 0.42 & 0.56 & 0.52 & 0.51 & 0.58 \\
CT Gas & 6.21 & 8.12 & 1.44 & 4.80 & 1.30 \\
\hline Wt. Avg. & 0.39 & 0.44 & 0.40 & 0.41 & 0.41
\end{tabular}

Combined-cycle start-up costs cost were negatively impacted, increasing between $21 \%$ and $38 \%$.

\subsection{Ramp Effects}

The ramping impact caused by the addition of the new, large generators also varied with generator type. In all cases, the average coal plant ramped more. This is because the new generation forced some of the more traditional load-following plants (the combined-cycle units) offline, and some of the coal plants provided load following. This was especially true when the inflexible generator was added.

Ramps for combined-cycle machines decreased, mostly because the combined-cycle units were displaced by coal plants in all scenarios and additionally by combustion turbines in the increased reserves scenarios.

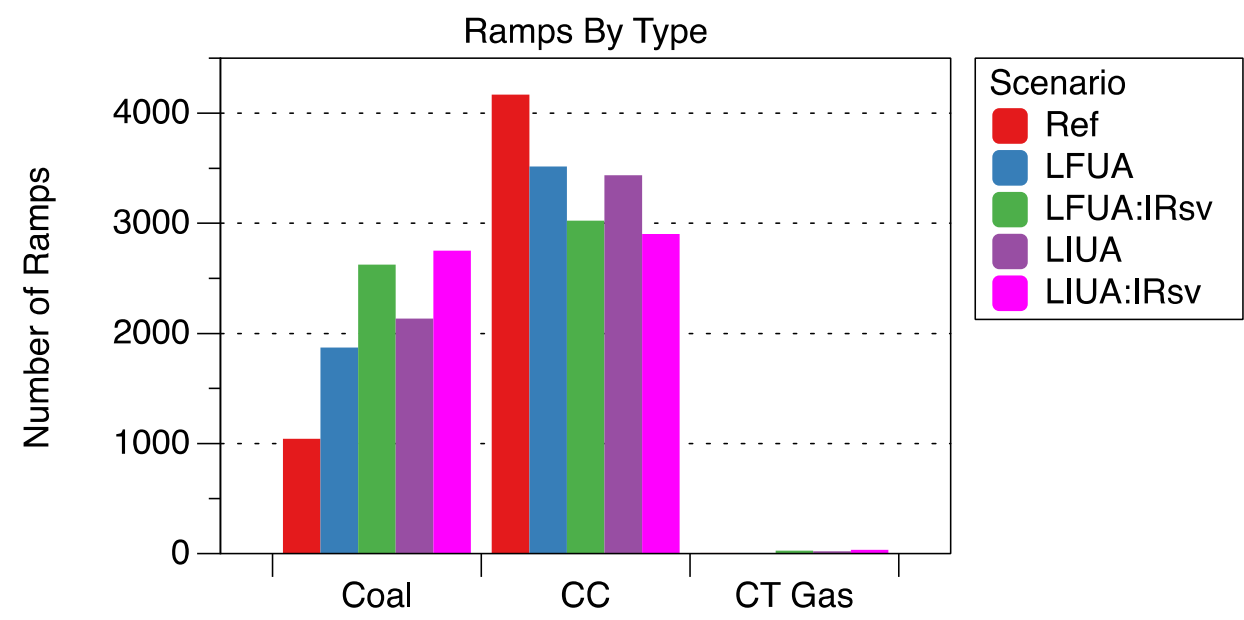

Generator Type

Figure 25. Number of ramps per generator start

The results for the ramps per energy delivered (Figure 26) show several interesting patterns. First, the addition of a new generation plant caused both the coal and combined-cycle plants to ramp more for each unit of energy delivered. The increases were between $31 \%$ and $77 \%$ for the coal plants and between $14 \%$ and $24 \%$ for the combined-cycle units. Second, in the increased reserve simulations, the amount of ramping per unit of energy delivered dropped by almost $75 \%$ for the combustion turbines. 


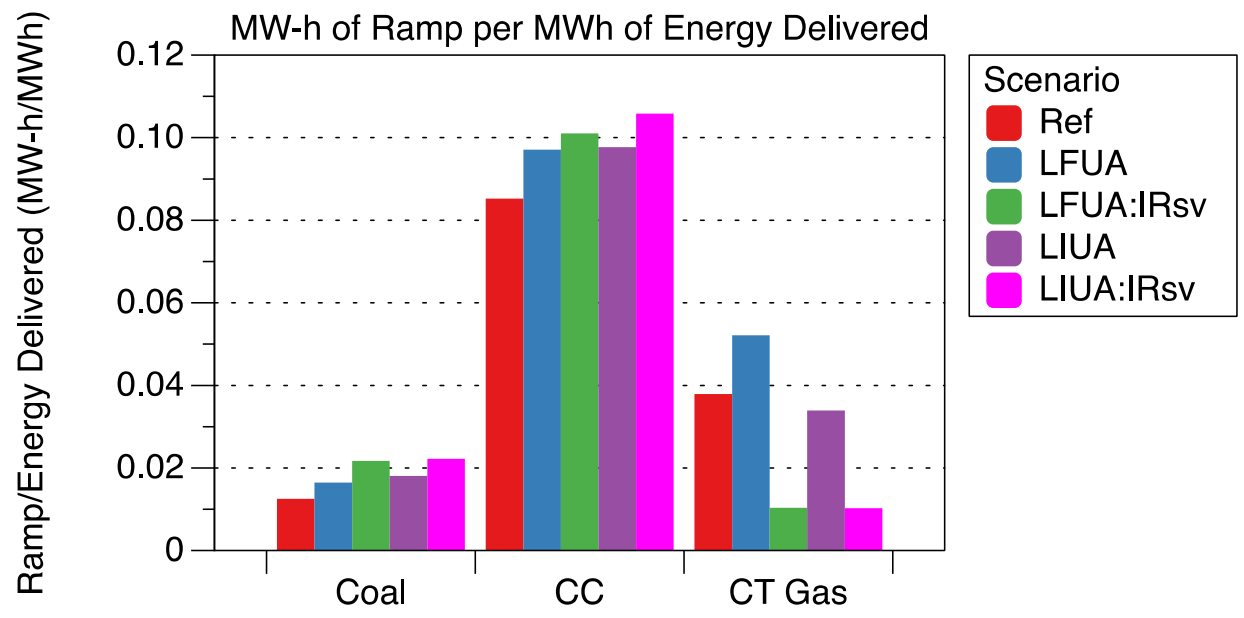

Generator Type

Figure 26. Large conventional generation simulations: average amount of ramp per unit of energy delivered

The financial implications of the changes in ramping are shown in Table 34. In general, the per-unit ramping costs increased with the addition of the new generators. The weighted average costs increased between $25 \%$ and $50 \%$, and the largest increase for a given generation type was $100 \%$ for the average coal plant.

Table 34. Large Conventional Generation Simulations: Average Ramping Costs by Generator Type (\$/MWh)

\begin{tabular}{lrrrrr} 
Type & Ref & LFUA & LFUA:IR & LIUA & LIUA:IR \\
\hline Coal & 0.04 & 0.05 & 0.07 & 0.06 & 0.08 \\
CC & 0.06 & 0.07 & 0.07 & 0.07 & 0.07 \\
CT Gas & 0.12 & 0.16 & 0.03 & 0.11 & 0.03 \\
\hline Wt. Avg. & 0.04 & 0.05 & 0.06 & 0.05 & 0.06
\end{tabular}

One exception to the trend was the ramping costs for the combustion turbines in the two increased reserves simulations. In these runs, the ramping costs decreased by $75 \%$. The reduction was because the turbines remained online to provide energy and reserves.

\subsection{Reserves Effects}

This section investigates how adding a new, large, coal-fired generator to a preexisting system affects reserves provisioning costs. Table 35 presents the reserves provisioning costs for the four simulations with the addition of large conventional generation and the reference scenario. 
Table 35. Large Conventional Generation Simulations: Reserves Provisioning Costs

\begin{tabular}{lrrrr} 
Simulation & $\begin{array}{r}\text { Reserves Provisioning } \\
\text { Cost }(\mathbf{\$ 0 0 0 , 0 0 0 )}\end{array}$ & $\begin{array}{r}\Delta \text { Cost } \\
(\mathbf{\$ 0 0 0 , 0 0 0 )}\end{array}$ & $\mathbf{\$} / \mathbf{M W h}$ Energy & $\boldsymbol{\Delta} \mathbf{\$} / \mathbf{M W h}$ Energy \\
\hline Ref & 2 & - & 0.02 & - \\
LFUA & 1 & $(1)$ & 0.02 & $(0.01)$ \\
LFUA:IR & 6 & 5 & 0.10 & 0.07 \\
LIUA & 2 & - & 0.03 & 0.01 \\
LIUA:IR & 7 & 5 & 0.10 & 0.08
\end{tabular}

The reserves provisioning results were near the limits of the simulations' precision; however, there appeared to be several trends. First, adding a large, flexible unit appeared to reduce provision costs. The addition of the new, flexible generation created a situation in which units that previously ran at maximum capacity ran at reduced generation levels throughout much of the year, and this excess online capacity provided low-cost reserves. Second, if increased reserves provisions are required to accommodate the installation of new generation, the cost impacts can be significant. (Costs appeared to approximately triple.)

\subsection{Capacity Factor and Curtailment Effects}

This section reports how configuration changes affect the system's capacity factors and curtailment values.

Figure 27 shows how the capacity factors were affected with the addition of new generation, and the general, downward trend in capacity factors is not surprising given that $840 \mathrm{MW}$ of inexpensive, baseload generation was added to an existing system. An exception was the increase in the capacity factors of the combustion turbines in the two reserves addition simulations (LFUA:IR and LIUA:IR). For these two runs, the capacity factors of the combustion turbines increased because the combustion turbine units provided much of the new reserves. 


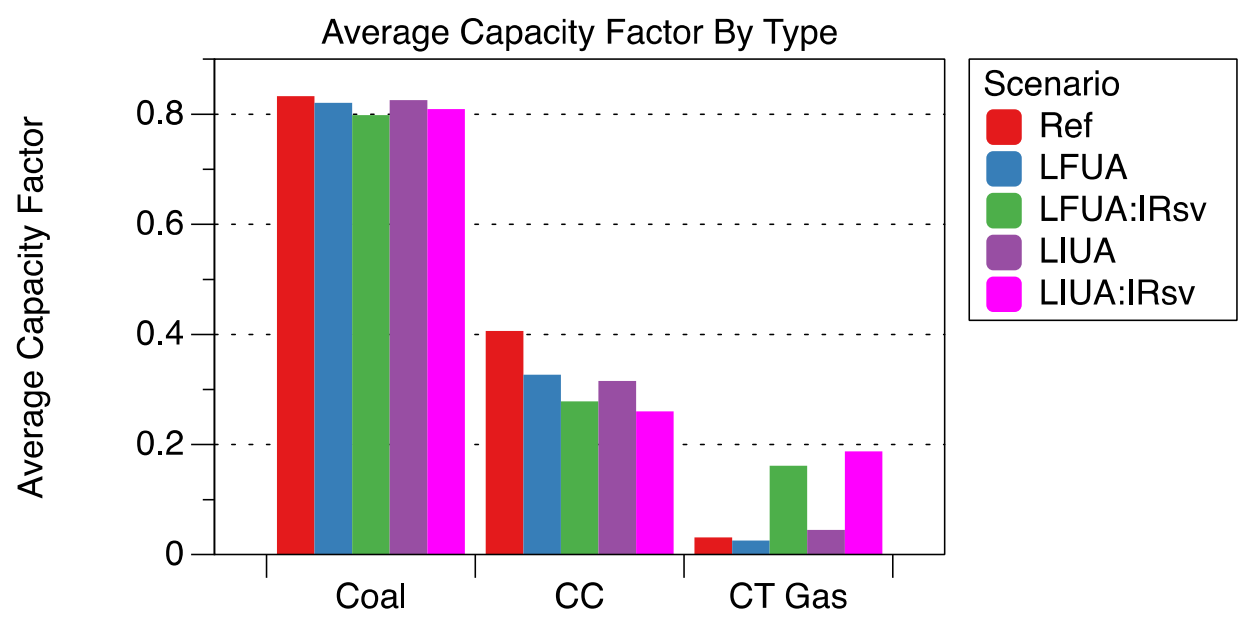

Generator Type

Figure 27. Large conventional generation simulations: average capacity factors by generator type

Finally, adding new generation increased curtailment, with the inflexible generation addition having a slightly larger impact on the amount of the curtailment (see Figure 28).

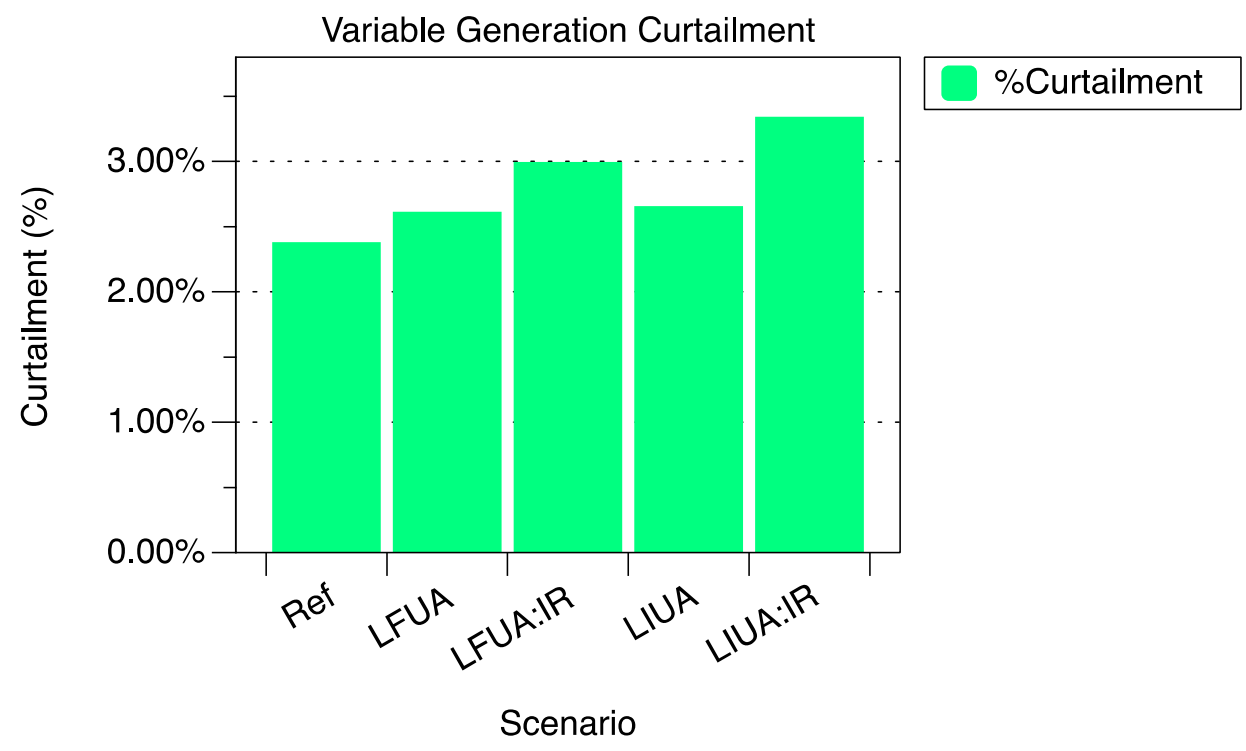

Figure 28. Large conventional generation simulations: variable generation curtailment

\subsection{Large Conventional Generation Study Summary}

This section summarizes the overall cost-related findings of the large conventional generation experiments. The results are divided into two: costs per unit of new generation and costs per unit of overall system generation. 


\subsubsection{Large Conventional Generation Summary: Cost Impacts per Unit of New Generation}

The cost impacts per unit of new generation are highlighted in Table 36.

Table 36. Large Conventional Generation Simulations:

Cost Summaries per Unit of New Generation Added

\begin{tabular}{|c|c|c|}
\hline Topic & Subtopic & Results Summary \\
\hline \multirow[t]{4}{*}{$\begin{array}{l}\text { New Generation Impacts } \\
\text { (Changes per Unit of New } \\
\text { Generation Added) }\end{array}$} & - Fuel Costs & $\begin{array}{l}\text { Fuel costs decreased as new generation was } \\
\text { added. Cost reductions ranged from } \$ 10.45 \\
\text { to } \$ 13.51 \text { per MWh of new generation } \\
\text { added. }\end{array}$ \\
\hline & $\begin{array}{l}\text { - Cycling Costs (Combined Start } \\
\text { + Ramp Costs) }\end{array}$ & $\begin{array}{l}\text { Cycling costs increased as new generation } \\
\text { was added. Cost increases ranged from } \\
\$ 0.31 \text { to } \$ 0.57 \text { per MWH of new generation } \\
\text { in the inflexible generation case. }\end{array}$ \\
\hline & - VO\&M Costs & $\begin{array}{l}\text { VO\&M costs increased as new generation } \\
\text { was added. Costs increased by } \$ 1.83 \text { per } \\
\text { MWh of new generation for the flexible } \\
\text { generator simulation and by } \$ 1.69 \text { per MWh } \\
\text { of new generation for the inflexible } \\
\text { generation addition. }\end{array}$ \\
\hline & - Non-Fuel Operating Costs & $\begin{array}{l}\text { Non-fuel operating costs increased with the } \\
\text { addition of new baseload generation. Costs } \\
\text { increased by } \$ 2.40 \text { per MWh of new } \\
\text { generation for the flexible baseload } \\
\text { generation and by } \$ 2.00 \text { for the inflexible } \\
\text { baseload addition. }\end{array}$ \\
\hline
\end{tabular}

Adding new baseload generation decreased overall system costs; however, it had significant cost impacts on the system's cycling costs and VO\&M costs. Non-fuel system costs increased between $\$ 2.00$ and $\$ 2.40$ per MWh of new generation added. 


\subsubsection{Large Conventional Generation Summary: Overall System Costs per Unit of Overall System Generation}

The cost impacts at the system level are summarized in Table 37.

Table 37. Large Conventional Generation Simulations: Cost Summaries

\begin{tabular}{|c|c|c|}
\hline Topic & Subtopic & Results Summary \\
\hline \multirow[t]{5}{*}{ Overall System Impacts } & - Total Generation Costs & $\begin{array}{l}\text { Total generation costs decreased } 4.3 \% \\
(\$ 1.05 / \mathrm{MWh}) \text { when a large, flexible } \\
\text { generator was added and } 3.6 \%(\$ 0.88 / \mathrm{MWh}) \\
\text { when a large, inflexible generator was } \\
\text { added. }\end{array}$ \\
\hline & - Fuel Costs & $\begin{array}{l}\text { Fuel costs decreased } 6 \%(\$ 1.27 / \mathrm{MWh}) \text { in the } \\
\text { flexible generator scenario and } 5 \% \\
(\$ 1.09 / \mathrm{MWh}) \text { in the inflexible simulation. }\end{array}$ \\
\hline & $\begin{array}{l}\text { - Cycling Costs (Combined Start } \\
\text { + Ramp Costs) }\end{array}$ & $\begin{array}{l}\text { Cycling costs increased } 14 \%(\$ 0.06 / \mathrm{MWh}) \\
\text { with the flexible generator and } 9 \% \\
\text { (\$0.04/MWh) with the inflexible generator. }\end{array}$ \\
\hline & - VO\&M Costs & $\begin{array}{l}\text { VO\&M costs increased } 11 \%(\$ 0.17 / \mathrm{MWh}) \text { in } \\
\text { both the flexible generator and inflexible } \\
\text { generator simulations. }\end{array}$ \\
\hline & - Non-Fuel Operating Costs & $\begin{array}{l}\text { Costs increased with the addition of the new } \\
\text { generation. The non-fuel operating costs } \\
\text { rose } 11 \%(\$ 0.23 / \mathrm{MWh}) \text { in the flexible } \\
\text { generator simulation and } 10 \%(\$ 0.21 / \mathrm{MWh}) \\
\text { in the inflexible generator scenario. }\end{array}$ \\
\hline Start Effects & - Start Costs & $\begin{array}{l}\text { Start costs effects were small, increasing by } \\
13 \%(\$ 0.05 / \mathrm{MWh}) \text { with the flexible } \\
\text { generator and } 5 \%(\$ 0.02 / \mathrm{MWh}) \text { for the } \\
\text { inflexible generator. }\end{array}$ \\
\hline Ramp Effects & - Ramp Costs & $\begin{array}{l}\text { Average ramping costs increased } 25 \% \\
(\$ 0.01 / \mathrm{MWh}) \text { for both large conventional } \\
\text { generation simulations. }\end{array}$ \\
\hline Reserves Effects & - Reserves Costs & $\begin{array}{l}\text { Reserves costs decreased } 33 \%(\$ 0.01 / \mathrm{MWh}) \\
\text { in the flexible generator simulation and were } \\
\text { unchanged in the inflexible generator } \\
\text { scenario. }\end{array}$ \\
\hline
\end{tabular}

The key finding in the large conventional generation experiments was that although the addition of a generator decreased overall generation costs, its addition increased both the system-wide cycling costs and normal VO\&M costs.

\subsubsection{Future Work}

The interaction of the inflexible baseload generation and the penetration levels of variable generation should be investigated in more detail. Historically, the thinking seems to be that the addition of new baseload generation has little impact on integration costs; however, this study has 
shown that such costs can be pronounced and, at least in the current system, exceed costs associated with adding variable generation. A better understanding of how these two very important assets interact at high penetrations of variable generation would be helpful to the electric power community. 


\section{Results of the Generation Mix Experiments}

The next set of simulations explores how generation mix affects economic dispatch operations. The generation mixes considered for this study were:

- Reference (Ref)-40\% nominal coal

- High coal/low gas (HCLG) - 65\% nominal coal

- Low coal/high gas (LCHG)-15\% nominal coal.

The reference scenario was used as a baseline throughout the study, and many of the study results are reported in terms of how the results compare to this baseline.

All scenarios in the generation mix study had the same overall installed capacity: 17,564 MW. The three scenarios differed in the number of combined-cycle plants and coal-fired steam units installed, and the installed capacity for each generation type in the three scenarios is shown in Figure 29.

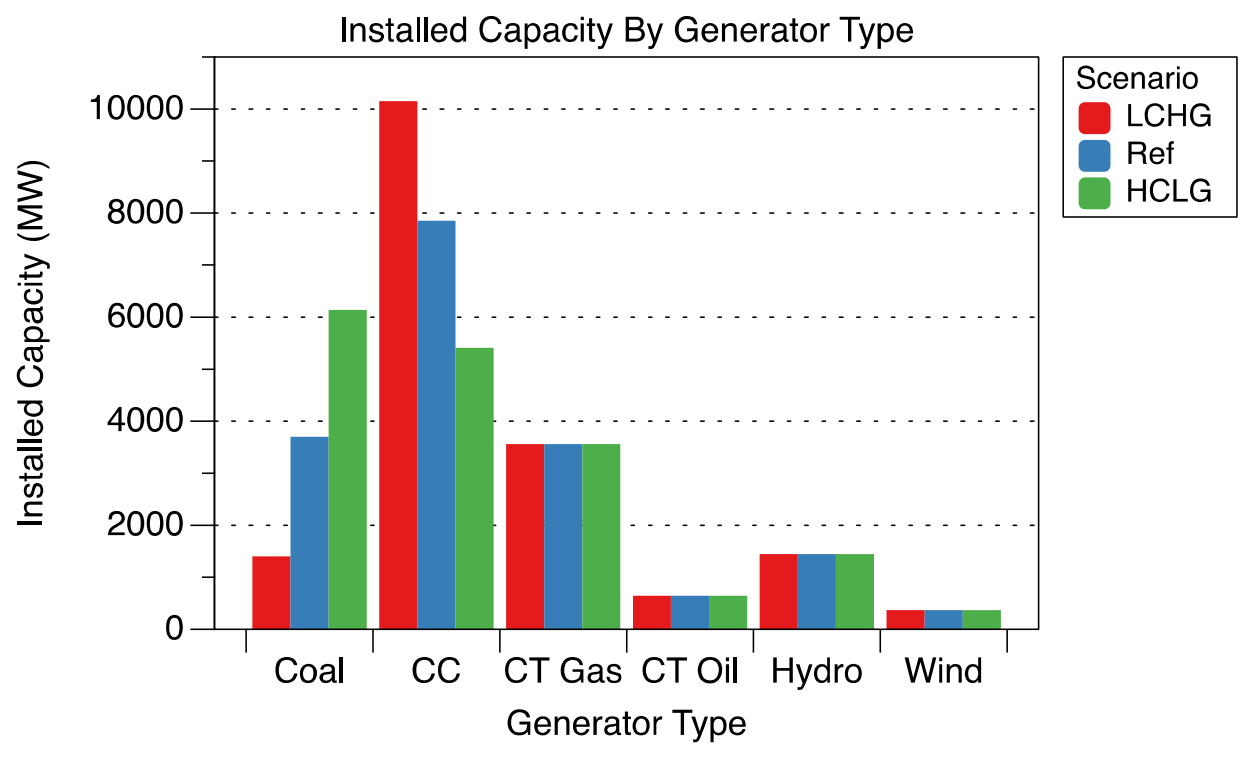

Figure 29. Generation mix simulations: installed capacity by generator type

\subsection{Overall System Impacts}

The overall generation costs are shown in Figure 30. As expected, the system costs dropped with increasing coal penetration. The costs decreased $16 \%$ as the coal increased from $15 \%$ penetration to $65 \%$ penetration. 


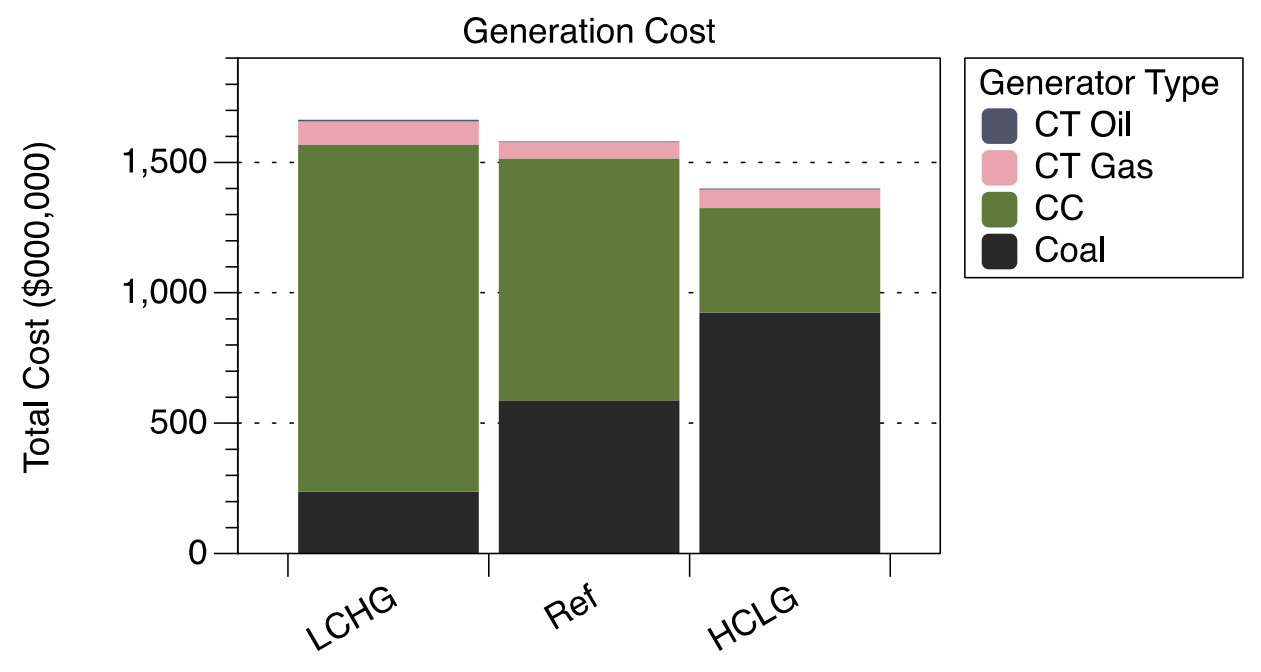

Scenario

Figure 30. Generation mix simulations: total cost of generation

Figure 31 shows the generation mix as a percentage of energy delivered. Interestingly, the amount of energy delivered by the combustion turbines decreased as the coal penetration increased. This is because the coal units had a slightly more favorable ramp rate $(1.1 \%$ of the rated capacity per minute compared to $0.9 \%$ for the combined-cycle fleet).

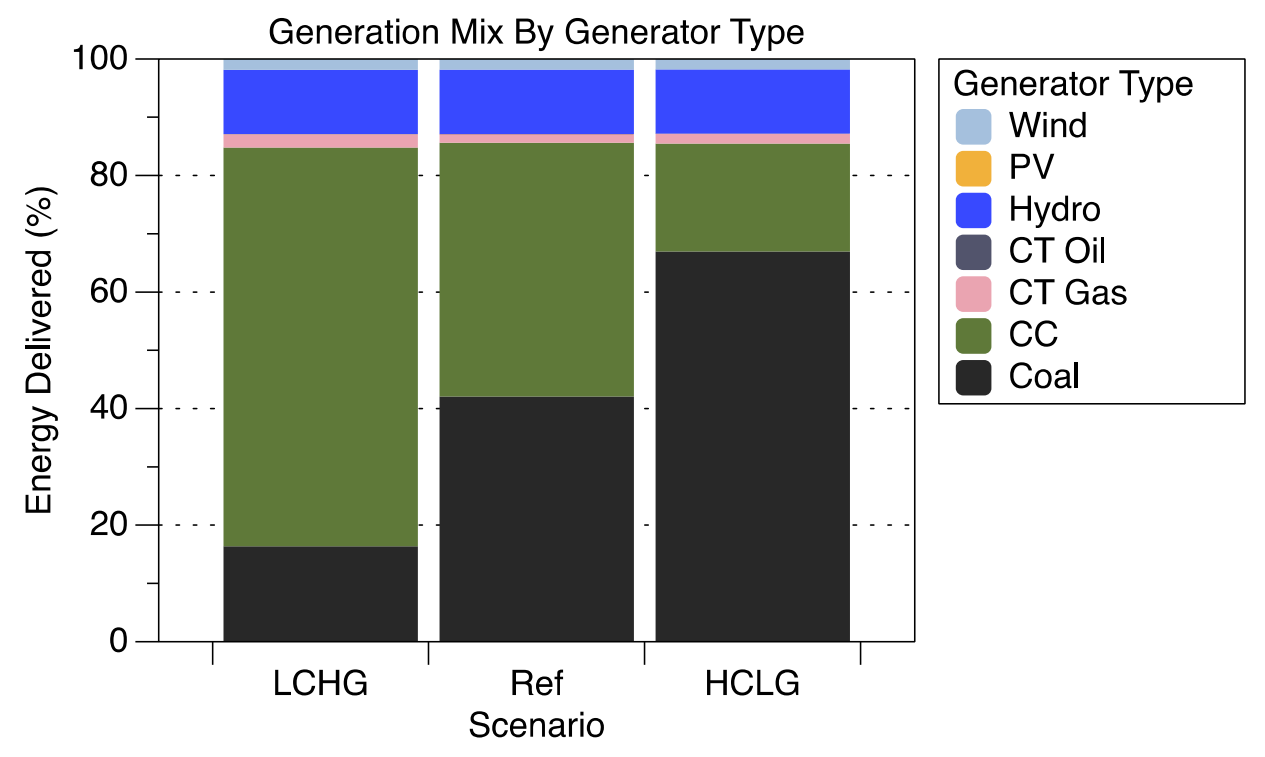

Figure 31. Generation mix simulations: energy delivered by generator type

A detailed breakout of the generation mix based on energy delivered is shown in Table 38 . 
Table 38. Generation Mix Simulations: Energy Delivered by Generator Type (GWh)

\begin{tabular}{lrrr} 
Generator Type & LCHG & Ref & HCLG \\
\hline Coal & 10,484 & 26,982 & 42,955 \\
CC & 43,934 & 27,946 & 11,875 \\
CT Gas & 1,459 & 979 & 1,097 \\
CT Oil & 19 & 8 & 9 \\
Hydro & 7,066 & 7,065 & 7,063 \\
PV & - & - & - \\
Wind & 1,193 & 1,174 & 1,155 \\
\hline Total & 64,154 & 64,154 & 64,154
\end{tabular}

Although the differences in the amount of energy provided by coal are similar in the low-coal and reference simulations and the reference and high-coal simulations, the overall cost differences were not (see Table 39). Adding 16,000 GWh of coal to the low-coal system decreased system costs by $\$ 1.31 / \mathrm{MWh}$, whereas adding $16,000 \mathrm{GWh}$ of coal to the reference system decreased costs by more than twice that much $(\$ 2.81 / \mathrm{MWh})$.

Table 39. Generation Mix Simulations: Average Generation Costs (\$/MWh)

\begin{tabular}{lrrr} 
Type & LCHG & Ref & HCLG \\
\hline Coal & 22.73 & 21.80 & 21.52 \\
CC & 30.29 & 33.19 & 33.75 \\
CT Gas & 61.20 & 62.91 & 64.90 \\
\hline Wt. Avg. & 25.95 & 24.64 & 21.83
\end{tabular}

Not surprisingly, the average fuel cost decreased as the coal penetration increased, with the price dropping by almost $25 \%$ as the coal penetration reached $65 \%$.

Table 40. Generation Mix Simulations: Average Fuel Cost (\$/MWh)

\begin{tabular}{lrrr} 
Type & LCHG & Ref & HCLG \\
\hline Wt. Avg. & 24.40 & 22.60 & 19.24
\end{tabular}

The cycling for each of the three scenarios is shown in Figure 32, in which the cycling costs are the sum of the start costs and ramping costs for each generator type. These cost components are described in detail in sections 9.3 and 9.4 . 


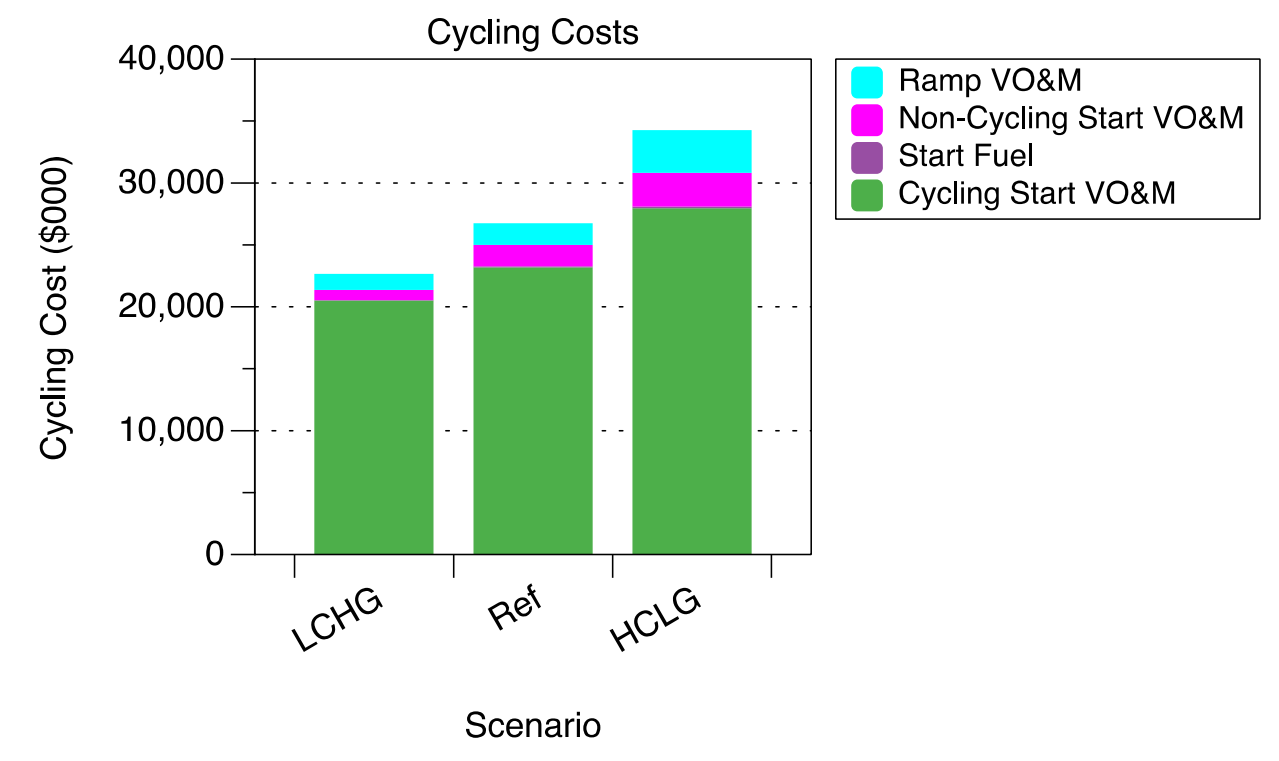

Figure 32. Generation mix simulations: cycling costs by cost component type

Table 41 provides the cycling costs by generator type, with the largest increase for the combinedcycle units. (Cycling-related costs increased by $258 \%$ for the combined-cycle units.) The weighted average costs increased from $\$ 0.37 / \mathrm{MWh}$ to $\$ 0.55 / \mathrm{MWh}$, an increase of $49 \%$.

Table 41. Generation Mix Simulations:

Average Cycling Costs by Generator Type (\$/MWh Delivered)

\begin{tabular}{lrrr} 
Type & LCHG & Ref & HCLG \\
\hline Coal & 0.22 & 0.26 & 0.29 \\
CC & 0.30 & 0.47 & 1.08 \\
CT Gas & 4.51 & 6.34 & 7.67 \\
\hline Wt. Avg. & 0.37 & 0.43 & 0.55
\end{tabular}

The VO\&M costs increased as the coal plants, which are more expensive to maintain, displaced gas-fired generation, with the costs almost doubling as the coal penetration increased from $15 \%$ to $65 \%$ (see Table 7).

Table 42. Generation Mix Simulations: Average VO\&M Costs (\$/MWh)

\begin{tabular}{lrrr} 
Type & LCHG & Ref & HCLG \\
\hline Wt. Avg. & 1.18 & 1.61 & 2.04
\end{tabular}

Table 43 shows the sum of the cycling costs and VO\&M costs and provides a summary of the nonfuel operating costs for the various generator types as well as the overall system. 
Table 43. Generation Mix Simulations:

Average Non-Fuel Operating Costs by Generator Type (\$/MWh)

\begin{tabular}{lrrr} 
Type & LCHG & Ref & HCLG \\
\hline Coal & 3.04 & 3.00 & 3.03 \\
CC & 1.33 & 1.50 & 2.11 \\
CT Gas & 5.08 & 6.90 & 8.23 \\
\hline Wt. Avg. & 1.54 & 2.04 & 2.59
\end{tabular}

The table shows that the non-fuel operating costs increased by almost $70 \%$ as the coal penetration increased from $15 \%$ to $65 \%$.

\subsection{System Impacts per Unit of New Generation Added}

The generation mix experiments did not include additional generation, so results are reported only from an overall system perspective.

The following sections show how changing the generation mix in the test system affects the number and type of generator starts as well as generator ramping and capacity factors.

\subsection{Start Effects}

The trend in the percentage of coal in the generation mix was that as the percentage of coal increased, so did the number of starts that occurred each year (see Figure 33).

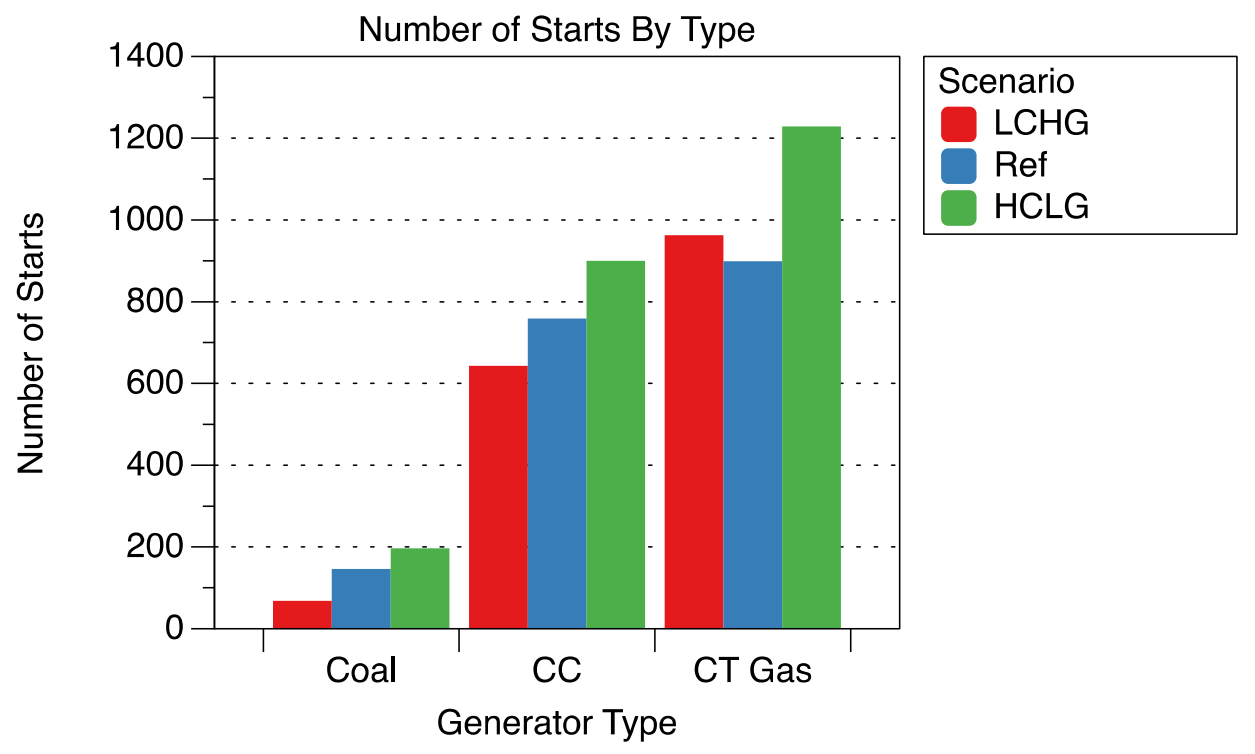

Figure 33. Generation mix simulations: numbers of generator starts

Given that coal supplied a larger part of the load as the amount of coal increased, it was expected that coal plants would have to start and stop more often to meet the load. However, the increase in coal also affected the starts of the other types of generators as well. At the highest coal penetration, the combined-cycle units started $40 \%$ more often, and the number of gas combustion turbine starts increased $28 \%$. Although combined-cycle starts increased with coal penetration, there was no clear 
trend in the combustion turbine operations. The average number of starts actually decreased slightly as the percentage of coal rose from $15 \%$ to $40 \%$ (from 963 to 899) but then increased from 899 to 1,229 as the percentage of coal reached $65 \%$.

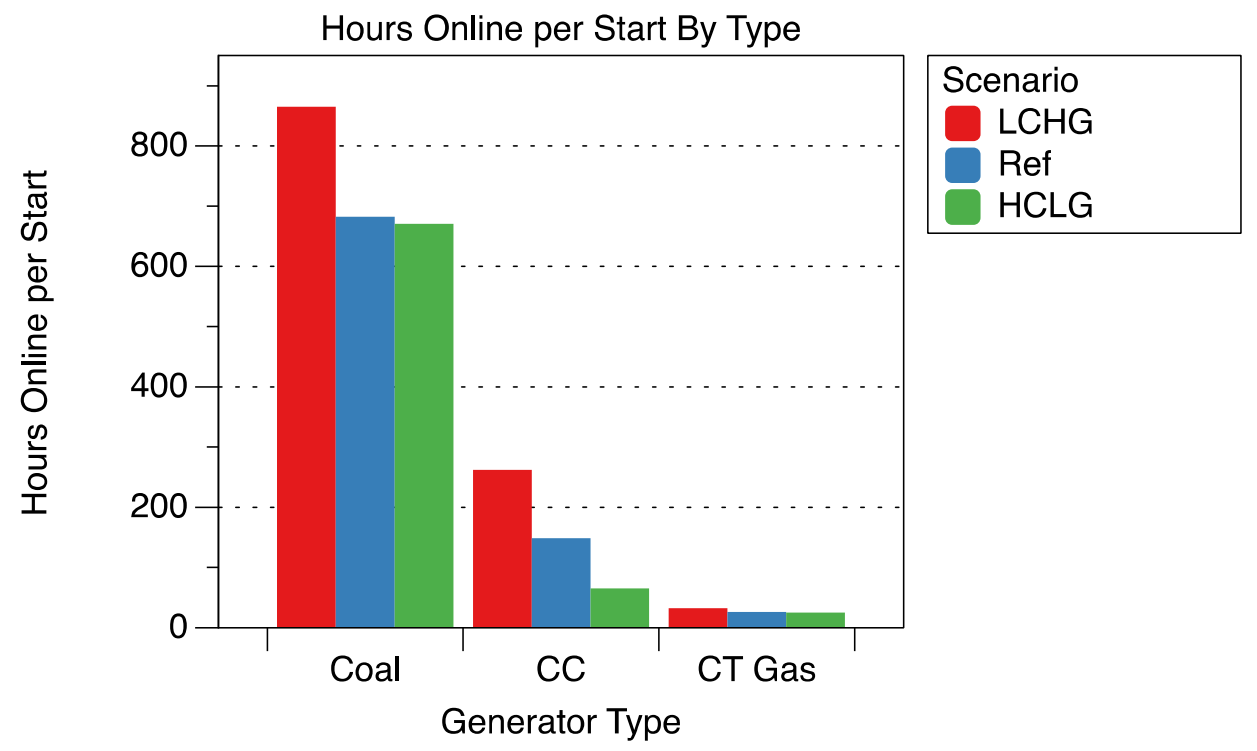

Figure 34. Generation mix simulations: average hours online per generator start

As the amount of coal increased, the average number of hours that generators stayed online decreased. This trend held true for all generator types, with the largest percentage change shown in the operation of the combined-cycle plants in which the average time online decreased from 262 hours to fewer than 66 hours per start as the coal penetration hit $65 \%$, a decrease of $75 \%$.

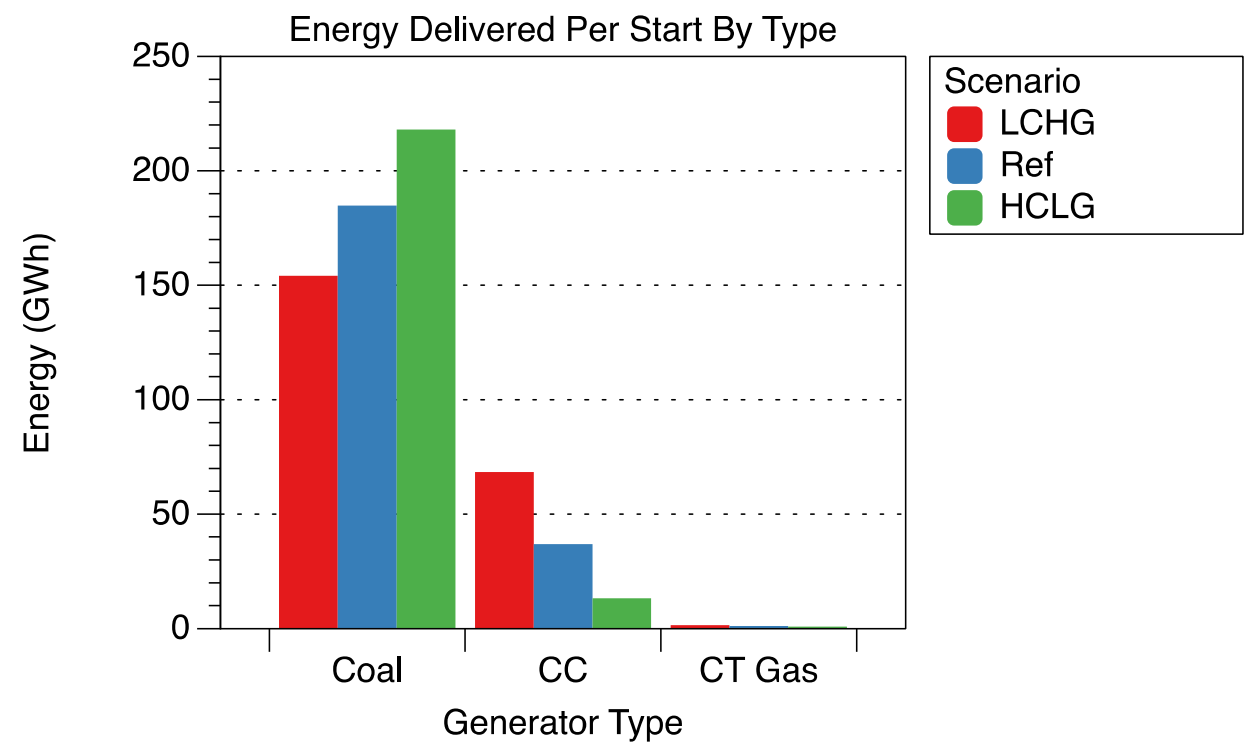

Figure 35. Generation mix simulations: average energy delivered per generator start 
For the coal-fired steam plants, the average energy delivered per start increased as the amount of coal increased, rising from $154 \mathrm{GWh} /$ start to $218 \mathrm{GWh} /$ start, a gain of $41 \%$. The trend for the other types of generators was downward, with the combined-cycle plants most affected by the increase in coal. The average energy delivered per combined-cycle start dropped from $68 \mathrm{GWh}$ to $13 \mathrm{GWh}$ at the highest coal penetrations, a decrease of more than $80 \%$. The trend for the gas combustion turbine units was also downward, with the average energy per start decreasing from $1.5 \mathrm{GWh}$ to slightly less than $0.9 \mathrm{GWh}$, a decrease of $41 \%$.

The largest changes in start-related operating costs when considered from the perspective of energy delivered were the start-up costs related to combined-cycle operation (see Table 44). (Combinedcycle units delivered a majority of the energy in the LCHG and Ref scenarios, and they were second only to coal in the HCLG scenario.) As the amount of coal in the system increased, the average start-up costs for the combined-cycle plants increased by $282 \%$. Most of this increase is because as the amount of coal in the system increased, the combined-cycle units switched from baseload to load following.

Table 44. Generation Mix Simulations: Average Combined Start Costs by Generator Type (\$/MWh Delivered)

\begin{tabular}{lrrr} 
Type & LCHG & Ref & HCLG \\
\hline Coal & 0.20 & 0.22 & 0.22 \\
CC & 0.26 & 0.42 & 1.00 \\
CT Gas & 4.43 & 6.21 & 7.50 \\
\hline Wt. Avg. & 0.33 & 0.39 & 0.48
\end{tabular}

\subsection{Ramp Effects}

The average number of ramps of the coal units increased as the amount of energy supplied by coal increased, and the average number of ramps for the combined-cycle units decreased as the energy provided by these plants decreased (see Figure 36). The number of gas combustion turbine ramps in the three scenarios is so small $(10,6$, and 18$)$ that it was difficult to draw meaningful conclusions.

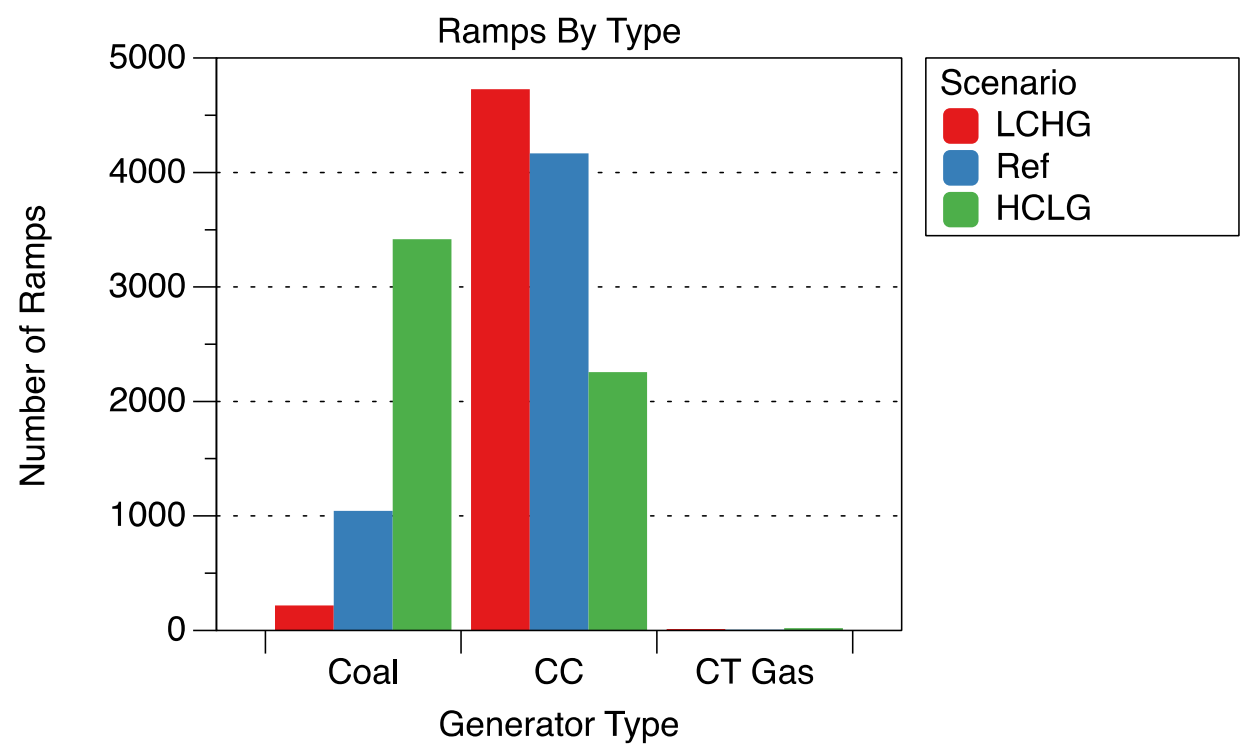


Figure 36. Generation mix simulations: number of ramps by generator type

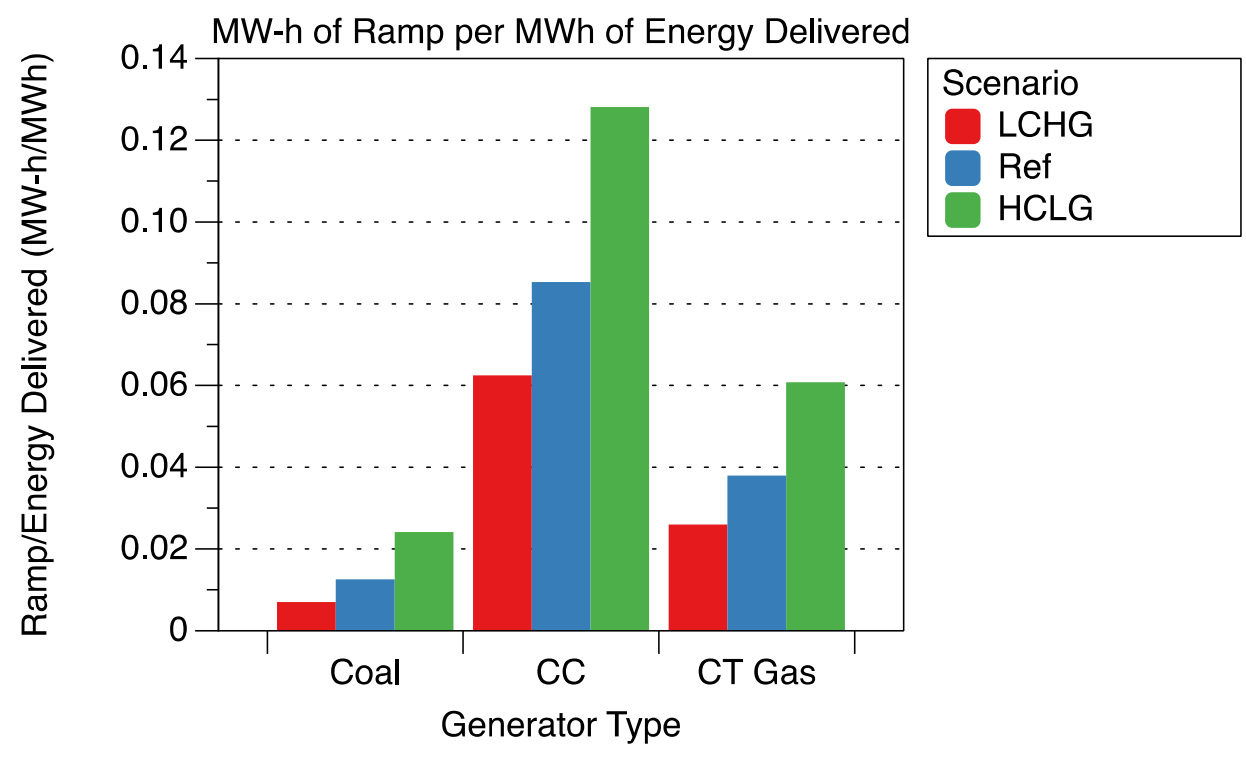

Figure 37. Generation mix simulations: average amount of ramp per unit of energy delivered

The results for the ramps per unit of energy delivered provide insight into how much generator movement, in terms of power output, is necessary to meet customer load (Figure 37). For the coal, combined-cycle, and gas combustion turbine generators, the amount of ramp per unit of energy delivered increased as the amount of energy delivered by coal increased, with the largest impact on a percentage increase to the coal plants. (The amount of generator movement per unit of energy delivered increased by $245 \%$ as the coal penetration increased from $15 \%$ to $65 \%$.)

Table 45. Generation Mix Simulations:

Average Rampi

\begin{tabular}{lccc} 
Type & LCHG & Ref & HCLG \\
\hline \multicolumn{2}{c}{ ng Costs by } & Generator Type & \multicolumn{2}{c}{ \$MWh Delivered) } \\
\hline Coal & 0.03 & 0.04 & 0.07 \\
CC & 0.04 & 0.06 & 0.09 \\
CT Gas & 0.09 & 0.12 & 0.17 \\
\hline Wt. Avg. & 0.04 & 0.04 & 0.07
\end{tabular}

Table 45 shows that the ramping-related costs approximately doubled for all generator types when considered by percentage change. The weighted average costs followed a similar trend, with the per-unit charges almost doubling as the coal penetration increased.

\subsection{Reserves Effects}

This section investigates how changes in the generation mix affect the cost of provisioning reserves. 
Table 46. Generation Mix Simulations: Reserves Provisioning Costs

\begin{tabular}{lrrrr} 
Scenario & $\begin{array}{r}\text { Reserves } \\
\text { Provisioning Costs }\end{array}$ & $\Delta$ Cost & \$/MWh Energy & $\Delta$ \$/MWh Energy \\
\hline LCHG & 2 & - & 0.02 & 0.00 \\
Ref & 2 & - & 0.02 & - \\
HCLG & 1 & $(1)$ & 0.01 & $(0.01)$
\end{tabular}

Table 46 shows that the reserves cost differences were near the limits of precision for the three simulations, with the high-coal simulation having lower costs. ${ }^{18}$

\subsection{Capacity Factors and Curtailment Effects}

This section reports how configuration changes affect the system's capacity factors and curtailment values.

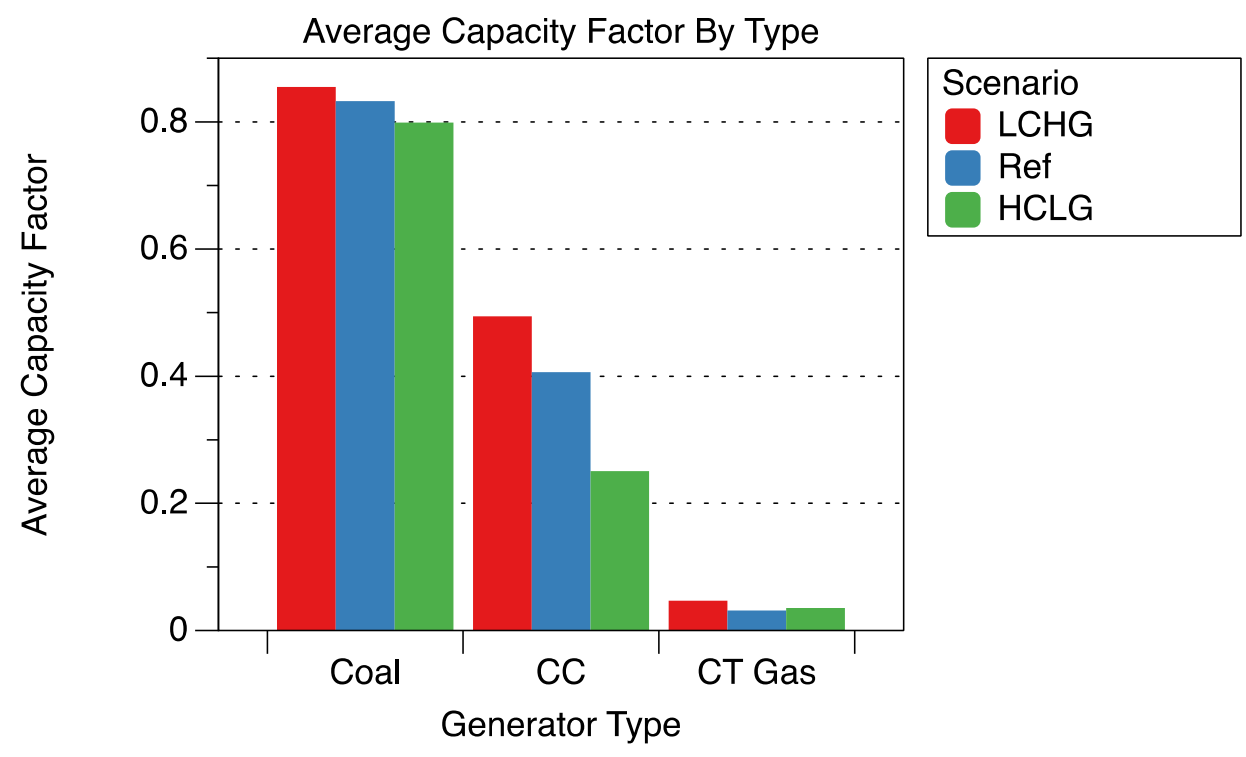

Figure 38. Generation mix simulations: average capacity factors by generator type

The capacity factors for both the coal and combined-cycle plants decreased as the amount of coal increased. The decrease in the coal capacity factors was modest, dropping from 0.85 at $15 \%$ coal to 0.80 at $65 \%$ coal; however, the capacity factor changes in the combined-cycle units were more significant: 0.49 at $15 \%$ coal and down to 0.25 at the $65 \%$ coal penetration level.

\footnotetext{
${ }^{18}$ In the high-coal simulation, there was significant coal capacity that was running at less than maximum generation.
} 


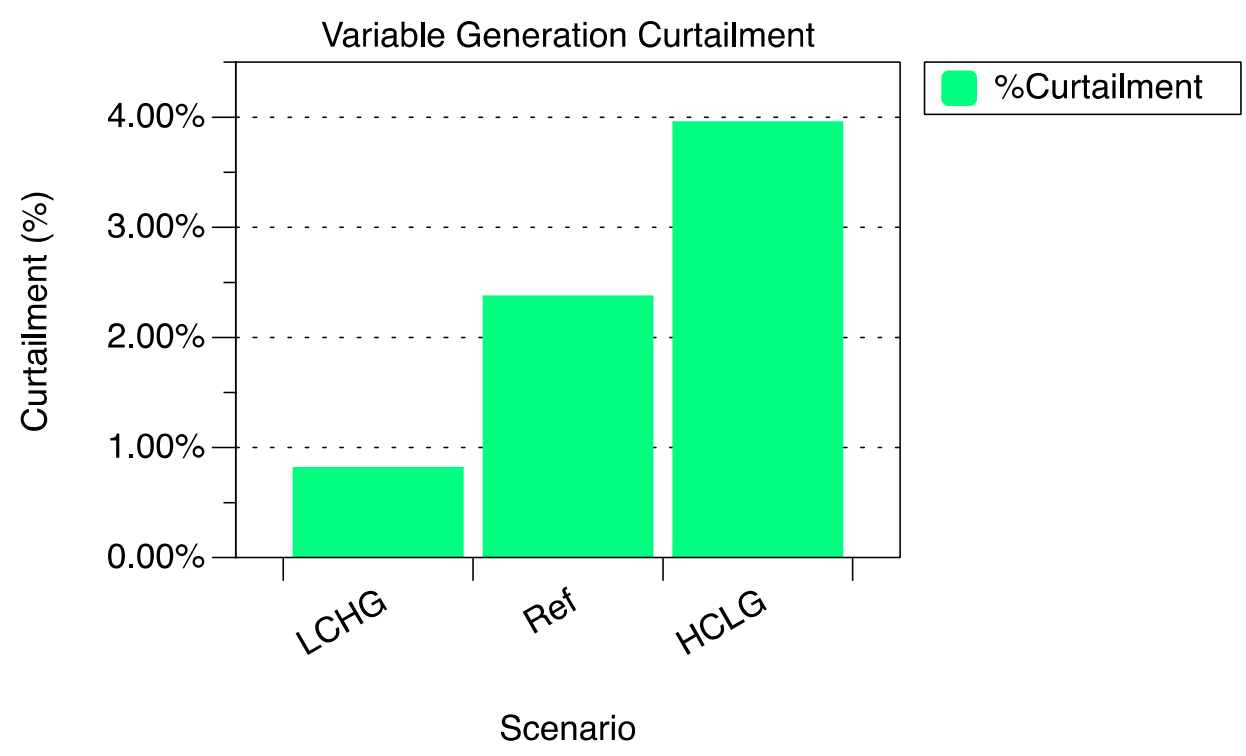

Figure 39. Generation mix simulations: amount of variable generation curtailed

Although the curtailment for the high-coal system was more than four times as high as it was in the low-coal system, the cost increase from curtailment is small compared to the fuel cost savings from burning coal (Figure 15). 


\subsection{Generation Mix Study Summary}

This section summarizes the overall cost-related findings of the generation mix experiments. The cost impacts at the system level are summarized in Table 47. Note that only overall cost impacts are shown because no new generation was added to the system.

Table 47. Generation Mix Simulations:

Cost Summaries per Unit of Overall System Generation

\begin{tabular}{ll} 
Topic & Subtopic \\
\hline Overall System Impacts & $\bullet$ Total Generation Costs \\
$\bullet$ Fuel Costs \\
\\
$\qquad$ Cycling Costs (Combined Start \\
+ Ramp Costs)
\end{tabular}

Results Summary

Total generation costs decreased as the penetration of coal increased, and at the $65 \%$ coal level, costs decreased by $11 \%$ (\$2.81/MWh) compared to the reference scenario and by $19 \%(\$ 4.12 / \mathrm{MWh})$ compared to the low-coal scenario.

Fuel costs decreased with increasing coal penetration, with the average fuel cost decreasing by $15 \%$ ( $\$ 3.36 / \mathrm{MWh}$ ) compared to the reference scenario fuel cost and by $21 \%(\$ 5.16 / \mathrm{MWh}$ ) compared to the low-coal scenario.

Average cycling costs increased with increasing coal penetration. The cycling costs in the high-coal scenario were $28 \%$ higher $(\$ 0.12 / \mathrm{MWh})$ than the reference scenario and $49 \%$ higher $(\$ 0.18 / \mathrm{MWh})$ than the lowcoal scenario.

- VO\&M Costs

VO\&M costs increased with increasing coal penetration. The costs in the high-coal scenario were $28 \%$ higher $(\$ 0.43 / \mathrm{MWh})$ than the reference scenario and $73 \%$ higher (\$0.86/MWh) than the low-coal scenario.

- Non-Fuel Operating Costs

Start Effects

- Start Costs

Non-fuel operating costs increased with increasing coal penetration. The costs in the in high-coal scenario were $27 \%$ higher (\$0.55/MWh) than the reference scenario and $68 \%$ higher $(\$ 1.05 / \mathrm{MWh})$ than the lowcoal scenario.

Start costs increased with increasing coal penetration. The average start costs in the high-coal scenario were 23\% (\$0.09/MWh) higher than the reference scenario and $45 \%$ higher (\$0.15/MWh) than the low-coal scenario. 


\begin{tabular}{|c|c|c|}
\hline Topic & Subtopic & Results Summary \\
\hline Ramp Effects & - Ramp Costs & $\begin{array}{l}\text { Ramp costs increased with increasing coal } \\
\text { penetration. Average ramping costs in the } \\
\text { high-coal scenario were } 52 \% \text { higher } \\
\text { (\$0.02/MWh) than the reference scenario } \\
\text { and } 92 \% \text { higher }(\$ 0.03 / \mathrm{MWh} \text { ) than the low- } \\
\text { coal scenario. }\end{array}$ \\
\hline Reserves Effects & - Reserves Costs & $\begin{array}{l}\text { Reserves costs decreased in the high-coal } \\
\text { scenario compared to both the low-coal and } \\
\text { reference scenarios. }\end{array}$ \\
\hline
\end{tabular}

The key finding in the generation mix experiments was that as coal penetration increased the total generation costs decreased, but the system-wide cycling and VO\&M costs increased. In terms of the magnitude of the changes, total generation costs decreased by $15 \%(\$ 3.36 / \mathrm{MWh})$, and the cycling costs and VO\&M costs increased by $28 \%(\$ 0.12 / \mathrm{MWh})$ and $28 \%(\$ 0.86 / \mathrm{MWh})$ in the reference ( $40 \%$ coal) and high-coal ( $65 \%$ coal) scenarios. When the high-coal scenario was compared to the low-coal scenario, the magnitude of the differences increased, with generation cost savings of $19 \%$ $(\$ 4.12 / \mathrm{MWh})$ and cycling cost and VO\&M cost increases of $49 \%(\$ 0.18 / \mathrm{MWh})$ and $73 \%$ (\$0.86/MWh).

\subsubsection{Future Work}

The current generation mix studies were done with modest penetration levels of variable generation (2\%). With many balancing authorities quickly approaching $20 \%$ penetration levels, investigations into cost impacts for systems with various mixes of high-penetration variable generation would be helpful. 


\section{Results of the Gas Price Experiments}

The fourth set of simulations examined the impact of gas prices on system operations. All three scenarios were based on the reference scenario and differed only in gas price. The three gas prices examined were \$2.50/MMBtu, \$4.50/MMBtu, and \$6.50/MMBtu. The scenario names and their run designations are:

- Reference with low-priced gas (Ref:LGP)— \$2.50/MMBtu gas

- Reference (Ref)— \$4.50/MMBtu gas

- Reference with high-priced gas (Ref:HGP) — \$6.50/MMBtu gas.

\subsection{Overall System Impacts}

The generation costs for the three runs are shown in Figure 40, and the overall trend was as expected: as the gas price increased, overall cost increased. At low gas prices, the combined-cycle plants served the base load; however, the role quickly shifted, and coal plants served the baseload by the time gas prices hit $\$ 4.50 / \mathrm{MMBtu}$. Increasing the gas price further had little effect on the coal generation (i.e., the cost attributable to coal stayed flat), and most coal was generating near capacity at the $\$ 4.50 / \mathrm{MMBtu}$ price.

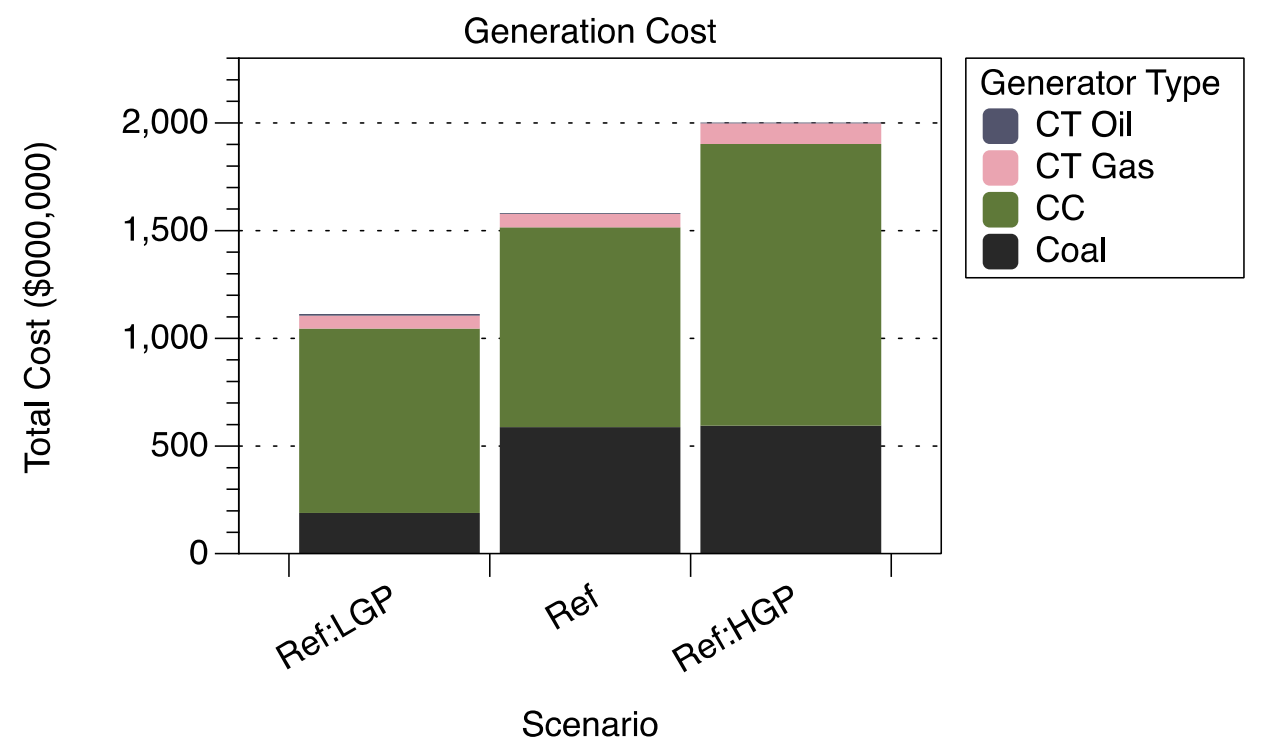

Figure 40. Gas price simulations: total cost of generation

Also of note is that at the $\$ 4.50$ and $\$ 6.50$ gas prices, some of the flexibility that had been previously provided by the gas turbines was provided by coal (see Figure 41). 


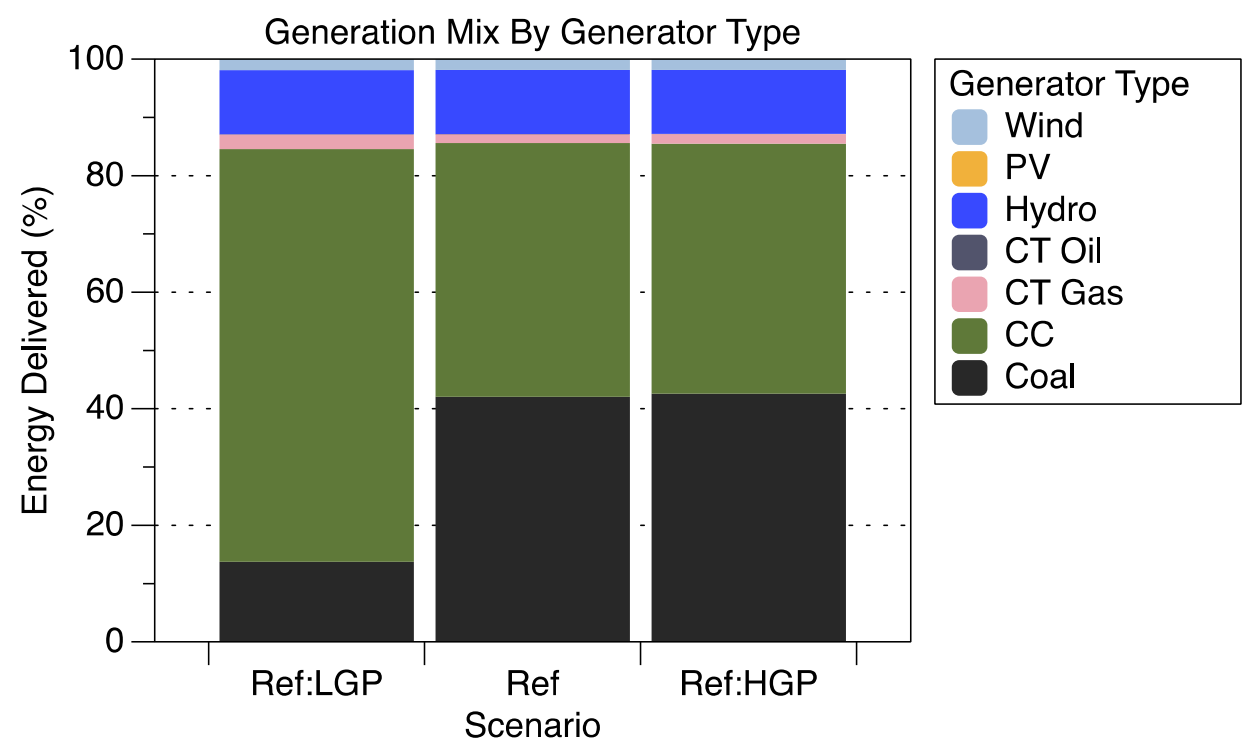

Figure 41. Gas price simulations: generation mix by generator type

Per-unit generation costs are shown in Table 48. Note how the coal costs rose with gas price. Although initially counterintuitive, the cost rise is because only the larger coal plants that are less expensive to operate were online at the low gas price. However, as the gas prices increased, baseload was shifted from the combined-cycle machines to the coal plants, and both the large and small coal units were necessary to meet the load requirement.

Table 48. Gas Price Simulations: Average Generation Costs (\$/MWh)

\begin{tabular}{lrrr} 
Type & Ref:LGP & Ref & Ref:HGP \\
\hline Coal & 21.53 & 21.80 & 21.79 \\
CC & 18.84 & 33.19 & 47.50 \\
CT Gas & 37.07 & 62.91 & 88.79 \\
\hline Wt. Avg. & 17.36 & 24.64 & 31.20
\end{tabular}

The per-unit costs for the combined-cycle units increased as the gas prices increased. Most of the increase was because of the increase in gas price; however, a portion of the increase was because of the increased cycling costs. These increases are discussed below and in more detail in the sections on start effects and ramping effects (10.3 and 10.4).

Table 49 summarizes how the average fuel costs changed as the gas prices increased. As expected, as natural gas prices rose, the average fuel costs increased accordingly, with the average cost almost doubling as the natural gas prices increased from $\$ 2.50 / \mathrm{MMBtu}$ to $\$ 6.50 / \mathrm{MMBtu}$.

Table 49. Gas Price Simulations: Average Fuel Costs (\$/MWh)

\begin{tabular}{lrrr} 
Type & Ref:LGP & Ref & Ref:HGP \\
\hline Wt. Avg. & 15.78 & 22.60 & 29.04
\end{tabular}


The overall cycling costs (Figure 42) had a minimum near the $\$ 4.50 / \mathrm{MMBtu}$ gas price. Further discussion about this phenomenon is provided in the section on start effects (10.3).

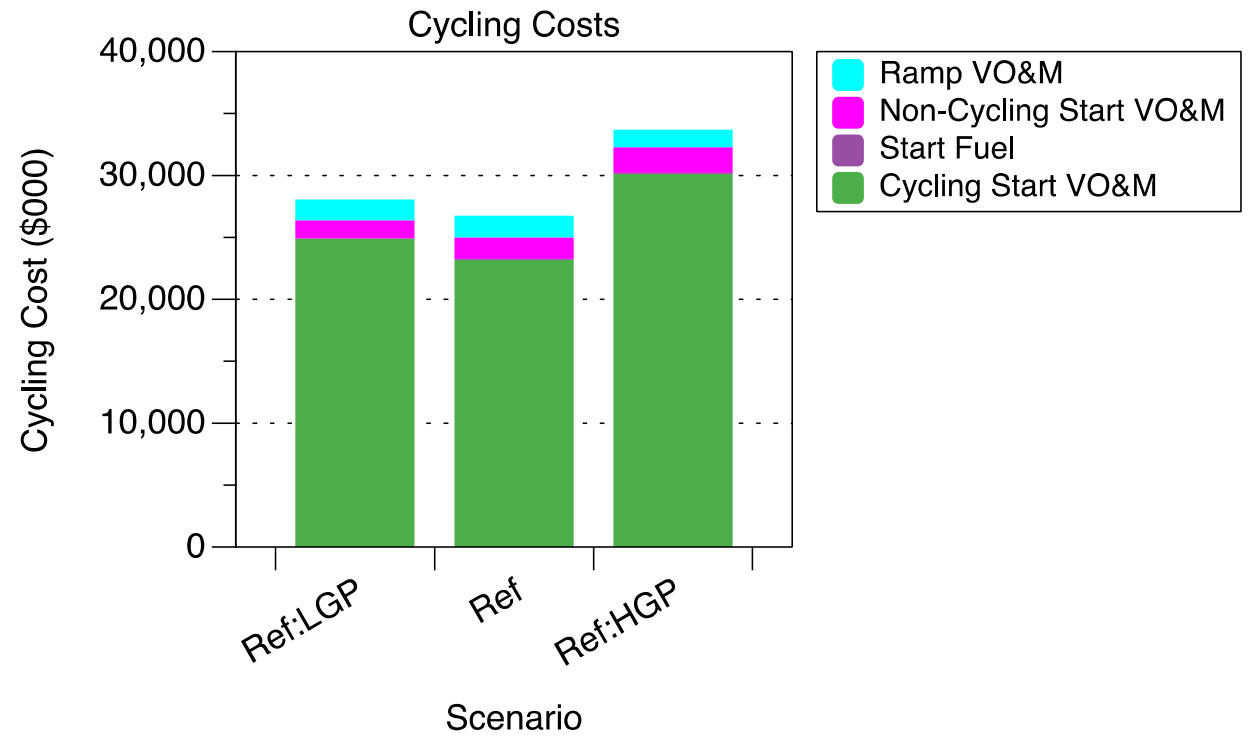

Figure 42. Cycling costs by cost component type

The per-unit costs highly correlated to generation function (baseload or load following) for the coal and combined-cycle plants (Table 50).

Table 50. Gas Price Simulations: Average Cycling Costs by Generator Type

\begin{tabular}{lrrr} 
Type & Ref:LGP & Ref & Ref:HGP \\
\hline Coal & 0.56 & 0.26 & 0.25 \\
CC & 0.28 & 0.47 & 0.69 \\
CT Gas & 5.68 & 6.34 & 7.60 \\
\hline Wt. Avg. & 0.46 & 0.43 & 0.55
\end{tabular}

The cycling costs of the combustion turbines, which served as peakers in all three simulations, were less strongly affected by gas price increases.

Table 51. Gas Price Simulations: Average VO\&M Costs by Generator Type (\$/MWh)

\begin{tabular}{lrrr} 
Type & Ref:LGP & Ref & Ref:HGP \\
\hline Wt. Avg. & 1.12 & 1.61 & 1.62
\end{tabular}

Table 52 shows how the non-fuel operating costs (the sum of the cycling costs and VO\&M costs) increased as the coal penetration increased. The increase was expected because the non-fuel operating costs of the coal fleet were higher than those of the combined-cycle units that they displaced (see Table 7). 
Table 52. Gas Price Simulations: Average Non-Fuel Operating Costs by Generator Type (\$/MWh)

\begin{tabular}{lrrr} 
Type & Ref:LGP & Ref & Ref:HGP \\
\hline Coal & 3.25 & 3.00 & 2.98 \\
CC & 1.32 & 1.50 & 1.71 \\
CT Gas & 6.24 & 6.90 & 8.16 \\
\hline Wt. Avg. & 1.58 & 2.04 & 2.16
\end{tabular}

\subsection{System Impacts per Unit of New Generation Added}

This gas price experiments did not include additional generation, so results are reported only from an overall system perspective.

\subsection{Start Effects}

As gas prices rose, the coal plants provided more of the baseload. When the gas price hit $\$ 4.50 / \mathrm{MMBtu}$, the coal plants reached a plateau in energy production, as shown in the results for energy delivered per start (see Figure 43).

The energy per start for the combined-cycle plants decreased with increasing gas price, leading to higher average combined start costs, which is discussed below.

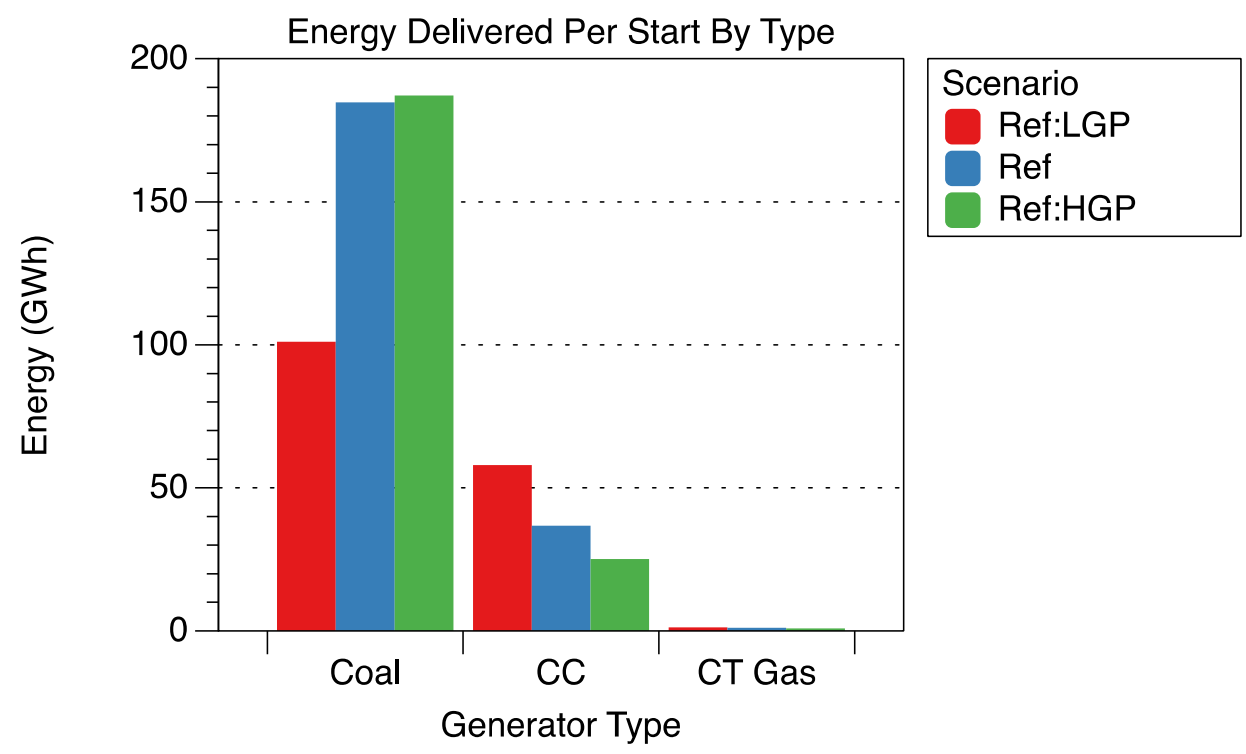

Figure 43. Gas price simulations: average energy delivered per generator start

Combined-cycle start-up costs increased with gas price (Table 53), partially because of the gas price increase (start fuel contributes to start costs). However, the primary reason for the increase is that the gas plants were used less per start as the gas prices increased. A similar pattern held for the combustion turbine units. 
Table 53. Gas Price Simulations:

Average Combined Start Costs by Generator Type (\$/MW Delivered)

\begin{tabular}{lrrr} 
Type & Ref:LGP & Ref & Ref:HGP \\
\hline Coal & 0.44 & 0.22 & 0.22 \\
CC & 0.25 & 0.42 & 0.62 \\
CT Gas & 5.52 & 6.21 & 7.45 \\
\hline Wt. Avg. & 0.41 & 0.39 & 0.50
\end{tabular}

One item of note is that the overall average weighted start costs were less at the reference gas price. At low gas prices, coal was not baseloaded, and coal cycling increased total start costs. At high gas prices, the higher fuel costs contributed to increased combined-cycle cycling as machines ran for shorter periods of time per start to minimize fuel use. (With high fuel prices, the importance of start costs became less relative to fuel-use costs.)

\subsection{Ramp Effects}

Figure 44 shows a pattern indicative of a shift in the coal plants from load following to baseload. The amount of ramp/energy delivered decreased markedly as the gas price increased from $\$ 2.50 / \mathrm{MMBtu}$ to $\$ 4.50 / \mathrm{MMBtu}$ and then leveled as the gas price increased to $\$ 6.50 / \mathrm{MMBtu}$.

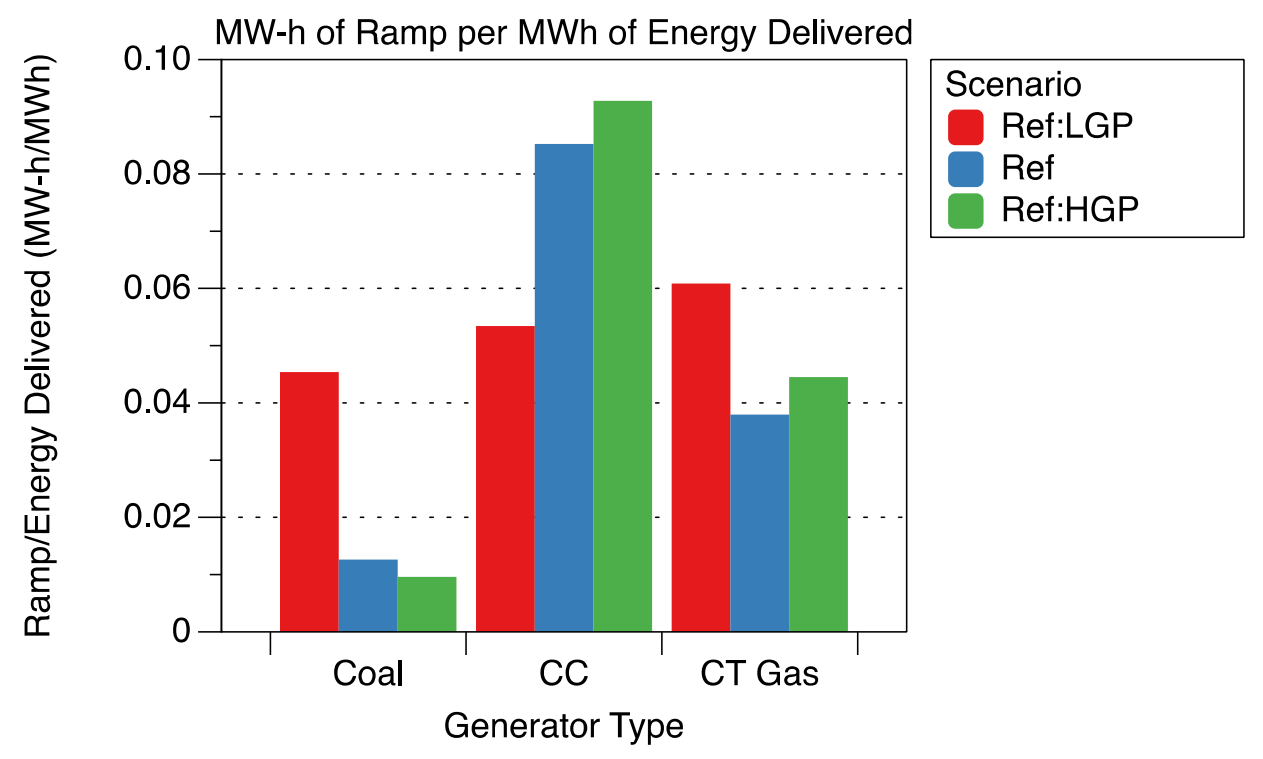

Figure 44. Gas price simulations: average amount of ramp per unit of energy delivered

Ramp-related costs for coal and combined-cycle plants (Table 54) followed a pattern similar to that of the start costs, with the per-unit costs highly dependent on whether the generator class served baseload or acted as a load follower. The weighted average ramping costs decreased slightly as the gas prices increased. 
Table 54. Gas Price Simulations: Average Ramping Costs by Generator Type

\begin{tabular}{lrrr} 
Type & Ref:LGP & Ref & Ref:HGP \\
\hline Coal & 0.12 & 0.04 & 0.03 \\
CC & 0.04 & 0.06 & 0.06 \\
CT Gas & 0.15 & 0.12 & 0.15 \\
\hline Wt. Avg. & 0.05 & 0.04 & 0.04
\end{tabular}

\subsection{Reserves Effects}

This section investigates how changes in gas prices affect the cost of provisioning reserves.

Table 55. Gas Price Simulations: Reserves Provisioning Costs

\begin{tabular}{lrrrr} 
Scenario & $\begin{array}{r}\text { Reserves Provisioning } \\
\text { Cost }(\mathbf{\$ 0 0 0 , 0 0 0 )}\end{array}$ & $\begin{array}{r}\boldsymbol{\Delta} \mathbf{0} \text { Cost } \\
\mathbf{( \$ 0 0 0 , 0 0 0 )}\end{array}$ & $\mathbf{\$} /$ MWh Energy & $\Delta \mathbf{\Delta} / \mathbf{M W h}$ Energy \\
\hline Ref:LGP & 2 & - & 0.03 & 0.01 \\
Ref & 2 & - & 0.02 & - \\
Ref:HGP & 2 & - & 0.03 & 0.01
\end{tabular}

For the test cases, the impact on reserves provisioning cost was not significant (see Table 55).

\subsection{Capacity Factor and Curtailment Effects}

The average capacity factors for the various generation types are shown in Figure 45. Note that the capacity factors for all three generator classes tended to flatten when gas prices hit $\$ 4.50 / \mathrm{MMBtu}$ because the dispatch did not change much among these cases.

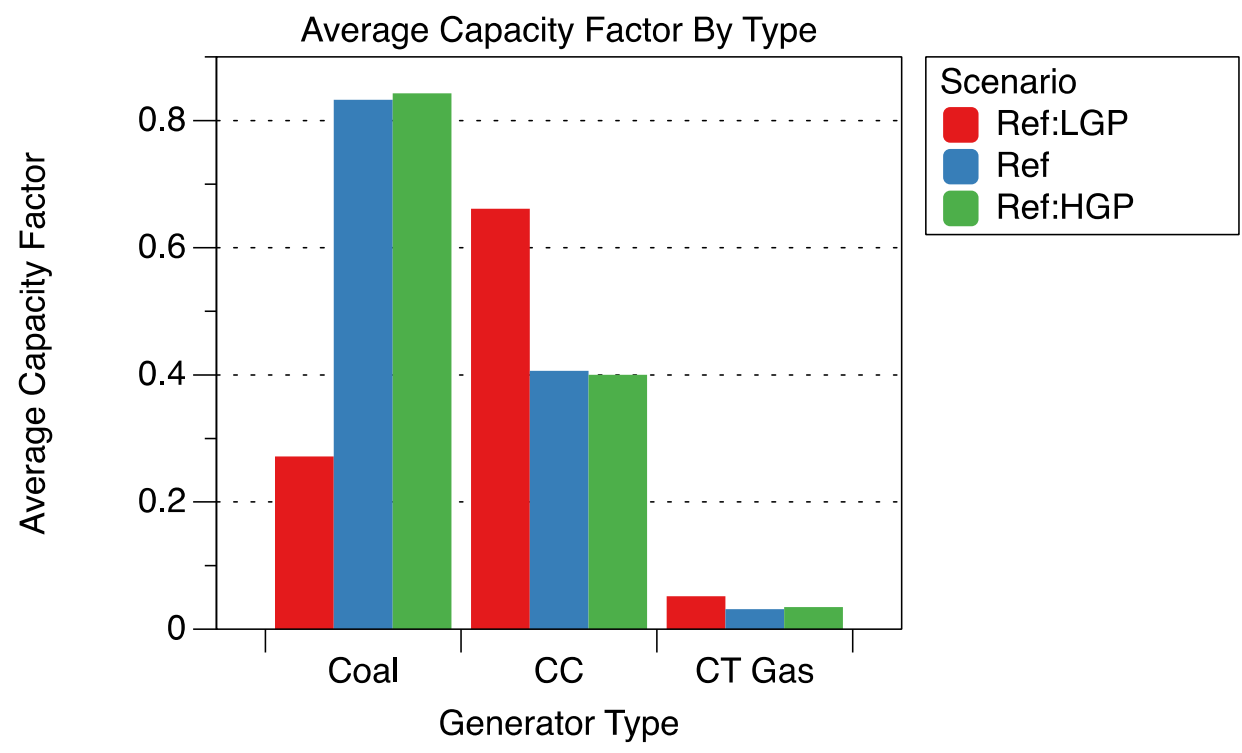

Figure 45. Gas price simulations: average capacity factor by generator type 
At the low gas price, there was so much low-cost flexibility in the system that the curtailment fell to near zero (see Figure 46).

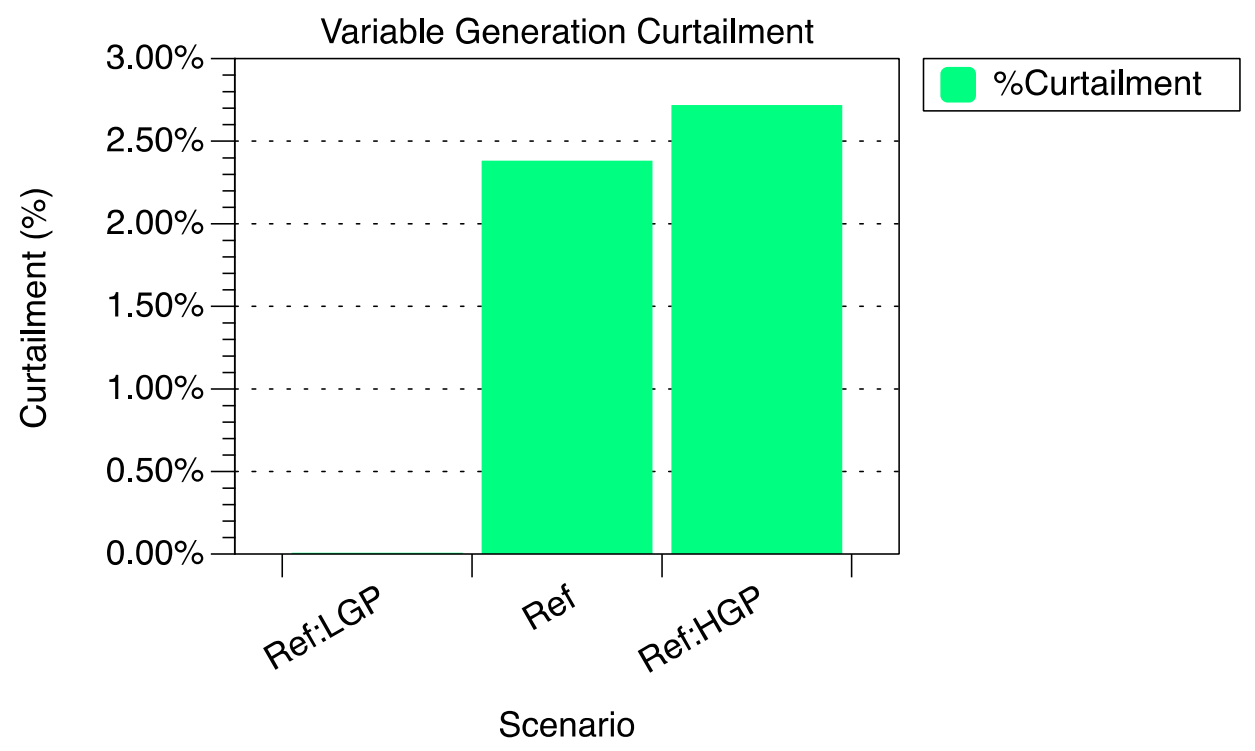

Figure 46. Gas price simulations: amount of variable generation curtailed

\subsection{Gas Price Study Summary}

This section summarizes the overall cost-related findings of the gas price experiments (see Table 56). Note that only overall cost impacts are shown because no new generation was added to the system.

Table 56. Gas Price Simulations: Cost Summaries per Unit of Overall System Generation

\begin{tabular}{|c|c|c|}
\hline Topic & Subtopic & Results Summary \\
\hline \multirow[t]{3}{*}{ Overall System Impacts } & - Total Generation Costs & $\begin{array}{l}\text { Total generation costs increased with } \\
\text { increasing gas prices. At the highest price, } \\
\text { costs increased by } 25 \% \text { ( } \$ 6.56 / \mathrm{MWh}) \\
\text { compared the reference scenario and by } \\
80 \% \text { ( } \$ 13.84 / \mathrm{MWh}) \text { when compared to the } \\
\text { low gas price scenario. }\end{array}$ \\
\hline & - Fuel Costs & $\begin{array}{l}\text { Average fuel costs increased with increasing } \\
\text { gas prices. At the highest gas price, system- } \\
\text { wide fuel costs were } 29 \% \text { higher } \\
(\$ 6.44 / \mathrm{MWh} \text { ) than the reference scenario } \\
\text { and } 84 \%(\$ 13.26 / \mathrm{MWh}) \text { higher than in the } \\
\text { low gas price scenario. }\end{array}$ \\
\hline & $\begin{array}{l}\text { - Cycling Costs (Combined Start } \\
\text { + Ramp Costs) }\end{array}$ & $\begin{array}{l}\text { Cycling costs were mixed with respect to gas } \\
\text { prices. At the highest gas price, cycling costs } \\
\text { were } 43 \% \text { higher (\$0.12/MWh) than in the } \\
\text { reference scenario; however, the cycling } \\
\text { costs at the low gas price were also higher } \\
(7 \%, \$ 0.03 / \mathrm{MWh}) \text { than the reference } \\
\text { scenario. }\end{array}$ \\
\hline
\end{tabular}




\begin{tabular}{|c|c|c|}
\hline Topic & Subtopic & Results Summary \\
\hline & - VO\&M Costs & $\begin{array}{l}\text { VO\&M costs increased with increasing gas } \\
\text { price, albeit most of the increase was } \\
\text { between the low and reference gas price } \\
\text { scenarios. The costs in the high gas price } \\
\text { scenario were } 1 \% \text { higher ( } \$ 0.01 / \mathrm{MWh}) \text { than } \\
\text { the reference scenario and } 45 \% \text { higher } \\
(\$ 0.50 / \mathrm{MWh}) \text { than the low gas price } \\
\text { scenario. }\end{array}$ \\
\hline & - Non-Fuel Operating Costs & $\begin{array}{l}\text { Non-fuel operating costs increased with } \\
\text { increasing gas price. The costs in high gas } \\
\text { price scenario were } 6 \% \text { higher }(\$ 0.12 / \mathrm{MWh}) \\
\text { than the reference scenario and } 37 \% \text { higher } \\
\text { (\$0.58/MWh) than the low-coal scenario. }\end{array}$ \\
\hline Start Effects & - Start Costs & $\begin{array}{l}\text { Start costs were mixed with respect to gas } \\
\text { prices. At the highest gas price, start costs } \\
\text { were } 28 \% \text { higher }(\$ 0.11 / \mathrm{MWh}) \text { than in the } \\
\text { reference scenario; however, the start costs } \\
\text { at the low gas price were also higher }(5 \% \text {, } \\
\$ 0.02 / \mathrm{MWh}) \text { than the reference scenario. }\end{array}$ \\
\hline Ramp Effects & - Ramp Costs & $\begin{array}{l}\text { Ramp costs were mixed with respect to gas } \\
\text { prices. At the highest gas price, ramping } \\
\text { costs were unchanged from the reference } \\
\text { scenario. Ramp costs at the low gas price } \\
\text { were higher }(25 \%, \$ 0.01 / \mathrm{MWh}) \text { than the } \\
\text { reference scenario. }\end{array}$ \\
\hline Reserves Effects & - Reserves Costs & Reserves cost impacts were not significant. \\
\hline
\end{tabular}

Not surprisingly, total generation costs increased with increasing gas price. The impacts on cycling costs and VO\&M costs were mixed. The minimum cycling costs occurred in the reference scenario, with costs increasing in both the low and high gas price scenarios. VO\&M costs rose with gas price; however, most of the cost increase was between the low gas price and reference gas price scenarios. Above the reference gas price ( $\$ 4.50 / \mathrm{MMBtu})$, VO\&M costs were flat.

\subsubsection{Future Work}

The gas price work done here was at modest penetration levels of variable generation (2\%). Investigation into how a system's ability to accommodate high-penetration variable generation at various gas prices would like benefit many in the electric power sector. 


\section{Results of the Fast-Start Generator Experiments}

These two simulations investigated the effects that generator start times and ramp rates have on integration costs. The two models used in this investigation were identical except the start times in the fast-start simulation were reduced and the ramp rates in the combined-cycle and combustion turbine plants were increased. The two test cases were:

- Reference (Ref)

- Reference with fast-start generators (Ref:FSG).

The inspiration for this set of scenarios was the recent development of combined-cycle plants that ramp from cold start to full power in 30 minutes.

The generator start times and ramps rates for both the reference and fast-start test cases are shown in Table 57.

Table 57. Fast-Start Generation Simulations: Start Times and Ramp Rates

\begin{tabular}{lrrrr} 
Type & $\begin{array}{r}\text { Ref Start Time } \\
\text { (hrs) }\end{array}$ & $\begin{array}{r}\text { FSG Start Time } \\
\text { (hrs) }\end{array}$ & $\begin{array}{r}\text { Ref Ramp Rate } \\
\text { (\%/min) }\end{array}$ & $\begin{array}{r}\text { FSG Ramp } \\
\text { Rate (\%/min) }\end{array}$ \\
\hline Coal & 24 & 4 & 1.1 & 1.1 \\
CC & 4 & 1 & 0.9 & 3.3 \\
CT Gas & 1 & 0 & 4.5 & 20
\end{tabular}

Note that the reference scenario used day-ahead and 4-hour-ahead forecasts, and the fast-start generation forecast used 4-hour-ahead and hour-ahead forecasts. All other generation parameters were kept constant.

Finally, as a reminder to the reader, these reference-based simulations had relatively low penetrations of variable generation, and no attempt was made to evaluate how fast-start generation might help accommodate variable generation at high penetration levels. Such work is left for future studies.

\subsection{Overall System Impacts}

The impact of increased flexibility on the overall generation cost (Figure 47) was found to be insignificant. Costs for the fast-start were slightly higher than for the reference case; however, the differences were related to forecast errors and not because the fast-start system was more expensive to operate. ${ }^{19}$

\footnotetext{
${ }^{19}$ With all other factors being equal, in the worst case the fast-start system would cost the same to operate as the reference system. (The fast-start system was not required to use the increased flexibility if it was uneconomical to do so, and no cost penalties were imposed related to the system's additional capability.) Consequently, cost differences were attributed to forecast horizons.
} 


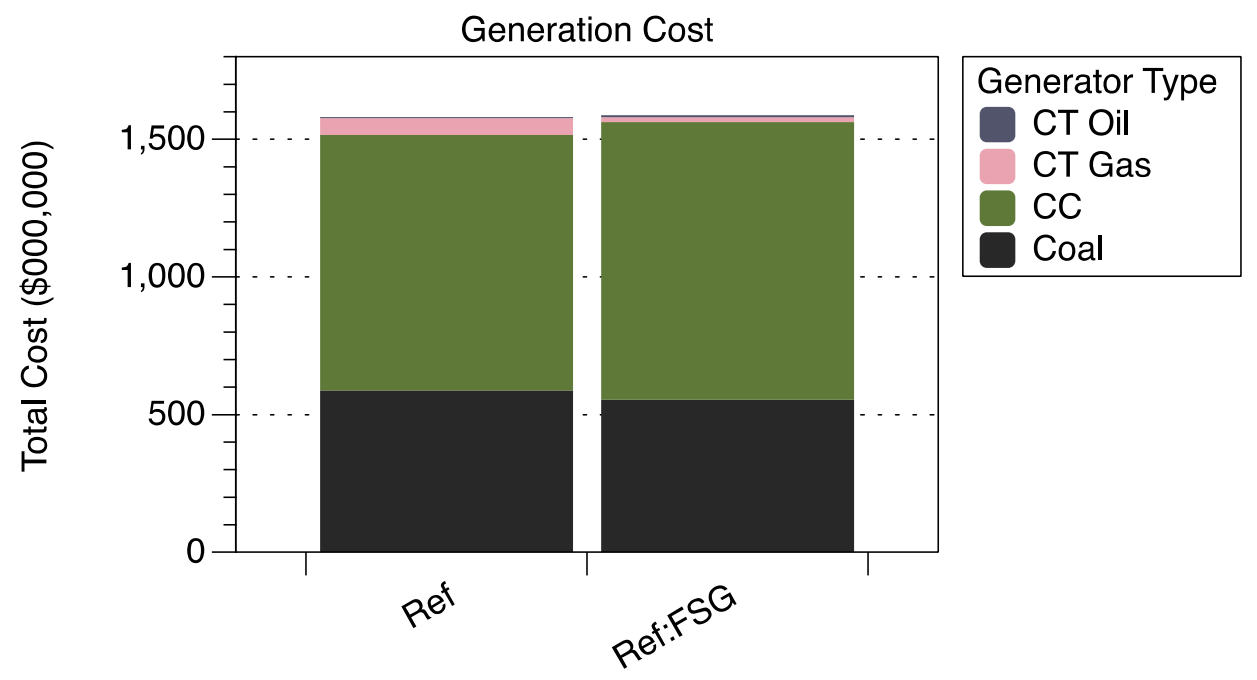

Scenario

Figure 47. Total generation cost

The impacts of generation mix are shown in Figure 48, in which the combined-cycle units displaced both coal and combustion turbines in the fast-start scenario.

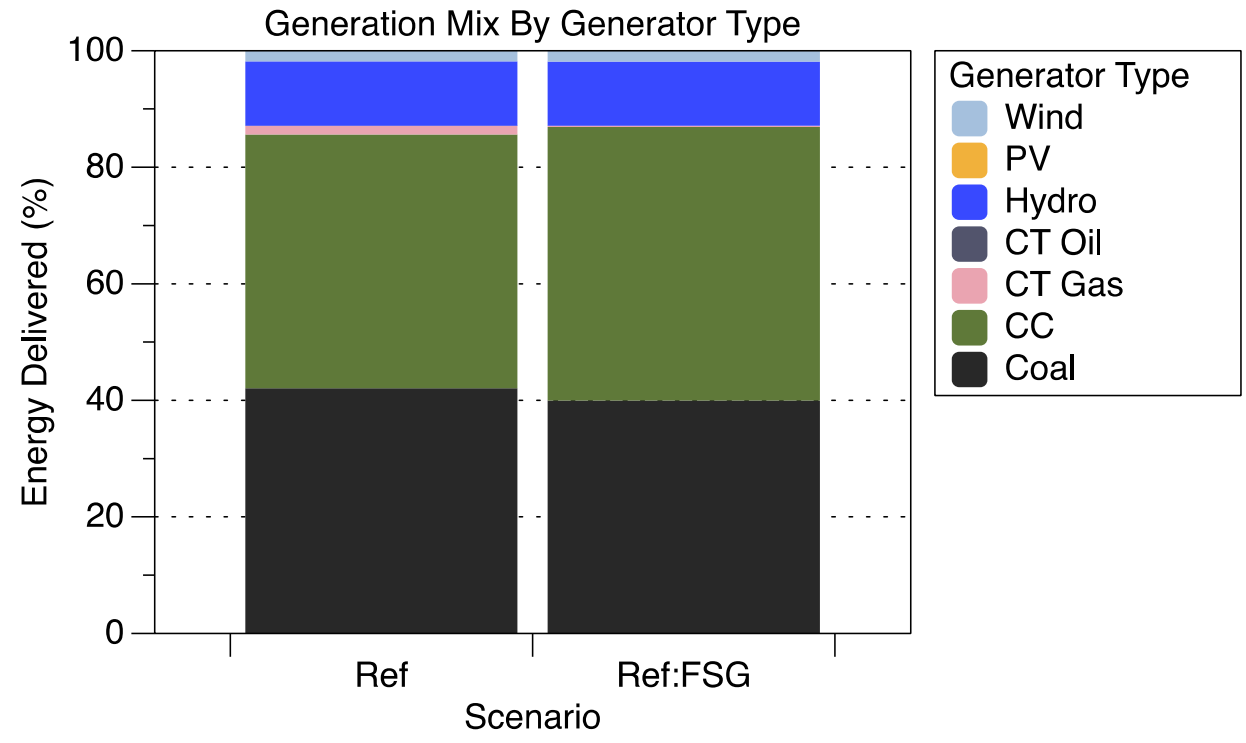

Figure 48. Fast-start generation simulations: energy delivered by generator type

The highly flexible combined-cycle units even replaced some of the load following that was previously handled by excess coal capacity. Table 58 shows the generation types. 
Table 58. Fast-Start Generation Simulations: Generation by Type

\begin{tabular}{lrr} 
Generator Type & Ref (GWh) & Ref:FSG (GWh) \\
\hline Coal & 26,982 & 25,642 \\
CC & 27,946 & 30,131 \\
CT Gas & 979 & 113 \\
CT Oil & 8 & 8 \\
Hydro & 7,065 & 7,067 \\
Wind & 1,174 & 1,194 \\
\hline Total & 64,154 & 64,154
\end{tabular}

The average generation costs are shown in Table 59, and the cycling components of these costs are discussed in the following sections.

Table 59. Fast-Start Generation Simulations: Average Generation Costs (\$/MWh)

\begin{tabular}{lrr} 
Type & Ref & Ref:FSG \\
\hline Coal & 21.80 & 21.60 \\
CC & 33.19 & 33.48 \\
CT Gas & 62.91 & 157.25 \\
\hline Wt. Avg. & 24.64 & 24.74
\end{tabular}

Note that although the average per-unit costs for the coal and combined-cycle plants decreased in the fast-start scenario, the cost of energy generated by combustion turbine units increased. The cost differences are likely because of differences in system forecasts. (The reference scenario used dayahead and 4-hour-ahead forecasts; the fast-start generation forecast used 4-hour-ahead and hourahead forecasts.)

As start times decreased, overall fuel costs decreased. The cost reduction is because the gas turbines were displaced by flexible combined-cycle plants and because the shorter start times allowed plants that would have kept running in anticipation of being needed a few hours later to be shut down and then restart when needed.

Table 60. Fast-Start Generation Simulations: Average Fuel Costs (\$/MWh)

\begin{tabular}{lrr} 
& Ref & Ref:FSG \\
\hline Wt. Avg. & 22.60 & 22.35
\end{tabular}

For the fast-start experiment, the cycling costs approximately doubled (Figure 49) compared to those of the reference case, with most of the increase coming from the cost associated with the improved flexibility of the combined-cycle units (Table 61). 


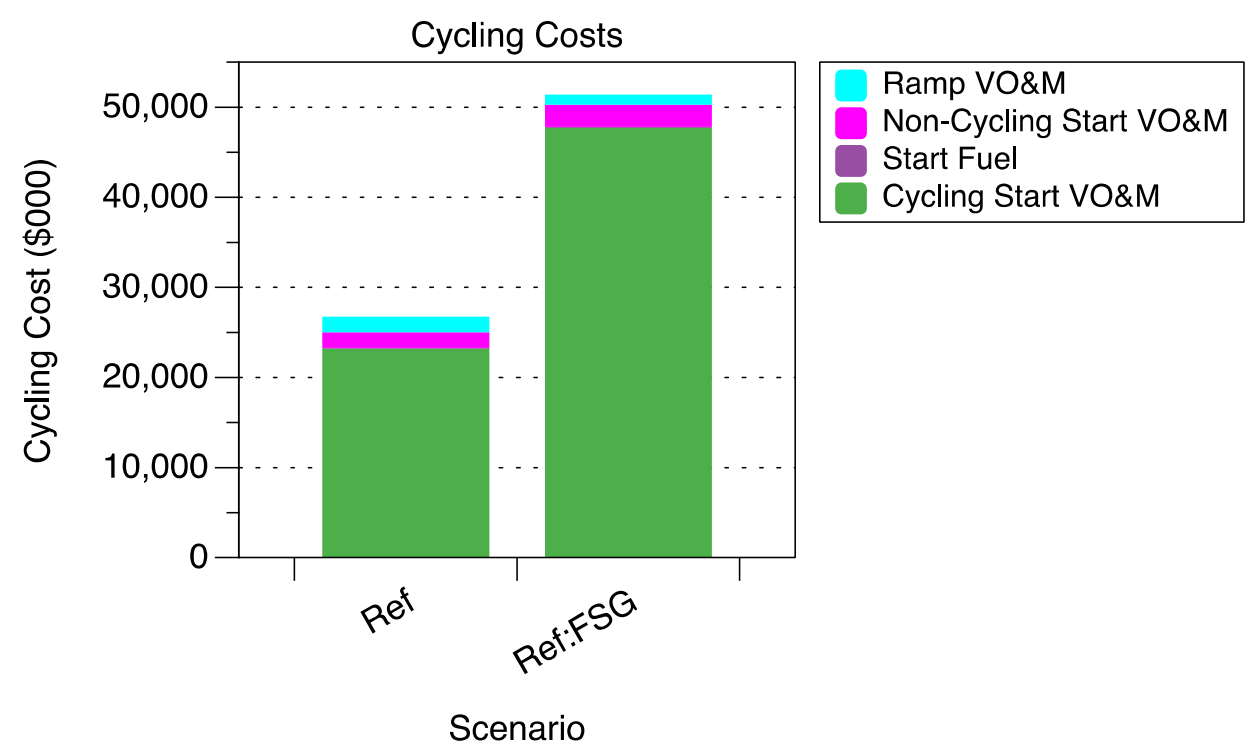

Figure 49. Fast-start generation simulations: cycling costs by cost component type

The average coal start costs decreased because the increased system flexibility allowed the coal plants to operate near peak capacity for most of the time a given unit was online. (There was little idling at the minimum generation levels in anticipation of an expected ramp up a few hours later.) The forecasts used during commitment decisions were also better (because they were shorter term), which led to more efficient usage of the coal and combined-cycle units (which was also shown in the fuel cost reductions).

The high ramp rates and faster start times once reserved to combustion turbines were available to combined-cycle plants at a significantly reduced cost compared to those for the combustion turbines. This operational change is reflected in the increased combustion turbine cycling costs (i.e., the combustion turbine units were used less often, and this change increased their average cycling costs).

Table 61. Fast-Start Generation Simulations: Average Cycling Costs by Generator Type (\$/MWh)

\begin{tabular}{lrr} 
Type & Ref & Ref:FSG \\
\hline Coal & 0.26 & 0.22 \\
CC & 0.47 & 1.03 \\
CT Gas & 6.34 & 99.98 \\
\hline Wt. Avg. & 0.43 & 0.83
\end{tabular}

VO\&M costs decreased slightly because combined-cycle units displaced the more expensive coal plants in the fast-start generation scenario. 
Table 62. Fast-Start Generation Simulations: Average VO\&M Costs (\$/MWh)

\begin{tabular}{lrr} 
& Ref & Ref:FSG \\
\hline Wt. Avg. & 1.61 & 1.57
\end{tabular}

The non-fuel operating costs (the sum of the cycling costs and VO\&M costs) increased in the faststart scenario, a trade-off made by the production cost optimizer to decrease fuel use. (The faster start times allowed less time at minimum generation levels on the coal and combined-cycle fleets.)

Table 63. Fast-Start Generation Simulations:

Average Non-Fuel Operating Costs by Generator Type (\$/MWh)

\begin{tabular}{lrr} 
Type & Ref & Ref:FSG \\
\hline Coal & 3.00 & 2.94 \\
CC & 1.50 & 2.05 \\
CT Gas & 6.90 & 100.47 \\
\hline Wt. Avg. & 2.04 & 2.39
\end{tabular}

\subsection{System Impacts per Unit of New Generation Added}

The fast-start generation experiments did not include additional generation, so results are reported only from an overall system perspective.

\subsection{Start Effects}

The new ramp rates, along with the comparatively low cost of starting a combined-cycle unit (see Table 7), allowed combined-cycle units to both follow load and serve as peakers. Consequently, combined-cycle unit starts increased by a factor of 2.5 (Figure 50).

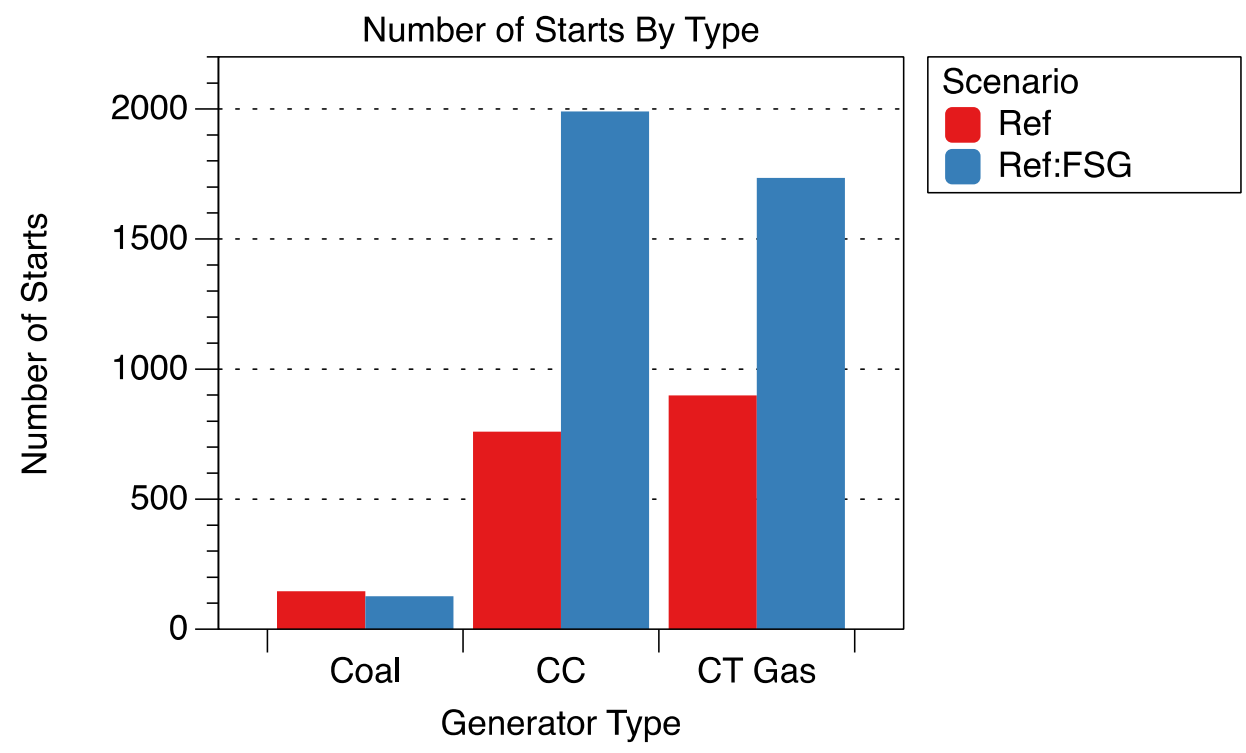

Figure 50. Fast-start generation simulations: number of starts per year 
Once started, the combined-cycle units were online for much shorter periods on average than they were in the reference case (Figure 51).

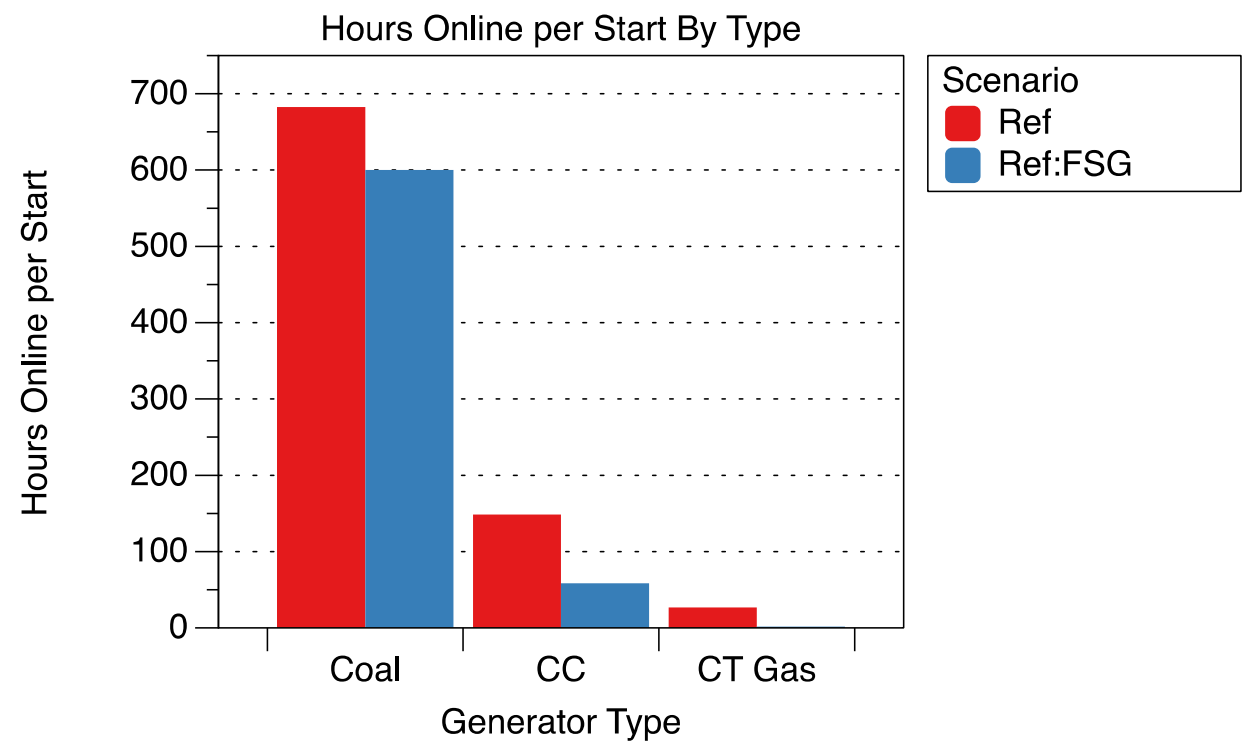

Figure 51. Fast-start generation simulations: average hours online per generator start

These two factors combined to result in combined-cycle starts that delivered less than half the energy per start than they delivered in the reference case (see Figure 52), thereby increasing the average start costs of the combined-cycle units.

The average combustion turbine start costs, which increased 15 fold in the fast-start run, increased for a different reason. Although the combustion turbine units remained peakers, the added flexibility of the combined-cycle units displaced much of the combustion turbine use in the fast-start runs, leaving the combustion turbine units to cover only the more extreme events and only very short periods of time. (The energy delivered per start dropped by $94 \%$.)

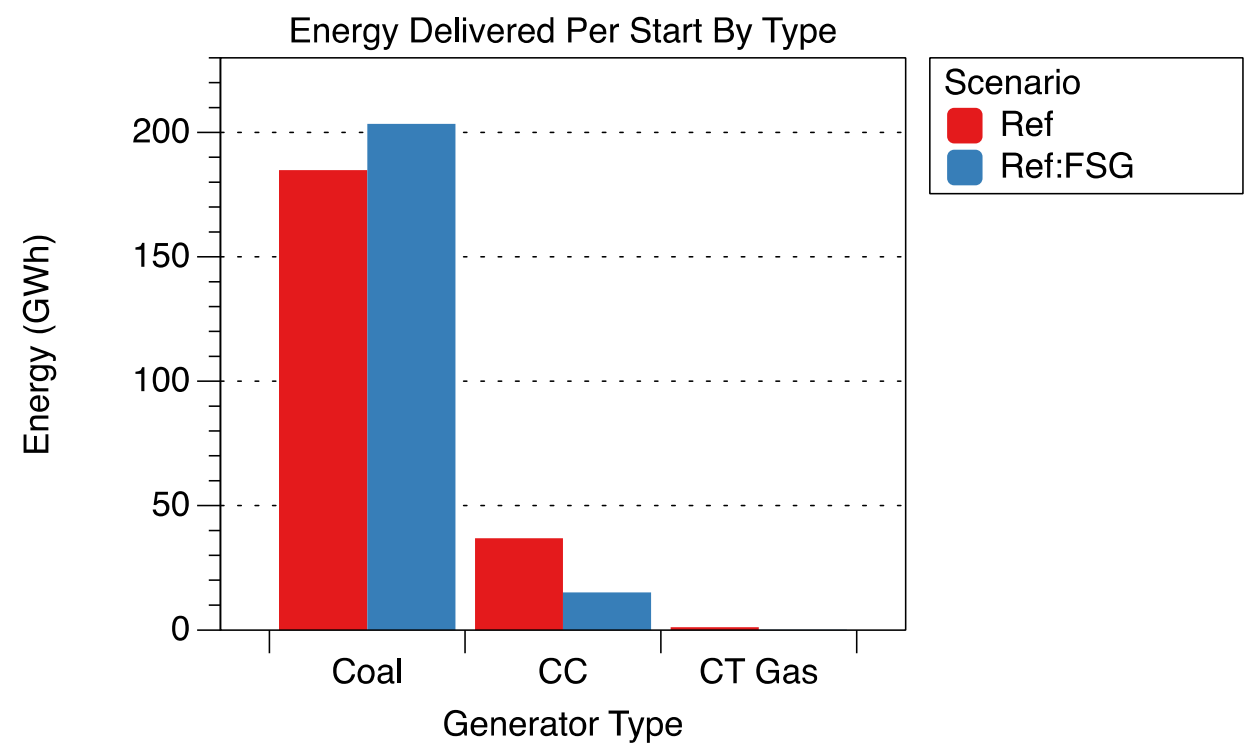


Figure 52. Fast-start generation simulations: average energy delivered per generator start

The new operating capabilities led to some rather dramatic changes in average start costs (see Table 64). In the fast-start simulation, coal plants were better matched to the load, starting and stopping as needed and ramping very little. Consequently, the average per-unit start cost for coal decreased. Combined-cycle plants started much more often, and when they started they were online for much shorter periods of time. This behavior more than doubled the average per-unit start costs for the combined-cycle units. And combustion turbine units, once used for following quickly changing loads, were seldom needed given the fast-start load-following capabilities of the combined-cycle units. This reduction in use markedly increased their average start costs.

The net result is that weighted average start costs doubled, with the increase in the combined-cycle costs outweighing the decrease in coal start costs.

Table 64. Average Combined Start Costs by Generator Type (\$/MWh)

\begin{tabular}{lrr} 
Type & Ref & Ref:FSG \\
\hline Coal & 0.22 & 0.21 \\
CC & 0.42 & 0.96 \\
CT Gas & 6.21 & 98.15 \\
\hline Wt. Avg. & 0.39 & 0.78
\end{tabular}

\subsection{Ramp Effects}

The improvements in the start flexibility of the various unit types become apparent when examining ramp effects. Coal plants, rather than ramping to meet load, were able to start and stop as needed, thus reducing the ramping required (see Figure 53 and Figure 54). Combustion turbine units were only required to meet the needs of more extreme ramping events. (The ratio of the number of ramps, which is a count of the large generator movements, to the amount of ramp indicates how much of a generator's movement is in response to large load changes.)

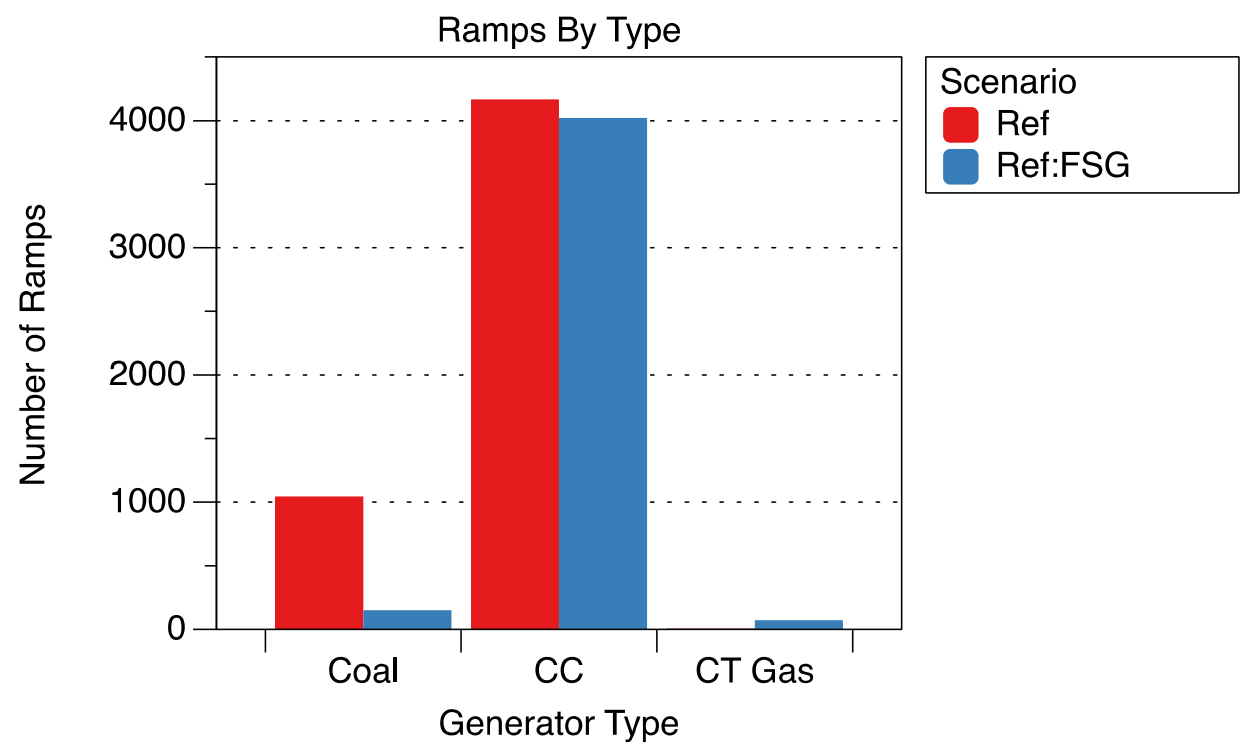


Figure 53. Fast-start generation simulations: number of ramps by generator type

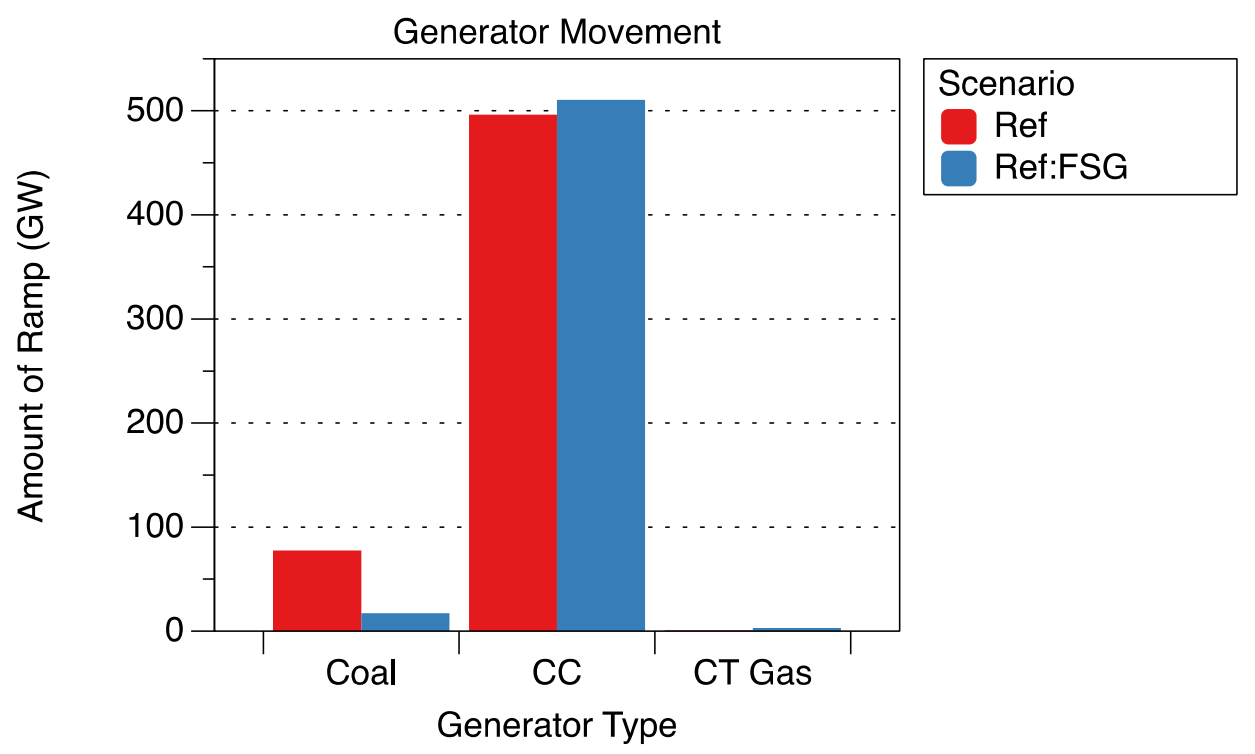

Figure 54. Fast-start generation simulations: amount of generator movement by generator type

The ratio of generator movement to energy delivered (Figure 55) is an indicator of the types of events that a given generator class is servicing. The ratio for coal dropped markedly, indicating that combinations of coal units can be used to meet load requirements with little ramping.

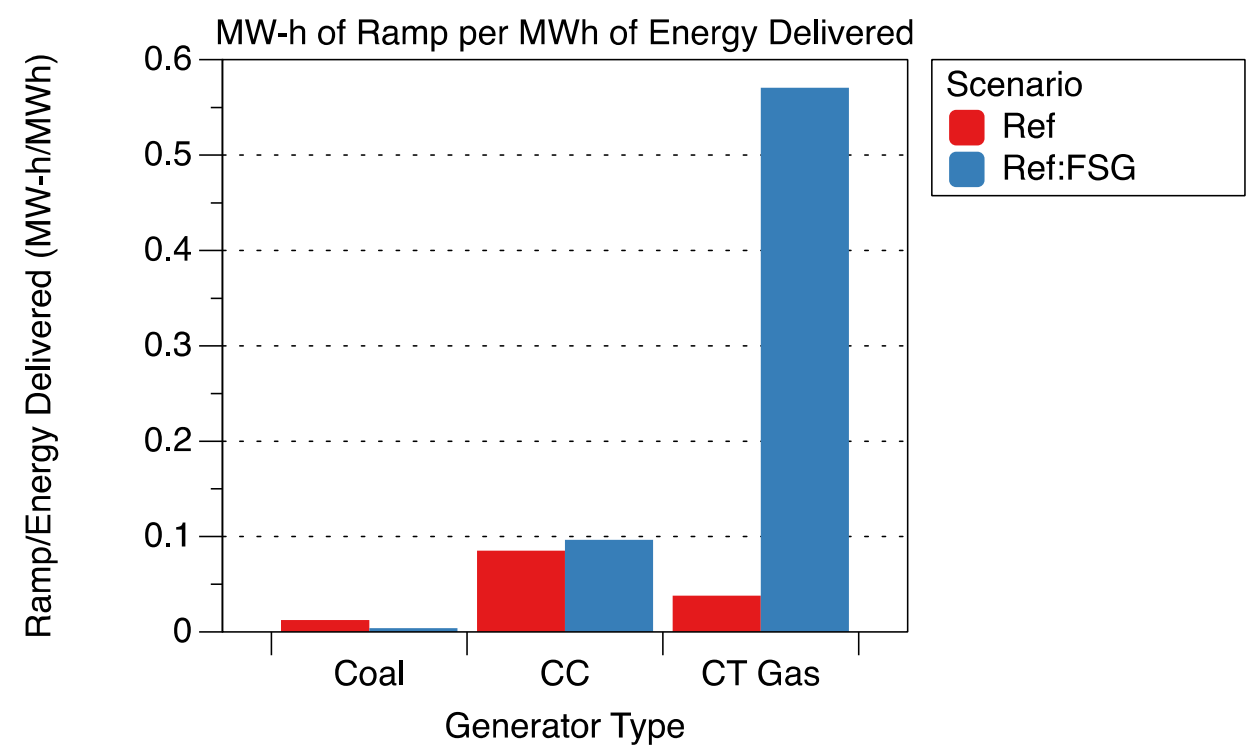

Figure 55. Fast-start generation simulations: average energy delivered per generator start

Another noticeable change is in how the combustion turbine units were used. Combustion turbines, which have quick start times and high ramp rates, would typically be used to follow fast load changes. However, the fast-start combined-cycle plants, which have improved flexibility, were able to serve load changes that were once only within the domain of combustion turbine operation. The 
impact of this change is shown in Figure 55 and Table 65, in which combustion turbine ramping costs increased by almost 15 fold.

Table 65. Fast-Start Generation Simulations: Average Ramping Costs by Generator Type (\$/MWh)

\begin{tabular}{lrr} 
Type & Ref & Ref:FSG \\
\hline Coal & 0.04 & 0.01 \\
CC & 0.06 & 0.07 \\
CT Gas & 0.12 & 1.84 \\
\hline Wt. Avg. & 0.04 & 0.04
\end{tabular}

The new flexibility of the coals plants is also captured in Table 65, in which ramp-related costs for coal in the fast-start scenario dropped to one-third of what they were in the reference case.

\subsection{Reserves Effects}

This section investigates how changes in generator start times affect the cost of provisioning reserves.

Table 66. Fast-Start Generation Simulations: Reserves Provisioning Costs

\begin{tabular}{lrrrr} 
Scenario & $\begin{array}{r}\text { Reserves Provisioning } \\
\text { Cost }(\mathbf{\$ 0 0 0 , 0 0 0 )}\end{array}$ & $\begin{array}{r}\Delta \text { Cost } \\
(\mathbf{\$ 0 0 0 , 0 0 0 )}\end{array}$ & $\mathbf{\$} /$ MWh Energy & $\Delta \mathbf{\Delta} /$ MWh Energy \\
\hline Ref & 2 & - & 0.02 & - \\
Ref:FSG & 1 & $(1)$ & 0.01 & $(0.01)$
\end{tabular}

The differences in the reserves provisioning costs (see Table 68) were small and near the limits of the simulation's precision, with the costs for the fast-start simulation less than those for the reference simulation.

\subsection{Capacity Factor and Curtailment Effects}

Interestingly, the average capacity factors of the coal plants in the fast-start scenario dropped slightly (Figure 56). This decrease can be attributed to a new operating pattern for the coal plants, in which they ramped very little and instead responded to load by starting and stopping as necessary. As a result, the coal plants were online for less time each year, and when they were online they tended to operate near full capacity.

The capacity factors for the combined-cycle units increased slightly for two reasons. First, the improved ramp rates and start times of the of the combined-cycle units allowed them to displace the more expensive combustion turbine units, and second the small amount of ramping that used to be provided by the coal units was now provided by the combined-cycle units. 


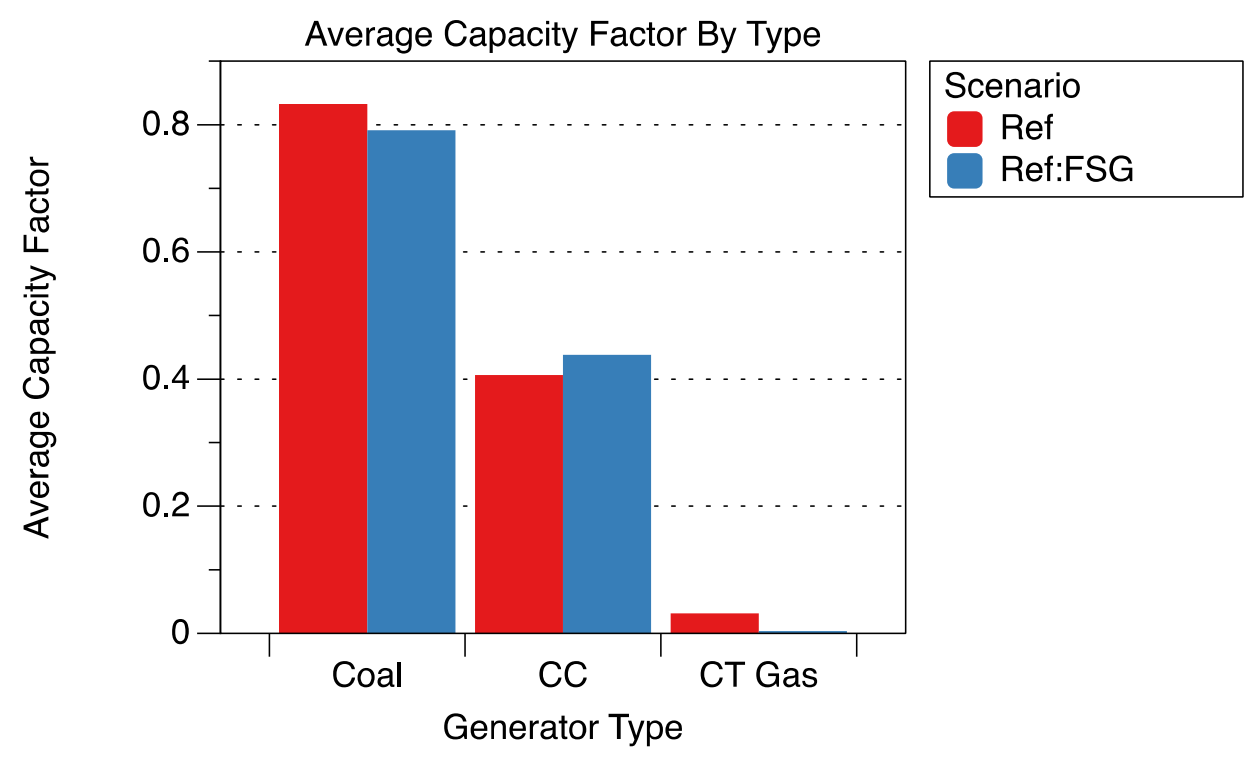

Figure 56. Fast-start generation simulations: average capacity factor by generator type

The increased flexibility afforded by the improved generator start times and ramp rates allowed the system to better accommodate the variability of wind, and the curtailment rates of the fast-start scenario were reduced by more than $70 \%$ (Figure 57 ).

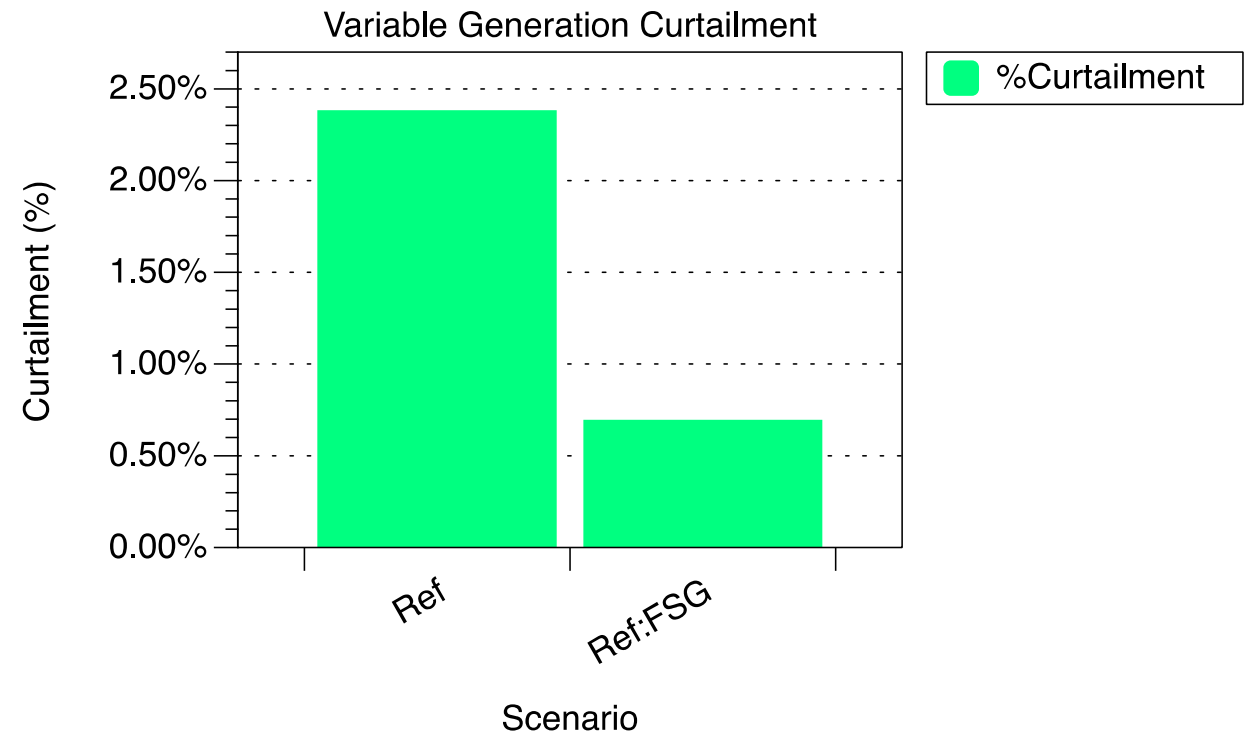

Figure 57. Fast-start generation simulations: variable generation curtailment 


\subsection{Fast-Start Generation Study Summary}

This section summarizes the overall cost-related findings of the fast-start generation experiments, and the system-level cost impacts are shown in Table 67 . Note that only overall cost impacts are shown because no new generation was added to the system.

Table 67. Fast-Start Generation Simulations:

Cost Summaries per Unit of Overall System Generation

\begin{tabular}{|c|c|c|}
\hline Topic & Subtopic & Results Summary \\
\hline \multirow[t]{5}{*}{ Overall System Impacts } & - Total Generation Costs & $\begin{array}{l}\text { The cost differences between the two } \\
\text { scenarios were not significant. }\end{array}$ \\
\hline & - Fuel Costs & $\begin{array}{l}\text { Fuel costs decreased in the fast-start } \\
\text { generation simulation by } 1 \%(\$ 0.25 / \mathrm{MWh}) \text {. }\end{array}$ \\
\hline & $\begin{array}{l}\text { - Cycling Costs (Combined Start } \\
\text { + Ramp Costs) }\end{array}$ & $\begin{array}{l}\text { Average cycling costs increased in the fast- } \\
\text { start generation simulation by } 93 \% \\
\text { (\$0.40/MWh) }\end{array}$ \\
\hline & - VO\&M Costs & $\begin{array}{l}\text { VO\&M costs decreased by } 2 \%(\$ .04 / \mathrm{MWh}) \\
\text { in the fast-start generation simulation. }\end{array}$ \\
\hline & - Non-Fuel Operating Costs & $\begin{array}{l}\text { Non-fuel operating costs increased by } 17 \% \\
(\$ 0.35 / \mathrm{MWh}) \text { in the fast-start generation } \\
\text { simulation. }\end{array}$ \\
\hline Start Effects & - Start Costs & $\begin{array}{l}\text { Start costs increased } 100 \%(\$ 0.39 / \mathrm{MWh}) \text { in } \\
\text { the fast-start generation simulation. }\end{array}$ \\
\hline Ramp Effects & - Ramp Costs & $\begin{array}{l}\text { Ramp costs were unchanged in the fast-start } \\
\text { simulation. }\end{array}$ \\
\hline Reserves Effects & - Reserves Costs & $\begin{array}{l}\text { Reserves costs decreased in the fast-start } \\
\text { simulation; however, the difference was } \\
\text { near the precision limits of the simulation. }\end{array}$ \\
\hline
\end{tabular}

Total generation costs in the fast-start experiments changed little. Although cycling costs increased, these increases were offset by fuel cost savings and VO\&M cost reductions. The most likely situation in which the advantages of fast-start generation would be observed would be in scenarios with high penetrations of variable generation; however, such scenarios were not included in the current study.

\subsubsection{Future Work}

Fast-start generation should be investigated at higher penetration levels of variable generation. Strategically deployed fast-start generation may be able to alleviate many of the ramping concerns associated with high PV penetration. 


\section{Results of the Self-Scheduling Experiments}

The self-commitment and self-scheduling runs, collectively known as the self-scheduling simulations, were designed to help provide insight into how self-scheduling affects overall grid operations. Two sets of self-scheduling runs were performed: reference-based and high-coal based. The three runs based on the reference scenario were:

- Reference (Ref)

- Reference with $50 \%$ of the coal plants self-committed (Ref:50SC)

- Reference with $50 \%$ of the coal plants self-dispatched at full capacity (Ref:50SD).

Note that the $50 \%$ level for commitment is similar to the amount of coal that was committed via the production cost co-optimization.

The three runs based on the high-coal scenario are:

- High coal/low gas (HCLG)

- High coal/low gas with $50 \%$ of the coal plants self-committed (HCLG:50SC)

- High coal/ low gas with $50 \%$ of the coal plants self-dispatched at full capacity (HCLG:50SD).

In the self-commitment runs, $50 \%$ of the coal plants (by energy) were committed for the whole year. No attempt was made to optimize which plants self-scheduled or to optimize when a given plant self-committed. In practice, self-scheduling is admittedly complicated and varies with time and among generators; however, the results presented here are believed to be representative of the general magnitude of self-scheduling effects.

For the self-dispatch runs, the coal commitment schedules from the self-commitment runs (Ref:50SC and HCLG:50SC) were used to determine which plants self-dispatched, and these plants were dispatched at full capacity and then kept at full capacity throughout the year (barring forced outages). As in the self-commitment runs, no attempt was made to optimize which plants selfscheduled or to optimize when a given plant dispatched.

As a reminder to the reader, these reference-based simulations had relatively low penetration levels of variable generation, and no attempt was made to evaluate if self-scheduling might affect the integration costs in scenarios of high penetrations of variable generation. Such work is left for future studies.

\subsection{Overall System Impacts}

The total costs for the self-scheduling simulations are shown in Figure 58. The most obvious impact is that self-dispatch increased the overall generation costs: the overall operating costs increased 3\% in the reference-based scenario and almost $7 \%$ in the high-coal scenario. 


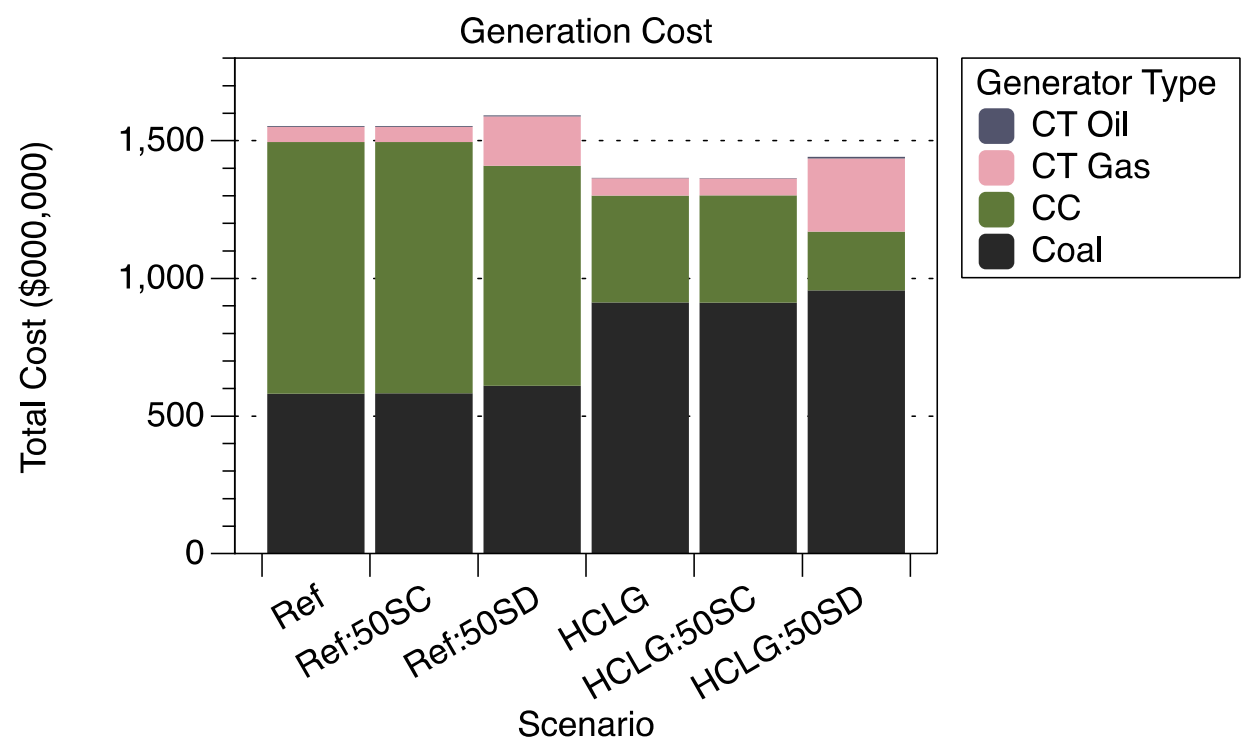

Figure 58. Self-scheduling simulations: total cost of generation

The impact of self-scheduling on the generation mix is shown in Figure 59. In general, selfcommitment had little effect on the generation mix, and self-dispatch increased the energy delivered by both coal and combustion turbines. The amount of energy delivered by coal increased by $5 \%$ in the self-dispatch simulations. Interestingly, self-dispatch at the 50\% level markedly increased combustion turbine generation use because the load-following capabilities of the combined-cycle units were exceeded. Combustion turbine generation tripled in the reference case and quadrupled in the high-coal simulation.

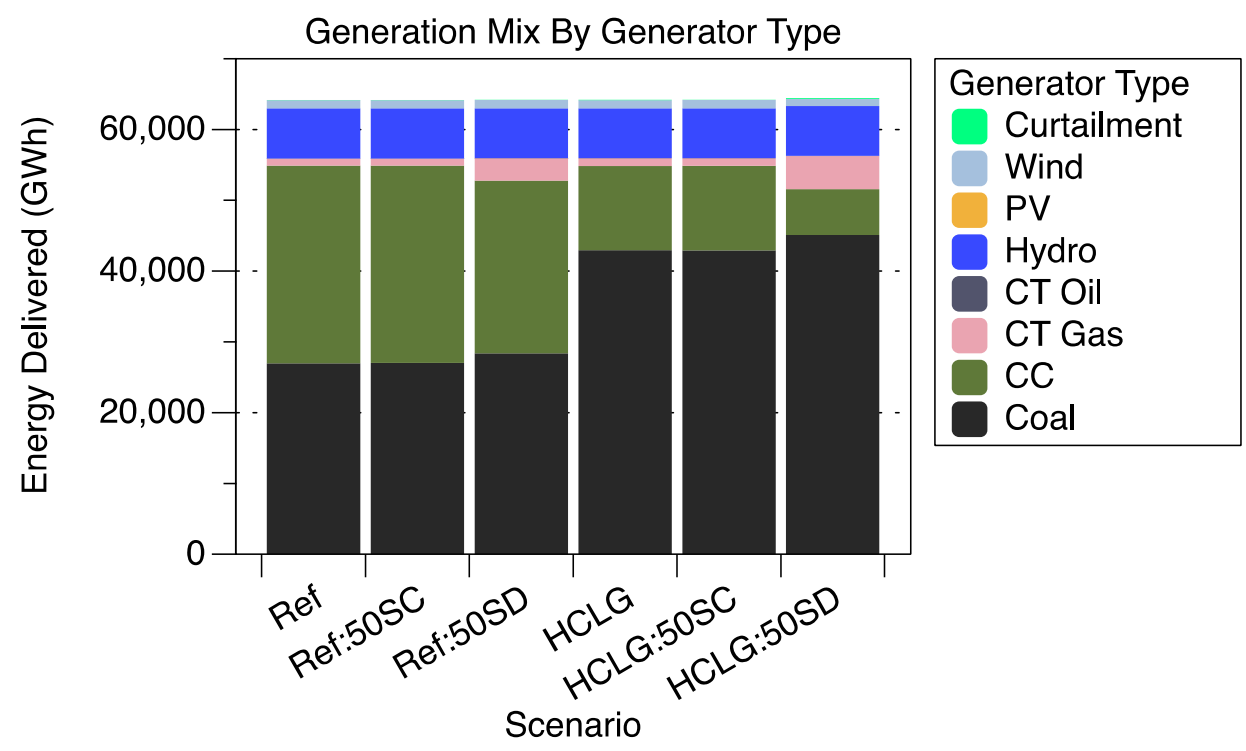

Figure 59. Self-scheduling simulations: energy delivered by generator type

Related to the changes in generation are the per-unit costs of generation (Table 68). Restricting the system's degrees of freedom to optimize all generation had little effect in the self-commitment 
experiments but increased overall per-unit costs between $3 \%$ and $6 \%$ in the self-dispatch scenarios. For the self-dispatch runs, per-unit combined-cycle costs increased, and coal and combustion turbine costs decreased.

Table 68. Self-Scheduling Simulations: Average Generation Costs by Generator Type (\$/MWh)

\begin{tabular}{lrrrrrr} 
Type & Ref & Ref:50SC & Ref:50SD & HCLG & HCLG:50SC & HCLG:50SD \\
\hline Coal & 21.80 & 21.80 & 21.76 & 21.52 & 21.52 & 21.48 \\
CC & 33.19 & 33.22 & 33.33 & 33.75 & 33.69 & 36.19 \\
CT Gas & 62.91 & 63.09 & 59.44 & 64.90 & 65.45 & 60.35 \\
\hline Wt. Avg. & 24.64 & 24.65 & 25.31 & 21.83 & 21.81 & 23.21
\end{tabular}

Similarly, self-commitment had little if any effect on the average fuel costs for the system, whereas self-dispatch increased the average fuel costs by $3 \%$ for the reference-based scenario and by $6 \%$ for the high-coal scenario.

Table 69. Self-Scheduling Simulations: Average Fuel Costs (\$/MWh)

\begin{tabular}{lrrrrrr} 
& Ref & Ref:50SC & Ref:50SD & HCLG & HCLG:50SC & HCLG:50SD \\
\hline Wt. Avg. & 22.60 & 22.60 & 23.19 & 19.24 & 19.23 & 20.32
\end{tabular}

The cycling (i.e., start-up and ramping) costs are shown in Figure 60 and with per-unit costs in Table 70 . The weighted average cycling costs were minimally affected in the self-commitment scenarios; however, they were significantly affected in the self-dispatch scenarios, in which overall costs increased $14 \%$ for the reference case and $47 \%$ for the high-coal case.

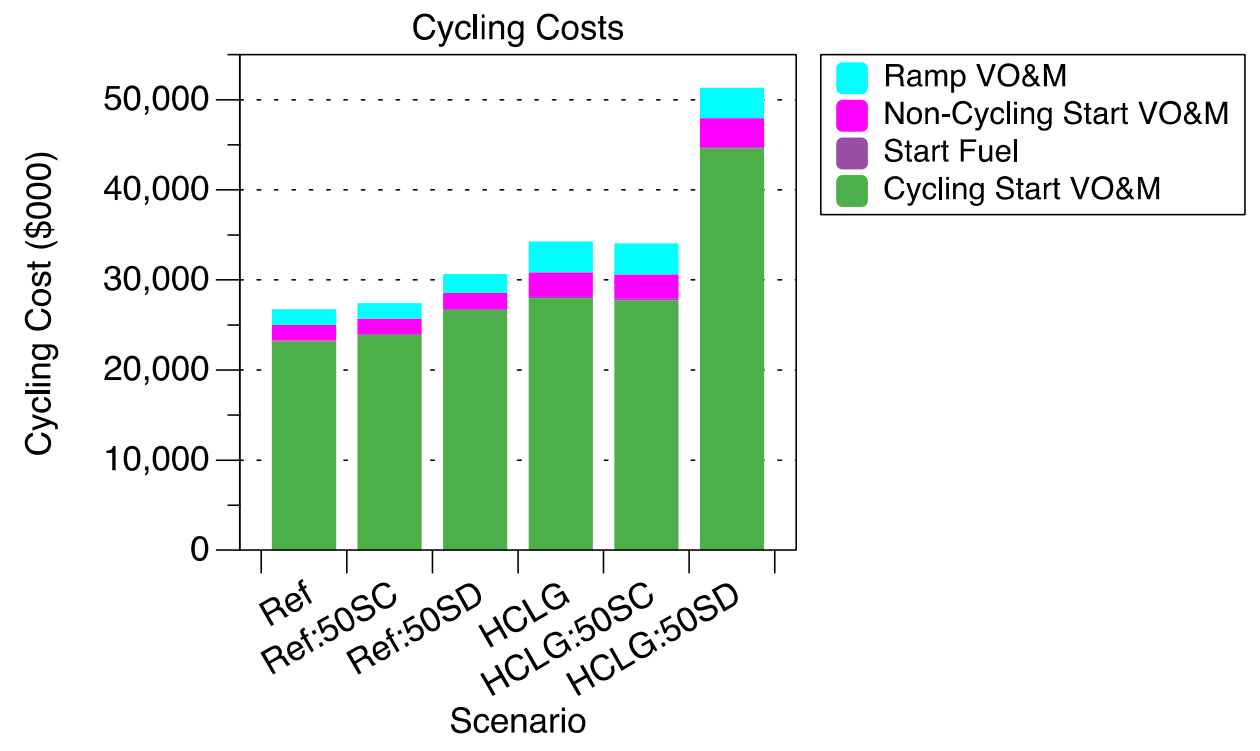

Figure 60. Self-scheduling simulations: cycling costs by cost component type

Per unit, the cycling cost changes varied by generator type. As with the other metrics, selfcommitment had minimal impact, whereas self-dispatch as much as tripled combined-cycle costs 
and more than halved combustion turbine costs (see Table 70). As mentioned above, the overall cycling costs increased between $14 \%$ and $47 \%$ in the self-dispatch scenarios.

Table 70. Self-Scheduling Simulations: Average Cycling Costs by Generator Type
\begin{tabular}{lrrrrrr} 
Type & Ref & Ref:50SC & Ref:50SD & HCLG & HCLG:50SC & HCLG:50SD \\
\hline Coal & 0.26 & 0.25 & 0.25 & 0.28 & 0.28 & 0.27 \\
CC & 0.47 & 0.49 & 0.61 & 1.08 & 1.06 & 3.40 \\
CT Gas & 6.33 & 6.62 & 2.54 & 7.66 & 7.97 & 3.25 \\
\hline Wt. Avg. & 0.43 & 0.44 & 0.49 & 0.55 & 0.54 & 0.81
\end{tabular}

The VO\&M cost patterns matched what would be expected given the changes in generation mix. As shown in Table 71, the VO\&M costs decreased in the simulations with lower coal penetrations (the self-commitment runs) and increased in the simulations with higher coal penetrations (the selfdispatch runs).

\section{Table 71. Self-Scheduling Simulations: Average VO\&M Costs (\$/MWh)}

\begin{tabular}{lrrrrrr} 
& Ref & Ref:50SC & Ref:50SD & HCLG & HCLG:50SC & HCLG:50SD \\
\hline Wt. Avg. & 1.61 & 1.61 & 1.63 & 2.04 & 2.04 & 2.07
\end{tabular}

Combining the cycling costs and VO\&M costs provided an average non-fuel operating cost that is representative of the cost impacts to the system. Cost impacts in the self-commitment case were minimal, but they were significant in the self-dispatch runs-ranging from $4 \%$ in the reference scenario to $12 \%$ in the high-coal scenario.

Table 72. Self-Scheduling Simulations: Average Non-Fuel Operating Costs by Generator Type (\$/MWh)

\begin{tabular}{lrrrrrr} 
Type & Ref & Ref:50SC & Ref:50SD & HCLG & HCLG:50SC & HCLG:50SD \\
\hline Coal & 3.00 & 2.99 & 2.99 & 3.03 & 3.03 & 3.03 \\
CC & 1.50 & 1.51 & 1.63 & 2.11 & 2.08 & 4.42 \\
CT Gas & 6.90 & 7.19 & 3.11 & 8.23 & 8.54 & 3.82 \\
\hline Wt. Avg. & 2.04 & 2.05 & 2.12 & 2.59 & 2.58 & 2.89
\end{tabular}

The following sections examine how self-scheduling impacts start and ramping operating costs and operations.

\subsection{System Impacts per Unit of New Generation Added}

The self-scheduling experiments did not include additional generation, so results are reported only from an overall system perspective.

\subsection{Start Effects}

In general, start effects in the self-scheduling runs were similar to those in the reference and highcoal runs; however, there were some notable differences in the high-coal, self-dispatch scenario (see Figure 61). For the high-coal, self-dispatch scenario, the number of starts for the combined-cycle 
and combustion turbines almost doubled, with the change owed to the additional flexibility provided by the lower start costs of the combined-cycle units and combustion turbine units.

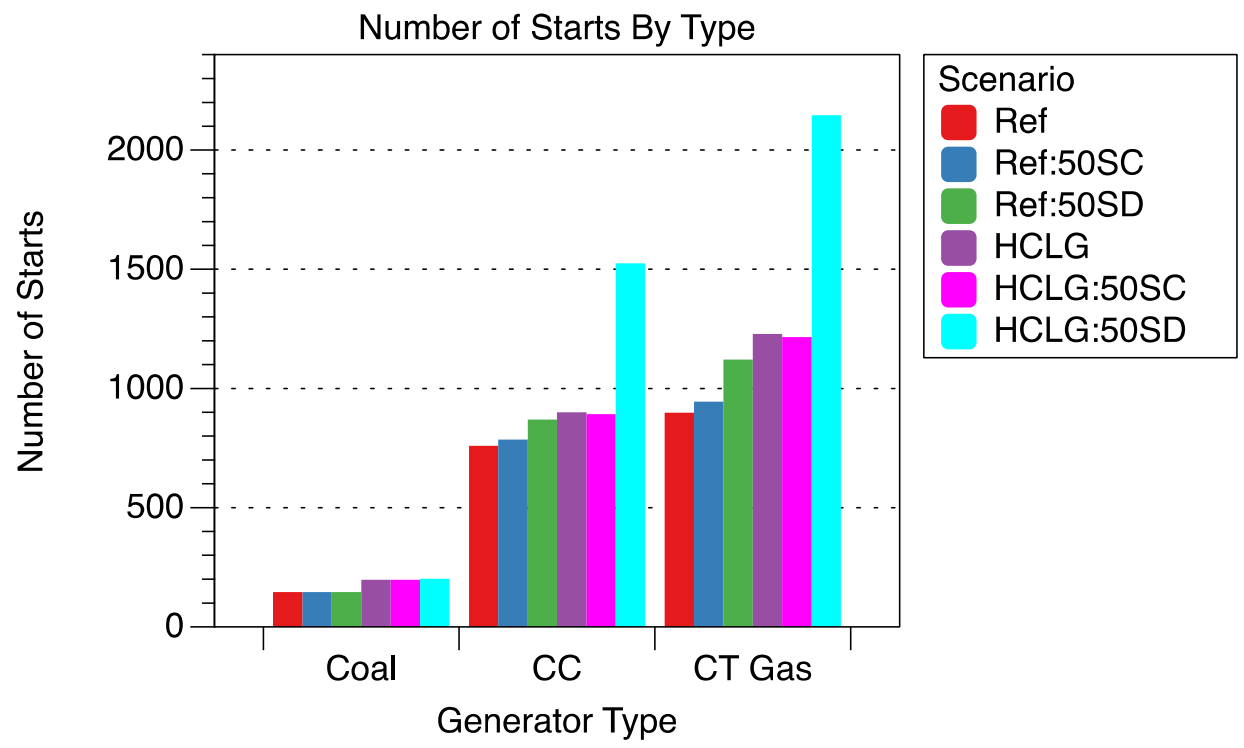

Figure 61. Self-scheduling simulations: number of starts by generator type

Hours online for both the combined-cycle and combustion turbine units also increased in the selfdispatch runs (see Figure 62); however, the reason for the changes differed by generator type.

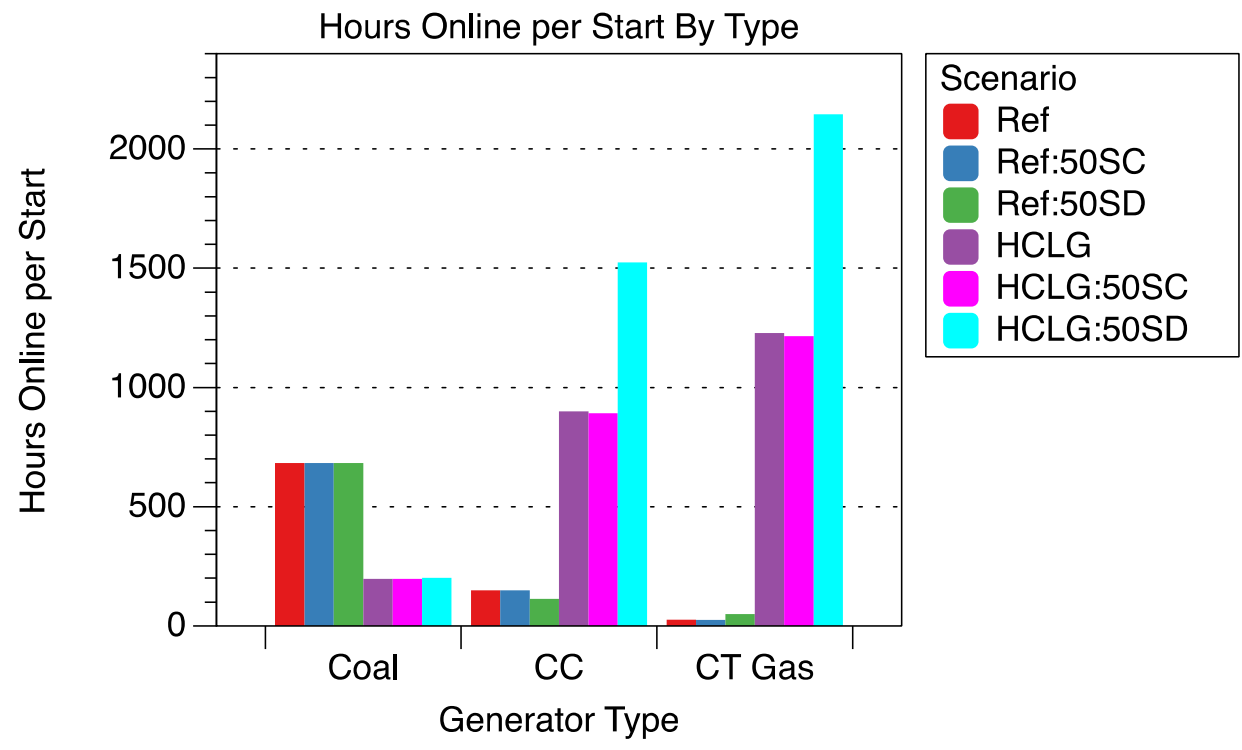

Figure 62. Self-scheduling simulations: hours online per generator start

Although the number of starts and hours online increased for the combined-cycle units, the energy delivered per start actually decreased by two-thirds (see Figure 63). The combined-cycle units that were brought online ran at near minimum power settings, often providing reserves for the system, and energy output dropped by half. Compare this change to that of the combustion turbine 
operation. The number of starts for the combustion turbine units also increased, and they, too, provided more reserves than in the base case; however, the energy output of the combustion turbine units almost tripled.

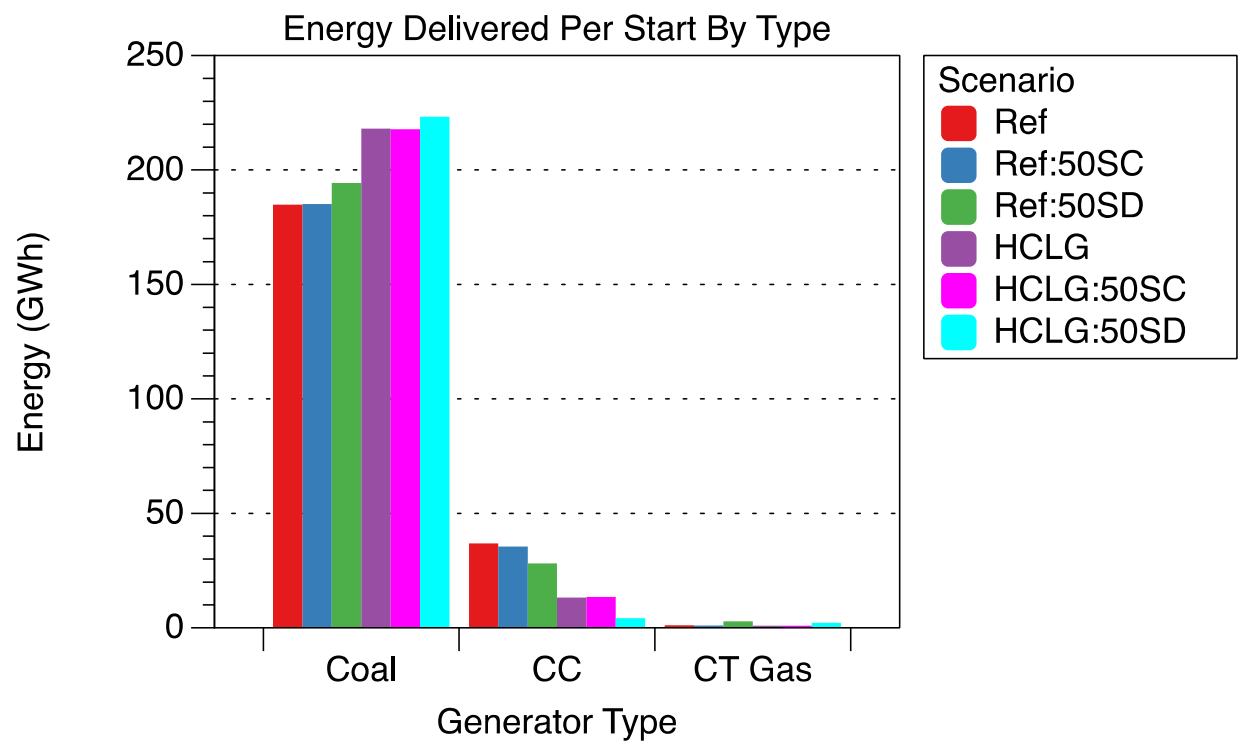

Figure 63. Self-scheduling simulations: energy delivered per start by generator type

The overall start costs for the self-commitment runs changed little; they increased slightly in the reference case and decreased slightly in the high-coal scenario. However, start cost impacts of selfdispatching were significant (see Table 73); costs increased by $13 \%$ in the reference coal scenario and by $54 \%$ in the high-coal case.

Table 73. Self-Scheduling Simulations: Average Combined Start Costs by Generator Type (\$/MWh)

\begin{tabular}{lrrrrrr} 
Type & Ref & Ref:50SC & Ref:50SD & HCLG & HCLG:50SC & HCLG:50SD \\
\hline Coal & 0.22 & 0.21 & 0.20 & 0.21 & 0.21 & 0.21 \\
CC & 0.42 & 0.43 & 0.55 & 0.99 & 0.97 & 3.26 \\
CT Gas & 6.21 & 6.50 & 2.48 & 7.49 & 7.79 & 3.15 \\
\hline Wt. Avg. & 0.39 & 0.40 & 0.44 & 0.48 & 0.47 & 0.74
\end{tabular}

The added flexibility needed for the self-dispatch runs positively impacted the starts costs of the combustion turbines, decreasing them by approximately $60 \%$ for both the reference and high-coal simulations. These cost decreases were enough to partially offset the increased start costs of the combined-cycle units.

\subsection{Ramp Effects}

The pattern in ramp effects (see Figure 64) was clear for the coal plants, and less so for the other two types of generation. Self-commitment caused the combined-cycle plants to ramp more, and the self-dispatched coal plants caused the system-dispatched coal plants to ramp more. Also of note is how self-dispatch decreased the number of the combined-cycle ramps and increased the number of combustion turbine ramps. 


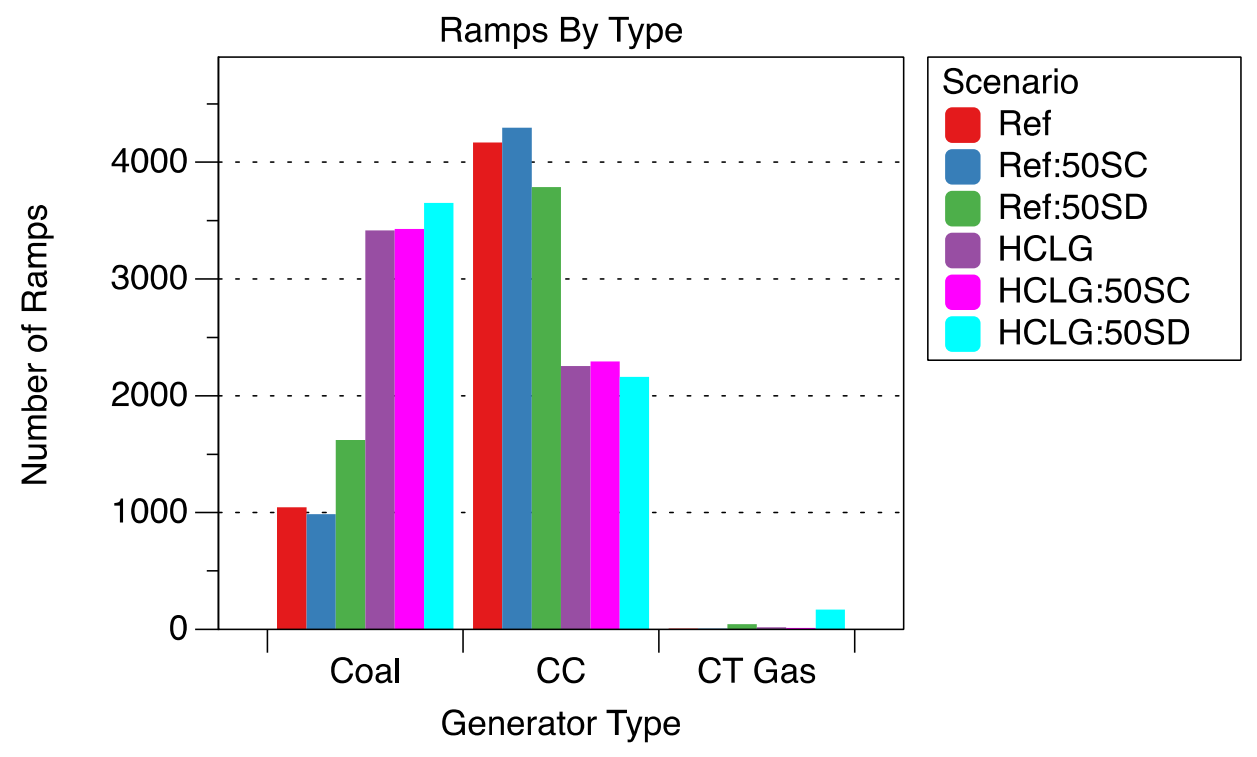

Figure 64. Self-scheduling simulations: number of ramps by generator type

The effects of the ramps per unit of energy delivered were largely unchanged for the selfcommitment runs but were significant for the self-dispatch simulations (see Figure 65). For the selfdispatch runs, the values of ramps per unit of energy increased for the combined-cycle plants and decreased for the combustion turbines.

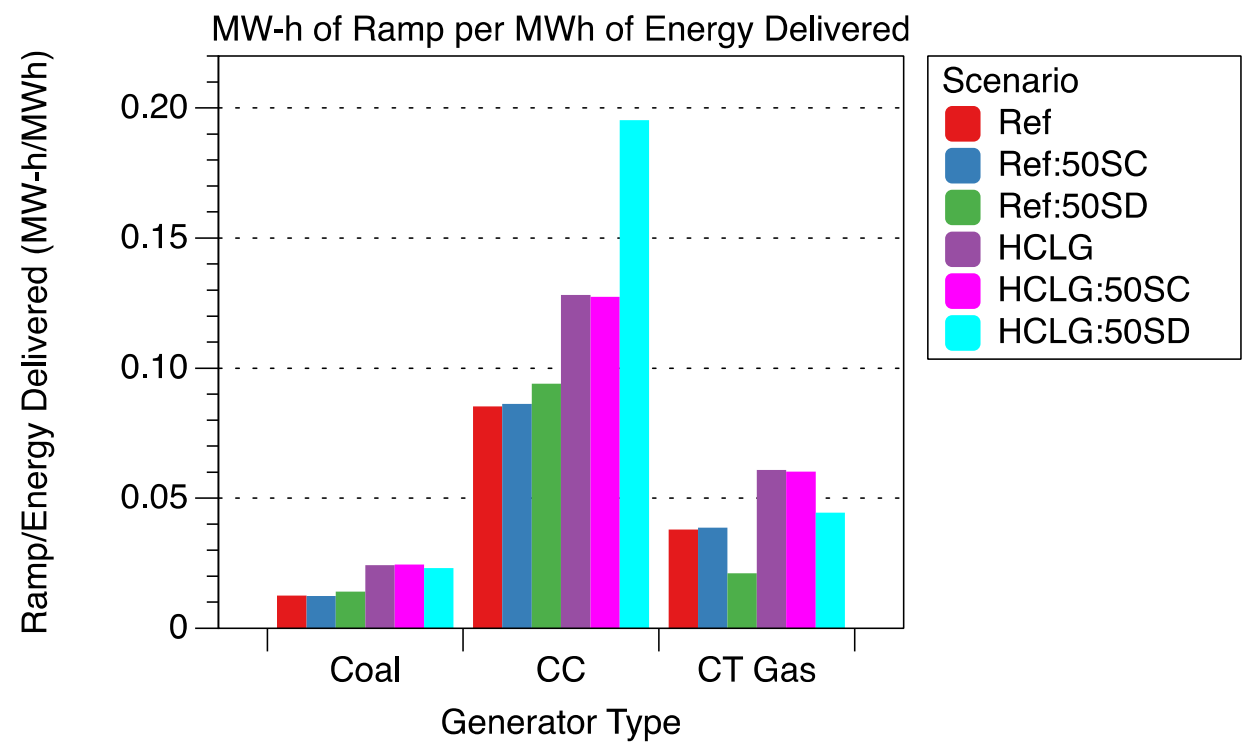

Figure 65. Self-scheduling simulations: average amount of ramp per unit of energy delivered

The weighted average ramping costs changed little, with cost decreases for one type of generation typically offsetting increases for another (see Table 74). 
Table 74. Self-Scheduling Scenario: Average Ramping Costs by Generator Type (\$/MWh)

\begin{tabular}{lrrrrrr} 
Type & Ref & Ref:50SC & Ref:50SD & HCLG & HCLG:50SC & HCLG:50SD \\
\hline Coal & 0.04 & 0.04 & 0.05 & 0.07 & 0.07 & 0.07 \\
CC & 0.06 & 0.06 & 0.06 & 0.09 & 0.09 & 0.14 \\
CT Gas & 0.12 & 0.13 & 0.06 & 0.17 & 0.17 & 0.11 \\
\hline Wt. Avg. & 0.04 & 0.04 & 0.05 & 0.07 & 0.07 & 0.07
\end{tabular}

All ramping-related cost impacts were modest, less than $0.1 \%$ of the overall generation cost (see Table 68).

\subsection{Reserves Effects}

This section investigates how self-commitment and self-dispatch affect the cost of provisioning reserves.

Table 75. Self-Scheduling Simulations: Reserves Provisioning Costs

\begin{tabular}{lrrrr} 
Scenario & $\begin{array}{r}\text { Reserves Provisioning } \\
\text { Cost }(\mathbf{\$ 0 0 0 , 0 0 0 )}\end{array}$ & $\begin{array}{r}\boldsymbol{\Delta} \text { Cost } \\
(\mathbf{\$ 0 0 0 , 0 0 0 )}\end{array}$ & $\mathbf{\$} / \mathbf{M W h}$ Energy & $\boldsymbol{\Delta} \mathbf{\mathbf { S } / \text { MWh Energy }}$ \\
\hline Ref & 2 & - & 0.02 & - \\
Ref:50SC & 2 & - & 0.03 & 0.01 \\
Ref:50SD & 5 & 4 & 0.08 & 0.06 \\
HCLG & 1 & - & 0.01 & - \\
HCLG:50SC & 1 & - & 0.02 & 0.01 \\
HCLG:50SD & 2 & 2 & 0.04 & 0.03 \\
\hline
\end{tabular}

The reserves provisioning cost differences were near the precision limit of the simulations (see Table 75). Although the cost differences were small in absolute terms, self-dispatching $50 \%$ of the coal fleet resulted in the reserves provisioning costs more than doubling for both the referencebased and high-coal simulations.

\subsection{Capacity Factor and Curtailment Effects}

The results for the capacity factors were straightforward. The effect of self-commitment was minimal; however, the effect of self-dispatch was significant (see Figure 66). Combined-cycle capacity factors were reduced between $13 \%$ and $45 \%$, and combustion turbine capacity factors increased by $220 \%$ and $325 \%$. 


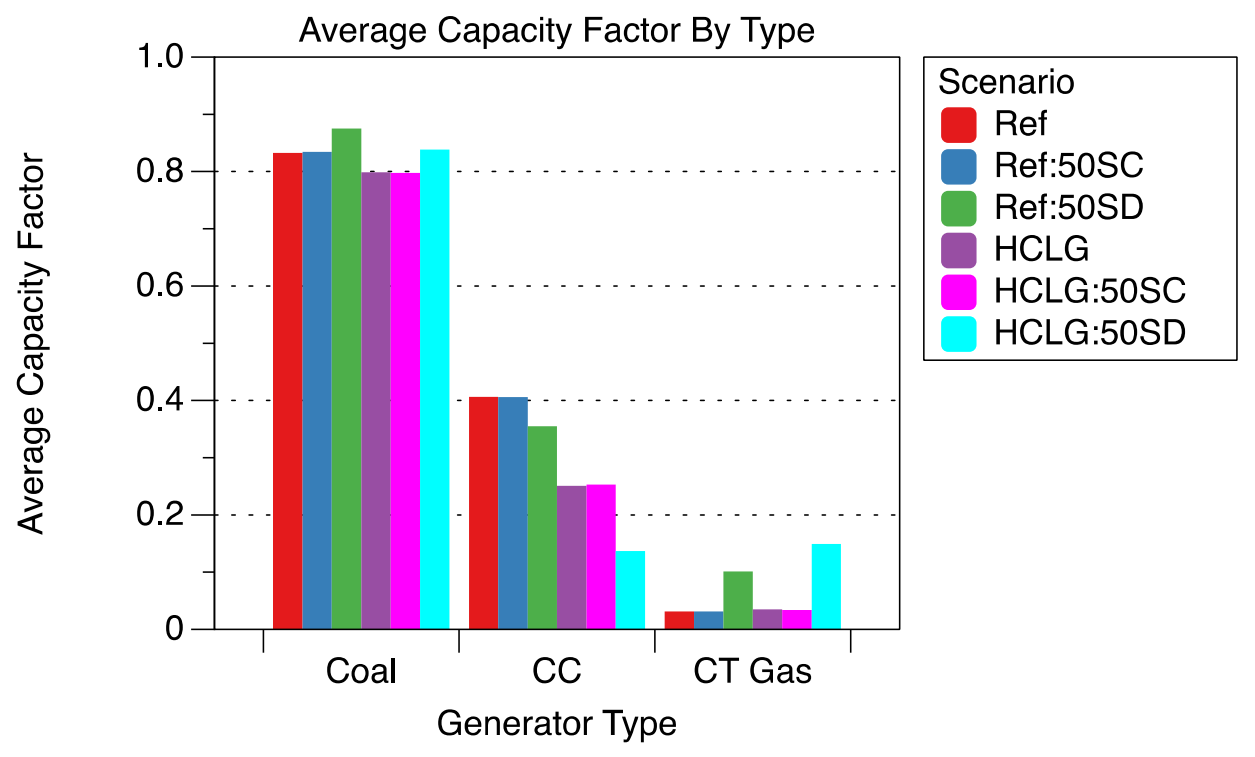

Figure 66. Self-scheduling simulations: average capacity factor by generator type

The trends for curtailment were also clear: curtailment decreased somewhat in the self-commitment runs and increased markedly in the self-dispatch runs. The highest curtailment was in the high-coal, self-dispatch case, in which curtailment almost doubled. Note that although the changes to curtailment were significant, the amount of variable generation was small in the self-scheduling simulations, so the dollar cost impact to the overall system was small.

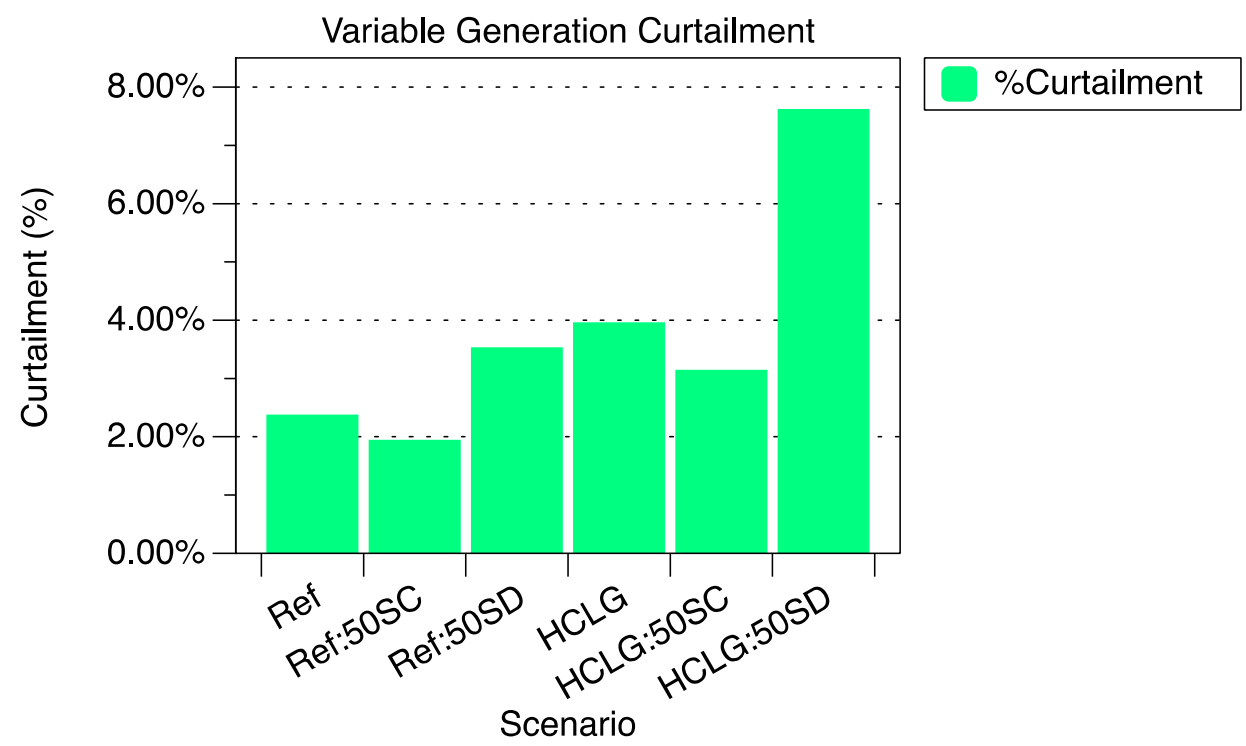

Figure 67. Self-scheduling simulations: variable generation curtailment 


\subsection{Self-Scheduling Conclusions}

This section summarizes the overall cost-related findings of the gas price experiments. The systemlevel cost impacts are summarized in Table 76. Note that only overall cost impacts are shown because no new generation was added to the system.

Table 76. Self-Scheduling Simulations: Cost Summaries per Unit of Overall System Generation

\begin{tabular}{ll} 
Topic & Subtopic \\
\hline Overall System Impacts & $\bullet$ Total Generation Costs \\
\\
\\
$\qquad$ Fuel Costs \\
\\
\\
\\
\\
\\
\\
\end{tabular}
Results Summary

Total generation costs were largely unchanged in the self-commitment simulations and increased noticeably in the self-dispatch simulations. In the selfcommitment simulations, costs increased by less than $0.1 \%(\$ 0.01 / \mathrm{MWh})$ in the reference-based simulation and decreased by less than $0.1 \%(\$ 0.01 / \mathrm{MWh})$ in the highcoal-based simulation. In the self-dispatch simulations, costs increased by $3 \%$ $(\$ 0.67 / \mathrm{MWh})$ in the reference-based simulation and by $6 \%(\$ 1.38 / \mathrm{MWh})$ in the high-coal-based simulation.

System-wide fuel costs were unchanged in the self-commitment runs and increased significantly in the self-dispatch simulations. In the self-dispatch simulations, costs increased by $3 \%(\$ 0.59 / \mathrm{MWh})$ in the reference-based simulation and by $6 \%$ (\$1.08/MWh) in the high-coal-based simulation.

Average cycling costs were minimally impacted by self-commitment and were markedly increased by self-dispatch. In the self-dispatch simulations, costs increased by $7 \%(\$ 0.06 / \mathrm{MWh})$ in the reference simulation and by $47 \%$ (\$0.26/MWh) in the high-coalbased simulation.

- VO\&M Costs

- Non-Fuel Operating Costs

VO\&M costs were mixed. Costs remained unchanged in the self-commitment runs and increased by $1 \%(\$ 0.02 / \mathrm{MWh})$ in the reference-based simulation and by $1 \%$ $(\$ 0.03 / \mathrm{MWh})$ in the high-coal-based simulation.

Non-fuel operating costs were largely unchanged in the self-commitment simulations and increased in the selfdispatch runs. In the self-commitment simulations, costs increased by $0.5 \%$ ( $\$ 0.01$ /MWh) in the reference simulation and decreased by $0.4 \%(\$ 0.01 / \mathrm{MWh})$ in the highcoal-based simulation. In the self-dispatch 


\begin{tabular}{|c|c|c|}
\hline Topic & Subtopic & Results Summary \\
\hline & & $\begin{array}{l}\text { simulations, costs increased by } 4 \% \\
(\$ 0.08 / \mathrm{MWh}) \text { in the reference simulation } \\
\text { and by } 12 \% \text { (\$0.30 /MWh) in the high-coal- } \\
\text { based simulation. }\end{array}$ \\
\hline Start Effects & - Start Costs & $\begin{array}{l}\text { Start costs were largely unchanged in the } \\
\text { self-commitment simulations and increased } \\
\text { markedly in the self-dispatch runs. In the } \\
\text { self-commitment simulations, costs } \\
\text { increased by } 3 \% \text { (\$0.01/MWh) in the } \\
\text { reference simulation and decreased by } 2 \% \\
\text { (\$0.01/MWh) in the high-coal-based } \\
\text { simulation. In the self-dispatch simulations, } \\
\text { costs increased by } 13 \% \text { (\$0.05/MWh) in the } \\
\text { reference simulation and by } 54 \% \\
\text { (\$0.26/MWh) in the high-coal-based } \\
\text { simulation. }\end{array}$ \\
\hline Ramp Effects & - Ramp Costs & $\begin{array}{l}\text { Average ramping costs were unchanged } \\
\text { except in the reference-based self-dispatch } \\
\text { scenario, in which they increased by } 25 \% \\
(\$ 0.0 .01 / \mathrm{MWh}) \text {. }\end{array}$ \\
\hline Reserves Effects & - Reserves Costs & $\begin{array}{l}\text { Reserves cost impacts were near the limits } \\
\text { of the simulations. Self-commitment impacts } \\
\text { were not significant; however, self-dispatch } \\
\text { increased costs by a factor of two or more. }\end{array}$ \\
\hline
\end{tabular}

Total generation and cycling costs were largely unchanged in the self-commitment simulations but increased significantly in the self-dispatch simulations. In the self-dispatch simulations, every cost metric showed an increase, with the largest an increase in the per-unit system-wide fuel cost of $\$ 1.08 / \mathrm{MWh}$ for the high-coal run. (Self-dispatch altered the generation mix, displacing combinedcycle units with combustion turbines.) Start-up costs also significantly increased: by $\$ 0.05 / \mathrm{MWh}$ $(13 \%)$ for the reference case and by $\$ 0.26 / \mathrm{MWh}$ (54\%) for the high-coal scenario.

Although self-commitment had minimal impact on the overall costs, it increased reserves costs by $26 \%$ to $57 \%$. Although these increases were not as large as those created by self-dispatch (reserves costs increased $250 \%-260 \%$ ), the cost increases were significant.

\subsubsection{Future Work}

Two potential areas for future work are investigating higher self-scheduling levels and examining whether the effects of self-scheduling are more pronounced in systems with higher penetration levels of variable generation.

First, in some balancing authority areas, self-scheduling is believed to have approached $80 \%$. At such levels, the impacts of self-scheduling on both cycling and reserves provisioning are likely to become more pronounced; however, it is unclear how much cycling and reserves provisioning costs increase at such levels of self-scheduling. Second, several balancing authority areas are quickly approaching penetration levels of variable generation of $20 \%$ with expectations of reaching $30 \%$ in 
the near future. Self-dispatch, in particular, is likely to negatively affect a system's ability to accommodate high levels of variable generation, and further study is necessary to characterize the interactions between self-scheduling and penetration levels of variable generation. 


\section{Results of the Gas Supply Experiments}

The final set of simulations was designed to investigate how well day-ahead natural gas orders matched actual production needs in high-penetration variable generation simulations. The study borrowed heavily from the variable generation study above (see Chapter 0), and it was based on these four simulation runs:

- Reference (Ref)-2\% wind

- Low-penetration variable generation (LPVG)-13\% wind

- Medium-penetration variable generation (MPVG)-5\% PV, 16\% wind

- High-penetration variable generation (HPVG)-11\% PV, 32\% wind.

Consideration was given to performing these studies as part of the production cost optimization; however, to perform such a study would require additional software development, so these experiments were conducted as ex post analyses of the variable generation experiments.

\subsection{Day-Ahead Production Forecasts Compared to Actual Production}

The gas demand forecasts, which were generated as a part of the day-ahead commitment simulations, were compared to the actual amount of gas that was required in the real-time economic dispatch simulations. The forecasts and actual consumption values were compared in two ways. First, the sum of the daily gas forecasts were compared to the annual gas consumption to see if there was any sort of bias in the gas forecast data (see Table 78).

Table 77. Annual Gas Forecast and Consumption (1,000,000 MMBtu)

\begin{tabular}{lrrr} 
Run Name & $\begin{array}{r}\text { Day-Ahead } \\
\text { Order Total }\end{array}$ & $\begin{array}{r}\text { Real-Time } \\
\text { Actual Total }\end{array}$ & Error \\
\hline Ref & 209 & 209 & $0.10 \%$ \\
LPVG & 170 & 170 & $0.35 \%$ \\
MPVG & 135 & 139 & $-2.29 \%$ \\
HPVG & 84 & 89 & $-5.76 \%$
\end{tabular}

As shown, a bias in natural gas orders was found in the forecasts for the higher penetration simulations; the day-ahead wind and solar forecasts, on average, overpredicted the amount of variable generation resource available in the higher penetration simulations, and, consequently, gas orders fell short. ${ }^{20}$ Part of the problem is because as penetration levels of variable generation increase, small absolute errors in the variable generation forecasts can lead to large percentage errors in the gas orders.

Next, simple daily gas use error values (e.g., forecast minus actuals) were calculated, and then these values were divided into bins, as shown in Table 78 .

\footnotetext{
${ }^{20}$ At higher penetrations, variable generation data (including forecasts) were synthesized, and it is appears that there was a bias in the method used to create this data.
} 
Table 78. Gas Order Percentage Error Bin Data (Days in Each Error Range)

\begin{tabular}{lrrrr} 
Error Bin & Ref & LPVG & MPVG & HPVG \\
\hline$-40 \%,-30 \%$ & 0 & 0 & 0 & 4 \\
$-30 \%,-20 \%$ & 0 & 4 & 5 & 7 \\
$-20 \%,-10 \%$ & 0 & 20 & 19 & 25 \\
$-10 \%, 0 \%$ & 195 & 163 & 122 & 62 \\
$0 \%, 10 \%$ & 170 & 153 & 146 & 130 \\
$10 \%, 20 \%$ & 0 & 21 & 50 & 80 \\
$20 \%, 30 \%$ & 0 & 2 & 16 & 37 \\
$30 \%, 40 \%$ & 0 & 1 & 5 & 12 \\
$40 \%, 50 \%$ & 0 & 0 & 2 & 3 \\
$50 \%, 60 \%$ & 0 & 1 & 0 & 4 \\
$60 \%, 70 \%$ & 0 & 0 & 0 & 1 \\
\hline Total & 365 & 365 & 365 & 365
\end{tabular}

The bin data were then grouped according to the magnitude of the errors, and this information was summarized in Table 79.

Table 79. Gas Order Percentage Error Summary

\begin{tabular}{lrrrr} 
Error Magnitude & Ref & LPVG & MPVG & HPVG \\
\hline$<10 \%$ Error & $100.0 \%$ & $86.6 \%$ & $73.4 \%$ & $52.6 \%$ \\
$10 \%-20 \%$ Error & $0.0 \%$ & $11.2 \%$ & $18.9 \%$ & $28.8 \%$ \\
$20 \%-30 \%$ Error & $0.0 \%$ & $1.6 \%$ & $5.8 \%$ & $12.1 \%$ \\
$>30 \%$ Error & $0.0 \%$ & $0.5 \%$ & $1.9 \%$ & $6.6 \%$
\end{tabular}

As shown in the table, the number of higher percentage errors increased with increasing variable generation, and the histograms below show how the error distributions changed with increasing distribution. Note that a contributing factor to the increase in the higher percentage errors in the simulations that had higher penetration levels of variable generation was that much less gas (less than half; see Table 77) was used in the higher penetration studies, so what was a 10\% error in the reference simulation became a $24 \%$ error in the high-penetration run. Although the aforementioned is a known problem when presenting errors in percentage terms, results are presented this way because gas purchase obligations are often linked to the expected amount of purchase. 


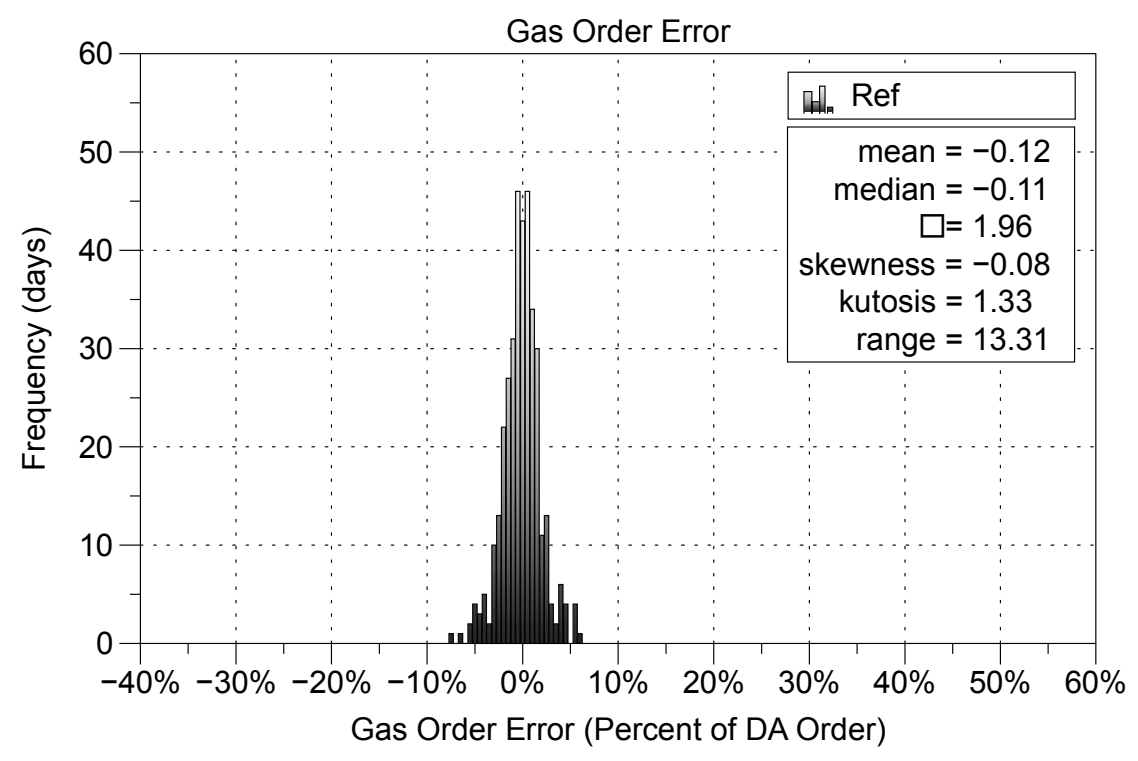

Figure 68. Histogram of gas order errors: ref scenario

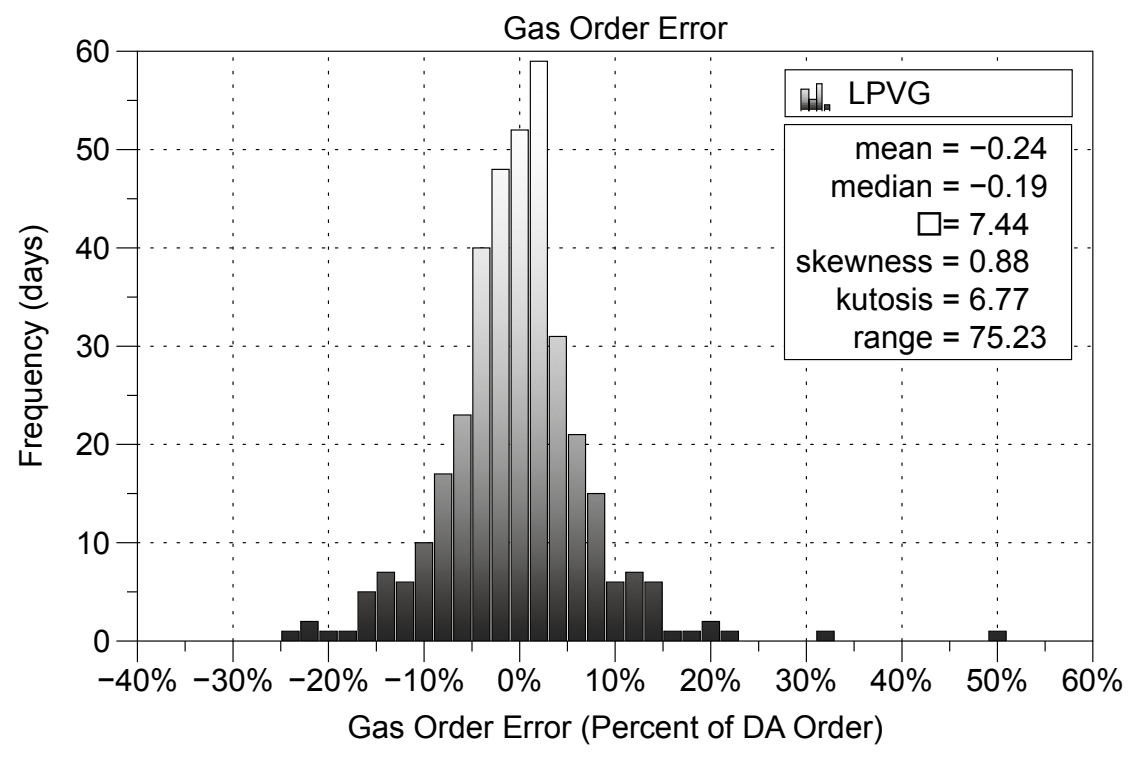

Figure 69. Histogram of gas order errors: LPVG scenario 


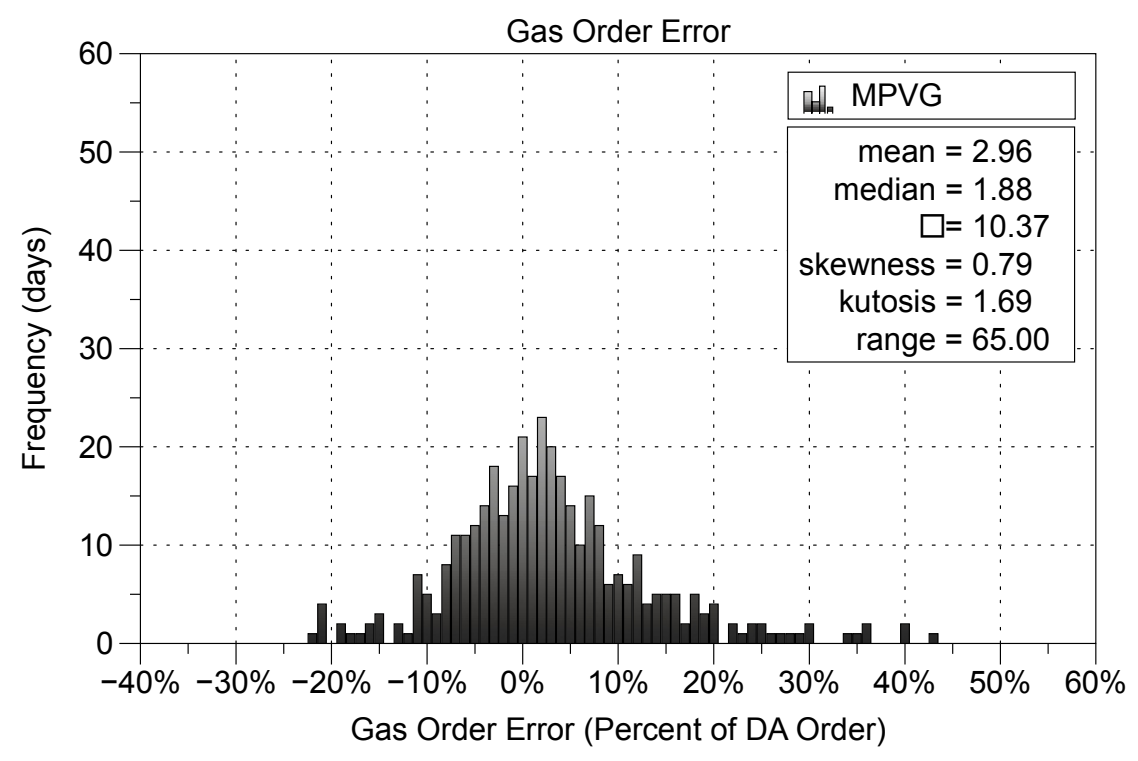

Figure 70. Histogram of gas order errors: MPVG scenario

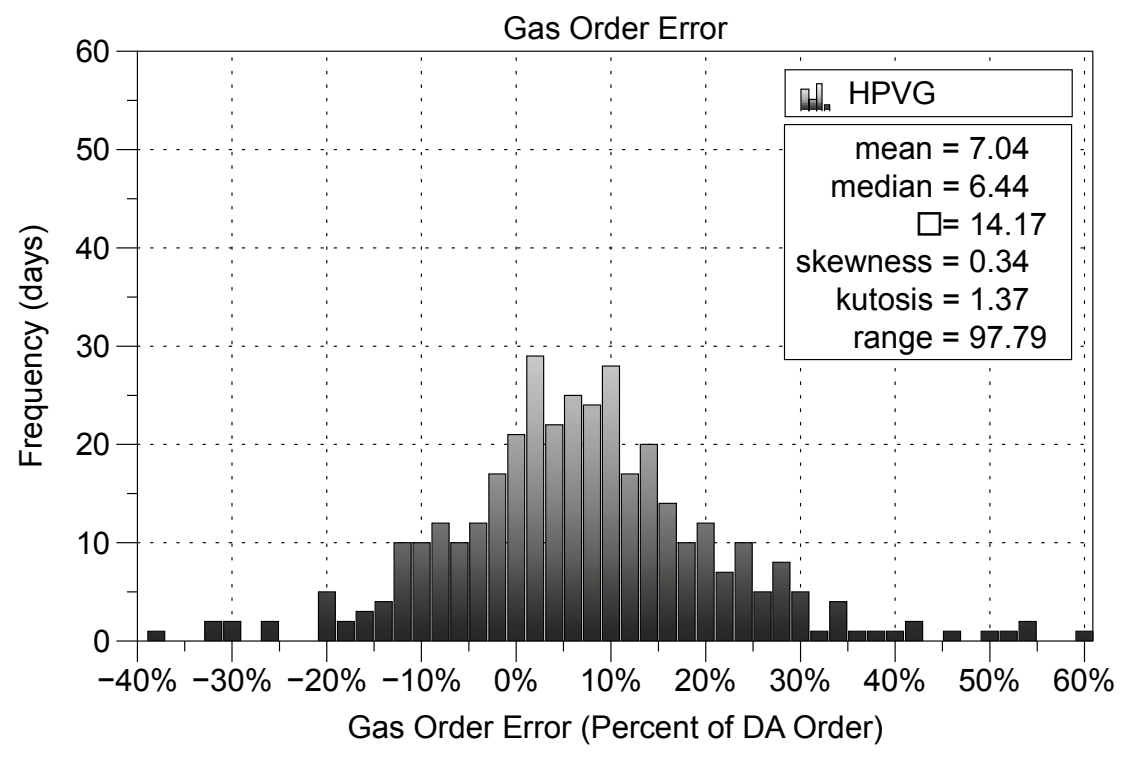

Figure 71. Histogram of gas order errors: HPVG scenario

As shown in the histograms, as the penetration of variable generation increased, the error distributions broadened, with occasional gas order errors exceeding 50\% in the highest penetration simulations.

\subsubsection{Future Work}

Given the increasing reliance on natural gas within the United States, two areas that should be explored further are rolling or cumulative errors and monthly or seasonal biases. Longer-term work could include the co-optimization of both electricity and natural gas networks along with an investigation of whether gas transport constraints will negatively impact electricity generation at high penetrations of natural gas. 


\section{Conclusions}

A detailed operational analysis was performed for seven sets of experiments:

- Variable generation

- Large conventional generation

- Generation mix

- Gas prices

- Fast-start generation

- Self-scheduling

- Gas supply constraints.

The experiments were conducted with PLEXOS production cost modeling software utilizing an updated version of the IEEE 118-bus test system overlaid with WECC-projected operating loads from SMUD, PSCO, and PSE in the year 2020. The test system was selected in consultation with an industry-based technical review committee to be a reasonable approximation of an interconnection yet small enough to allow the research team to investigate a large number of scenarios and sensitivity combinations. In each set of experiments, four components of integration costs were investigated: cycling costs, non-cycling VO\&M costs, fuel costs, and reserves provisioning costs.

Please note that the results below are reported in terms of overall system generation except when explicitly stated otherwise. This method of reporting differs from previous work (e.g., WWSIS-2) because those studies reported the amount of new generation added. However, because many of the scenarios in this study did not include new generation, this method of normalization was chosen to allow comparisons among scenarios. For those who would like to review results reported in terms of new generation added, please see the conclusions of the chapters on variable generation (Section 7.7.1) and large conventional generation (Section 8.7.1).

\subsection{Variable Generation Effects}

In the variable generation experiments, the addition of wind and solar PV was found to increase annual cycling costs to $\$ 0.13 / \mathrm{MWh}(29 \%)$ at low penetrations (13\% of the energy from variable generation) and $\$ 0.61 / \mathrm{MWh}(140 \%)$ at high penetrations ( $43 \%$ of the energy from variable generation). System-wide non-cycling VO\&M costs decreased between $\$ 0.15 / \mathrm{MWh}(9 \%)$ and $\$ 0.62 / \mathrm{MWh}(39 \%)$, with variable generation, which is less costly to maintain, displacing the more costly to maintain assets.

Fuel costs decreased with increasing variable generation, with costs decreasing by $\$ 7.77 / \mathrm{MWh}$ $(45 \%)$ at the highest penetration level of variable generation. Reserves provisioning costs rose with increasing penetration levels of variable generation, with costs more than doubling in the simulation with the highest penetration level of variable generation.

The overall findings were that the VO\&M cost savings offset the increased cycling costs, and there was little to no cost from a non-fuel operating cost perspective to adding variable generation to the system. At most penetrations, overall non-fuel operating costs actually decreased slightly with the addition of variable generation. 
Finally, to allow easy comparison to earlier studies, the following results are reported normalized by the amount of generation added to the system. Non-fuel operating cost impacts ranged between a decrease of $\$ 0.21 / \mathrm{MWh}$ and an increase of $\$ 0.07 / \mathrm{MWh}$. Overall generation costs decreased by $\$ 27.94 / \mathrm{MWh}$ of variable generation added in the low-penetration simulation and by $\$ 25.08 / \mathrm{MWh}$ of variable generation added in the high-penetration simulation.

\subsection{New Baseload Generation Effects}

Adding new baseload generation to the large conventional generation experiments increased cycling costs to between $\$ 0.04 / \mathrm{MWh}(9 \%)$ and $\$ 0.06 / \mathrm{MWh}(14 \%)$. System-wide non-cycling VO\&M costs increased by $\$ 0.17 / \mathrm{MWh}(40 \%)$ for both the flexible and inflexible unit additions. Fuel costs decreased by $\$ 1.27 / \mathrm{MWh}(6 \%)$ with the addition of the large, flexible generator and by $\$ 1.09 / \mathrm{MWh}$ $(5 \%)$ with the addition of the large, inflexible generator. Reserves provisioning costs dropped with the addition of a large, flexible generator and increased, albeit slightly, with the addition of a large, inflexible generator.

The overall findings were that the addition of new baseload generation increased the non-fuel operating costs by $\$ 0.23 / \mathrm{MWh}$ of system-wide generation (11\%) for the scenario with the addition of flexible baseload and by $\$ 0.21 / \mathrm{MWh}(10 \%)$ for the scenario with the addition of inflexible baseload.

To simplify comparisons to earlier studies and the variable generation results shown above, the following results are reported normalized by the amount of new, baseload generation added to the system. Non-fuel operating costs increased by $\$ 2.40 / \mathrm{MWh}$ of new, flexible baseload generation and by $\$ 2.00 / \mathrm{MWh}$ of new, inflexible baseload generation. Overall generation costs decreased by $\$ 11.12 / \mathrm{MWh}$ of new, flexible generation and $\$ 8.45 / \mathrm{MWh}$ of new, inflexible generation.

\subsection{Generation Mix Effects}

In the generation mix experiments, average cycling costs increased with increasing coal penetration. Costs in the low-coal scenario ( $15 \%$ coal) were reduced by $\$ 0.06 / \mathrm{MWh}(14 \%)$, and costs increased by $\$ 0.12 / \mathrm{MWh}(28 \%)$ in the high-coal $(65 \%$ coal) scenario. VO\&M costs also increased with increasing coal. The costs were reduced by $\$ 0.43 / \mathrm{MWh}(27 \%)$ in the low-coal scenario, and costs increased by $\$ 0.43 / \mathrm{MWh}(27 \%)$ in the high-coal scenario. Reserves provisioning costs were unaffected at the low-coal penetration and decreased by approximately half in the high-coal simulation.

Non-fuel marginal costs decreased in the low-coal scenario by $\$ 0.50 / \mathrm{MWh}(25 \%)$ and increased by $\$ 0.50 / \mathrm{MWh}(25 \%)$ in the high-coal scenario, with integration costs showing a high correlation to coal penetration.

\subsection{Gas Price Effects}

Cycling costs increased in the gas price experiments for both the low and high gas price scenarios. Costs increased by $\$ 0.03 / \mathrm{MWh}(7 \%)$ in the $\$ 2.50 / \mathrm{MMBtu}$ gas price scenario and by $\$ 0.12 / \mathrm{MWh}$ $(28 \%)$ in the $\$ 6.50 / \mathrm{MMBtu}$ gas price scenario. VO\&M costs decreased by $\$ 0.49 / \mathrm{MWh}(30 \%)$ at the low gas price, but they were largely unchanged at the high gas price, with a $\$ 0.01 / \mathrm{MWh}(1 \%)$ increase. Reserves provisioning costs changes were not significant among gas prices studied. 
The overall findings were that non-fuel operating costs increased with gas price. Costs were reduced by $\$ 0.46 / \mathrm{MWh}(23 \%)$ at the $\$ 2.50 / \mathrm{MMB}$ tu gas price and increased by $\$ 0.12 / \mathrm{MWh}(6 \%)$ at the $\$ 6.50 /$ MMBtu price.

\subsection{Fast-Start Generation Effects}

The cycling costs increased in the fast-start generation scenario, increasing by $\$ 0.40 / \mathrm{MWh}(93 \%)$. Conversely, VO\&M costs dropped by $\$ 0.04 / \mathrm{MWh}(2.5 \%)$. Reserves provisioning costs decreased by $\$ 0.01 / \mathrm{MWh}(56 \%)$. Overall, non-fuel operating costs increased by $\$ 0.35 / \mathrm{MWh}(17 \%)$. Reserves provisioning costs decreased in the fast-start generation simulation by approximately half.

The overall findings were that non-fuel operating costs increased in the fast-start generation simulation by $\$ 0.35 / \mathrm{MWh}(17 \%)$; however, these cost increases were offset by fuel savings. The overall generation costs differences were not significant.

\subsection{Self-Scheduling Effects}

Self-scheduling effects varied by type. At the reference coal (40\%) penetrations, self-commitment increased cycling costs by $\$ 0.01 / \mathrm{MWh}(2 \%)$, whereas self-dispatch increased costs by $\$ 0.06 / \mathrm{MWh}$ (14\%). At high coal (65\%) penetrations, cycling costs decreased by $\$ 0.01 / \mathrm{MWh}(2 \%)$ in the selfcommitment simulation and increased $\$ 0.26 / \mathrm{MWh}(47 \%)$ during self-dispatch. VO\&M costs were unchanged in the self-commitment simulations and increased $\$ 0.02 / \mathrm{MWh}(1 \%)$ and $\$ 0.03 / \mathrm{MWh}$ $(1 \%)$ in the reference- and high-coal simulations. Reserves provisioning costs increased in all selfscheduling scenarios.

For the self-commitment simulations, costs increased $\$ 0.01 / \mathrm{MWh}(26 \%)$ for the reference coal simulation and $\$ 0.01 / \mathrm{MWh}(60 \%)$ in the high-coal simulation. In the self-dispatch simulations, reserves provisioning costs increased $\$ 0.06 / \mathrm{MWh}(260 \%)$ for the reference-coal simulation and $\$ 0.03 / \mathrm{MWh}(250 \%)$ in the high-coal simulation.

The overall findings were that non-fuel operating cost results for the self-scheduling simulations also varied by type. Self-commitment incremental cost differences were not significant; however, self-dispatching $50 \%$ of the coal fleet increased costs by $\$ 0.08 / \mathrm{MWh}(4 \%)$ at low coal penetrations and by $\$ 0.30 / \mathrm{MWh}(12 \%)$ at high coal penetrations.

\subsection{Gas Supply Effects}

The gas supply experiments differed because they were not a study of costs but rather of how dayahead gas orders differed from actual gas use. The findings of the study were that the differences between the day-ahead orders and actual gas use increased with penetration levels of variable generation. At the lower penetrations (13\% variable generation), less than $1 \%$ of the differences were greater than $30 \%$. At the higher penetrations (43\% variable generation), the day-ahead orders and actual use differences were greater than $20 \%$ more than $19 \%$ of the time and greater than $30 \%$ for more than $6 \%$ of the year.

\subsection{Closing and Future Work}

Based on the above findings, we suggest three areas for future work: (1) an assessment of how differing types of integration costs affect both the system and its various generator classes, (2) further investigation into how dispatch schemes impact operational costs at high variable generation 
penetration levels, and (3) the development of a better understanding of the effect of gas order errors on system operations.

Increases in cycling costs can happen for very different reasons. In some cases, such as fast-start generation, increased cycling costs were traded for fuel use reductions, with the overall system costs decreasing because the fuel cost savings were greater than the cycling cost increases. In other situations, such as self-dispatch, increased cycling costs led to increased overall system costs because reducing a coal fleet's flexibility increased its fuel use. Further investigation is suggested to better understand the nature of cycling costs impacts.

Self-dispatching negatively impacted integration costs even at moderate self-dispatching levels $(50 \%)$ and in the effective absence $(<2 \%)$ of variable generation. Additional work is suggested to develop a better understanding of the interrelationship between system flexibility and variable generation penetration.

Finally, the finding that gas order errors increased markedly with increasing variable generation penetration, especially given the recent reports of gas shortages in California, ${ }^{21}$ suggests that a better understanding of the relationship between variable generation penetration and natural gas use is needed.

\footnotetext{
${ }^{21}$ See http://www.argusmedia.com/News/Article?id=1069150\&sector=POWER\&region=ALLREGION.
} 


\section{References}

3Tier. 2010. Development of Regional Wind Resource and Wind Plant Output Data Sets. (Technical Report). NREL/SR-550-47676. Golden, CO: NREL. Accessed January 2013: www.nrel.gov/docs/fy10osti/47676.pdf.

Hummon, M., E. Ibanez, G. Brinkman, and D. Lew, D. 2012. "Sub-Hour Solar Data for Power System Modeling From Static Spatial Variability Analysis: Preprint.” Prepared for the 2nd International Workshop on Integration of Solar Power into Power Systems, November 12-13, Lisbon, Portugal. NREL/CP-6A20-56204. Golden, CO: NREL. 9 pp. Accessed January 2013: www.nrel.gov/docs/fy13osti/56204.pdf.

IIT. 2013. "Index of Data Illinois Institute of Technology.” Accessed January 2013: motor.ece.iit.edu/data/.

Kumar, N., P. Besuner, S. Lefton, D. Agan, and D. Hilleman. 2012. Power Plant Cycling Costs. (Technical Report). NREL/SR-5500-55433. Work performed by Intertek-APTECH, Sunnyvale, California. Golden, CO: NREL. Accessed January 2013: www.nrel.gov/docs/fy12osti/55433.pdf.

Lew, D., G. Brinkman, E. Ibanez, A. Florita, M. Heaney, B. Hodge, M. Hummon, and G. Stark. 2013. The Western Wind and Solar Integration Study Phase 2. NREL/TP-5500-55588. Golden, CO: NREL.

Milligan, M., B. Kirby, H. Holttinen, J. Kiviluoma, A. Estanqueiro, S. Martin- Martinez, E. GomezLazaro, I. Peneda, and C. Smith. 2013. Wind Integration Cost and Cost-Causation. (Technical Report). Golden, CO: NREL. Accessed 2013: http://www.nrel.gov/docs/fy14osti/60411.pdf.

Perez, R. 2002. “Time-Specific Irradiances Derived From Geostationary Satellite Images.” Journal of Solar Energy Engineering-Transactions of the ASME 124(1): 1-1.

Perez, R., P. Ineichen, K. Moore, M. Kmiecik, C. Chain, R. George, and F. Vignola, F. 2002. “A New Operational Satellite-to-Irradiance Model.” Solar Energy 75(5): 307-317.

Potter, C., H. Gil, and J. McCaa. 2007. "Wind Power Data for Grid Integration Studies." IEEE Power Engineering Society General Meeting Proceedings, June 24-28, Tampa, Florida.

Potter, C., D. Lew, J. McCaa, S. Cheng, S. Eichelberger, and E. Grimit, E. 2008. "Creating the Dataset for the Western Wind and Solar Integration Study." Wind Engineering 32(4). Accessed January 2013: http://dx.doi.org/10.1260/0309-524X.32.4.325.

WECC. 2011. Assumptions Matrix for the 2020 TEPPC Dataset. Accessed January 2013: www.wecc.biz/library/StudyReport/Documents/Assumptions\%20Matrix\%20for\%20the\%202020 $\% 20$ TEPPC\%20Dataset.pdf. 


\section{Appendix A. NREL IEEE 118-Bus Test System}

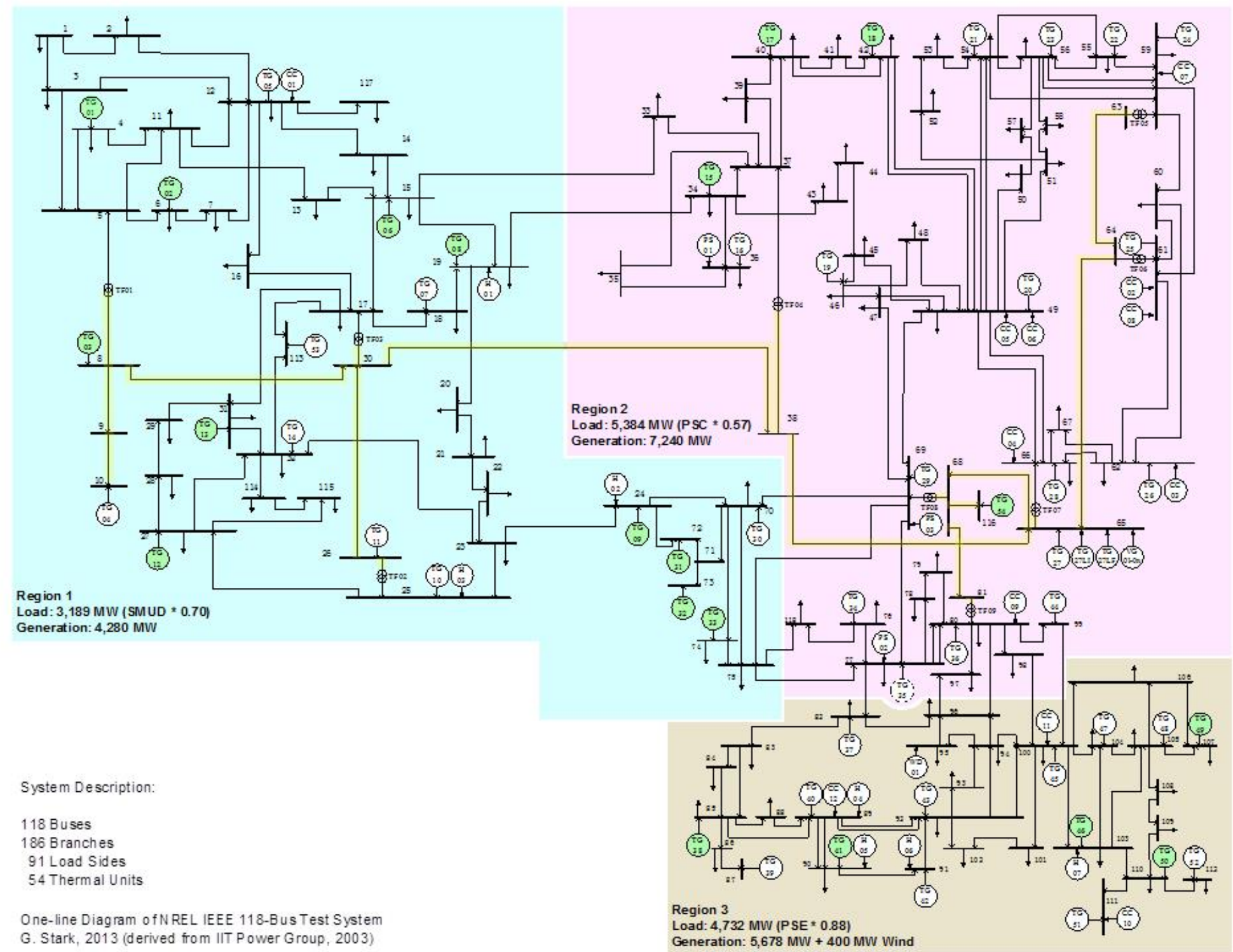




\section{Appendix B. Monthly Natural Gas Prices}

Table B-1. Monthly Natural Gas Price Multipliers

\begin{tabular}{lr} 
Time Period & Multiplier \\
\hline January & 1.1370 \\
February & 1.1338 \\
March & 1.1051 \\
April & 0.9544 \\
May & 0.9338 \\
June & 0.9381 \\
July & 0.9423 \\
August & 0.9465 \\
September & 0.9433 \\
October & 0.9467 \\
November & 0.9946 \\
December & 1.0244 \\
\hline
\end{tabular}




\section{Appendix C. Fuel Costs by Generator Type}

Table C-1. Variable Generation Simulations: Average Fuel Costs by Generator Type (\$/MWh)

\begin{tabular}{lrrrrrrr} 
Type & Ref & LPVG & LPVG:IR & MPVG & HPVG & HPVG:HGP & HPVG:Ret \\
\hline Coal & 18.80 & 18.79 & 18.79 & 18.78 & 18.75 & 18.77 & 18.54 \\
CC & 31.69 & 31.46 & 31.47 & 31.48 & 30.97 & 44.84 & 31.12 \\
CT Gas & 56.01 & 57.03 & 56.97 & 56.89 & 56.81 & 81.99 & 56.88 \\
\hline Wt. Avg. & 22.60 & 19.52 & 19.51 & 17.26 & 12.33 & 14.83 & 12.93
\end{tabular}

Table C-2. Large Conventional Generation Simulations: Average Fuel Costs by Generator Type (\$/MWh)

\begin{tabular}{lrrrrr} 
Type & Ref & LFUA & LFUA:IR & LIUA & LIUA:IR \\
\hline Coal & 18.80 & 18.64 & 18.64 & 18.63 & 18.63 \\
CC & 31.69 & 31.70 & 31.69 & 31.70 & 31.70 \\
CT Gas & 56.01 & 55.90 & 56.50 & 56.20 & 56.52 \\
\hline Wt. Avg. & 22.60 & 21.33 & 23.16 & 21.51 & 23.37
\end{tabular}

Table C-3. Generation Mix Simulations: Average Fuel Costs by Generator Type (\$/MWh)

\begin{tabular}{lrrr} 
Type & LCHG & Ref & HCLG \\
\hline Coal & 19.69 & 18.80 & 18.49 \\
CC & 28.96 & 31.69 & 31.65 \\
CT Gas & 56.12 & 56.01 & 56.67 \\
\hline Wt. Avg. & 24.40 & 22.60 & 19.24
\end{tabular}

Table C-4. Gas Price Simulations: Average Fuel Costs by Generator Type (\$/MWh)

\begin{tabular}{lrrr} 
Type & Ref:LGP & Ref & Ref:HGP \\
\hline Coal & 18.28 & 18.80 & 18.81 \\
CC & 17.51 & 31.69 & 45.80 \\
CT Gas & 30.83 & 56.01 & 80.63 \\
\hline Wt. Avg. & 15.78 & 22.60 & 29.04
\end{tabular}

Table C-5. Fast-Start Generation Simulations: Average Fuel Costs by Generator Type (\$/MWh)

\begin{tabular}{lrr} 
Type & Ref & Ref:FSG \\
\hline CC & 31.69 & 31.43 \\
Coal & 18.80 & 18.66 \\
CT Gas & 56.01 & 56.79 \\
\hline Wt. Avg. & 22.60 & 22.35
\end{tabular}


Table C-6. Self-Scheduling Simulations: Average Fuel Costs by Generator Type (\$/MWh)

\begin{tabular}{lrrrrrr} 
Type & Ref & Ref:50SC & Ref:50SD & HCLG & HCLG:50SC & HCLG:50SD \\
\hline Coal & 18.80 & 18.80 & 18.77 & 18.49 & 18.49 & 18.45 \\
CC & 31.69 & 31.70 & 31.70 & 31.65 & 31.61 & 31.77 \\
CT Gas & 56.01 & 55.90 & 56.33 & 56.67 & 56.92 & 56.52 \\
\hline Wt. Avg. & 22.60 & 22.60 & 23.19 & 19.24 & 19.23 & 20.32
\end{tabular}




\section{Appendix D. VO\&M Costs by Generator Type}

Table D-1. Variable Generation Simulations: Average VO\&M Costs by Generator Type (\$/MWh)

\begin{tabular}{lrrrrrrr} 
Type & Ref & LPVG & LPVG:IR & MPVG & HPVG & HPVG:HGP & HPVG:Ret \\
\hline Coal & 2.74 & 2.74 & 2.74 & 2.74 & 2.73 & 2.74 & 2.72 \\
CC & 1.02 & 1.02 & 1.02 & 1.02 & 1.02 & 1.02 & 1.02 \\
CT Gas & 0.57 & 0.57 & 0.57 & 0.57 & 0.57 & 0.57 & 0.57 \\
\hline Wt. Avg. & 1.61 & 1.46 & 1.46 & 1.36 & 0.99 & 1.02 & 0.89
\end{tabular}

Table D-2. Large Conventional Generation Simulations: Average VO\&M Costs by Generator Type (\$/MWh)

\begin{tabular}{lrrrrr} 
Type & Ref & LFUA & LFUA:IR & LIUA & LIUA:IR \\
\hline Coal & 2.74 & 2.78 & 2.78 & 2.78 & 2.78 \\
CC & 1.02 & 1.02 & 1.02 & 1.02 & 1.02 \\
CT Gas & 0.57 & 0.57 & 0.57 & 0.57 & 0.57 \\
\hline Wt. Avg. & 1.61 & 1.78 & 1.72 & 1.78 & 1.73
\end{tabular}

Table D-3. Generation Mix Simulations: Average VO\&M Costs by Generator Type (\$/MWh)

\begin{tabular}{lrrr} 
Type & LCHG & Ref & HCLG \\
\hline Coal & 2.82 & 2.74 & 2.75 \\
CC & 1.03 & 1.02 & 1.02 \\
CT Gas & 0.57 & 0.57 & 0.57 \\
\hline Wt. Avg. & 1.18 & 1.61 & 2.04
\end{tabular}

Table D-4. Gas Price Simulations: Average VO\&M Costs by Generator Type (\$/MWh)

\begin{tabular}{lrrr} 
Type & Ref:LGP & Ref & Ref:HGP \\
\hline Coal & 2.69 & 2.74 & 2.74 \\
CC & 1.04 & 1.02 & 1.02 \\
CT Gas & 0.57 & 0.57 & 0.57 \\
\hline Wt. Avg. & 1.12 & 1.61 & 1.62
\end{tabular}

Table D-5. Fast-Start Generation Simulations: Average VO\&M Costs by Generator Type (\$/MWh)

\begin{tabular}{lrr} 
Type & Ref & Ref:FSG \\
\hline Coal & 2.74 & 2.73 \\
CC & 1.02 & 1.02 \\
CT Gas & 0.57 & 0.57 \\
\hline Wt. Avg. & 1.61 & 1.57
\end{tabular}


Table D-6. Self-Scheduling Simulations: Average VO\&M Costs by Generator Type (\$/MWh)

\begin{tabular}{lrrrrrr} 
Type & Ref & Ref:50SC & Ref:50SD & HCLG & HCLG:50SC & HCLG:50SD \\
\hline Coal & 2.74 & 2.74 & 2.74 & 2.75 & 2.75 & 2.75 \\
CC & 1.02 & 1.03 & 1.02 & 1.02 & 1.02 & 1.02 \\
CT Gas & 0.57 & 0.57 & 0.57 & 0.57 & 0.57 & 0.57 \\
\hline Wt. Avg. & 1.61 & 1.61 & 1.63 & 2.04 & 2.04 & 2.07
\end{tabular}




\section{Appendix E. Study-Wide Production Cost Comparisons}

This section provides comparisons among all simulation types to easily review the various results of the integration cost experiments.

Table E-1 provides a list of the scenarios ranked according to their generation costs. The list at the top of the table provides the scenarios that were compared to the reference scenario, and the list at the bottom of the table provides the scenarios that were compared to the high-coal, low-gas scenario.

Table E-1. Total Generation Costs for All Simulations

\begin{tabular}{|c|c|c|c|c|c|}
\hline Scenario & Basis & $\begin{array}{l}\text { Total Generation } \\
\text { Costs }(\$ 000,000)\end{array}$ & $\begin{array}{r}\Delta \text { Total } \\
\text { Generation } \\
\text { Costs } \\
(\$ 000,000) \\
\end{array}$ & $\$ / M W h$ & $\Delta \$ / \mathrm{MWh}$ \\
\hline HPVG & Ref & $\$ 921$ & $\$(660)$ & $\$ 14.36$ & $\$(10.28)$ \\
\hline HPVG:Ret & Ref & $\$ 957$ & $\$(623)$ & $\$ 14.92$ & $\$(9.72)$ \\
\hline HPVG:HGP & Ref & $\$ 1,091$ & $\$(489)$ & $\$ 17.01$ & $\$(7.63)$ \\
\hline Ref:LGP & Ref & $\$ 1,113$ & $\$(467)$ & $\$ 17.35$ & $\$(7.28)$ \\
\hline MPVG & Ref & $\$ 1,239$ & $\$(342)$ & $\$ 19.31$ & $\$(5.33)$ \\
\hline LPVG:Flex & Ref & $\$ 1,380$ & $\$(200)$ & $\$ 21.51$ & $\$(3.12)$ \\
\hline LPVG & Ref & $\$ 1,381$ & $\$(199)$ & $\$ 21.53$ & $\$(3.11)$ \\
\hline HCLG & Ref & $\$ 1,400$ & $\$(180)$ & $\$ 21.83$ & $\$(2.81)$ \\
\hline LFUA & Ref & $\$ 1,514$ & $\$(67)$ & $\$ 23.59$ & $\$(1.05)$ \\
\hline LIUA & Ref & $\$ 1,524$ & $\$(56)$ & $\$ 23.76$ & $\$(0.88)$ \\
\hline Ref & Ref & $\$ 1,581$ & $\$-$ & $\$ 24.64$ & $\$-$ \\
\hline Ref:50SC & Ref & $\$ 1,582$ & $\$ 1$ & $\$ 24.65$ & $\$ 0.02$ \\
\hline Ref:FSG & Ref & $\$ 1,587$ & $\$ 7$ & $\$ 24.74$ & $\$ 0.10$ \\
\hline Ref:50SD & Ref & $\$ 1,624$ & $\$ 43$ & $\$ 25.31$ & $\$ 0.67$ \\
\hline LFUA:IR & Ref & $\$ 1,625$ & $\$ 45$ & $\$ 25.34$ & $\$ 0.70$ \\
\hline LIUA:IR & Ref & $\$ 1,640$ & $\$ 60$ & $\$ 25.57$ & $\$ 0.93$ \\
\hline LCHG & Ref & $\$ 1,664$ & $\$ 84$ & $\$ 25.94$ & $\$ 1.30$ \\
\hline \multirow[t]{2}{*}{ Ref:HGP } & Ref & $\$ 2,001$ & $\$ 421$ & $\$ 31.20$ & $\$ 6.56$ \\
\hline & Basis & $\begin{array}{c}\text { Total Generation } \\
\text { Costs }(\$ 000,000)\end{array}$ & $\begin{array}{r}\Delta \text { Total } \\
\text { Generation } \\
\text { Costs } \\
(\$ 000,000) \\
\end{array}$ & $\$ / M W h$ & $\Delta \$ / M W h$ \\
\hline HCLG:50SC & HCLG & $\$ 1,399$ & $\$(1)$ & $\$ 23.28$ & $\$ 1.45$ \\
\hline HCLG & HCLG & $\$ 1,400$ & $\$-$ & $\$ 21.83$ & $\$-$ \\
\hline HCLG:50SD & HCLG & $\$ 1,534$ & $\$ 134$ & $\$ 23.92$ & $\$ 2.09$ \\
\hline
\end{tabular}


The fuel costs for the experiments are shown in Table E-2. As expected, the scenarios that had the highest levels of variable generation had the lowest fuel costs. Of interest is how changes in operational acts in identical systems (e.g., Ref and Ref:50SD, in which the only difference between the simulations is whether machines were self-dispatched) can affect system fuel costs.

Table E-2. Fuel Costs for All Simulations

\begin{tabular}{|c|c|c|c|c|c|}
\hline Scenario & Basis & $\begin{array}{r}\text { Fuel Costs } \\
(\$ 000,000)\end{array}$ & $\begin{array}{r}\Delta \text { Fuel Costs } \\
(\$ 000,000)\end{array}$ & \$/MWh & $\Delta \$ / M W h$ \\
\hline HPVG & Ref & $\$ 791$ & (\$659) & $\$ 12.33$ & $\$(10.26)$ \\
\hline HPVG:Ret & Ref & $\$ 830$ & $(\$ 620)$ & $\$ 12.93$ & $\$(9.67)$ \\
\hline HPVG:HGP & Ref & $\$ 952$ & $(\$ 498)$ & $\$ 14.83$ & $\$(7.77)$ \\
\hline Ref:LGP & Ref & $\$ 1,012$ & $(\$ 438)$ & $\$ 15.78$ & $\$(6.82)$ \\
\hline MPVG & Ref & $\$ 1,107$ & $(\$ 343)$ & $\$ 17.25$ & $\$(5.34)$ \\
\hline HCLG & Ref & $\$ 1,235$ & $(\$ 215)$ & $\$ 19.24$ & $\$(3.35)$ \\
\hline LPVG:Flex & Ref & $\$ 1,252$ & (\$198) & $\$ 19.51$ & $\$(3.09)$ \\
\hline LPVG & Ref & $\$ 1,252$ & (\$198) & $\$ 19.52$ & $\$(3.08)$ \\
\hline LFUA & Ref & $\$ 1,368$ & $(\$ 82)$ & $\$ 21.33$ & $\$(1.27)$ \\
\hline LIUA & Ref & $\$ 1,380$ & $(\$ 70)$ & $\$ 21.51$ & $\$(1.09)$ \\
\hline Ref:FSG & Ref & $\$ 1,434$ & $(\$ 16)$ & $\$ 22.35$ & $\$(0.25)$ \\
\hline Ref & Ref & $\$ 1,450$ & $\$-$ & $\$ 22.60$ & $\$-$ \\
\hline Ref:50SC & Ref & $\$ 1,450$ & $\$ 0$ & $\$ 22.60$ & $\$ 0.00$ \\
\hline LFUA:IR & Ref & $\$ 1,486$ & $\$ 36$ & $\$ 23.16$ & $\$ 0.56$ \\
\hline Ref:50SD & Ref & $\$ 1,488$ & $\$ 38$ & $\$ 23.19$ & $\$ 0.60$ \\
\hline LIUA:IR & Ref & $\$ 1,499$ & $\$ 49$ & $\$ 23.37$ & $\$ 0.77$ \\
\hline LCHG & Ref & $\$ 1,565$ & $\$ 115$ & $\$ 24.40$ & $\$ 1.80$ \\
\hline Ref:HGP & Ref & $\$ 1,863$ & $\$ 413$ & $\$ 29.04$ & $\$ 6.44$ \\
\hline Scenario & Basis & $\begin{array}{l}\text { Fuel Costs } \\
(\$ 000,000)\end{array}$ & $\begin{array}{r}\Delta \text { Fuel Costs } \\
(\$ 000,000)\end{array}$ & \$/MWh & $\Delta \$ / M W h$ \\
\hline HCLG:50SC & HCLG & $\$ 1,234$ & (\$1) & $\$ 19.23$ & $\$(0.01)$ \\
\hline HCLG & HCLG & $\$ 1,235$ & $\$-$ & $\$ 19.24$ & $\$-$ \\
\hline HCLG:50SD & HCLG & $\$ 1,307$ & $\$ 73$ & $\$ 20.38$ & $\$ 1.14$ \\
\hline
\end{tabular}

The simulations in the self-scheduling experiments were all based on the same underlying system (the reference scenario); however, changes in operational approach caused a $\$ 38$ million spread (a $\$ 0.60 / \mathrm{MWh}$ difference) in the amount of money spent on fuel. 
The cycling costs for all the integration cost scenarios are shown in Table E-3. As expected, the scenarios that had highest penetration levels of variable generation had the highest cycling costs. Also of note is how changes in generation mix affected cycling costs. (The low-coal simulation had the lowest overall cycling costs, whereas the high-coal simulation had considerably higher costs.)

Table E-3. Cycling Costs for All Simulations

\begin{tabular}{|c|c|c|c|c|c|}
\hline Scenario & Basis & $\begin{array}{r}\text { Cycling Costs } \\
(\$ 000,000)\end{array}$ & $\begin{array}{r}\Delta \text { Cycling Costs } \\
(\$ 000,000)\end{array}$ & \$/MWh & $\Delta \$ / M W h$ \\
\hline LCHG & Ref & $\$ 24$ & (\$4) & $\$ 0.37$ & $\$(0.06)$ \\
\hline Ref & Ref & $\$ 28$ & $\$-$ & $\$ 0.43$ & $\$-$ \\
\hline Ref:50SC & Ref & $\$ 28$ & $\$ 1$ & $\$ 0.44$ & $\$ 0.01$ \\
\hline LFUA:IR & Ref & $\$ 29$ & $\$ 1$ & $\$ 0.45$ & $\$ 0.02$ \\
\hline Ref:LGP & Ref & $\$ 29$ & $\$ 2$ & $\$ 0.46$ & $\$ 0.02$ \\
\hline LIUA & Ref & $\$ 30$ & $\$ 2$ & $\$ 0.46$ & $\$ 0.03$ \\
\hline LIUA:IR & Ref & $\$ 30$ & $\$ 2$ & $\$ 0.46$ & $\$ 0.03$ \\
\hline LFUA & Ref & $\$ 31$ & $\$ 3$ & $\$ 0.49$ & $\$ 0.05$ \\
\hline Ref:50SD & Ref & $\$ 32$ & $\$ 4$ & $\$ 0.49$ & $\$ 0.06$ \\
\hline Ref:HGP & Ref & $\$ 35$ & $\$ 7$ & $\$ 0.54$ & $\$ 0.11$ \\
\hline HCLG & Ref & $\$ 35$ & $\$ 7$ & $\$ 0.55$ & $\$ 0.11$ \\
\hline LPVG:Flex & Ref & $\$ 35$ & $\$ 7$ & $\$ 0.55$ & $\$ 0.11$ \\
\hline LPVG & Ref & $\$ 36$ & $\$ 8$ & $\$ 0.56$ & $\$ 0.12$ \\
\hline MPVG & Ref & $\$ 45$ & $\$ 17$ & $\$ 0.70$ & $\$ 0.26$ \\
\hline Ref:FSG & Ref & $\$ 53$ & $\$ 25$ & $\$ 0.82$ & $\$ 0.39$ \\
\hline HPVG & Ref & $\$ 66$ & $\$ 39$ & $\$ 1.04$ & $\$ 0.60$ \\
\hline HPVG:Ret & Ref & $\$ 71$ & $\$ 43$ & $\$ 1.10$ & $\$ 0.67$ \\
\hline HPVG:HGP & Ref & $\$ 74$ & $\$ 47$ & $\$ 1.16$ & $\$ 0.73$ \\
\hline Scenario & Basis & $\begin{array}{r}\text { Cycling Costs } \\
(\$ 000,000)\end{array}$ & $\begin{array}{r}\Delta \text { Cycling Costs } \\
(\$ 000,000)\end{array}$ & \$/MWh & $\Delta \$ / M W h$ \\
\hline HCLG:50SC & $\mathrm{HCLG}$ & $\$ 35$ & (\$0) & $\$ 0.54$ & $\$(0.00)$ \\
\hline HCLG & HCLG & $\$ 35$ & $\$-$ & $\$ 0.55$ & $\$-$ \\
\hline HCLG:50SD & $\mathrm{HCLG}$ & $\$ 52$ & $\$ 17$ & $\$ 0.82$ & $\$ 0.27$ \\
\hline
\end{tabular}


The simulations that had the highest penetration levels of variable generation had some of the lowest overall VO\&M costs (see Table E-4). These cost decreases were due to the avoided maintenance costs of the generation that the variable generation displaced.

Table E-4. VO\&M Costs for All Simulations

\begin{tabular}{|c|c|c|c|c|c|}
\hline Scenario & Basis & $\begin{array}{r}\text { VO\&M Costs } \\
(\$ 000,000)\end{array}$ & $\begin{array}{r}\Delta V O \& M \text { Costs } \\
(\$ 000,000)\end{array}$ & $\$ / M W h$ & $\Delta \$ / M W h$ \\
\hline HPVG:Ret & Ref & $\$ 57$ & $(\$ 46)$ & $\$ 0.89$ & $\$(0.72)$ \\
\hline HPVG & Ref & $\$ 63$ & $(\$ 40)$ & $\$ 0.99$ & $\$(0.62)$ \\
\hline HPVG:HGP & Ref & $\$ 65$ & $(\$ 38)$ & $\$ 1.02$ & $\$(0.59)$ \\
\hline Ref:LGP & Ref & $\$ 72$ & $(\$ 31)$ & $\$ 1.12$ & $\$(0.49)$ \\
\hline LCHG & Ref & $\$ 75$ & $(\$ 28)$ & $\$ 1.18$ & $\$(0.43)$ \\
\hline MPVG & Ref & $\$ 87$ & $(\$ 16)$ & $\$ 1.36$ & $\$(0.25)$ \\
\hline LPVG:Flex & Ref & $\$ 94$ & $(\$ 10)$ & $\$ 1.46$ & $\$(0.15)$ \\
\hline LPVG & Ref & $\$ 94$ & (\$9) & $\$ 1.46$ & $\$(0.15)$ \\
\hline Ref:FSG & Ref & $\$ 101$ & $(\$ 2)$ & $\$ 1.57$ & $\$(0.04)$ \\
\hline Ref & Ref & $\$ 103$ & $\$-$ & $\$ 1.61$ & $\$-$ \\
\hline Ref:50SC & Ref & $\$ 103$ & $\$ 0$ & $\$ 1.61$ & $\$ 0.00$ \\
\hline Ref:HGP & Ref & $\$ 104$ & $\$ 1$ & $\$ 1.62$ & $\$ 0.01$ \\
\hline Ref:50SD & Ref & $\$ 104$ & $\$ 1$ & $\$ 1.63$ & $\$ 0.02$ \\
\hline LFUA:IR & Ref & $\$ 111$ & $\$ 8$ & $\$ 1.72$ & $\$ 0.12$ \\
\hline LIUA:IR & Ref & $\$ 111$ & $\$ 8$ & $\$ 1.73$ & $\$ 0.13$ \\
\hline LFUA & Ref & $\$ 114$ & $\$ 11$ & $\$ 1.78$ & $\$ 0.17$ \\
\hline LIUA & Ref & $\$ 114$ & $\$ 11$ & $\$ 1.78$ & $\$ 0.18$ \\
\hline HCLG & Ref & $\$ 131$ & $\$ 28$ & $\$ 2.04$ & $\$ 0.43$ \\
\hline Scenario & Basis & $\begin{array}{r}\text { VO\&M Costs } \\
(\$ 000,000)\end{array}$ & $\begin{array}{r}\Delta V O \& M \text { Costs } \\
(\$ 000,000)\end{array}$ & $\$ / M W h$ & 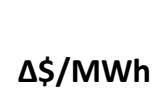 \\
\hline HCLG:50SC & HCLG & $\$ 131$ & $(\$ 0)$ & $\$ 2.04$ & $\$(0.00)$ \\
\hline HCLG & HCLG & $\$ 131$ & $\$-$ & $\$ 2.04$ & $\$-$ \\
\hline HCLG:50SD & HCLG & $\$ 133$ & $\$ 3$ & $\$ 2.08$ & $\$ 0.04$ \\
\hline
\end{tabular}


The low-coal and variable generation simulations had some of the lowest overall variable nonfuel operating costs (see Table E-5). For the low-coal simulation, the cost decreases were caused by the lower cycling costs and VO\&M costs associated with the combined-cycle units. For the variable generation simulations, cost decreases were caused by the avoided maintenance costs of the generation that the variable generation displaced. As with other costs, changes in operating practices of otherwise identical systems can have significant impacts on costs. (For example, compare the reference simulation, Ref, to the reference-based simulation in which half of the coal fleet self-committed, Ref:50SC.)

Table E-5. Non-Fuel Operating Costs for All Simulations

\begin{tabular}{|c|c|c|c|c|c|}
\hline Scenario & Basis & $\begin{array}{r}\text { Non-Fuel } \\
\text { Operating Costs } \\
(\$ 000,000) \\
\end{array}$ & $\begin{array}{r}\Delta \text { Non-Fuel } \\
\text { Operating Costs } \\
(\$ 000,000)\end{array}$ & $\$ / \mathrm{MWh}$ & $\Delta \$ / M W h$ \\
\hline LCHG & Ref & $\$ 99$ & $(\$ 32)$ & $\$ 1.54$ & $\$(0.50)$ \\
\hline Ref:LGP & Ref & $\$ 101$ & $(\$ 30)$ & $\$ 1.58$ & $\$(0.46)$ \\
\hline HPVG:Ret & Ref & $\$ 128$ & $(\$ 3)$ & $\$ 1.99$ & $\$(0.05)$ \\
\hline LPVG:Flex & Ref & $\$ 129$ & $(\$ 2)$ & $\$ 2.00$ & $\$(0.04)$ \\
\hline LPVG & Ref & $\$ 129$ & $(\$ 2)$ & $\$ 2.02$ & $\$(0.02)$ \\
\hline HPVG & Ref & $\$ 130$ & $(\$ 1)$ & $\$ 2.02$ & $\$(0.02)$ \\
\hline Ref & Ref & $\$ 131$ & $\$-$ & $\$ 2.04$ & $\$-$ \\
\hline Ref:50SC & Ref & $\$ 132$ & $\$ 1$ & $\$ 2.05$ & $\$ 0.01$ \\
\hline MPVG & Ref & $\$ 132$ & $\$ 1$ & $\$ 2.05$ & $\$ 0.01$ \\
\hline Ref:50SD & Ref & $\$ 136$ & $\$ 5$ & $\$ 2.12$ & $\$ 0.08$ \\
\hline Ref:HGP & Ref & $\$ 139$ & $\$ 8$ & $\$ 2.16$ & $\$ 0.12$ \\
\hline LFUA:IR & Ref & $\$ 140$ & $\$ 9$ & $\$ 2.18$ & $\$ 0.14$ \\
\hline HPVG:HGP & Ref & $\$ 140$ & $\$ 9$ & $\$ 2.18$ & $\$ 0.14$ \\
\hline LIUA:IR & Ref & $\$ 141$ & $\$ 10$ & $\$ 2.20$ & $\$ 0.16$ \\
\hline LIUA & Ref & $\$ 144$ & $\$ 13$ & $\$ 2.25$ & $\$ 0.21$ \\
\hline LFUA & Ref & $\$ 145$ & $\$ 14$ & $\$ 2.27$ & $\$ 0.23$ \\
\hline Ref:FSG & Ref & $\$ 154$ & $\$ 23$ & $\$ 2.39$ & $\$ 0.35$ \\
\hline HCLG & Ref & $\$ 166$ & $\$ 35$ & $\$ 2.59$ & $\$ 0.55$ \\
\hline
\end{tabular}

\begin{tabular}{llrrrr} 
Scenario & Basis & $\begin{array}{r}\text { Non-Fuel } \\
\text { Operating Costs } \\
\mathbf{( \$ 0 0 0 , 0 0 0 )}\end{array}$ & $\begin{array}{r}\Delta \text { Non-Fuel } \\
\text { Operating Costs } \\
\mathbf{( \$ 0 0 0 , 0 0 0 )}\end{array}$ & $\mathbf{\$} / \mathbf{M W h}$ & $\Delta \mathbf{\Delta} / \mathbf{M W h}$ \\
\hline HCLG:50SC & HCLG & $\$ 166$ & $(\$ 0)$ & $\$ 2.58$ & $\$(0.00)$ \\
HCLG & HCLG & $\$ 166$ & $\$-$ & $\$ 2.59$ & $\$-$ \\
HCLG:50SD & HCLG & $\$ 186$ & $\$ 20$ & $\$ 2.90$ & $\$ 0.31$
\end{tabular}


Reserves costs differed from other costs in that the simulations that tended to have the highest cycling costs often had the lowest reserves costs (see Table E-6). This can make sense in the simulations that had high cycling costs because if it is expensive to cycle the fleet, excess capacity will likely be online (i.e., it is cheaper to idle the generation than to shut down and restart later). The lowest reserve cost was in the fast-start generation simulation, which was followed closely by the high-coal simulation.

Table E-6. Reserves Provisioning Costs for All Simulations

\begin{tabular}{|c|c|c|c|c|c|}
\hline Scenario & Basis & $\begin{array}{r}\text { Reserves } \\
\text { Provisioning Cost } \\
(\$ 000,000) \\
\end{array}$ & $\begin{array}{r}\Delta \text { Reserves } \\
\text { Provisioning } \\
\text { Cost } \\
(\$ 000,000) \\
\end{array}$ & \$/MWh & $\Delta \$ / M W h$ \\
\hline Ref:FSG & Ref & $\$ 1$ & (\$1) & $\$ 0.01$ & $\$(0.01)$ \\
\hline HCLG & Ref & $\$ 1$ & $(\$ 1)$ & $\$ 0.01$ & $\$(0.01)$ \\
\hline LFUA & Ref & $\$ 1$ & $(\$ 1)$ & $\$ 0.02$ & $\$(0.01)$ \\
\hline Ref & Ref & $\$ 2$ & $\$-$ & $\$ 0.02$ & $\$-$ \\
\hline LCHG & Ref & $\$ 2$ & $\$ 0$ & $\$ 0.02$ & $\$ 0.00$ \\
\hline HPVG:Ret & Ref & $\$ 2$ & $\$ 0$ & $\$ 0.03$ & $\$ 0.01$ \\
\hline Ref:50SC & Ref & $\$ 2$ & $\$ 0$ & $\$ 0.03$ & $\$ 0.01$ \\
\hline Ref:LGP & Ref & $\$ 2$ & $\$ 0$ & $\$ 0.03$ & $\$ 0.01$ \\
\hline Ref:HGP & Ref & $\$ 2$ & $\$ 0$ & $\$ 0.03$ & $\$ 0.01$ \\
\hline LIUA & Ref & $\$ 2$ & $\$ 0$ & $\$ 0.03$ & $\$ 0.01$ \\
\hline LPVG & Ref & $\$ 2$ & $\$ 0$ & $\$ 0.03$ & $\$ 0.01$ \\
\hline LPVG:Flex & Ref & $\$ 2$ & $\$ 1$ & $\$ 0.03$ & $\$ 0.01$ \\
\hline MPVG & Ref & $\$ 3$ & $\$ 1$ & $\$ 0.04$ & $\$ 0.02$ \\
\hline HPVG & Ref & $\$ 4$ & $\$ 2$ & $\$ 0.06$ & $\$ 0.04$ \\
\hline HPVG:HGP & Ref & $\$ 5$ & $\$ 3$ & $\$ 0.07$ & $\$ 0.05$ \\
\hline Ref:50SD & Ref & $\$ 5$ & $\$ 4$ & $\$ 0.08$ & $\$ 0.06$ \\
\hline LFUA:IR & Ref & $\$ 6$ & $\$ 5$ & $\$ 0.10$ & $\$ 0.07$ \\
\hline LIUA:IR & Ref & $\$ 7$ & $\$ 5$ & $\$ 0.10$ & $\$ 0.08$ \\
\hline
\end{tabular}

\begin{tabular}{|c|c|c|c|c|c|}
\hline Scenario & Basis & $\begin{array}{r}\text { Reserves } \\
\text { Provisioning Cost } \\
(\$ 000,000) \\
\end{array}$ & $\begin{array}{r}\Delta \text { Reserves } \\
\text { Provisioning } \\
\text { Cost } \\
(\$ 000,000) \\
\end{array}$ & \$/MWh & $\Delta \$ / M W h$ \\
\hline HCLG & HCLG & $\$ 1$ & $\$-$ & $\$ 0.01$ & $\$-$ \\
\hline HCLG:50SC & HCLG & $\$ 1$ & $\$ 0$ & $\$ 0.02$ & $\$ 0.01$ \\
\hline HCLG:50SD & HCLG & $\$ 2$ & $\$ 2$ & $\$ 0.04$ & $\$ 0.03$ \\
\hline
\end{tabular}


The low-coal and variable generation simulations had some of the lowest overall combined costs (see Table E-7). For most simulations, the VO\&M costs were the largest component of these costs, so generation fleets that had low maintenance costs (high gas fleets) or that displaced conventional generation had the lowest costs.

As with other costs, changes in operating practices of an otherwise identical system can have a significant impact on costs. (For example, compare the reference simulation, Ref, to the reference-based simulation in which half of the coal fleet self-dispatched, Ref:50SD.)

Table E-7. Non-Fuel Operating Costs Plus Reserves Provisioning Costs for All Simulations

\begin{tabular}{|c|c|c|c|c|c|}
\hline Scenario & Basis & $\begin{array}{r}\text { Non-Fuel + } \\
\text { Reserves Costs } \\
(\$ 000,000)\end{array}$ & $\begin{array}{r}\Delta \text { Non-Fuel + } \\
\text { Reserves Costs } \\
(\$ 000,000)\end{array}$ & \$/MWh & $\Delta \$ / M W h$ \\
\hline LCHG & Ref & $\$ 101$ & $(\$ 32)$ & $\$ 1.57$ & $\$(0.50)$ \\
\hline Ref:LGP & Ref & $\$ 103$ & $(\$ 29)$ & $\$ 1.61$ & $\$(0.46)$ \\
\hline HPVG:Ret & Ref & $\$ 129$ & $(\$ 3)$ & $\$ 2.02$ & $\$(0.05)$ \\
\hline LPVG:Flex & Ref & $\$ 131$ & $(\$ 2)$ & $\$ 2.04$ & $\$(0.03)$ \\
\hline LPVG & Ref & $\$ 131$ & $(\$ 1)$ & $\$ 2.05$ & $\$(0.02)$ \\
\hline Ref & Ref & $\$ 132$ & $\$-$ & $\$ 2.06$ & $\$-$ \\
\hline Ref:50SC & Ref & $\$ 134$ & $\$ 1$ & $\$ 2.08$ & $\$ 0.02$ \\
\hline HPVG & Ref & $\$ 134$ & $\$ 1$ & $\$ 2.08$ & $\$ 0.02$ \\
\hline MPVG & Ref & $\$ 134$ & $\$ 2$ & $\$ 2.09$ & $\$ 0.03$ \\
\hline Ref:HGP & Ref & $\$ 141$ & $\$ 8$ & $\$ 2.19$ & $\$ 0.13$ \\
\hline Ref:50SD & Ref & $\$ 141$ & $\$ 9$ & $\$ 2.20$ & $\$ 0.14$ \\
\hline HPVG:HGP & Ref & $\$ 144$ & $\$ 12$ & $\$ 2.25$ & $\$ 0.19$ \\
\hline LFUA:IR & Ref & $\$ 146$ & $\$ 14$ & $\$ 2.28$ & $\$ 0.21$ \\
\hline LIUA & Ref & $\$ 146$ & $\$ 14$ & $\$ 2.28$ & $\$ 0.21$ \\
\hline LFUA & Ref & $\$ 146$ & $\$ 14$ & $\$ 2.28$ & $\$ 0.22$ \\
\hline LIUA:IR & Ref & $\$ 148$ & $\$ 15$ & $\$ 2.30$ & $\$ 0.24$ \\
\hline Ref:FSG & Ref & $\$ 154$ & $\$ 22$ & $\$ 2.40$ & $\$ 0.34$ \\
\hline HCLG & Ref & $\$ 167$ & $\$ 34$ & $\$ 2.60$ & $\$ 0.53$ \\
\hline
\end{tabular}

\begin{tabular}{lcrrrr} 
Scenario & Basis & $\begin{array}{r}\text { Non-Fuel + } \\
\text { Reserves Costs } \\
(\mathbf{\$ 0 0 0 , 0 0 0 )}\end{array}$ & $\begin{array}{r}\Delta \text { Non-Fuel + } \\
\text { Reserves Costs } \\
\mathbf{( \$ 0 0 0 , 0 0 )}\end{array}$ & \$/MWh & $\Delta$ \$ $/ \mathbf{M W h}$ \\
\hline HCLG & HCLG & $\$ 167$ & $\$-$ & $\$ 2.60$ & $\$-$ \\
HCLG:50SC & HCLG & $\$ 167$ & $\$ 0$ & $\$ 2.60$ & $\$ 0.00$ \\
HCLG:50SD & HCLG & $\$ 188$ & $\$ 22$ & $\$ 2.94$ & $\$ 0.34$
\end{tabular}


Table E-8 provides a summary of each simulation's ranked according to each of the cost metrics. The simulations are listed alphabetically.

Table E-8. Cost Rankings (Rank $=1$ for the Lowest Cost)

\begin{tabular}{llrrrrrrr} 
Scenario & Basis & $\begin{array}{r}\text { Fuel } \\
\text { Rant }\end{array}$ & $\begin{array}{r}\text { Cycling } \\
\text { Cost } \\
\text { Rank }\end{array}$ & $\begin{array}{r}\text { Vo\&M } \\
\text { Cost } \\
\text { Rank }\end{array}$ & $\begin{array}{r}\text { Non-Fuel } \\
\text { Cost Rank }\end{array}$ & $\begin{array}{r}\text { Reserves } \\
\text { Cost Rank }\end{array}$ & $\begin{array}{r}\text { Non-Fuel + } \\
\text { Reserves } \\
\text { Cost Rank }\end{array}$ & $\begin{array}{r}\text { Generation } \\
\text { Cost Rank }\end{array}$ \\
\hline HCLG & Ref & 6 & 11 & 18 & 18 & 2 & 18 & 8 \\
HPVG & Ref & 1 & 16 & 2 & 6 & 14 & 8 & 1 \\
HPVG:HGP & Ref & 3 & 18 & 3 & 13 & 15 & 12 & 3 \\
HPVG:Ret & Ref & 2 & 17 & 1 & 3 & 6 & 3 & 2 \\
LCHG & Ref & 17 & 1 & 5 & 1 & 5 & 1 & 17 \\
LFUA & Ref & 9 & 8 & 16 & 16 & 3 & 15 & 9 \\
LFUA:IR & Ref & 14 & 4 & 14 & 12 & 17 & 13 & 15 \\
LIUA & Ref & 10 & 6 & 17 & 15 & 10 & 14 & 10 \\
LIUA:IR & Ref & 16 & 7 & 15 & 14 & 18 & 16 & 16 \\
LPVG & Ref & 8 & 13 & 8 & 5 & 11 & 5 & 7 \\
LPVG:Flex & Ref & 7 & 12 & 7 & 4 & 12 & 4 & 6 \\
MPVG & Ref & 5 & 14 & 6 & 9 & 13 & 9 & 5 \\
Ref & Ref & 12 & 2 & 10 & 7 & 4 & 6 & 11 \\
Ref:50SC & Ref & 13 & 3 & 11 & 8 & 7 & 7 & 12 \\
Ref:50SD & Ref & 15 & 9 & 13 & 10 & 16 & 11 & 14 \\
Ref:FSG & Ref & 11 & 15 & 9 & 17 & 1 & 17 & 13 \\
Ref:HGP & Ref & 18 & 10 & 12 & 11 & 9 & 10 & 18 \\
Ref:LGP & Ref & 4 & 5 & 4 & 2 & 8 & 2 & 4
\end{tabular}

\begin{tabular}{llrrrrrrr} 
Scenario & Basis & $\begin{array}{r}\text { Fuel } \\
\text { Cost } \\
\text { Rank }\end{array}$ & $\begin{array}{r}\text { Cycling } \\
\text { Cost } \\
\text { Rank }\end{array}$ & $\begin{array}{r}\text { Vo\&M } \\
\text { Cost } \\
\text { Rank }\end{array}$ & $\begin{array}{r}\text { Non-Fuel } \\
\text { Cost Rank }\end{array}$ & $\begin{array}{r}\text { Reserves } \\
\text { Cost Rank }\end{array}$ & $\begin{array}{r}\text { Non-Fuel + } \\
\text { Reserves } \\
\text { Cost Rank }\end{array}$ & $\begin{array}{r}\text { Total } \\
\text { Generation } \\
\text { Cost Rank }\end{array}$ \\
\hline HCLG & HCLG & 2 & 2 & 2 & 2 & 1 & 1 & 2 \\
HCLG:50SC & HCLG & 1 & 1 & 1 & 1 & 2 & 2 & 1 \\
HCLG:50SD & HCLG & 3 & 3 & 3 & 3 & 3 & 3 & 3
\end{tabular}


Table E-9 provides the costs for all of the simulations. Scenarios are ranked according to nonfuel operating costs plus reserves costs.

\begin{tabular}{|c|c|c|c|c|c|c|c|c|}
\hline \multicolumn{9}{|c|}{ Table E-9. Costs for All Simulations $(\$ 000,000)$} \\
\hline \multirow[b]{3}{*}{ Simulation } & \multirow[b]{3}{*}{ Basis } & \multirow[b]{3}{*}{ Fuel Costs } & \multicolumn{3}{|c|}{ Non-Fuel Operating Costs } & \multirow[b]{3}{*}{$\begin{array}{r}\text { Total } \\
\text { Generation } \\
\text { Costs }\end{array}$} & \multirow[b]{3}{*}{$\begin{array}{r}\text { Reserves } \\
\text { Provisioning } \\
\text { Costs }\end{array}$} & \multirow{3}{*}{$\begin{array}{r}\text { Non-Fuel } \\
\text { Operating } \\
\text { Costs }+ \\
\text { Reserves } \\
\text { Costs }\end{array}$} \\
\hline & & & \multicolumn{2}{|c|}{ Cycling Costs } & \multirow{2}{*}{$\begin{array}{r}\begin{array}{r}\text { VO\&M } \\
\text { Costs }\end{array} \\
\text { VO\&M } \\
\text { Costs }\end{array}$} & & & \\
\hline & & & $\begin{array}{l}\text { Start } \\
\text { Costs }\end{array}$ & $\begin{array}{r}\text { Ramp } \\
\text { Costs }\end{array}$ & & & & \\
\hline LCHG & Ref & $\$ 1,565$ & $\$ 21$ & $\$ 2$ & $\$ 75$ & $\$ 1,664$ & $\$ 2$ & $\$ 101$ \\
\hline Ref:LGP & Ref & $\$ 1,012$ & $\$ 26$ & $\$ 3$ & $\$ 72$ & $\$ 1,113$ & $\$ 2$ & $\$ 103$ \\
\hline HPVG:Ret & Ref & $\$ 830$ & $\$ 65$ & $\$ 6$ & $\$ 57$ & $\$ 957$ & $\$ 2$ & $\$ 129$ \\
\hline LPVG:Flex & Ref & $\$ 1,252$ & $\$ 31$ & $\$ 4$ & $\$ 94$ & $\$ 1,380$ & $\$ 2$ & $\$ 131$ \\
\hline LPVG & Ref & $\$ 1,252$ & $\$ 32$ & $\$ 4$ & $\$ 94$ & $\$ 1,381$ & $\$ 2$ & $\$ 131$ \\
\hline Ref & Ref & $\$ 1,450$ & $\$ 25$ & $\$ 3$ & $\$ 103$ & $\$ 1,581$ & $\$ 2$ & $\$ 132$ \\
\hline Ref:50SC & Ref & $\$ 1,450$ & $\$ 26$ & $\$ 3$ & $\$ 103$ & $\$ 1,582$ & $\$ 2$ & $\$ 134$ \\
\hline HPVG & Ref & $\$ 791$ & $\$ 60$ & $\$ 7$ & $\$ 63$ & $\$ 921$ & $\$ 4$ & $\$ 134$ \\
\hline MPVG & Ref & $\$ 1,107$ & $\$ 40$ & $\$ 5$ & $\$ 87$ & $\$ 1,239$ & $\$ 3$ & $\$ 134$ \\
\hline Ref:HGP & Ref & $\$ 1,863$ & $\$ 32$ & $\$ 3$ & $\$ 104$ & $\$ 2,001$ & $\$ 2$ & $\$ 141$ \\
\hline Ref:50SD & Ref & $\$ 1,488$ & $\$ 28$ & $\$ 3$ & $\$ 104$ & $\$ 1,624$ & $\$ 5$ & $\$ 141$ \\
\hline HPVG:HGP & Ref & $\$ 952$ & $\$ 67$ & $\$ 7$ & $\$ 65$ & $\$ 1,091$ & $\$ 5$ & $\$ 144$ \\
\hline LFUA:IR & Ref & $\$ 1,486$ & $\$ 25$ & $\$ 4$ & $\$ 111$ & $\$ 1,625$ & $\$ 6$ & $\$ 146$ \\
\hline LIUA & Ref & $\$ 1,380$ & $\$ 26$ & $\$ 3$ & $\$ 114$ & $\$ 1,524$ & $\$ 2$ & $\$ 146$ \\
\hline LFUA & Ref & $\$ 1,368$ & $\$ 28$ & $\$ 3$ & $\$ 114$ & $\$ 1,514$ & $\$ 1$ & $\$ 146$ \\
\hline LIUA:IR & Ref & $\$ 1,499$ & $\$ 26$ & $\$ 4$ & $\$ 111$ & $\$ 1,640$ & $\$ 7$ & $\$ 148$ \\
\hline Ref:FSG & Ref & $\$ 1,434$ & $\$ 50$ & $\$ 3$ & $\$ 101$ & $\$ 1,587$ & $\$ 1$ & $\$ 154$ \\
\hline \multirow[t]{4}{*}{ HCLG } & Ref & $\$ 1,235$ & $\$ 31$ & $\$ 4$ & $\$ 131$ & $\$ 1,400$ & $\$ 1$ & $\$ 167$ \\
\hline & & & \multicolumn{3}{|c|}{ Non-Fuel Operating Costs } & & & \\
\hline & & & \multicolumn{2}{|c|}{ Cycling Costs } & $\begin{array}{r}\text { VO\&M } \\
\text { Costs }\end{array}$ & & & \\
\hline & Basis & Fuel Costs & $\begin{array}{l}\text { Start } \\
\text { Costs }\end{array}$ & $\begin{array}{c}\text { Ramp } \\
\text { Costs }\end{array}$ & $\begin{array}{r}\text { VO\&M } \\
\text { Costs }\end{array}$ & Total Costs & $\begin{array}{r}\text { Reserves } \\
\text { Provisioning } \\
\text { Costs }\end{array}$ & $\begin{array}{r}\text { Non-Fuel } \\
\text { Operating } \\
\text { Costs }+ \\
\text { Reserves } \\
\text { Costs }\end{array}$ \\
\hline HCLG & $\begin{array}{l}\text { High } \\
\text { Coal }\end{array}$ & $\$ 1,235$ & $\$ 31$ & $\$ 4$ & $\$ 131$ & $\$ 1,400$ & $\$ 1$ & $\$ 167$ \\
\hline HCLG:50SC & $\begin{array}{l}\text { High } \\
\text { Coal }\end{array}$ & $\$ 1,234$ & $\$ 30$ & $\$ 4$ & $\$ 131$ & $\$ 1,399$ & $\$ 1$ & \$167 \\
\hline HCLG:50SD & $\begin{array}{l}\text { High } \\
\text { Coal }\end{array}$ & $\$ 1,307$ & $\$ 48$ & $\$ 5$ & $\$ 133$ & $\$ 1,493$ & $\$ 2$ & $\$ 188$ \\
\hline
\end{tabular}

